

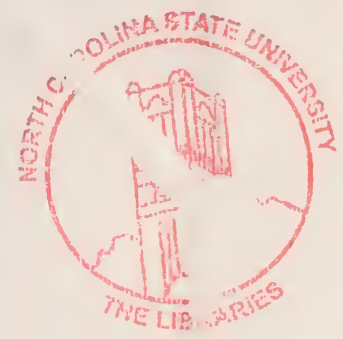

NORTH CAROLINA STATE UNIVERSITY LIBRARIES

-

||||||||||||||||||||||||||||||||||||||

S02066322 L 
This book is due on the date indicated unless recalled by the Libraries. Books not returned on time are subject to replacement charges. Borrowers may access their library accounts at: http://www.lib.ncsu.edu/ads/borrow.html 







\section{SCIENGE OF PLANT LIFE}

A High School Botany

TREATING OF THE PLANT AND ITS RELATION TO THE ENVIRONMENT 


\section{NEW-WORLD SCIENCE SERIES}

Edited by John II. Ritchic

SCIENCE FOR BEGINTERS

By Dilos Fall

TreF.s, STARs, AND BIRDS

By L. L. Moselcy

SCIENCE of Everitiay Life

By Carlcton W. Washbume

Humax Physiology

By John W. Ritchie

Sanitation AND Physiology

By John W. Ritchie

Laboratory Manual for USE with

"Human Physiology"

By Carl Hartman

Exercise and Review Book in Biology

By J. G. Blaisdell

Personal itrgiene and IIome Nursing

By Louisa M. Lippitt

Science of Plant Life

By E. $N$. Transeau

Principles of Zö̈logy

By $T$. D. A. Cockerell

EXPERinental Organic Chemistry

By $A$. P. West 
NEW-WORLD SCIENCE SERIES Edited by fobn $W$. Ritchie

\section{SCIENCE}

OF PLANT LIFE

A High School Botany

Treating of the Plant and Its Relation to the Environment

by

Edgar Nelson Transeau, Ph.D. Professor of Botany, The Ohio State University

\section{ILLUSTRATED}

with engravings, diagrams, and maps

and with 120 original drarvings by

Robert 7. Sim

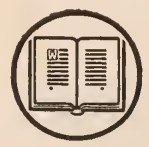

Yonkers-on-Hudson, New York

WORLD BOOK COMPANY

I 9 I 9 
THE HOUSE OF APPLIED KNOWLEDGE

Established, 1905, by Caspar W. Hodgson

YoNkERS-ON-HudSON, NEW YORK

2126 Prairie Avenue, Chicago

World Book Company offers Science of Plant Life for high school use. The book embodies a response to the attractiveness of plant life, a steadfast scientific spirit that yields neither to sentiment nor to utility, and an appreciation of the fact that the fundamental reason for giving botany a place in our general scheme of education is that it is the natural scientific background for the great plant-producing arts. It is a text that accords well with our motto, "Books that apply the world's knowledge to the world's needs"

Copyright, 1919, by World Book Company Copyright in Great Britain 


\section{PREFACE}

THE most important question that confronts the teacher of elementary botany is the selection of the subject matter for the course. Shall the work consist chiefly of the naming of plants and of learning the meanings of terms descriptive of plants and of plant organs, as was common 30 years ago? Does a course emphasizing a study of the anatomy of plant organs provide the best introduction to the subject of botany for pupils of secondary school grade? Have those courses been satisfactory in which the work centered about the evolutionary development of the plant kingdom, with studies of the reproductive organs and life histories of types representative of the great plant groups, or shall we teach physiology and ecology? Shall we select as material for study wild plants, often obscure and unfamiliar to the pupil, because they show certain structures significant in determining the relationships of plants, or shall we use the familiar plants of the farm and garden, on which man depends in large part for his livelihood, to exemplify botanical principles? Is it best to try to give a "practical" turn to the course by inserting chapters from other subjects like agriculture, forestry, and plant breeding; or shall the course be kept within the strict confines of botany and the relation of botanical facts and principles to plant production be shown by appropriate references and illustrations? Upon the answers given to these questions the content of the course to be offered will largely depend.

The author is one of those who think that our work in botany should serve as a basis for agriculture, horticulture, and forestry, just as physics and chemistry form the natural background of our manufacturing and industrial life. His teaching experience has led him to believe, moreover, that a very 
general course in botany that presents and organizes the more important facts of plant physiology, morphology, ecology, and economics is interesting to pupils of high school age and is valuable to any one who later engages in the growing of plants. The fundamental aim of this text, therefore, is to give the pupil an understanding of how a plant lives and is affected by its environment. The nutrition of the plant is the central theme. Sufficient anatomy and morphology have been introduced to make possible a discussion of the important plant processes, including reproduction. The environment of plants and their adjustments to various environmental factors have been discussed because a knowledge of these subjects is essential to an understanding of many agricultural practices. Attention is called to the uses that are made of plants and plant materials and to the applications of botanical principles in plant production in order that the economic importance of plants and of a knowledge of plant life may be evident. In the final chapter an attempt is made to give the pupil an understanding of what is meant by the term "evolution" - to present a definition rather than a discussion.

The most valuable part of any course in botany is the study of plants in the field and laboratory. It is through the work with the plants themselves that the teacher has the best opportunity to give pupils the insight into plant life that will justify the expenditure of their time and energy on the course. The laboratory work has been fairly well standardized in secondary schools, and the methods of handling classes are well known. This is not true of field work, although it is no more difficult than laboratory work and is no less important. Two methods of conducting field observation have been eminently successful. One is to take the class into the 
field to study a particular topic, - not to make random observations on plants. A second method is to give each pupil a carefully prepared outline containing questions and directions by which he can make a trip and discover for himself the answers to the questions. Both these methods deserve to be used far more than they are.

This book has been written to supplement laboratory and field work with plants, not to take the place of such work. Suggestions for laboratory and field work will be found preceding each chapter, but these suggestions include more work than can be accomplished in most high school courses. The teacher should, therefore, select those exercises that are best suited to the needs of a particular class, and which are best adapted to the laboratory equipment and the plant material available. 


\section{ACKNOWLEDGMENTS}

THE author wishes to thank many friends and students who have made suggestions regarding the book. Especially is he under obligation to the following, who have critically read the manuscript or the proofs: Dr. Harris M. Benedict, University of Cincinnati; Dr. J. M. Lewis, University of Texas; Dr. Burton E. Livingston, Johns Hopkins University; Dr. S. O. Mast, Johns Hopkins University; Dr. Charles A. Shull, University of Kentucky; Dr. A. B. Stout, New York Botanical Garden; Dr. G. H. Transeau, Columbus, Ohio; to his colleagues at Ohio State University, especially Dr. Jay B. Park, Dr. H. C. Sampson, Dr. A. E. Waller, Professor W. G. Stover, and Mr. Paul Sears; to Mr. G. W. Salisbury, Principal of Atchison County High School, Effingham, Kansas; Mr. J. R. Locke and Miss Edith E. Pettee, Highland Park High School, Detroit, Michigan; Miss Ella M. Bennett, High School, Ann Arbor, Michigan; Miss Lucy M. Phelon, High School of Commerce, Springfield, Massachusetts; Miss Ruth Jackson, High School, Wichita, Kansas; and Miss Maude Flynn, High School, Columbus, Ohio. 


\section{CONTENTS}

CHAPTER

PAGE

I. Plant Life in General . . . • . . . . . I

2. Leaves and Their Structures . . . . . . . I3

3. The Manufacture of Food . . . . . . . 25

4. Leaves in Relation to Light . . . . . . 37

5. The Water Relations of Leaves . . . . . 48

-6. Leaf Coloration and the Fall of Leaves . . . 63

7. Digestion, Transfer, and Accumulation of Foods 74

8. The Utilization of Foods . . . . . . . . $\quad$. 82

9. Herbs, Shrubs, ANd Trees . . . . . . . . 94

io. Stems and Their External Features . . . . io2

il. The Structures and Processes of Stems . . . I I 8

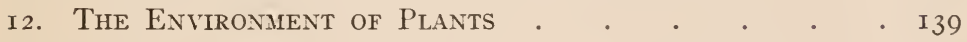

I3. Ecological Groups of Stems . . . . . . . . I 54

I4. The Structures and Processes of Roots . . . I66

I5. RoOts AND Their Environment . • . . . . . I82

i6. Reproduction in Flowering Plants: Flowers, Fruits, AND SEEDS . . . . . . . . . . . . . 197

I7. Reproduction in Relation to Agriculture . . . 2 I7

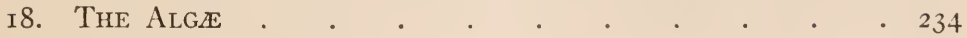

I9. BACTERIA AND FUNGI . . . . . . . . . . . 249

20. Liverworts AND Mosses . . . . . . . . . 272

2I. The Ferns AND Their Allies . . . . . . . 283

22. Seed Plants: Gymnosperms . . . . . . 294

23. Seed Plants: Angiosperms . . . . . . 303

24. The Evolution of Plants . . . . . . 3 3

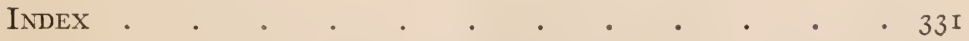


Flower in the crannied wall, I pluck you out of the crannies,

I hold you here, root and all, in my hand, Little flower - but if I could understand What you are, root and all, and all in all, I should know what God and man is.

Tennyson 


\section{SCIENCE OF PLANT LIFE}

\section{CHAPTER ONE}

PLANT LIFE IN GENERAL

\section{PLANTS FROM OUR STANDPOINT}

Probably all of us make our most frequent contact with nature through plants, and no part of our environment appeals to us more. The city dweller responds to the attraction of plants by growing a few flowers in a window box. The suburban resident finds great pleasure in his lawn and trees. The farmer enjoys the annual miracle of transforming his bare fields into acres of productive wheat and corn; and the forester delights in his work with the largest and most imposing of plants. This universal challenge of plant life is reflected in our literature; the stories of our childhood days and the novels and verse of our maturer years are made vivid by their backgrounds of garden and meadow, or of forest and desert.

The importance of plants. There are many reasons for studying and understanding plants besides the fact that they afford us pleasure.

(I) Plants furnish all the food there is in the world. Of all living beings, green plants alone are able to organize the simple materials found in the air, water, and soil into the complex substances which all plants and animals must have for food. The part of our own food which is not derived from plants comes from animals that directly or indirectly feed upon plants.

(2) By far the greater part of all the fabrics we use in the making of clothing is woven out of cotton, linen, and other 
plant fibers; and wool and silk come from animals that feed on plants.

(3) The trees supply the lumber that is used for the construction of most houses, and even when houses are built of stone or brick, wood is employed in finishing the interiors and in making the furniture. Wood is used also in the manufacture of paper, and in almost countless other ways.

(4) Most houses are heated in winter by the burning of wood, coal, or gas. The energy used in the driving of nearly all machinery is derived from wood, coal, petroleum, and natural gas. When we burn wood, we release, in the form of heat, the great store of energy which the tree obtained from the sunlight during its lifetime. When we burn coal, petroleum, or natural gas, we release energy which plants accumulated from the sunlight of millions of years ago.

(5) Certain small plants have other and quite different relations to human beings, and their activities are of the greatest consequence to man. These particular plants, the bacteria, are so minute that they can be seen only by the use of the microscope. Some of them take nitrogen from the air and build it into compounds that enrich the soil. Others render a useful service by breaking down the dead bodies and waste materials of plants and animals and converting them into substances that can be used by green plants in the making of foods. Still other kinds of bacteria cause many of the diseases to which plants and animals are subject, and it is necessary for us to learn about them in order that we may avoid or destroy them.

We see, therefore, that plants contribute to the pleasure of life; that, directly or indirectly, they furnish us with food and provide most of our clothing and shelter; that they sup- 


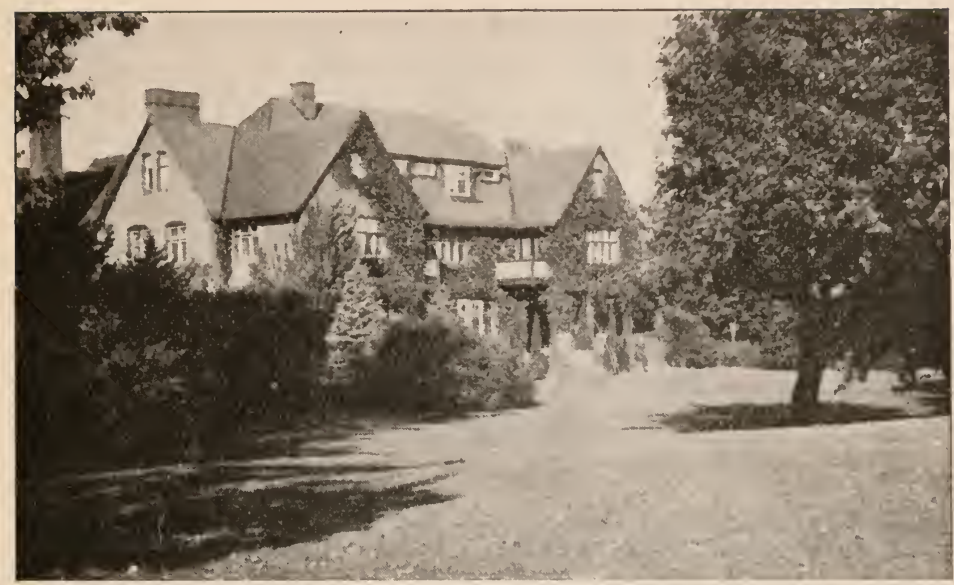

FIG. I. A country home made attractive by its trees and shrubs.

ply the greater part of the energy used in heating and lighting and in running machinery; and that as friends or foes, certain microscopic plants affect the health and well-being of animals and men. Since plant life is essential to our very existence, we should have a truly vital interest in the science of botany, which has grown out of the accumulated mass of information about plants.

Botany as a science. A science is a body of classified and systematized facts. The lore of the gardener, the forester, and the casual student of plants may have value, but it becomes a science only when it has been organized into a system whose principles have been tested and verified by experience, observation, or experiment. Botany is the science that treats of the structures, life histories, physiological processes, distribution, and classification of plants. It is one of the two divisions of biology; zoölogy, the science of animal life, is 
the other. Because so many of the fundamental processes and structures in plants and animals are similar, it is possible to include all living beings in the single science of biology. Yet because plants and animals differ in many important ways, botany and zoölogy may well be considered as distinct sciences.

How a knowledge of botany helps us. A knowledge of botany contributes directly to our enjoyment of life, because the more we know about plants, the more interest and meaning we find in every bit of vegetation. Botany helps us to understand the animal world, also, for plants and animals are so nearly related that much of what we learn in botany applies, with slight modifications, to animals as well as to plants.

Botany has great practical value also; it furnishes the scientific basis for many of the most important of human occupations. For example, agriculture and horticulture are arts dealing with the methods of field and garden crop production; they tell how and when a crop shall be planted, cared for, and harvested; but it is botany that furnishes the scientific knowledge on which these arts are based and explains the principles underlying the practices of the gardener and the farmer. Botany does not tell us of the methods to be used by the forester in developing timber; but no forester can practice intelligently or invent new and better methods without understanding the principles of botany. How to make a city or farm dwelling sanitary is an engineering problem; but the engineer must be thoroughly familiar with at least the part of botany which deals with the bacteria, if he is to be intelligent in his work. Botany, therefore, is of great practical importance in our daily life; without a knowledge 


\section{Plant Life in General}

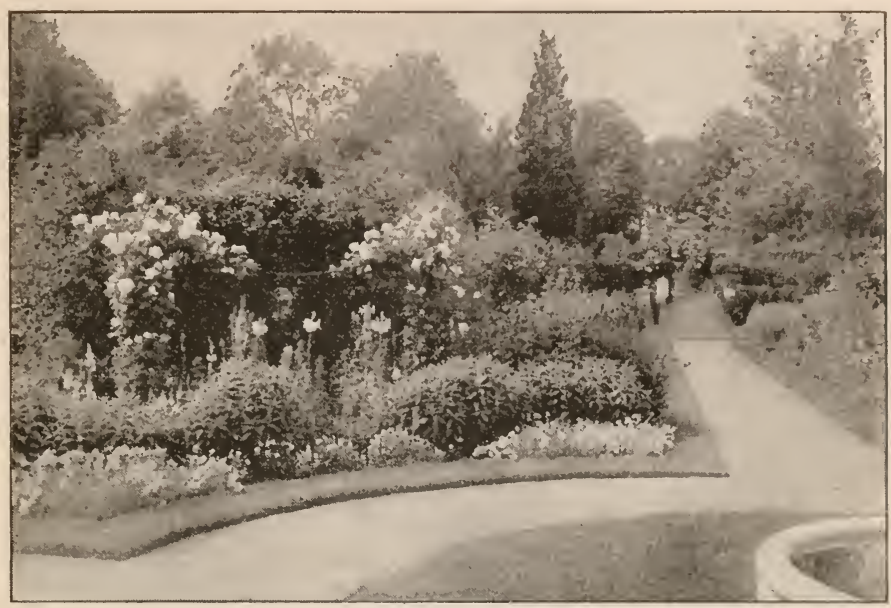

FIG. 2. A perennially beautiful garden.

of it many of our most important arts can be practiced only in a cumbersome way.

Nothing has as yet been said about our natural curiosity as an incentive to the study of plants. Yet the desire to know and understand is so strongly developed in all human beings that it has probably had more to do with the growth of the sciences than all other influences combined. We naturally want to understand why things are as we find them; we are ever seeking explanations of peculiar objects and unusual happenings that come to our attention. The study of botany will help to satisfy our wholesome curiosity about plants, and will direct our inquiries into profitable channels.

Newspapers and magazines often publish accounts of strange plants or of unusual plant habits. We read that wheat found in the tombs of ancient Egypt, where it had been buried for many centuries, was still alive. It is reported that a tree 


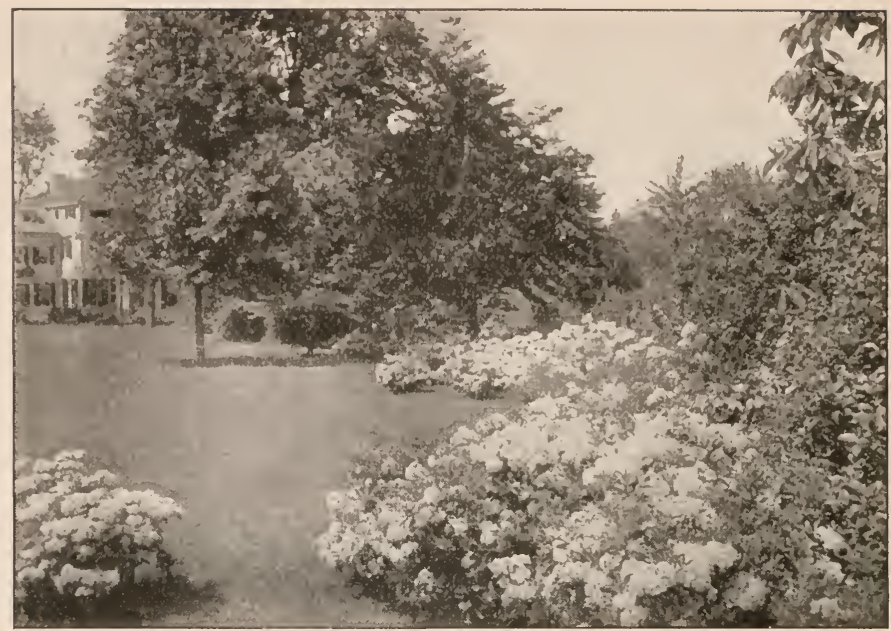

FIG. 3. The vegetation more than the house gives character to this suburban home.

that captures men and large animals and feeds on them has been found in central Africa. We are informed that a spineless cactus has been produced from a spiny one "by treating it kindly." Such published accounts and the descriptions and explanations that accompany them are purposely wrapped in mystery, and tend to give wrong impressions of plant life. Even a little knowledge of botany will keep one from being misled by such statements. In common with all the other sciences, botany enables us to recognize the truth, and so helps us to avoid errors due to mistaken observation, imperfect knowledge, or willful attempts to deceive.

\section{PLANTS FROM THEIR OWN STANDPOINT}

Thus far plants have been discussed in relation to man; they have been considered as objects of interest, and as a 
part of man's environment that may promote or interfere with his welfare. Of course plants do not grow, or flower, or fruit for the sake of the animals and man. The processes of plants are carried on and their structures developed solely to meet their own needs. The goal of plant life is the development of the individual and the production of young for the continuance of the species. A plant is successful in nature, therefore, (I) when it secures nourishment for its complete development, and (2) when it produces offspring and thus insures the reproduction of its kind.

Plants as living things. It is important for the beginner in the study of botany to realize that plants are living things. Because animals walk, or fly, or swim about, we are accustomed to think of movement as the necessary evidence of life. To one who has given no thought to the subject, a tree

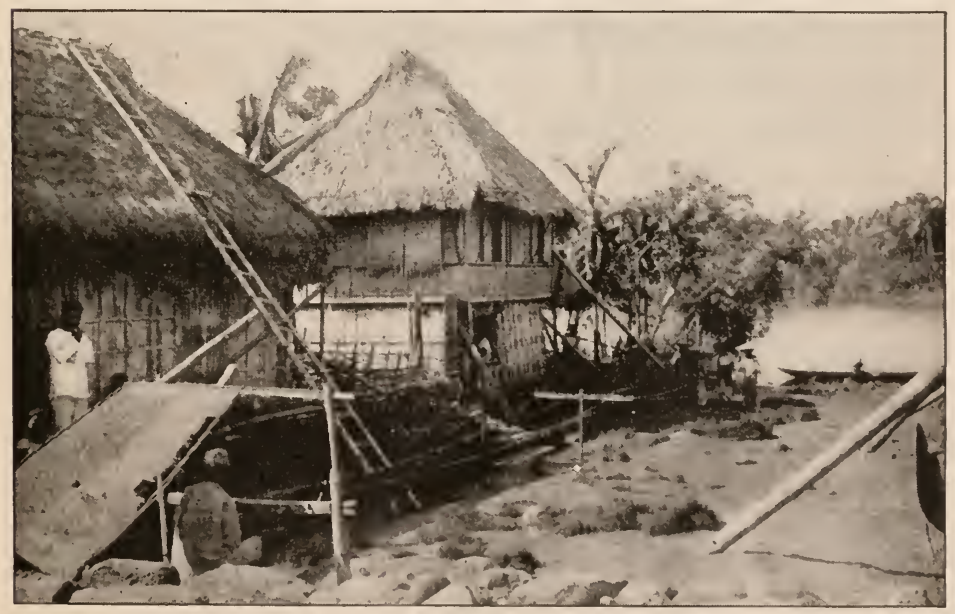

FIG. 4. Rope-making scene in a Philippine village. Out of plant materials the Filipinos make houses, mats, cloth, boats, and a great variety of household utensils. 
may seem more akin to the stones among which it is rooted than to the animals that live about it. But when we study living beings, we find that there are activities other than movement, such as respiration and growth, that are regularly associated with life. As we shall see later, these processes take place in plants the same as in animals and are evidence that plants are as truly alive as are animals.

A plant definitely related to its environment. The roots of the ordinary green plant penetrate the soil in all directions from the base of the plant, and enable it to take up water and mineral substances. The stem commonly grows upward and supports the leaves. Thus the leaves are displayed to sunlight and are in contact with the oxygen needed for respiration and the carbon dioxid required for the making of food. Each part of the plant is related to its environment in such a way that its natural processes and the life of the plant as a whole may be carried on.

Mutual dependence of the parts of a plant. The roots, stems, and leaves, together, make up the plant's machinery

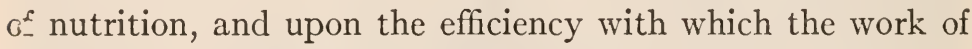
each part is done depends the successful nourishment of the plant. The chemical nature of the soil, the amount of water it contains, and its other characteristics, may facilitate or hinder the work of the roots. This may in turn aid or inter-. fere with the work of the leaves, and as a result the whole plant may flourish or be dwarfed. Likewise, the leaves may be exposed to favorable or unfavorable conditions of light and moisture, and their work may be accelerated or retarded. This in turn affects the stem and the roots, and the whole plant shows its abundant nutrition or its lack of food.

Under favorable conditions of light and moisture corn may 


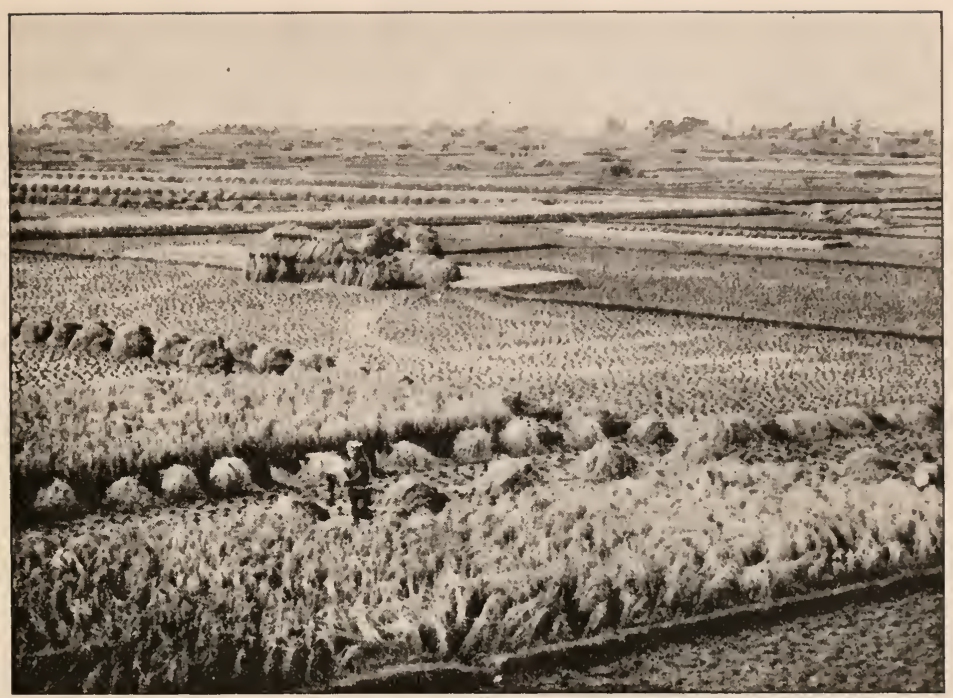

FIG. 5. Plants furnish the primary food supply of the world. The photograph shows a rice-harvesting scene in the Philippine Islands.

be grown in sand; but because sand does not provide the plant with the necessary mineral substances, the corn will not be of normal growth and will fail to produce good seed. Under. the same conditions of light and moisture, a rich garden soil would produce a normal plant. Or, if during the winter months corn is grown in the richest of soil in a greenhouse, it attains only a small size and may fail to produce good seeds, because in this case the amount of light is not sufficient. Hence, when we discuss the relations of any particular part of a plant to the energy-supplying and nutritive processes, we must ever keep in mind the interrelation and mutual dependence of all parts of the plant. As no part of the human body lives an independent life but is dependent for 
its welfare on the activities of the other parts, so the life of each part of a plant is bound up with the life of the plant as a whole.

Reproduction an essential process in plant life. Plants, to be successful, not only must maintain themselves but they must reproduce themselves. Some of them do this by further development of a part of the parent body, as the tuber of a potato or the runner of a strawberry plant. In many plants, however, reproduction takes place only through the production of flowers, fruits, and seeds. These structures in one way or another are concerned with the production of a small, undeveloped plant within the seed, and it is upon the further growth of this young plant that the production of another generation of that particular kind of plant depends. A sunflower may develop a tall stem and a large leaf area, but unless it flowers and produces good seed no young plants can be grown from it. If it were the only sunflower in existence, there could be no more sunflowers after its death. The process of reproduction must, therefore, be considered as an essential one in plants; without it plant life would soon disappear from the earth. 


\section{Suggestions for Laboratory and Field Work to Precede Chapter Two}

1. Review: physical and chemical changes; molecules and atoms ; elements and compounds; solids, liquids, and gases. If the pupils have had no introductory science, a few simple demonstrations should be given to make these topics clear.

2. Study a complete plant, noting the roots, stems, leaves, flowers, fruits, and seeds. Many of the common weeds show all these parts clearly. Examine the plant, not primarily to learn the names of the parts, but in order to get a conception of it as a living thing that is very different from the air and the soil in which it grows. Find out what the pupils already know concerning the plant's requirements, its manner of growth, and the functions of its several parts.

3. Study a number of leaves from different plants, and make drawings to illustrate a variety of leaf forms, simple and compound leaves, and the parallel and net arrangements of the veins. Note the thickness, texture, color, and surface in each of the different specimens. Note also that the veins reach every part of the leaf and connect through the petiole with the interior of the plant stem.

4. Study a skeletonized leaf to make clear the arrangement of veins and their intimate relation to the mesophyll cells. A nasturtium leaf that has been decolorized in alcohol may be studied under the microscope to show the small veins and the fine ramifications of the vessels.

5. Dissect a leaf from an Easter lily, live-for-ever, or Wandering Jew. Study especially the relative positions of the epidermis, mesophyll, and veins.

6. Study with a microscope cells from the epidermis, distinguishing the cell wall, protoplasm, nucleus, cytoplasm, and vacuole. The epidermis from an onion scale is good material for the study of the cell parts.

7. Draw some cells from a leaf of moss, such as Mnium, after it has been in good light for several hours. Note cell walls and chloroplasts. Staining with a weak iodin solution will show the starch grains within the chloroplasts. 
8. By experiment determine that light is necessary for the development and maintenance of the green color in leaves.

9. Study a freshly cut cross-section of a leaf, mounted in water, to show the detailed structure and the intimate connection between the epidermis, mesophyll, and veins. Prepared sections will show details of the stomata and intercellular spaces.

10. Take a field trip to study the variety of leaf forms. 


\section{CHAPTER TWO}

\section{LEAYES AND THEIR STRUCTURES}

Tre leaves of plants are their most conspicuous part. The summer landscape owes its color to them; and even when we look at a near-by plant, the leaves attract most of our attention and the plant stem, like the staff of a flag, is likely to be overlooked. The prominence of leaves is not the result of chance, for leaves manufacture food and sunlight is necessary for this process. In this chapter we shall study the structure of a leaf, and in subsequent chapters we shall discuss the work of the leaves and the processes that take place within these important organs of the plant.

The parts of a leaf. If we examine a leaf closely, we see

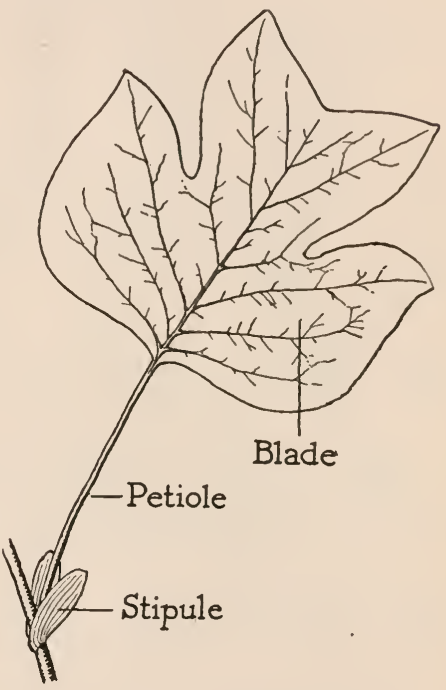

FIG. 6. Leaf of tulip tree, showing parts of a complete leaf. that it consists of a broad, thin blade, marked into small divisions by veins. The vein near the middle of the blade is commonly larger than the others and is called the midrib. In some forms of leaves there are several prominent veins, which we may call the principal veins. In general, the smallest veins form a network uniting with the larger ones, and these in turn connect with the midrib or with the principal veins. These large veins are smallest at the apex or outer end of the leaf, and gradually become larger toward the base 
of the blade. They continue down through the petiole or leafstalk into the interior of the stem. At the base of the Apex petiole there is in many leaves

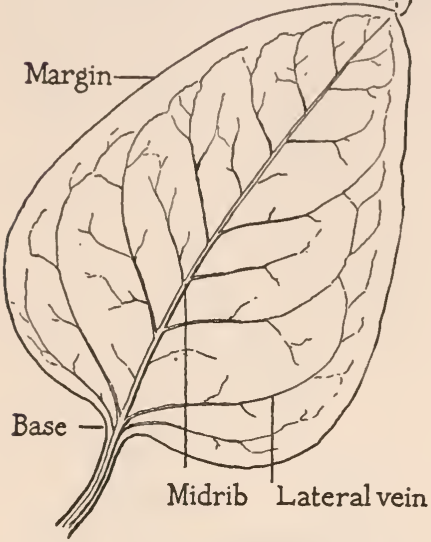

FIG. 7. Leaf of vinca, showing the parts of the blade. a pair of small appendages, the stipules. These are usually unimportant structures, but occasionally they are large and bladelike, and supplement the blade, or even take its place, in food manufacture. The primary divisions of the leaf are the blade, the petiole, and the stipules.

The leaf made up of tissues. The soft green tissue essential to food production is found chiefly in the blade of the leaf. This may be shown by dissecting a fleshy leaf like that of the common houseleek or the live-for-ever. Cutting across the blade of such a leaf, we

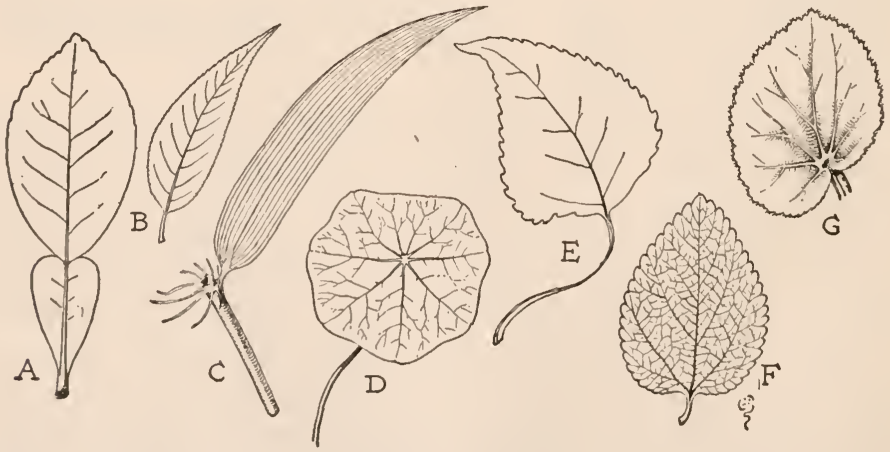

FIG. 8. Leaves showing variety of form and venation: $A$, orange; $B$, peach; $C$, bamboo; $D$, nasturtium; $E$, poplar; $F$, lantana; $G$, begonia. 
find that there is a skin covering it above and below. The skin is readily stripped off, leaving the interior of the leaf
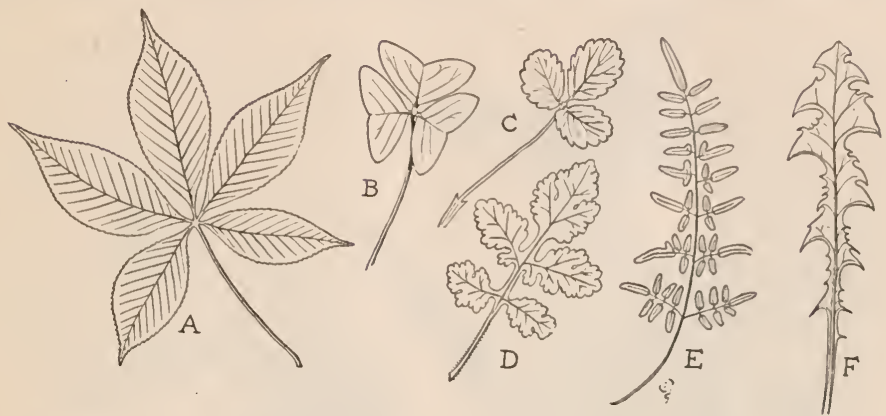

FIG. 9. Divided and compound leaves: $A$, buckeye; $B$, oxalis; $C$, avens; $D$, celandine; $E$, cliff fern; $F$, dandelion.

as a green, granular mass of cells with veins running through it in all directions. The skin is called the epidermis, or epidermal tissue (Greek: epi, upon, and derma, skin). The green part is the mesophyll tissue (Greek: meso, middle, and phyll, leaf). The veins consist of three tissues, the waterconducting, food-conducting, and mechanical tissues. The blade therefore commonly contains five tissues: the epidermis and mesophyll, and the three tissues of the veins.

Cells. When any one of the tissues of a leaf or other living part of a plant is magnified under a microscope, it is seen to be composed of small parts built together in much the same way as the little chambers in a honeycomb. These small parts are the plant cells (Fig. I I). Each cell consists of a small mass of jellylike living matter, the protoplasm, which is inclosed by a firm, transparent wall. The protoplasm is divided into a denser round or oval body, the mucleus, and a more liquid portion, the cytoplasm. The nucleus is of great importance; 
the cell dies when it is removed, and it is thought to control many of the activities that go on within the cell. The cells

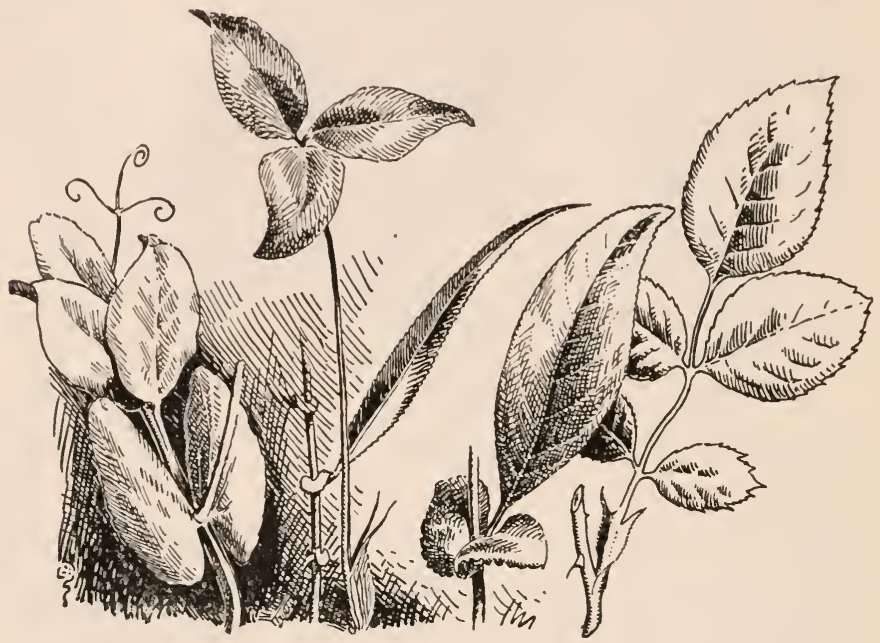

FIG. Io. Leaves with prominent stipules: pea, black willow, red clover, Japanese quince, rose.

are the structural units of plants. Figure 12 shows how a leaf is built of cells of different sizes and shapes.

The cytoplasm makes up the bulk of the living matter of a cell, but in mature plant cells most of the space inclosed by the cell wall is occupied by one or more vacuoles or cavities containing the cell sap. This is water with sugars, mineral salts, acids, and other substances dissolved in it. Lying within the cytoplasm are structures called plastids, small bodies that contain food substances and coloring matters.

The cell wall. The wall which surrounds the cell is composed of a transparent material called cellulose. Its importance lies in the fact that it gives firmness to the cell. It 
supports the soft cytoplasm as the wax of the honeycomb supports the honey within, and it helps to give stiffness to all parts of the plant. You have seen pure cellulose in the form of cotton. Filter paper and most book papers are made of cellulose fibers derived from wood. Water passes freely through the cellulose walls of plant cells, as do most substances that are dissolved in the water.

Animals, as well as plants, are composed of cells; but the animal cell, instead of having a stiff cellulose wall like a plant cell, has a soft wall, or, as in the case of nerve cells and white blood corpuscles, it may lack a wall entirely. Consequently, the

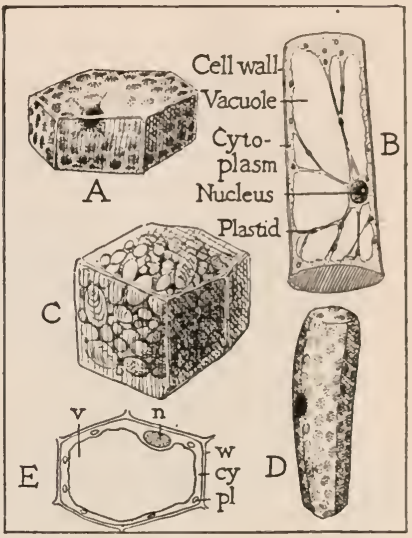

Fig. II. Plant cells: $A$ is from a moss leaf; $B$ is from a squash-vine hair; $C$ is a starch-filled cell from a potato tuber; and $D$ is a cell from the palisade layer of a leaf. $E$ shows a cell in cross section. tissues of animals (except the skeletal tissues) are usually softer and more pliable than plant tissues. This makes it easy for an animal to bend and to move about. The difference in cell walls and in the pliability of tissues is so general throughout the plant and animal kingdoms, that it is one of the important distinctions between plants and animals.

The epidermis and the stomata. The cells of the epidermis are flat, irregularly shaped, closely united, and, for the most part, colorless. The cell walls on the side of the epidermis which is exposed to the air become thickened with a waxlike material called cutin, which forms a layer over the surface of 
the leaf. This layer is called the cuticle. It is useful to the plant because water does not pass through it readily, and it

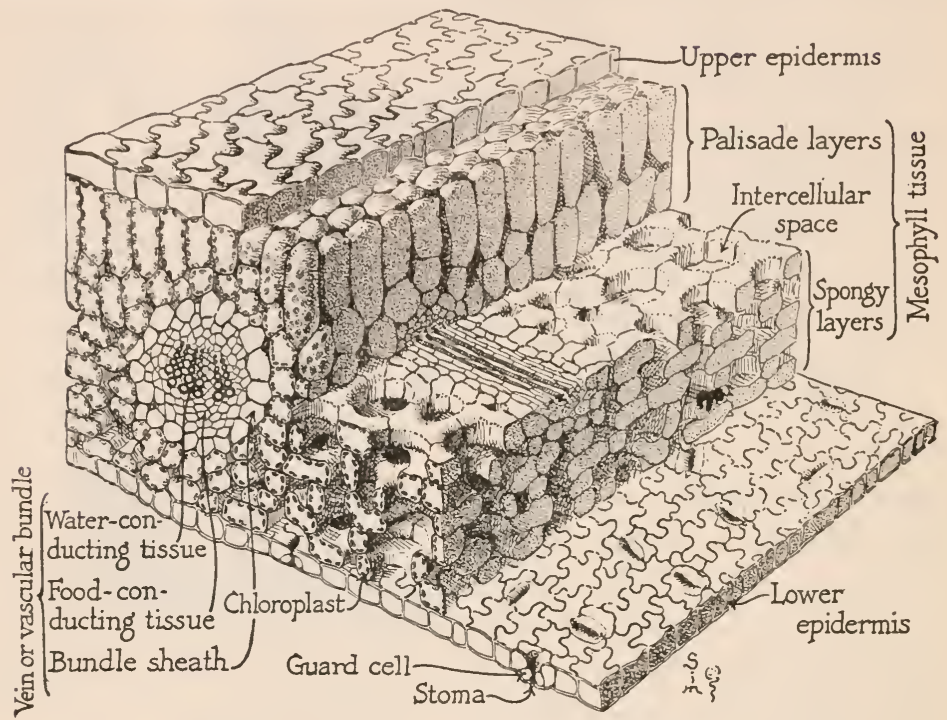

Tic. I2. Model of a small piece of vinca leaf, showing cells and tissues.

protects the plant from water loss. It may be compared to the enamel covering of oilcloth and acts in much the same way. The cuticle is useful to the plant also because it serves as a first line of defense against disease germs. The importance of the epidermis as a protective covering for the delicate inner tissues of the plant may be judged from the drying and decay that follow the breaking of the thin epidermal coat of an apple or a pear.

Scattered among the colorless cells of the epidermis are pairs of small, crescent-shaped green cells, the guard cells. Each pair of these surrounds a small opening or pore, the 
stoma (Greek: stoma, mouth; plural, stomata), ${ }^{1}$ which is opened or closed by the expansion or contraction of the guard
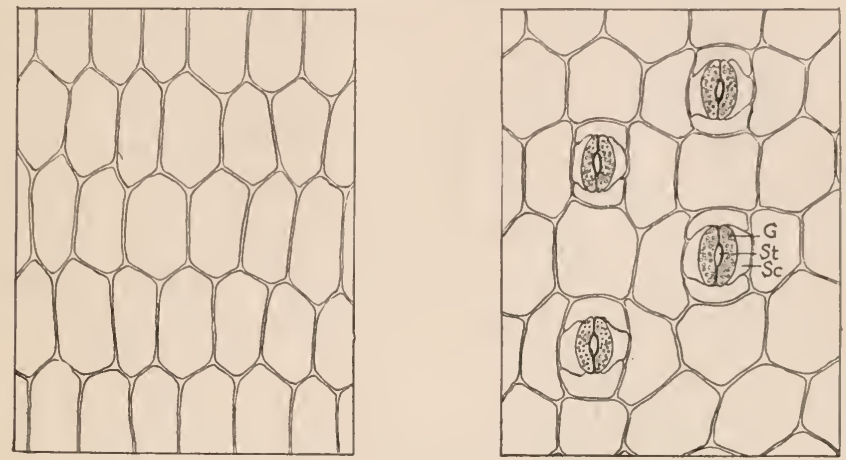

Figs. I3 and I4. Upper epidermis of "Wandering Jew" (Zebrina) leaf, on the left, and lower epidermis, on the right. $S t$ is a stoma, $G$ a guard cell, and $S c$ a subsidiary cell. The stomata are found only on the lower surface of the leaf.

cells. The stomata are very important, for they connect the air spaces among the cells inside the leaf with the external atmosphere. When open, they allow the exchange of water vapor and other gases through the epidermis; and when closed, they complete the barrier to gas movements in either direction. In many plants stomata occur only on the lower surfaces of the leaves; but in some plants they are found on both the upper and lower leaf surfaces.

The mesophyll. The mesophyll tissue is composed of the soft, thin-walled cells that lie among the veins in the interior of the leaf. In most leaves there is beneath the upper epidermis one or more palisade layers, which are composed of

${ }^{1}$ Stomata are so small that 2500 of them have an area about equivalent to that of an ordinary pin hole. They are so numerous, however, that they occupy about $\frac{1}{100}$ of the area of the average leaf. On a square centimeter of the lower surface of a sunflower leaf there are about 150,000 of them. 
elongated cells standing close together, as is shown in Figure I2. The remainder of the mesophyll tissue is made up of ovoid or irregularly shaped cells joined quite loosely, so that air spaces are left between them. In fact, a much larger part of the surfaces of these cells is in contact with air spaces than with other cells. The air spaces within the leaf are continuous, and through them the oxygen and carbon dioxid of the atmosphere can reach every cell in the leaf. We shall see later that the differences in the epidermal and mesophyll cells, and in the way they are arranged, are definitely related to the different processes carried on by each of them.

The veins. The veins in a leaf branch again and again, forming a fine meshwork through all its parts. Each vein is composed of a bundle of water-conducting and food-conducting tissues surrounded by a bundle sheath. The waterconducting tissues are located in the upper side of the vein. These tissues are made up of long, cylindrical cells placed end to end. Usually the inner walls of these cells have spiral thickenings, and sometimes the end walls of the cells are absorbed, leaving continuous tubes or vessels several cells in length. After the growth of the cells is completed, the living protoplasm within them dies, and the dead cases of the cells, with their porous walls, lie within the leaf like bundles of very fine pipes. Through these vessels, the water and mineral salts that are absorbed by the roots pass into the leaf to supply its living cells. The supplies of water and mineral salts pass out through the walls of the water-conducting vessels into the cells that adjoin them, and then from these they pass to the other cells of the leaf.

The food-conducting tissues, or vessels, lie below the waterconducting vessels within the leaf veins. They provide an 
elaborate system of channels by which the surplus foods manufactured in the leaf are distributed throughout the
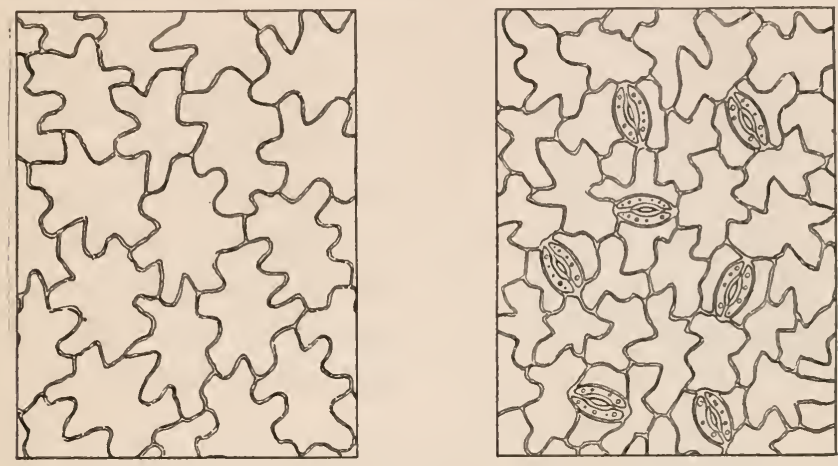

FIgs. 15 and 16 . Upper and lower epidermis of vinca leaf.

plant. The foods pass from the mesophyll cells into this food-conducting tissue, and then down through the petiole of the leaf to the living cells of the stem and roots.

In the smaller veins the bundle sheath is a layer of mesophyll cells. In the larger veins it contains one or more layers of thick-walled cells, which act as a mechanical or supporting tissue. The mechanical tissue is rigid and gives stiffness to the leaf.

Cells, tissues, and organs. We see, then, that the actual work of the plant is done in its cells, of which there are many millions, and it is the sum of the life and work of all these cells that makes up the life and work of the plant as a whole. All cells carry on certain fundamental life processes like respiration and the assimilation of food, but most cells are especially adapted to some particular work that is carried on for the benefit of the plant as a whole. Cells that have the same special function are similar in structure and are generally 
grouped together. Such groups of cells with like functions are called tissues. The epidermis of a leaf, for example, is a tissue covering the mesophyll and veins.

In order to do its work a tissue needs a source of supplies and a means of disposing of its products. Hence the grouping of the tissues may be mutually advantageous. When several kinds of tissues are arranged together so that by their coöperation they can carry on some general function of the plant, they form an organ. The leaf, for example, is an organ especially concerned with the manufacture of food. It is made up, as we have seen, of five different tissues, each composed of thousands of cells.

The chloroplasts. Of the several structures found within the mesophyll cells, the most important in the primary process of food manufacture are the chloroplasts. These are round or lens-shaped bodies which contain a green coloring matter called chlorophyll. They are composed of living material and belong to a group of structures called plastids, that are found in the cytoplasm of all plant cells. Cells may contain many or only a few chloroplasts, and these may be located deep within the leaf or near its surface (Fig. I7). Since the chloroplasts are the special apparatus for the manufacture of food, the amount of food produced by a plant under any given conditions is roughly proportional to their number.

The chlorophyll. Chlorophyll is held in the chloroplasts in much the same way that water is held in a sponge. It stains the chloroplasts green, and it may be removed from them by putting the leaf in alcohol, in which the chlorophyll is soluble. After the chlorophyll is dissolved, the chloroplasts remain in the cell, but they are colorless and the leaf is white 


\section{Leaves and Their Structures}

or yellowish instead of green. Light is usually necessary to the development of chlorophyll. The white sprouts on potatoes in a dark cellar, the blanching of celery when the lower part of the leaves is covered, and the whitening of grass under a board, are familiar evidences of this fact. In the inner tissues of plants and in the underground parts, the plastids are usually colorless; but in many plants these parts become green if they

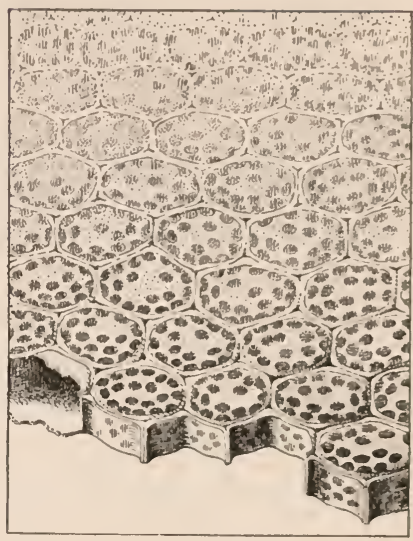

FIG. I7. Part of a moss leaf that is composed of a single layer of cells. are exposed to the light. This is why potatoes that grow at the surface of the soil are likely to be green. 
Suggestions for Laboratory Work to Precede Chapter Three

Answer the following questions by means of experiments :

1. Do leaves grow toward the light?

2. How is the blade moved into its position with reference to light?

3. Is light necessary for starch manufacture?

4. Is chlorophyll necessary for starch manufacture?

5. Does the manufactured starch remain in the leaves? 


\section{CHAPTER THREE}

\section{THE MANUFACTURE OF FOOD}

You will probably remember from your study of physiology that all the foods used by animals belong to three classes of chemical substances: carbohydrates, fats, and proteins. These same classes of substances constitute the food of plants. A grain of corn contains a supply of starch, oil, and protein for the young plant, and these same foods that are used by animals are accumulated in many plants. The difference in the nutrition of plants and animals lies, then, not in any differences in the foods used, but in the way their foods are secured. In this chapter the manner in which plants obtain their foods will be discussed.

Plants the source of all food. Mineral soils and the air do not contain any of the substances that we class as foods. Yet green plants may grow luxuriantly on mineral soils. It follows, therefore, that green plants are able to manufacture their own foods. They can synthesize, or build together, simple substances that they obtain from the soil and air into the complex foods that they require. Animals lack this power. They must have fcods that have already been built up, rather than the simple materials of which foods are made. These foods they secure either directly or indirectly from plants. The ability of plants to manufacture complex foods from simple substances brings up several questions :

What is the method by which plants produce food? Just what parts of the plants do the work? What constitutes the machinery? Out of what materials is the food manufactured? How is the energy supplied? And what are the conditions under which the process goes on? 
Photosynthesis. The primary step in the making of food is the building of carbohydrates through the process called photosynthesis (Greek: photos, light, and synthesis, putting together). In this process carbon dioxid from the air and water from the soil are brought together in the chloroplasts and united to form carbohydrates. Sugar is the first abundant product, but being soluble in the water of the cell, it is quite invisible. In most plants a large part of the sugar is rapidly changed to starch, and as the starch is insoluble in water, it accumulates temporarily in the chloroplasts in the form of little grains which may readily be seen with a microscope. There is a very simple test for the presence of starch. A solution of iodin stains most substances yellow or brown, but it stains starch blue or purple. So any object that contains starch - a cell, a leaf, or a piece of cloth - will be colored purple if iodin is applied to it.

Light and photosyrithesis. If we take a leaf from a plant that has been in the dark for two days, place the leaf in warm alcohol to remove the chlorophyll, and then put it in a solution of iodin, it is stained yellow. This proves the absence of starch. If the plant is then put in the light for a few hours, a leaf tested in the same way will be colored purple, showing that starch is present. Evidently light is necessary for photosynthesis. It is not surprising to find that light is so effective in building up compounds in the green parts of plants, for it is a powerful agent in causing chemical changes. You may be familiar with its use in photography. The film and the printing paper have on them a layer of gelatin containing certain chemicals. Exposure to the light for even a fraction of a second effects in these chemically treated surfaces changes which may be seen when the film or paper is developed. 
Many chemical substances kept in drug stores must be protected from the light; otherwise they soon change their composition and become different substances.

Chlorophyll necessary for photosynthesis. By using a plant with variegated leaves, the iodin test will show that the white parts form no starch. Since starch is formed only in the green part of the blade, it is evident that chlorophyll is necessary for photosynthesis. Any green part of a plant can. carry on photosynthesis, but the principal food factories are the leaves.

Effects of temperature on photosynthesis. The effects of temperature on photosynthesis may be demonstrated by taking plants that have been in the dark long enough for the starch to be removed from the leaves and placing them in the light, under different temperature conditions. Such tests will show that the ordinary summer temperatures are most favorable for photosynthesis, and that when the temperature falls nearly to the freezing point photosynthesis decreases rapidly or ceases entirely.

Materials and products. Experiments have shown that the materials used in photosynthesis are carbon dioxid and water. Carbon dioxid is a gas that makes up about three out of every 10,000 parts of the air. Its molecule contains one atom of carbon and two atoms of oxygen $\left(\mathrm{CO}_{2}\right)$. Water, which the plant gets from the soil, has two atoms of hydrogen and one atom of oxygen in every molecule $\left(\mathrm{H}_{2} \mathrm{O}\right)$. The carbohydrates made in photosynthesis from the carbon dioxid and water contain these same elements. ${ }^{1}$ The simple sugars,

${ }^{1}$ Carbohydrates include many substances commonly classified as sugars, starches, and celluloses. The simple sugars, glucose and fructose, have a formula $\mathrm{C}_{6} \mathrm{H}_{12} \mathrm{O}_{6}$. The double sugars like sucrose (cane and beet sugar) and 
like glucose, which are the first abundant products of photosynthesis, contain six atoms of carbon, twelve atoms of hydrogen, and six atoms of oxygen in each molecule. For every molecule of glucose manufactured, therefore, it would require six molecules of carbon dioxid to furnish the carbon and six molecules of water to provide the hydrogen. These amounts of water and carbon dioxid, however, contain eighteen atoms of oxygen, twelve more than are needed for the making of glucose,

$$
6 \mathrm{CO}_{2}+6 \mathrm{H}_{2} \mathrm{O}=\mathrm{C}_{6} \mathrm{H}_{12} \mathrm{O}_{6}+\mathrm{I}_{2} \mathrm{O} \text {. }
$$

We should therefore expect oxygen to be given off from leaves during photosynthesis. That this actually happens may easily be shown by inverting under water a bundle of the branches of some water plant, like Elodea, with the cut ends placed under the mouth of a test tube that is filled with water (Fig. I8). When exposed to the light for a day, the tube will be partly filled with gas. By testing with a glowing match or splinter, the gas may be shown to be mostly oxygen. ${ }^{1}$ maltose (malt sugar) may be built up by combining two simple sugars,

$$
\begin{aligned}
& \mathrm{C}_{6} \mathrm{H}_{12} \mathrm{O}_{6}+\mathrm{C}_{6} \mathrm{H}_{12} \mathrm{O}_{6} \\
& \text { glucose fructose }
\end{aligned} \underset{\text { cane sugar water }}{\mathrm{C}_{12} \mathrm{H}_{22} \mathrm{O}_{11}+\mathrm{H}_{2} \mathrm{O},}
$$

one molecule of water being lost in the process; and they may be split up into two of the simple sugars by the addition of a molecule of water. The starches and celluloses are formed by combining many molecules of sugar and removing as many molecules of water as there are molecules of sugar used. Consequently their formulas are $\left(\mathrm{C}_{6} \mathrm{H}_{10} \mathrm{O}_{5}\right)_{n}$, in which $n$ represents a rather large number. The starches and celluloses may also be split up into simple sugars by adding the required number of molecules of water. This last process is the one by which corn sirup (glucose) is made from corn starch. The process may be represented by the equation,

$$
\begin{aligned}
& \left(\mathrm{C}_{6} \mathrm{H}_{10} \mathrm{O}_{5}\right)_{n}+n\left(\mathrm{H}_{2} \mathrm{O}\right) \rightarrow n\left(\mathrm{C}_{6} \mathrm{H}_{12} \mathrm{O}_{6}\right) \text {. } \\
& \text { starch water glucose }
\end{aligned}
$$

${ }^{1}$ Water containing a considerable amount of dissolved carbon dioxid should be used in this experiment, so that photosynthesis may go on rapidly. For this reason pond water is better than tap water. 
How the supplies are obtained. Every industrial workshop must constantly be provided with the raw materials needed in the manufacture of its product. Likewise the leaf must be supplied with the substances that it uses in the making of food. These necessary supplies come to the leaf through the veins and the stomata. The water passes into the leaf through the water-conducting tissue of the veins. The supply of carbon dioxid reaches the cells of the mesophyll through the stomata and the intercellular spaces. When the stomata are closed, very little carbon dioxid can enter, and at such times the process of photosynthesis is of necessity greatly retarded.

How the products and wastes are removed. The manufacture of carbohydrates in the leaf goes on only during the hours of sunlight; the removal

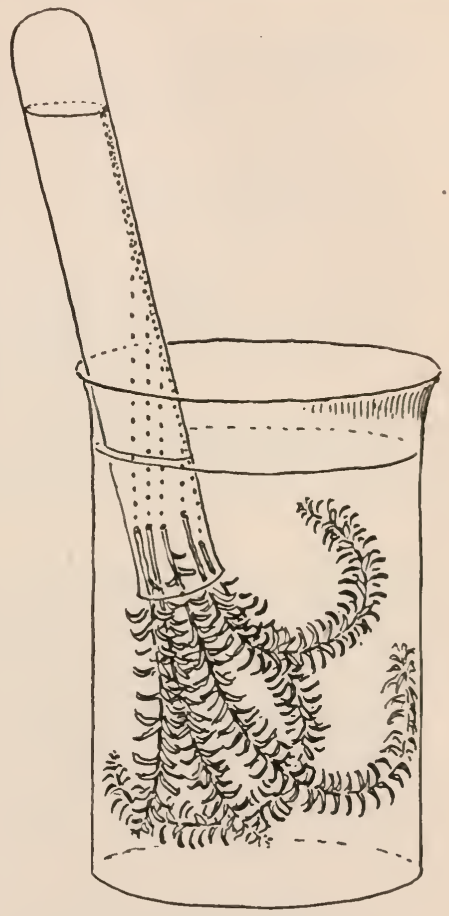

FIG. I8. Experiment to show the giving off of oxygen from a water plant (Elodea) during photosynthesis. of food goes on at all times. The food-conducting tissue of the veins furnishes the outlet for the product, which is transferred in the form of sugar. During the day the rate of manufacture is so much greater than the rate of removal of food, that starch and sugar accumulate. During the 
night the movement of food into the stem nearly empties the leaf, and by early morning the cells are again in good

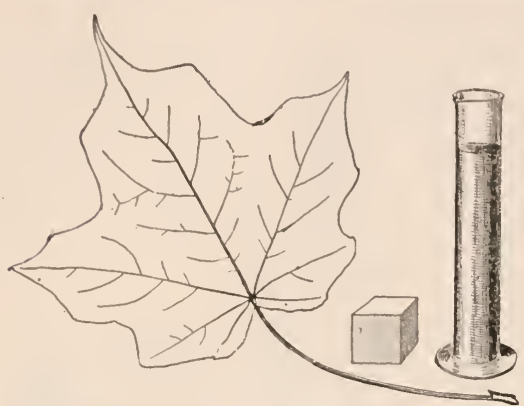

FIG. I9. A maple leaf and the sugar and maple sirup equivalent to the amount it could manufacture in a season. All drawn to the same scale.

and when the stomata are open. Even under these conditions the work may be interfered with if more than a certain amount of the products accumulate in the cells.

The amount of the product. The amount of carbohydrates produced in photosynthesis varies so greatly in different plants and under dissimilar conditions that it is very difficult to make a general estimate of it. The result of many experiments shows that under favorable conditions a square meter of leaf surface makes on an average about I gram of carbohydrate per hour. At this rate a square meter of leaf surface in midsummer would require 2 months to produce food equivalent to that consumed by the average man in a day. This average rate of carbohydrate manufacture may also be expressed by saying that the leaf makes enough sugar in a summer to cover it with a layer I millimeter thick (Fig. I9). 
Summary of photosynthesis. We may summarize the facts we have learned regarding photosynthesis by likening it to a manufacturing process of human invention:

The factory

The workrooms

The machinery

The energy

The raw materials

The supply department

The products is the green tissue, especially that of the leaves.

are the cells.

is the chloroplasts and the chlorophyll.

is the sunlight.

are the carbon dioxid and water $\left(\mathrm{CO}_{2}\right.$ and $\left.\mathrm{H}_{2} \mathrm{O}\right)$.

is the stomata and intercellular spaces, and the water-conducting tissue.

are carbohydrates: sugars $\left(\mathrm{C}_{6} \mathrm{H}_{12} \mathrm{O}_{6}\right)$ and starches $\left(\mathrm{C}_{6} \mathrm{H}_{10} \mathrm{O}_{5}\right)_{n}$.

The forwarding department is the food-conducting tissue, and it works both day and night. The waste material is oxygen, which escapes through the intercellular spaces and the stomata.

The working hours

The production of fats. In addition to carbohydrates, plants make and use two other classes of foods: fats and proteins. The fats are quite similar to the carbohydrates in composition. They contain the same chemical elements: carbon, hydrogen, and oxygen. The proportion of the oxygen to carbon, however, is smaller. At ordinary temperatures fats occur in plants both as solids and liquids. The 
liquid fats are commonly called oils. They are probably made directly from the carbohydrates. As there appears to be present in the cell no special fat-producing apparatus for bringing about this chemical change, it is probably effected by the protoplasm and fat can therefore be formed in any living part of the plant. Although fats are widely distributed in the plant body, they are especially abundant in seeds and fruits. Some of the commonest fats and oils of commerce derived from plants are corn oil, coconut oil, cottonseed oil, linseed oil, castor oil, olive oil, peanut oil, and cocoa butter.

The making and use of proteins. The proteins are the third class of foods. They too are constructed in large part from the carbohydrates; but their molecules are vastly more complex than are the molecules of carbohydrates and fats, and, in addition to carbon, hydrogen, and oxygen, they contain the elements nitrogen and sulfur, and occasionally phosphorus. In protein synthesis the amount of sulfur and phosphorus consumed is small, but a very large amount of nitrogen is required. Furthermore, nitrogen in the gaseous condition in which it occurs in the air does not readily unite with other substances; so, although it makes up four fifths of the atmosphere, green plants cannot take it directly from the air. For the nitrogen needed for protein-making they must depend, therefore, on the supply which comes from the soil in the form of nitrates. This is carried to the cells with the water that is absorbed by the roots. Protein synthesis, like the synthesis of fats, is probably effected by the protoplasm. It may occur in nearly all parts of a plant, but it takes place for the most part in the leaves. Proteins, because of their complex composition, are especially used in building up and repairing the protoplasm. They are trans- 
ported from the leaves by the food-conducting tissue of the bundles.

\section{Soy beans}

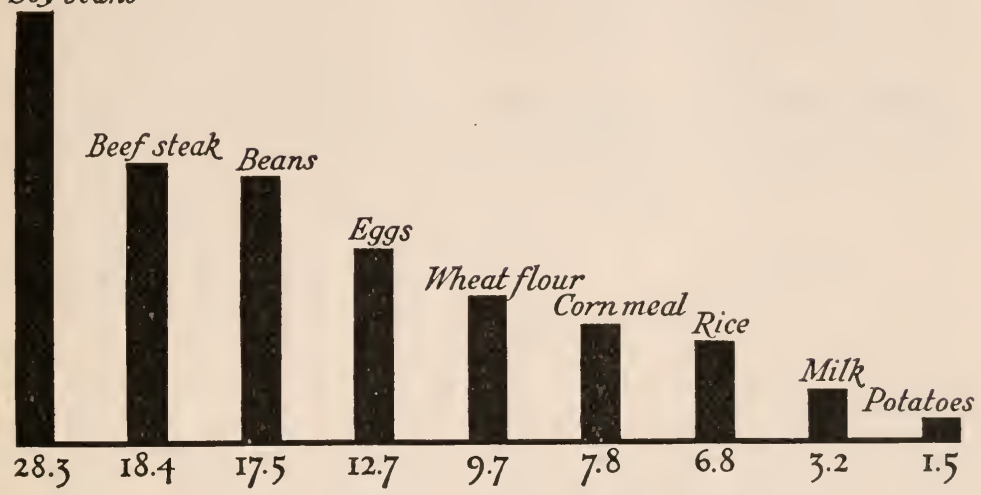

Fig. 20. Percentage of protein in various foods.

The most expensive portion of the diet of human beings is the proteins. Figure 20 shows that in soy beans we possess the richest source of protein. It also shows why the soy bean is one of the most important of foods in the Asiatic nations, where animal foods are very limited. One dollar will buy several times as much protein in soy beans as it will in any other plant or animal food. However, recent experiments in animal feeding have shown that for maintenance and growth some proteins are more valuable pound for pound than others.

Amount of food produced per acre. Since the food supply of all living beings depends primarily upon these synthetic processes that are carried on in plants, it is of interest to inquire how much food may be derived from an average acre of land when planted to different crops. It must be remem- 
bered that the plants that produce this food take a considerable part for their own maintenance, and that the part which the farmer harvests is the plants' surplus. The table given below shows the average yield per acre; its food value calculated in Calories; ${ }^{1}$ and the number of men that $\mathrm{I}$ acre planted to different crops might feed for I day, assuming that each man requires 3000 Calories per day.

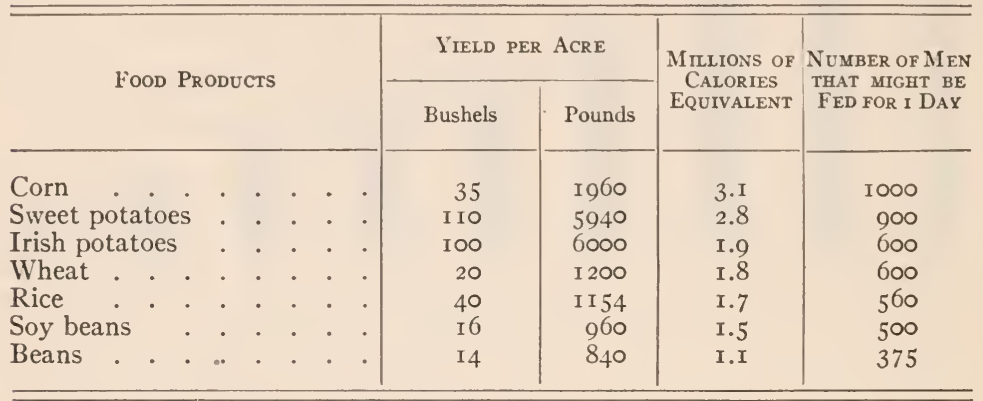

If the plant products of an average acre are fed to cattle, the dressed beef produced amounts to only I 25 pounds, yielding an energy equivalent to the food of 43 men for I day. If transformed into pork, the yield is 273 pounds, or sufficient food for 220 men for I day. ${ }^{2}$ This shows the great loss of energy that results when plant foods are converted into meat before they reach the human consumer. It is evident that as the human family becomes larger and food becomes scarcer, we shall have to take more and more of our foods directly from plants.

${ }^{1} \mathrm{~A}$ Calorie is the amount of heat necessary to raise the temperature of $\mathrm{I}$ kilo of water I degree Centigrade.

2 United States Department of Agriculture, Farmers' Bulletin No. 877. 


\section{The Manufacture of Food}

\section{PROBLEMS}

1. How do the white parts of a variegated leaf get food?

2. Occasionally in a field of young corn a stalk that lacks chlorephyll will be found. This white stalk dies as soon as the food supply in the grain from. which it came is exhausted. Why?

3. Geraniums with variegated leaves occasionally produce branches that are entirely white. A noted horticultural firm offered \$ 1000 to any one of its gardeners who would root one of these branches and thus produce a whiteleafed geranium. What was the chance for success? Why? 


\section{Suggestions for Laboratory and Field Work to Precede Chapter Four}

1. Examine one or more plants from each of the following groups, noting the arrangement of leaves on vertical and inclined stems:

Corn, elm, hackberry, wheat, rye, canna, bamboo.

Lilac, viburnum, catalpa, ash, maple.

Willow, poplar, pine, spruce, peach, apple, sunflower.

Cat-tail, iris, onion, hyacinth, yucca, century plant.

2. In the field, study some of the following plants, noting the positions their leaves take with reference to light:

Sugar maple, elm, beech, oak, catalpa, Virginia creeper,

Boston ivy.

Tulip tree, cottonwood, birch, willow, spirea, barberry.

Which cast the more complete shade, trees whose leaves are sensitive or insensitive to light?

3. On several of the following plants study the leaf positions, to determine how the blades reach their positions when mature:

Sunflower, mallow, Virginia creeper, Boston ivy, English ivy, wild prickly lettuce, nasturtium, ragweed, compass plant, water lily. Other plants of the locality will furnish additional material for study.

4. Examine submerged plants like pondweeds, Elodea, Ceratophyllum, and water buttercups, and compare their leaves with those of land plants.

5. Sections of leaves of different kinds may be used to show variations in internal structures.

6. Experiments:

Grow geraniums and nasturtiums with one-sided illumination. Mark the original position of the leaves with stakes and note changes in position.

Try the effects of light and darkness on the positions of leaves of sensitive plants, beans, or sweet clover. Black paper covers may be used to exclude the light. 


\section{CHAPTER FOUR}

\section{LEAVES IN RELATION TO LIGHT}

THE leaf, as we have seen, must receive light in order to produce food. Leaves are variously arranged on stems, and stems have all sorts of positions. Many of these leaf arrangements and stem positions are not advantageous for the display of leaves to the light. The leaf, however, and especially the petiole, is so influenced by light during its development, that the leaf when mature has the best possible position with respect to light. The raised leaves of the pumpkin, the mosaics of leaves formed on the sides of buildings by the Boston ivy, and

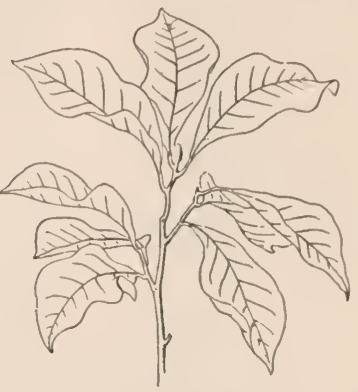

FIG. 21. Vertical branch of magnolia. Note the alternate arrangement of the leaves.

the successive tiers of leaves on a beech tree illustrate different arrangements by which large numbers of leaves are efficiently displayed to the light.

The arrangement of leaves on stems. Leaves develop from somewhat thickened places on the stems, called the

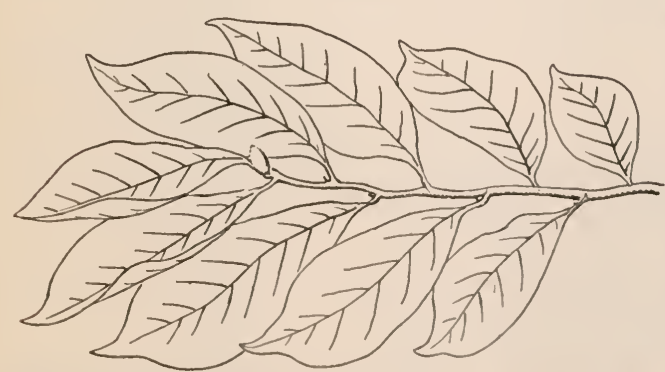

FIG. 22. Horizontal branch of magnolia. Compare leaf positions with those of Figure 2I. nodes. Each node may bear one, two, or several leaves. According to the number of leaves that the node bears, the leaf arrangement is designated as alternate, opposite, or whorled. 
In the alternate arrangement each node bears one leaf. This is also spoken of as the spiral arrangement, because a

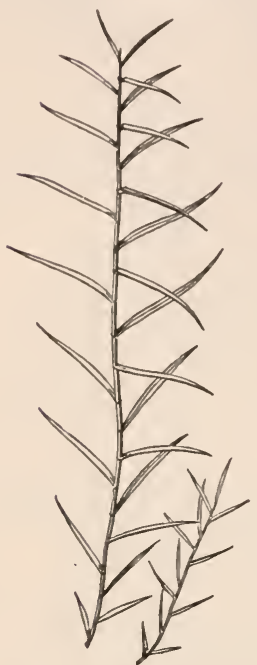

FIG. 23. A sedge (Dulichium), showing threeranked arrangement of the leaves. line drawn through successive leaf bases forms a spiral about the stem. Sometimes, as in the corn plant, the spiral passes half around the stem in going from one node to the next (page 50). In other plants, like the sedges, the spiral passes but a third around the stem between nodes. In several of our common fruit trees, as the apple and the peach, the spiral between nodes passes two fifths around the stem. These variations of the spiral arrangement are called the tworanked (Fig. 28), three-ranked (Fig. 23), and five-ranked arrangements.

In the opposite arrangement two leaves occur at each node. The leaves at successive nodes, however, are at right angles to each other (Fig. 25), giving four ranks of leaves. The maple, ash, dogwood, and lilac furnish examples of the opposite arrangement. In the whorled arrangement the leaves are in a circle about the node. The Indian cucumber root (Medeola) and the wood lily of the leaves.

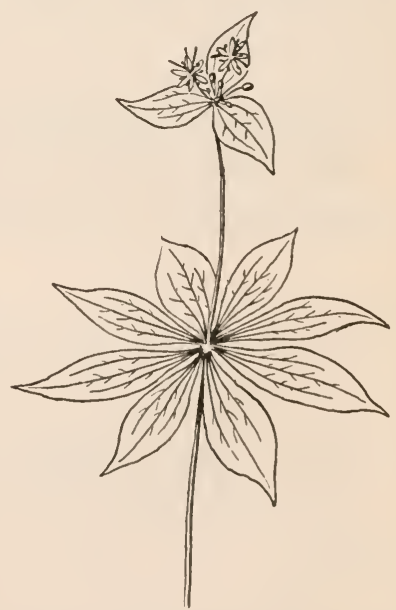

FIG. 24. Indian cucumber root, showing the whorled arrangement 
(page 310) furnish excellent examples of the whorled arrangement.

However, it is only on upright stems which receive the light equally on all sides, that the blades take their normal positions directly out from the nodes. If an erect shoot be placed in an inclined position, it is easy to see that the leaves are no longer well displayed to the light. As may be readily seen by examining the branches of trees and the stems of trailing plants, horizontal or inclined stems become twisted during development because of unequal illumination (Fig. 26). The twisting of the stems brings the leaves into better positions to receive light, but it often obscures the normal arrangement of the leaves.

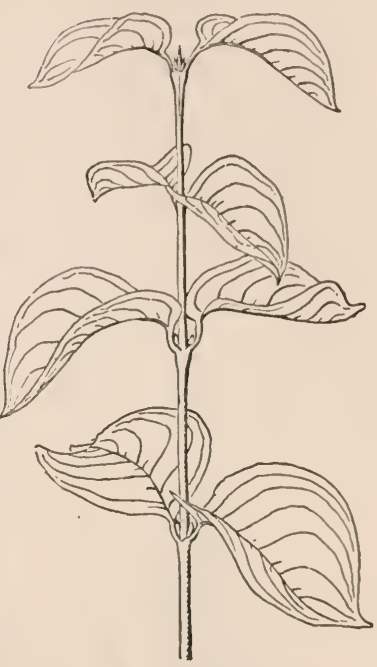

FIG. 25. Vertical branch of dogwood, showing the opposite arrangement of the leaves.

The positions of leaves with reference to light. If leaves are moderately sensitive to light, they assume a position

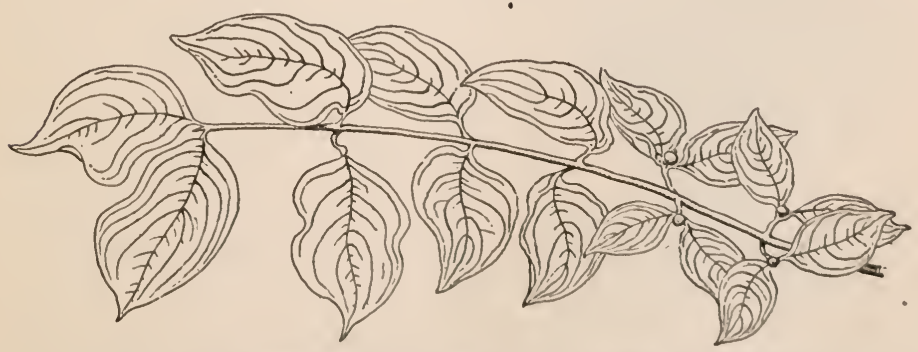

FIG. 26. Horizontal branch of dogwood. Compare with Figure 25. 
approximately at right angles to the line along which the greatest amount of light reaches them. Consequently the leaves on most of our common trees, shrubs, and herbs tend to take an approximately horizontal position. The sugar maple and the horse-chestnut are examples of trees whose leaves are displayed in this manner. In the cottonwood and tulip tree the leaves are only slightly sensitive to light, and the result is that their leaves assume a great variety of positions.

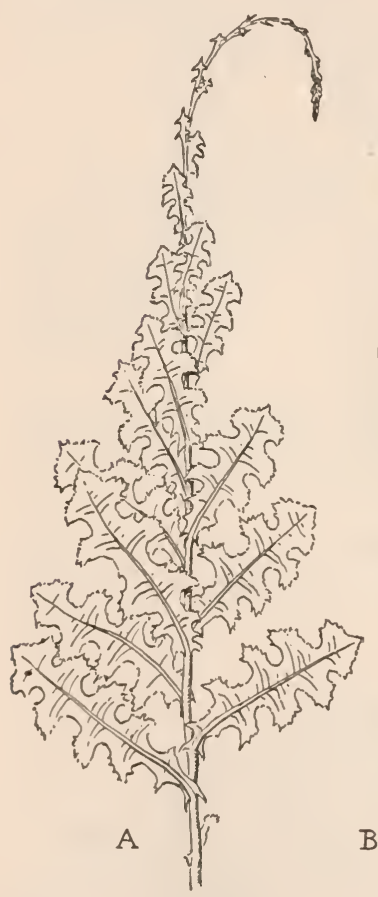

Fig. 27. Prickly lettuce plant: $A$, viewed from west; $B$, viewed from south. Drawn from a specimen grown under exposure to bright sunlight.
If leaves are extremely sensitive to light, the blades may turn toward the sun in the early morning and follow the sun throughout the day, always keeping the broad face of the leaf to the light. The leaves of the common mallow move in this way.

Compass plants. There is another class of plants which are sensitive to light, but which respond to it in a very different manner. These are the so-called compass plants, of which the wild prickly lettuce is a widely distributed example. In sunny situations the leaves of these plants tend to take positions edgewise to the direction of the most intense light. As the sunlight is most intense at noon, it is 
only in the morning and late afternoon that the flat sides of the leaves are perpendicular to the sun's rays. This response to the light also places most of the leaves in a vertical northand-south plane and suggests the name "compass plant." When grown in partial shade, the leaves of these same plants are horizontal. Hence it is clear that the position of their leaves in sunny situations is the result of light conditions.

How the blade attains its position with reference to the light. The attainment of its position by the leaf blade is partly accomplished, as has been noted, by the bending and twisting of the plant stem during its development. To a much greater extent the blade owes its position to the bending, twisting, and elongating of the petiole. Indeed, this is the particular advantage of the petiole. Its length and direction of growth are for the most part determined by the way in which the light falls on the blade during the period of development. An examination of a branch of a maple will disclose how the lengthening and bending of the petioles help to fit each leaf into a position where it will receive the light.

Vertical leaves. In a number of common plants, including the iris, cat-tail, calamus, and many grasses, the leaves are vertical because they are held

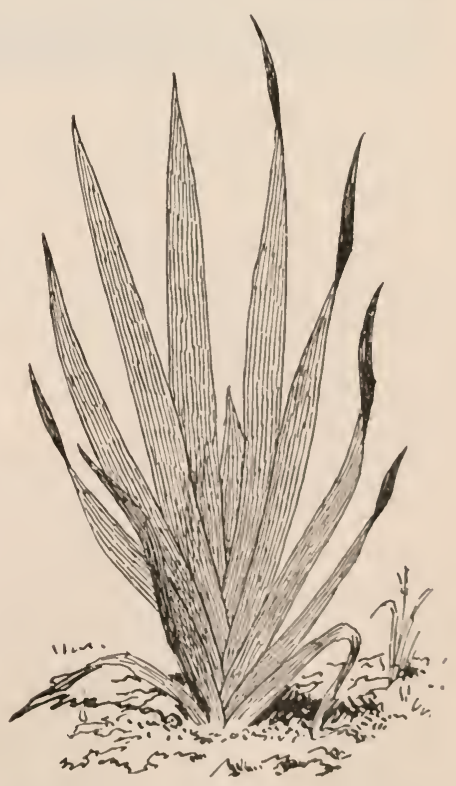

FIG. 28. Iris, showing leaves held in vertical position by the sheathing bases. 


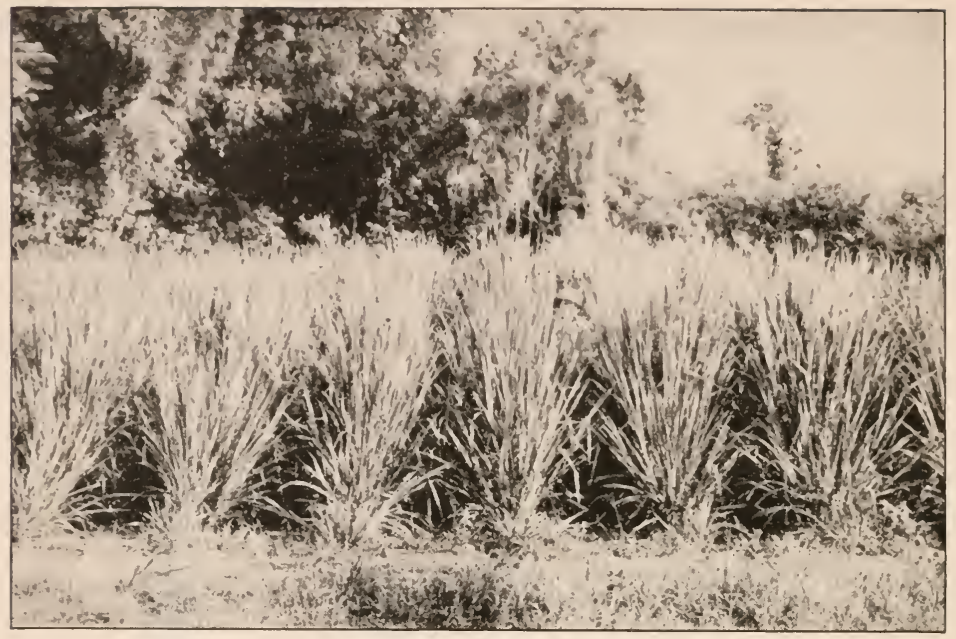

FIG. 29. Guinea grass, a plant grown in the tropics for fodder. Note the vertical leaves and the large amount of leaf surface exposed by the plant to the light.

in this position by their sheathing bases rather than because of a response to light. These plants usually occur in dense growths, and the vertical position of the leaves permits the light to penetrate to their bases. This has the advantage of allowing photosynthesis to go on throughout the entire length of the leaves.

Differences in vertical and horizontal leaves. Vertical leaves differ from horizontal leaves in several particulars:

In vertical leaves the mesophyll may be composed of spongy tissue, or it may be composed entirely of palisade cells. More rarely there are palisade layers on both sides, with a spongy layer between. In contrast, a horizontal leaf usually has a palisade layer beneath the upper epidermis, and the lower portion of the mesophyll is composed of loosely arranged cells. In vertical leaves stomata usually occur on 
both surfaces, while in most horizontal leaves the stomata are confined to the lower surface (page i8). Vertical leaves

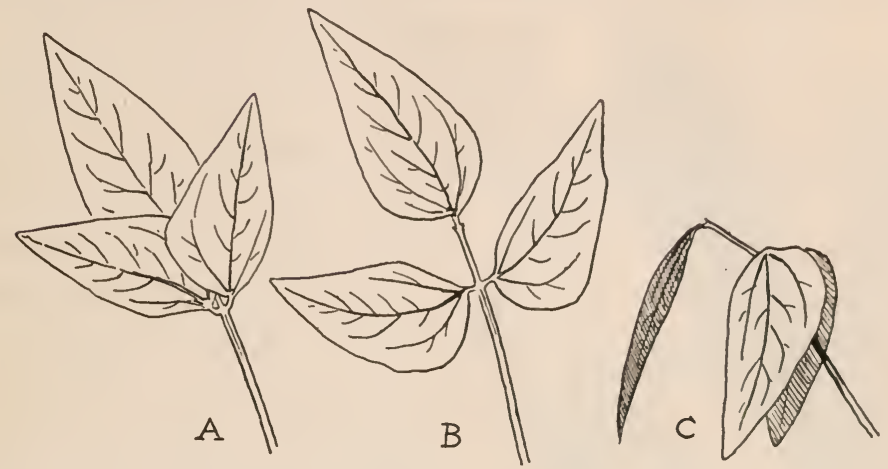

FIG. 30. Various positions taken by leaflets of lima bean: $A$, position in intense light; $B$, position in diffuse light; $C$, position in darkness.

are likely to be of the same color on both surfaces, while horizontal leaves are generally of a darker green on the upper surface.

The difference in the color of the two sides of a horizontal leaf is due to the presence of a larger amount of chlorophyll in the compact palisade layers of the mesophyll than in the loose spongy layers beneath. In vertical leaves, the similarity of structure in the mesophyll on each side, and the fact that both surfaces of the leaf are equally illuminated, account for the sameness of color of the two surfaces.

Motile leaves. The leaves of which we have been speaking have their positions rather definitely fixed when they reach maturity. There is another class of leaves, however, in which the positions of the blades are not fixed but are changed according to the intensity and direction of light. A familiar example is the roadside sweet clover. At night the three 
leaflets of the compound leaf droop downward from the petiole; in the medium light of a cloudy day they are held per-

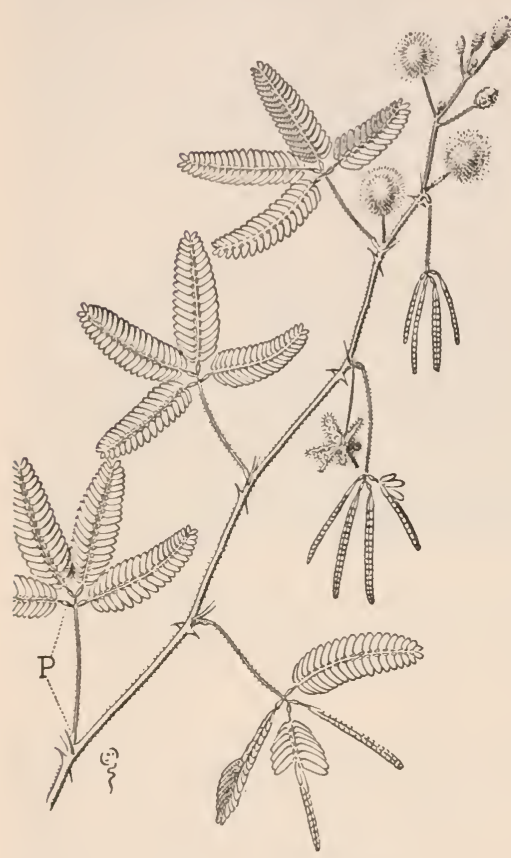

FIG. 31. Sensitive plant. The leaves on the left side are in normal positions; those on the right side have been touched and the leaflets have folded together wholly or in part and the petioles have folded toward the stem. $P$ is the pulvinus. pendicular to the light; in the most intense sunlight the blades are raised above the petiole until they are edgewise and point toward the light. Some observation of bean seedlings, which may readily be grown in the laboratory, will be instructive in this connection. Other examples of motile leaves may be seen in the honey locust, the leaflets of which fold upward at night, and in white clover, oxalis, and the red-bud tree. The leaflets of the sensitive plant vary their positions according to light intensity, and also when touched or injured in any way (Fig. 3I).

The change of position in motile leaves is brought about by changes in the water content of the cells on opposite sides of a special organ called the pulvinus (Fig. 32), which is located at the base of the leaflets. This device may readily be studied in the leaf of the bean.

The leaves of shade plants. As may be observed by a trip 
to the woods, the leaves of plants growing in the shade are usually darker and more bluish-green than the leaves of plants growing in full sunlight. This difference in color is accounted for in part by the amount of chlorophyll near the surface and in part by a slight difference in the color of the chlorophyll itself (page 63). In a few shade plants the depth of the green color is increased by the presence of chloroplasts in the epidermal cells. Shade plants are not subjected to drying, as are plants growing in exposed situations, and generally speaking their leaves are broad and thin. The leaves of these plants differ further from the ordinary leaf in that the cuticle is less developed, the mesophyll is composed al-

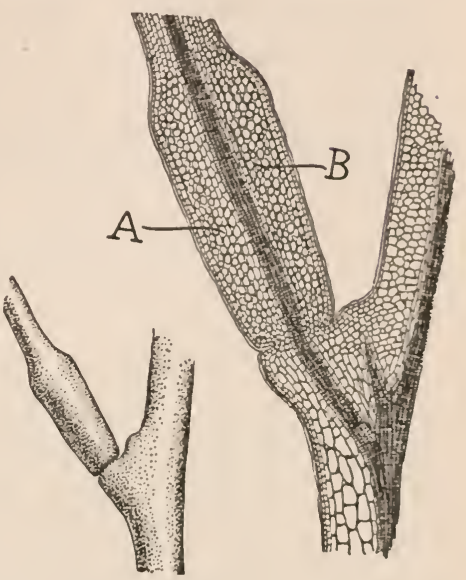

Fig. 32. Pulvinus and section of pulvinus from leaf of sensitive plant, both enlarged. When the leaf is touched, the water in the cells on the side $A$ passes outward into the intercellular spaces, causing the cells partially to collapse. The pressure of the cells on the side $B$ then forces the leaf downward. most entirely of spongy tissue, and usually stomata are present on both surfaces of the leaf.

Submerged leaves. Every one who has gone fishing or rowing knows that a great deal of sunlight is reflected from the surface of water. This means that the amount of light that penetrates the surface is reduced by just the amount that is reflected. The penetration of the water by the sun's rays is further interfered with by the fine sediment that clouds our ponds and lakes. Every one who has dived and opened his 
eyes under water knows that it is dark at a comparatively slight depth. Hence submerged plants always grow in light of reduced intensity. They receive an amount of light comparable to that received by the shade plants found in forest ravines. Submerged leaves, too, are of very soft texture, and are quite without mechanical tissue in the veins, so that they are unable to support themselves when lifted from the water. They are kept upright in the water by their buoyancy, which is due to the greatly enlarged air spaces among the mesophyll cells.

Summary. Light has a marked effect upon the positions, the color, and the structures of leaves. Leaves tend to be placed directly outward from the nodes to which they are attached, but light affects them during their development, and most leaves come to occupy positions that have more relation to the light than to the stem which bears them. Some leaves vary their positions constantly as the light changes.

Leaves of plants grown in weak light, including those of submerged plants, usually have the mesophyll made up wholly or largely of spongy cells. Leaves of plants grown in intense light usually have the mesophyll made up wholly or largely of palisade cells.

\section{PROBLEMS}

1. Why do house plants flourish best at south windows in the winter time?

2. What part of full sunlight is received by a plant that stands near a window?

3. Why do gardeners shade lettuce plants in midsummer?

4. What other condition, besides light intensity, is affected by shading? 


\section{Suggestions for Laboratory Work to Precede Chapter Five}

1. Cut a leaf from some plant, preferably under water. Then immerse the cut end in red ink or eosin and let it stand for some time, watching the movement of the red color in the veins. Thin leaves, like those of balsam and nasturtium, are especially suited to this experiment. If thick leaves are used, they may be split with a knife in order to show the veins.

2. Study the surface coverings - cuticle, wax, and hairs - on a series of leaves like the mullein, century plant, bur oak, tomato, and geranium.

3. Compare leaves of water plants and moist soil plants with those of desert forms like the yucca, agave, and cactus.

4. Examine free-hand sections of leaves or prepared microscope slides that will show variations in stomata, compactness of tissue, development of air chambers, and water storage.

5. Determine the relative time required for the wilting and complete drying out of several kinds of leaves, using leaves of different texture, thickness, and surface covering.

6. Take three similar leaves from a single plant. Cover with a thin layer of vaselin the upper surface of one, the lower surface of another, and both surfaces of the third. Determine the relative time required for the leaves to wilt and also to dry out completely.

7. Experiments :

Show that water is given off by plants, by covering a plant with a bell jar.

Ascertain the amount of water transpired by a potted plant, by covering the pot and soil with melted paraffin and weighing the plant at intervals. 


\section{CHAPTER FIVE}

\section{THE WATER RELATIONS OF LEAVES}

DURING a prolonged drought in Illinois, in I9I4, oats in some places failed to attain a height of more than 4 inches and produced practically no grain, and corn which should have averaged Io feet in height reached only 5 feet in many fields, and yielded only half the normal amount of grain. In the four great corn-growing states there must be 3 inches of rainfall in July for the best yield of corn; and if the rainfall during July is $2 \frac{1}{2}$ inches instead of 3 , it is estimated that at normal prices there is an average loss of $\$ 5$ an acre, or a total loss of $\$ 150,000,000$. Those who cultivate plants know from experience the importance of a sufficient water supply in the production of crops, and the reason why the water supply is important will be apparent when we understand the uses made of water by the plant.

Why water is necessary to a plant. The active protoplasm of all plant cells is in a semiliquid condition. More than $9 \circ$ per cent of its weight is made up of water, and in consistency it closely resembles white of egg. The several parts of the protoplasm - the cytoplasm, the nucleus, and the plastids - differ somewhat in their water content, but all of them must be nearly saturated with water to carry on the life processes. When the amount of water in the cell falls much below this point, the protoplasm becomes rigid and its processes are retarded. In many plants the protoplasm may even die if the water content is greatly reduced. Water is necessary for the life of the protoplasm of plant cells.

Water is one of the materials used in the production of carbohydrate. Without it the process of photosynthesis, 
upon which the world depends for its supply of food, cannot be carried on. Water is necessary for photosynthesis.

Substances can enter plants only when they are in solution. Both the gases and the mineral compounds that are used by the plant in its various processes must be in solution in water before they can be absorbed or pass from one cell to another within the plant. Indirectly as well as directly water is necessary to photosynthesis ; for water keeps the mesophyll cells wet and thus makes it possible for the carbon dioxid to enter the cells. Water is necessary for the absorption of minerals and gases and for the transfer of materials within the plant.

Vacuoles the reservoirs of the cells. The vacuoles inside the cytoplasm are minute reservoirs within the cells. They contain the cell sap, which consists of water holding in solution sugars, mineral salts, and acids. The relation of the vacuoles to the protoplasm is most important, for the protoplasm can secrete excess substances into the vacuole or remove substances from it as they are needed. In many industrial establishments individual machines are provided with small boxes or trays, some to hold raw materials and others to receive the manufactured product. The vacuoles have the same function as these storage boxes: they hold a supply of the raw material for the use of the protoplasm, and they receive some of the products that result from the activities within the cell.

Transpiration. If we expose a wet cloth to the air, the water evaporates; that is, it changes from a liquid to a vapor and passes off into the atmosphere. The same thing happens when a plant is exposed to the air. The mesophyll cells of the leaf are continually giving up water vapor to the intercellular spaces, from which, if the stomata are open, 
this vapor passes out into the atmosphere. The epidermis of the leaf also allows some water to pass through it, but in land plants this is a relatively small amount, because the cuticle hinders the process (page 54). The giving off of water vapor

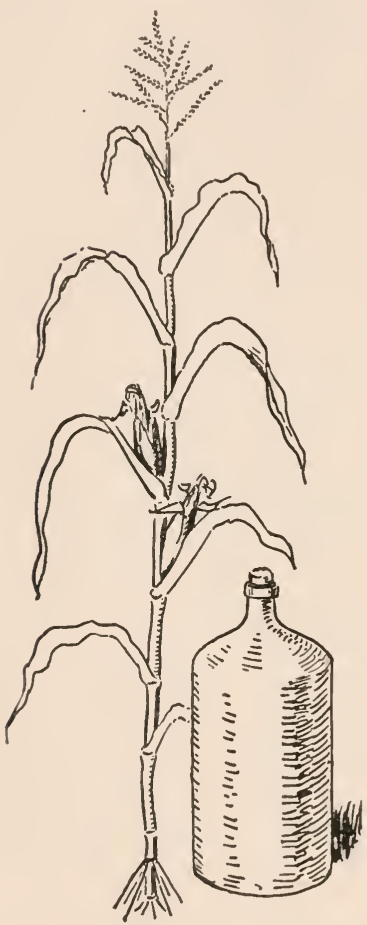

FIG. 33. Corn plant, and bottle of water equivalent to that transpired by the plant during its lifetime. (All drawn to the same scale.) In eastern Colorado the transpiration from a well-watered corn plant might be 3 times this amount. from plants is called transpiration.

The loss of water in the form of vapor is a process that takes place in animals as well as in plants. If you hold your hand near a windowpane on a cool day, a halo of minute water drops condenses on the glass. These water particles come from the moist cells of your skin. If you blow on a glass, water collects even more abundantly. The vapor in the breath is water that has evaporated from the moist cells of the lungs.

The amount of water transpired by plants. The amount of water given off in transpiration is surprisingly large. During its lifetime, a well-watered corn plant may give off 4 or 5 gallons of water. A sunflower plant may transpire more than i 8 gallons. The water given off by a field of wheat during its entire period of development would cover the field to a depth of 4 or 5 inches. For the best growth of plants, therefore, there must be available in the soil enough water to permit them to 
take what they need for transpiration. When we consider that the quantity of water transpired by wheat in cultivation is one fifth to one eighth of the rainfall of the central United States, we begin to realize how large a fraction of all the water that falls on the soil is actually used by the plants. In all rainfall, some water runs off the soil without penetrating the surface, some evaporates from the soil surface itself, and some sinks below the level of the plant roots. Consequently, it is only-when there are abundant rains, distributed throughout the growing season, that the amount of water needed by the plants for their best development is available in the upper layers of the soil. It has been shown by experiment that for the production of every pound of solid matter in the above-ground parts of crop plants, from 300 to 500 pounds of water are required in the central United States, and that from 400 to rooo pounds are needed on the plains of Colorado. The amount of water used in transpiration is, therefore, many times the amount used in the manufacture of food.

Water supply and crop yields. Knowing these water requirements, it is easy to understand why droughts are so disastrous to crops. When the rainfall is slight, not only is the amount of water that can be secured by the plant from the soil reduced, but the sunshine is brighter and the air is usually drier, so that transpiration from the plant is increased. It is in part because of the water requirement of crop plants that bottom lands - lands along streams in the bottoms of valleys - are more valuable for growing crops than are uplands. There the underground water is nearer the surface, and keeps the supply for plants more nearly constant. 
The balance between transpiration and absorption. The amount of water in the cells of the plant as a whole is determined largely by two processes: (I) the rate of absorption - the taking of water from the soil; and (2) the rate of transpiration. The relation between these two rates determines the water balance inside the plant. If the transpiration is rapid and absorption is slow, internal drought results and the plant may wilt. If the transpiration is slow and the water intake is rapid, the cells will be filled to their utmost capacity.

Importance of the water balance. Of all the factors that influence the growth of plants and modify the form, size, and structure of leaves, the water content of the cells is the most important. Abundant water permits a plant to grow to its greatest height, and permits the leaves to attain their largest size and number. Long-continued internal drought may cause the plant to be dwarfed and the leaves to be small and few in number. In the river bottom the bur oak may develop into a magnificent tree roo feet in height, while on the dry uplands it may attain only a stunted growth of less than I 5 feet. An average leaf on a large tree will have twice the area of a leaf on a stunted one, and the number of leaves on the larger tree will be many times the number on the smaller.

In the summer, when the soil is dry and the air is hot, transpiration may cause the leaves to lose water so rapidly that they droop, and we say that the plant is wilted. Water has passed out of the cells of the leaf faster than the waterconducting tissue has brought in water to replace it, and the cells are no longer distended and firm. They are like a football that is only partly inflated. After a heavy shower the plants quickly recover, because the water available in the 
soil has been increased and more water is taken into the plant. The shower has also covered the leaves with a film of water and made the air moist around them, and this reduces the water loss. Under these conditions, the cells of the plant quickly become turgid, - that is, become fully distended with water, - and the leaves recover their firmness. The leaves of many plants like lettuce, pumpkin, and ragweed depend for their firmness almost entirely upon the turgidity of the leaf cells.

The balance between the rate of water supply and the rate of water loss is the most important water relation of the plant.

The water balance illustrated. The internal water balance of the plant may be crudely illustrated by a glass tube with an inverted porous porcelain cup sealed to one end and with a stopcock attached near the other end. If the cup and tube are filled with water and the open lower end of the tube is placed in a dish of mercury, the mercury will rise as the water evaporates through the porous surface of the cup. If we nearly close the bottom of the tube by means of the stopcock, the rate at which the mercury rises is diminished. This is because the evaporation is decreased as the amount of water supplied to the cup is lessened. If we open the stopcock, but cover the outside of the cup with a thin layer of some substance like wax, which does not allow water to pass through it freely, the rate of evaporation will

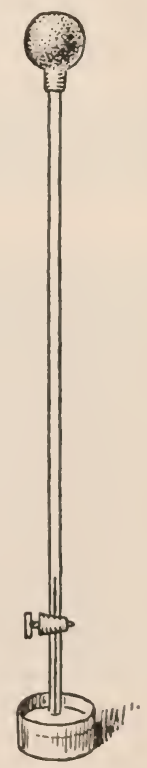

FIG. 34. Apparatus to illustrate the drawing up of water in a tree through transpiration from the leaves. 
again be checked. This time the water can pass through the tube freely, but it cannot evaporate through the cup so rapidly because of the wax covering.

How plants are adjusted to maintain the water balance. Plants become modified in many ways in response to the conditions of water supply and water loss under which they grow. Among the adjustments that help plants to maintain an advantageous water balance under dry conditions are:

(I) Thickened cuticle and "bloom." The cuticle of a leaf checks transpiration as does the wax film in the experiment, and in plants of dry.climates the cuticle may be so thick as
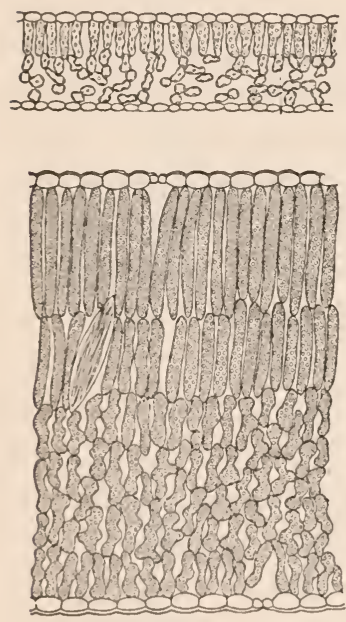

E. S. Clements

FIG. 35. Vertical sections of leaves of Mertensia, showing differences in structure when growing in moist, shaded situation (above), and when growing in dry, intensely lighted situation (below). to reduce transpiration through the epidermis to almost nothing. There are many plants which secrete, in addition to the cuticle, particles of wax on their leaves or other parts. This is the so-called "bloom" which may be seen on the leaves of the houseleek and cabbage and on the fruits of the grape, plum, and blueberry. The bloom consists of a layer of wax particles scattered thickly over the surface of a leaf or fruit. It forms a layer that is nearly impervious to water and helps to reduce water loss through the epidermis.

(2) Compact leaves. A plant may become adjusted to an inadequate water supply by the development of leaves with compact tissues. In such leaves the intercellular spaces are much 
reduced, so that evaporation from the mesophyll cells is greatly lessened. In extreme cases the mesophyll cells are all of the compact palisade type, which leaves the minimum of air space within the leaf.

(3) Small leaf area. A third way in which plants become adjusted to dry conditions is by a decrease in the total leaf area. When a plant is brought into the house in autumn, it drops a number of leaves. The air inside most houses being much drier than the air outside, transpiration is greatly increased. As the water supply remains about the same, the dropping of a few leaves restores the internal water balance of the plant. Some trees, like the cottonwood, shed part of their leaves during a summer drought. If a wet period follows, more leaves may be added, and in this way a nearly uniform water balance is maintained.

That plants growing under moist conditions have larger leaves and more leaves than the same kinds of plants growing under dry conditions has been noted by every one. The contrast may be observed by comparing weeds that grow along the base of a railroad embankment or the high bank of a stream with those that grow near the top.

Transplanting and the water balance. When the skillful gardener transplants a tree, he cuts off a number of branches to reduce the number of leaves, in order that the plant may not dry out before new water-absorbing roots are developed. Before lettuce, tomato, and cabbages are lifted for transplanting, the plants should be watered and allowed to become turgid; water should be poured into the holes in which they are placed, before the soil is closed in around the plants. It is customary also to cover the plants with boards or paper covers so as to reduce the transpiration. Maintaining the 
water balance in transplanted plants may prevent the loss of many of them and may save weeks of delay in the maturing of the crop.

The water balance and plant habitats. The place where a plant grows naturally is called its habitat. The willow grows beside a stream and the cactus grows in the desert, each in its natural habitat. If we put the willow in the desert and the cactus on a wet stream bank, both die. This means that the conditions that make up each habitat are favorable to one kind of plant and not to another. The conditions include not only the kind of soil and the amount of soil water, but also the evaporative power of the air. In selecting plants that may live in a particular habitat, the great importance of the dryness or the moistness of the air is to be kept in mind. Plants whose leaves are soft and transpire water rapidly can succeed only in moist air, while those that have a low transpiration rate can maintain a suitable water balance only in a dry atmosphere. This is one of the reasons why on a southern slope we find a set of plants that are different from

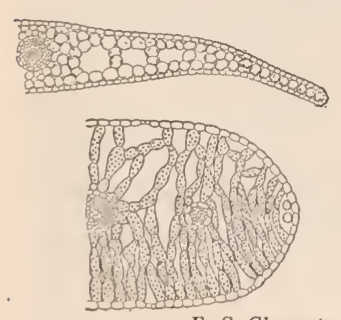

E. S. Clements

Fig. 36. Vertical sections of leaves of Hippuris, a water plant. The upper figure shows an aërial leaf, the lower figure a submerged leaf. . those on the northern slope.

Recent studies have shown that the leaves of plants growing near the bottom of a ravine transpire water ro to 20 times as fast as do those of plants growing higher up on an adjoining southern slope. Doubtless, each year seeds of plants that grow in the low ground germinate on the upper part of the slope; but each year the plants that spring from those seeds are eliminated through their inability to get the 
water needed for their high rate of transpiration. There are plants like the dandelion that can adjust themselves to both these conditions. Most plants, however, cannot do this, and those with a high transpiration rate die off on a dry hillside, while those with a low transpiration rate survive. This indicates only one of the factors which must be taken into account in the selection of plants for particular habitats; other

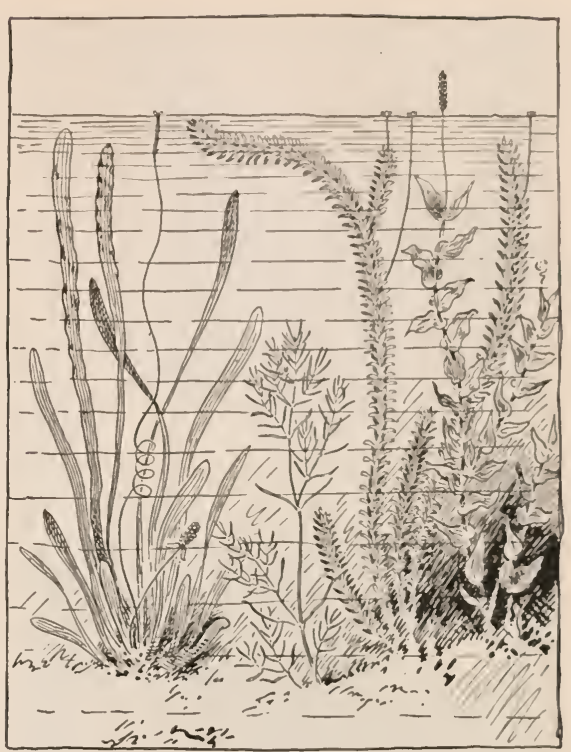

FIG. 37. Submerged plants. From left to right: eelgrass (Vallisncria), naiad (Najas), water weed (Elodea), and pondweed (Potamogeton). factors will be considered in connection with the study of stems and roots.

Submerged and floating leaves. An examination of a submerged leaf of any pondweed shows that it has no stomatal openings. The floating leaves of water lilies and other pond plants have stomata only on the upper surfaces. Evidently submerged plants have no transpiration. It is also certain that they get their carbon dioxid directly from the water through the epidermis, for carbon dioxid is found dissolved in pond waters, often in larger proportion than in the air.

In water-lily leaves the upper surface is covered by a cuticle that is not readily made wet, and it has stomata that 


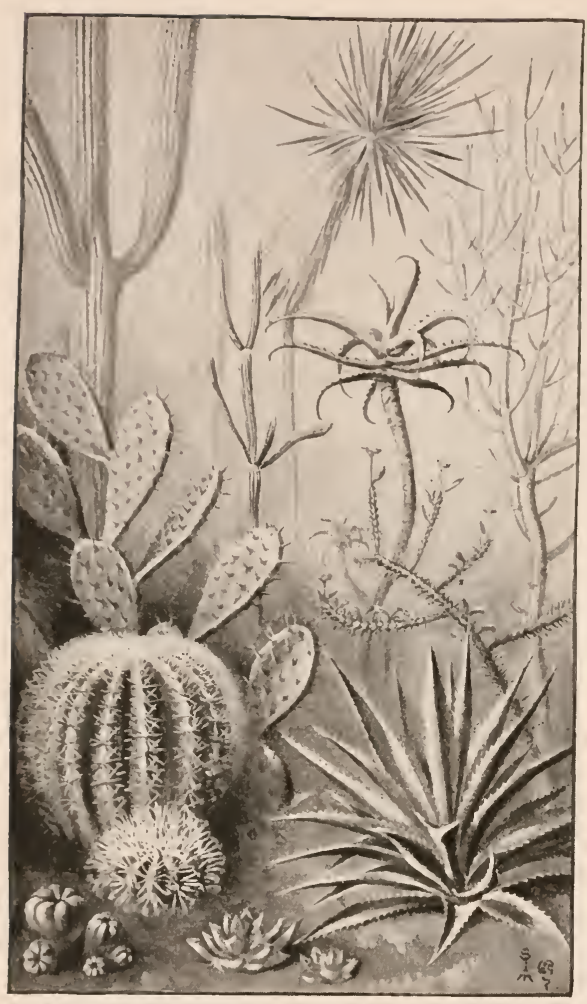

FIG. 38. Desert plants, including forms of Cereus, prickly pear (Opuntia), Yucca, Euphorbia, and century plant (Agave). do not open until the leaf is above water. If the leaves are raised entirely above the surface of the water, as sometimes happens when the plants are crowded, both surfaces develop stomata.

Desert plants and water storage. In the desert, where the air is very dry and the scanty rainfall is confined to one or two periods in the year, plants have very great difficulty in securing water. The perennial plants have various ways of conserving water from one rainy period to the next. The barrel cactus has no leaves at all, and the stem is a. thick cylinder composed largely of water-storage tissue; it may live without water for 2 years or longer. Some of the desert shrubs have leaves during the rainy periods only, and these are shed as soon as the drought comes. Still others, like the agaves, have very thick, leathery leaves with much internal water-storage tissue and a very low transpiration rate. 
Adjustment to desert conditions by ability to withstand drying. Another group of plants is adjusted to desert conditions by being able to withstand complete drying. The resurrection plant (Fig. 39) of Texas is an example of this group. During the rainy season it is green and has its many scale-leafed branches spread out for food manufacture and growth.

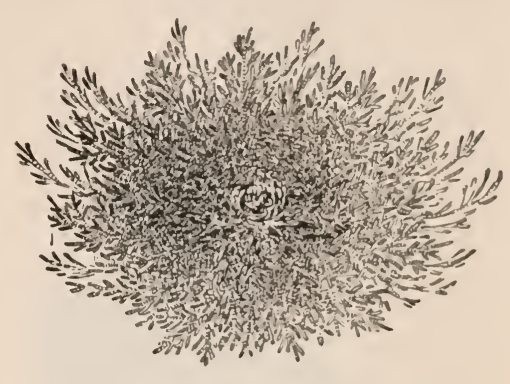
When drought comes, the plant dries out completely and its branches curl upward until it is in the form of a ball. In this condition it may be blown about by the wind and remain dormant for weeks and months, all of its physiological processes having ceased. When the plant again becomes wet it unfolds, and its processes begin anew. In the eastern United States we find plants of this same type in the lichens, mosses, and small ferns that grow on the bark of trees and on bare, dry rocks.

Plants classified according to their water relations. In the preceding paragraphs the importance of the water requirements of plants has been made clear. We have seen that the internal water balance of the plant is of great importance in modifying its physiological processes and the size and structure of its organs. Three great classes of plants are distinguished on the basis of their water relations: 


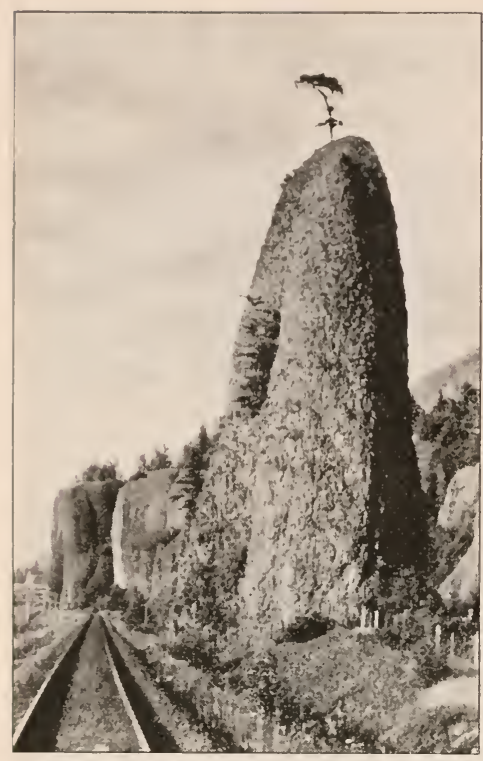

FIG. 40. Evergreen trees growing under extreme xerophytic conditions in Oregon. These "Pillars of Hercules" are by the side of the Lincoln Highway.
(I) The plants that naturally live where the evaporative power of the air is intense and the available water is limited are called xerophytes (Greek: xeros, dry, and phyton, plant). These are the plants that are adjusted to a nearly continuous dearth of water; the cacti, agaves, yuccas, and sagebrush of our Western plains and deserts are striking representatives. In the eastern United States there are less marked examples of xerophytes in the plants that live on dry cliffs and sand beaches, and in the mosses and lichens that grow on trees and rocks.

(2) The plants that live partly or wholly submerged in the water are known as hydrophytes (Greek : hudor, water, and phyton, plant). These plants have an excessive water supply, and transpiration is reduced or entirely wanting. In this class are included the water lilies, pondweeds, cat-tails, bulrushes, and many sedges. They are the common plants of fresh-water ponds, swamps, and marshes throughout the world.

(3) Between these extremes are the mesophytes (Greek: meso, middle, and phyton, plant), by far the largest class of plants. They have a medium rate of transpiration and grow 
best with a moderate water supply. In this group are included the plants that yield most of our garden, field, and meadow crops; also most of the forms that are found in the maple, beech, and elm forests of the Eastern states, and in the fir and spruce forests of the cañons and bottom lands of the Western states.

Xerophytes, hydrophytes, and mesophytes are readily distinguished as groups because of their great differences of habitat and appearance. But it is not always easy to decide whether a particular plant is a xerophyte, hydrophyte, or mesophyte, because we find all gradations of form among plants of the three classes. Nevertheless, these terms are useful in describing the water relations of many plants.

\section{PROBLEMS}

1. How do plants that are wilted in the late afternoon of a hot summer day recover their firmness during the night, even though there is no rain?

2. Where, near your home, do mesophytes, xerophytes, and hydrophytes occur?

3. In what regions of the United States are mesophytes most common?

4. In what parts of the United States are xerophytes abundant?

5. In what parts of the United States are hydrophytes common? What states have very few hydrophytes?

6. What xerophytes furnish useful products to man and animals? 
1. Collect from various plants leaves showing the autumn colors. Make a record of the colors found in different kinds of trees.

2. Look for different colors assumed by leaves of the same kind of tree when growing in shade and in bright sunlight.

3. Look for the red color in leaves that have been partly shaded. What is the effect of the shade?

4. Cut longitudinal sections through the stem and base of a leaf that is about ready to fall, and note the abscission layer.

5. Examine some evergreens and determine the number of years they hold their leaves. Differences in color of bark will help to distinguish the growths of different years.

6. Make a chlorophyll extract by placing leaves in warm alcohol. Dilute the alcohol with a little water, and add enough benzine to double the volume of the solution. Then shake thoroughly, and allow to stand until the benzine has separated. The benzine will contain the yellow pigments, while the chlorophyll will remain in the alcohol. 


\section{CHAPTER SIX}

\section{LEAF COLORATION AND THE FALL OF LEAVES}

IN spring and summer the most prominent feature of the landscape is the green color of the vegetation. The most striking feature in autumn is the varied colors of the foliage on the trees and shrubs. In the northern provinces of Canada most of the trees are evergreen, and the most abundant deciduous trees, like the aspen, birch, and tamarack, merely turn yellow. But in our Northern states the vivid greens of the sugar maple, white oak, gum, and sumac disappear in a blaze of red that contrasts strongly with the yellows of the hickory, linden, and poplar and with the dark greens of the hemlock, spruce, and pine. Every one who has seen the colors of autumn woods and the annual falling of the leaves must have wondered what processes go on within the leaves to bring about these changes.

The pigments in green leaves. We can best approach the matter of autumn colors by inquiring into the composition of the pigments that give the color to the leaves of deciduous trees in summer and to the leaves of evergreen trees throughout the year. The most abundant of these pigments is chlorophyll (Greek : chloros, green, and phyll, leaf), which is bright green in color. In addition to chlorophyll, two other pigments, one yellow and one orange, are found in a green leaf. These three pigments may exist quite independently of one another. ${ }^{1}$

1 The coloring matter in a green leaf is composed of about 66 per cent green pigment (chlorophyll); 23 per cent yellow pigment (xanthophyll); and ro per cent orange pigment (carotin, so named because of its abundance in the carrot). The green pigment is not a simple substance, however, but a mixture of two kinds of chlorophyll, one of which is blue-green and the other yellow-green. The depth of the green color in a leaf depends in part on the proportions in which these various pigments are combined. 
In the chloroplasts all three are present at the same time, so that we cannot distinguish them under the microscope. As the three are soluble in alcohol, the presence of the yellow and orange pigment does not become apparent when the coloring matter is extracted from leaves by means of alcohol. The chlorophyll within a leaf is constantly breaking down, and new chlorophyll is formed in the chloroplasts to take its place.

Conditions affecting the development of the pigments. Chlorophyll is produced only in the presence of light, but the yellow and orange pigments develop in the dark as well as in the light. When we lay a board on grass or shut out the light to blanch the leaves of celery, the green color gives way to yellow or orange. Likewise seedlings grown in the dark and the inner leaves of head lettuce show a yellow but not a green hue; and when the light is cut off from a green leaf, the green pigment disappears, leaving the yellow pigments visible. ${ }^{1}$ These facts make it clear that the yellow pigments do not require light to develop, while the green pigment does.

There are a number of conditions besides absence of light that result in the partial or complete disappearance of the green pigment, but these affect various plants quite differently. Low temperature, drought, and injuries and diseases of various kinds may interfere with the nutrition of the leaf; even a slight decrease in light may do so. All these factors tend to affect the green pigment more than the yellow and orange. Although these same influences - low temperature, drought, reduced light, injuries, and diseases - may be effective at other seasons, they become generally operative in late summer and autumn. Hence it is at this time of the year

${ }^{1}$ A number of evergreens are exceptions to this rule. 
that the green pigment disappears from the leaves of most deciduous plants and unmasks the yellow pigments in the chloroplasts. There is every gradation in the readiness with which the green pigment disappears from the leaves of different species of deciduous trees, from the cottonwood, in which the leaves become yellow during a midsummer drought, to the peach, in which they may still be vivid green when shed. In evergreens the chlorophyll is less sensitive and external conditions are not so effective in causing changes in the color of the leaves.

The red pigment. The red colors of autumn leaves are not due to changes in the content of the chloroplasts, but to the formation in the cell sap of a red pigment called anthocyan. This same pigment is present in the cells of many young leaves in early spring. It occurs also in beets, in red cabbage, in the petioles and veins of many different kinds of leaves, in the Coleus and other foliage plants, and in many flowers. The presence of anthocyan in the cell sap makes the whole cell red, and any or all of the cells may develop the pigment.

The development of the most brilliant red coloring of autumn is commonly ascribed to the action of frost. This explanation is probably incorrect, for careful observation indicates that the color is most intense when a moderately low temperature is accompanied by bright sunshine. In warm, cloudy autumns the colors are more likely to be dull, with the yellows predominant. That sunlight is important in the development of the red pigment may be shown also by an examination of a leaf that has been closely shaded by another. The pigment stops so abruptly where the shade begins that a perfect print of the uppermost leaf results.

The red colors of the fruits of peaches, apples, and pears 
likewise are due to anthocyan. Here again we may see the effects of sunlight on the intensity of color by comparing fruits from the brightly illuminated top of the tree with others from the shaded under parts. The apples grown in the Northwestern states are more brilliant in color than the same varieties grown in the Eastern states, and this higher coloration is probably due to exposure to more intense light.

Among different plants there is much variation in the amount of light that is required for the development of anthocyan colors. This accounts for the great variation in the brilliancy of autumn coloration in different years. One autumn affords light conditions which promote the formation of anthocyan in only a few trees and shrubs; another autumn furnishes conditions so favorable that many plants become brilliant.

The brown colors. In some trees the leaves turn brown immediately after the loss of their chlorophyll. In other trees the leaves may first turn yellow or red, and then gradually assume the shades of brown. These brown colors result from chemical and physical changes in the substances within the leaf. Just what the processes are is not fully understood, but it is reasonably certain that tannins and tannic acid are connected with the making of the brown pigments. The dead bark of trees also turns brown, probably because of chemical processes within it similar to those which take place in the leaves.

White leaves. One occasionally finds on plants leaves that are wholly or partly white. This is simply the natural color of living plant tissues that lack chlorophyll or other pigments. The protoplasm, cell sap, and cell walls are transparent and colorless. The presence of air spaces among 
the cells makes these tissues appear white. The ice crystals of which snow is composed are transparent, but the numerous air spaces between the crystals reflect the light and cause it to appear white. Ice likewise becomes white when it is filled with minute air bubbles. The white colors of leaves and flowers merely show the natural appearance of the parts in the absence of chlorophyll and other pigments.

The causes of leaf fall. There are two distinct stages in the process by which plants drop their leaves: (I) the FIg. 4r. Longitudinal secformation at the base of the petiole of tion of base of petiole, two or more plates of thin-walled cells, beginning of leaf fall. known as the abscission layer; this takes place during the development of the leaves and may require weeks or months for completion; and (2) the actual separation of the cells of the abscission layer, which is brought about by the softening or dissolving of the middle layer of the walls of the abscission cells. This stage of the process may take place within a few hours, or at most within a few days.

The plant is protected from disease and water loss at the scars left by the falling leaves, through the addition of woody and corky materials to the cell walls beneath the abscission layer. This protective layer is formed in some kinds of plants before the leaf drops, in other plants after the leaf has fallen.

Conditions promoting leaf fall. After an abscission layer has developed, there are many climatic and soil conditions 
that may accelerate the falling of the leaves. Among these

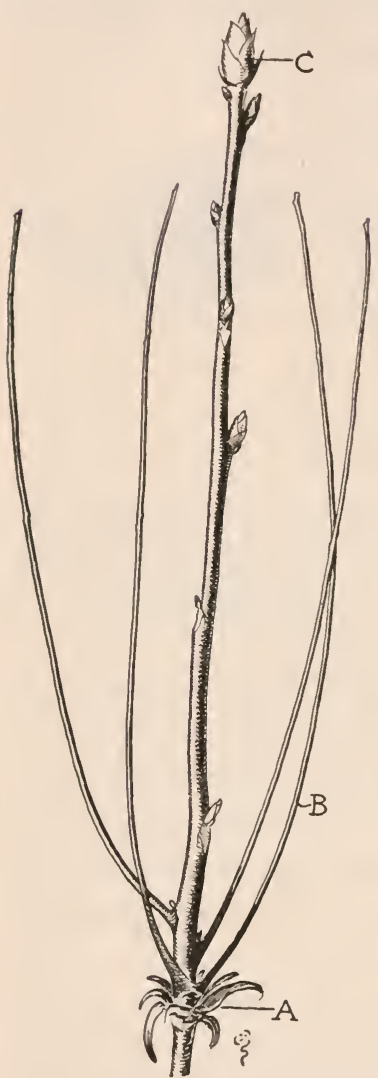

FIG. 42. Shagbark hickory twig. $A$ is the bud scales of the terminal bud of the previous year, $B$ several petioles remaining attached after leaf fall, and $C$ the terminal bud that will develop the following spring. Drawn from a specimen collected in December. are low temperature, reduced light intensity, and any disturbance of the water relations of the plant which results in internal drought. Disease and insect injuries to the blade frequently bring about abscission.

Leaves contain food materials when they fall. The materials used in building the cell walls in a leaf are lost to the tree when the leaf falls, and the fallen leaves still retain considerable amounts of starch, sugar, and protein. In the autumn, however, photosynthesis declines, and the amount of food lost by a deciduous tree through leaf fall is small in comparison with the quantity that has accumulated in other parts of the plant.

Abscission in compound leaves. In many compound leaves, like the horse-chestnut, ash, and hickory, abscission first takes place at the base of each leaflet. Later the petiole is cut off from the stem in the same way. Consequently the leaflets fall first and the petioles later. In the king-nut hickory the petiole remains attached to the tree through the following year (Fig. 42). 
Self-pruning. A large number of our common trees, like the cottonwood, maple, and elm, develop abscission layers which cut off twigs and sometimes branches an inch in thickness. In these trees we have twig fall as well as leaf fall. The falling of flowers, and of fruits like apples and nuts, is due to the abscission layers formed in the stems.

Evergreen and deciduous trees. In the Northern states many persons have come to think that the evergreen habit is associated only with needle leaves, because in the North the evergreens are mostly of the needle-leafed type. But in the Southern states there are many broad-leafed trees, like the magnolia, rhododendron, and

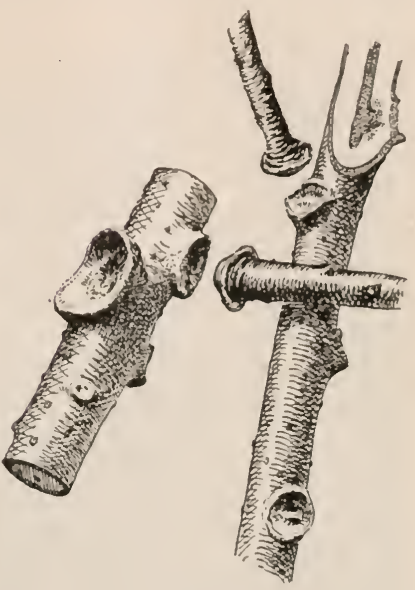

Fig. 43. Abscission of branches of cottonwood. Twigs and small branches as well as leaves and fruits are cut off by the formation of abscission layers.

holly, that are also evergreen. Moreover, the tamaracks of the North and the bald cypress of the South furnish examples of needle-leafed trees that are deciduous. If we include the shrubs, there are many broad-leafed plants, both in the North and in the South, that have the evergreen habit. In the tropics most of the trees are evergreen, and almost all have broad leaves. It must be noted that even in the case of evergreens individual leaves remain on the trees for only a limited number of years. The leaves of the evergreens are quite different structurally from the leaves of deciduous trees. The evergreens must be able to withstand freezing and thawing, and also the dry 


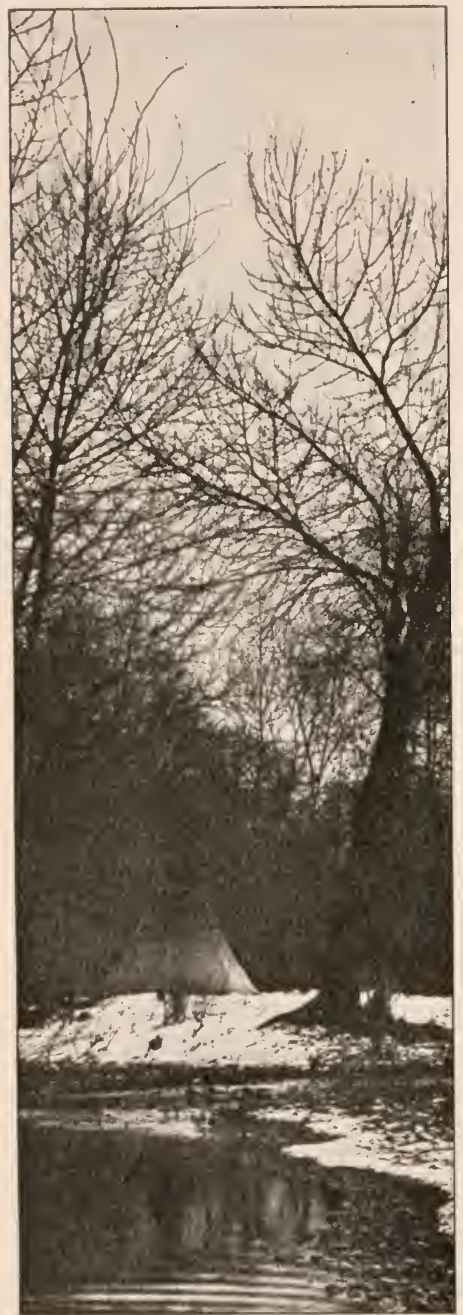

Lee Moorhouse

FIG. 44. Deciduous trees in winter, on Umatilla Indian Reservation, Oregon.

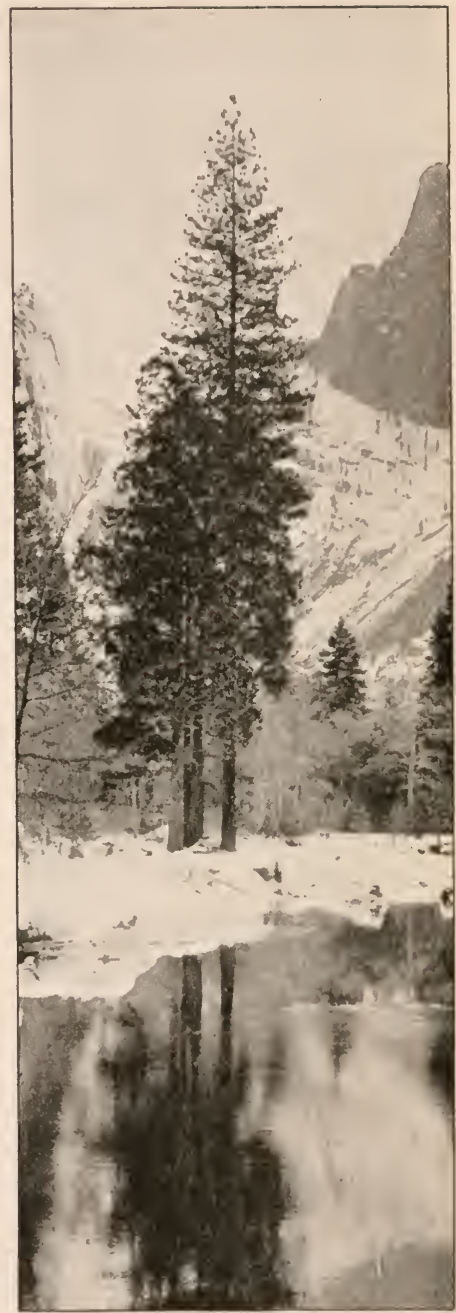

Caspar W. Hodgson

FIG. 45. Evergreen trees in winter, in Yosemite Valley. 


\section{Leaf Coloration and the Fall of Leaves}

winds of winter, which cause transpiration even when the ground is frozen. This suggests that their usual transpiration rate must be very low in comparison with that of the deciduous trees.

Evergreen versus deciduous habit. In temperate regions, where there are great changes in temperature and moisture, the deciduous and the evergreen habit each has certain advantages. The advantages of the evergreen habit are: (I) that the leaves can manufacture food even when the temperature is low; (2) that with their low water requirement, evergreens can withstand drier conditions throughout the year; (3) that the tree does not waste so much material each year in the construction of a complete set of new leaves. The disadvantages of the evergreen habit are: (I) that the heavy cuticle and compact tissues which aid in conserving water interfere with rapid photosynthesis; (2) that the lower rate of food manufacture prevents rapid growth; (3) that the leaves lose in efficiency by their longer service on the trees.

The advantages of the deciduous habit are: (I) that the leaves, being renewed each year, are more efficient organs of food manufacture; (2) that the leaves, with less cuticle and with tissues less compact, are better fitted for rapid food manufacture; (3) that the total leaf area may be much larger than in the case of the evergreens; $(4)$ that the trees are better fitted to withstand the winter drought, because at that season the entire tree is covered with cork. The disadvantages of the deciduous habit are: (I) that the foodmanufacturing season is only from 5 to 8 months, as compared with from 8 to io months in the evergreens; (2) that each year a large amount of food material is needed to make an entirely new set of leaves. 
Finally, we must observe that there are in trees all gradations between the deciduous and evergreen habits. In the rainy tropics there are many delicate-leafed evergreens. In the dry tropics the evergreens have thick, fleshy leaves, or they may be quite leafless. Some plants, like the holly and the Virginia creeper, may be of the deciduous habit in the North and of the evergreen habit in the South. Some deciduous trees, like the cherry, when planted within the tropics become evergreen; while the magnolia, which is evergreen in the Southern states, becomes deciduous when grown in a colder climate. Evidently leaf habits are adjustments to climatic conditions, especially to conditions of temperature and moisture.

\section{PROBLEMS}

1. What are the commonest evergreen trees and shrubs of your locality?

2. What trees of your vicinity develop leaves earliest in the spring? What trees put out their leaves last?

3. What trees develop flowers before putting out their leaves?

4. What trees drop their leaves first in autumn? What trees drop their leaves last in autumn?

5. What trees shed part of their leaves during the summer?

6. During how many months does each of these trees carry on food manufacture?

7. During how many months do the evergreen trees of your locality manufacture food?

8. For how many months do the three leading crop plants of your locality carry on photosynthesis? 


\section{Suggestions for Laboratory Work to Precede Chapter Seven}

1. Make a thin paste by boiling a little starch in water. Test a small portion of the paste with iodin. Test for sugar with Benedict's solution ${ }^{1}$; then add diastase solution (malt extract purchased at the drug store may be used) to the starch paste; after it has stood in a warm place for some hours, test it again for starch and for sugar. What is meant by digestion of starch? What enzyme brings this about?

2. Test for starch a leaf from a green plant that has been in sunlight by placing it (I) in boiling water for one minute, (2) in hot alcohol until bleached, and (3) in an iodin solution. If starch is present, put the plant in the dark, after cutting off one of its leaves. Place the severed leaf in a covered dish containing moist filter paper, and set the dish in the dark. On the following day test the severed leaf for starch; also test for starch a leaf freshly cut from the plant that was placed in the dark. What do the tests show regarding the movement of carbohydrate out of leaves?

3. Test seeds of corn, bean, and almond for starch, by placing a drop of iodin solution on a freshly cut section of each seed.

4. Test the same kinds of seeds for oil by scraping the seeds and crushing the scrapings on a sheet of white paper. Oil makes the paper translucent. Which contains the most oil?

5. Test the same kinds of seeds for protein by placing a drop of nitric acid on a section of each seed. Nitric acid stains protein yellow.

6. If time permits, other organs of the plant may be tested for food in the same way, and starch grains may be studied under the microscope. Scrapings from potato, the root of the canna, and various grains will furnish material for the study.

${ }^{1}$ Benedict's solution: Dissolve $173 \mathrm{gm}$. copper acetate and $100 \mathrm{gm}$. anhydrous sodium carbonate in $600 \mathrm{cc}$. of distilled water. Filter, and add water until the total solution is $850 \mathrm{cc}$. Dissolve $17.3 \mathrm{gm}$. of copper sulfate in $100 \mathrm{cc}$. of water and dilute to I $50 \mathrm{cc}$. Then mix the two solutions, which together will make a liter of Benedict's solution. It is ready for use immediately and keeps indefinitely. To make a test for sugar, add $3 \mathrm{cc}$. of Benedict's solution to I cc. of the solution to be tested, and boil. If sugar is present, a red or yellow precipitate will appear. 


\section{CHAPTER SEVEN}

\section{DIGESTION, TRANSFER, AND ACCUMULATION OF FOODS}

$W_{E}$ have seen that starch is formed in the leaves of a plant when it is exposed to light. We have also learned by experiment that starch disappears from leaves at night, but that if a leaf is removed from a plant it will still contain starch the next day. Furthermore, in many plants like the potato, turnip, or corn, we find starch in parts of the plant far removed from the leaves. These facts indicate that the starch is transferred from the leaves and is accumulated in the stems, roots, or seeds. In the present chapter we shall learn how this is done.

Digestion of starch. Starch is insoluble in water. It does not dissolve in the cell sap, and the starch within the cells is not divided into particles small enough to pass through the cell walls. Before it can be moved from one part of the plant to another, or even from one cell to another, it must be changed into some substance that is soluble. The process of changing starch into a soluble substance has been carefully studied; and we know that starch is first converted into maltose and that the maltose is further split into glucose (page 28). Glucose is readily soluble in water and consequently can be passed from cell to cell and so transferred to any part of the plant. The changing of insoluble substances like starch into simpler soluble substances like glucose is called digestion. Unlike animals, plants have no special organs of digestion. All their living cells are capable of digesting the insoluble substances that are required for their nutrition.

Digestion brought about by enzymes. Digestion is brought about by substances called enzymes. These are produced by the living protoplasm of the cells. A large number of differ- 
Digestion, Transfer, and Accumulation of Foods 75

ent kinds of enzymes have been recognized in plants; each enzyme digests only one particular kind of food, and there must be a different enzyme to digest each kind of food within the cell. The enzyme which digests starch is called diastase. The enzyme that digests fats is called lipase. There are other enzymes which act upon the insoluble forms of protein and render them soluble. It seems probable that enzymes are concerned in the principal activities of all living cells. Without them there could be none of the rapid changes in foods that are necessary for the transfer of foods within the plant and for carrying on the other processes described in this and the next chapter.

It is interesting to know that if an enzyme is put in a test tube, with the appropriate food substance, it will bring about digestion the same as if it were in the living cell. This proves that digestion is not directly carried on by the living protoplasm, and that to be digested, foods do not need to be in contact with living matter. It requires but a very minute quantity of enzyme to digest a large amount of the particular food upon which it acts; for example, a preparation of an enzyme extracted from the pancreas of an animal was found to digest $2,000,000$ times its weight of starch. The amount of diastase, therefore, that is needed in a mesophyll cell in order to transform to sugar the starch in that particular cell, is so small that it cannot be measured.

Accumulation of food. A healthy plant usually manufactures more food than it uses immediately. In the potato, surplus food is carried to underground stems, the tubers, and is there stored. Turnips and beets are examples of plants that accumulate excess food in their roots. In the maple, it accumulates in the branches, trunk, and roots. In the cab- 


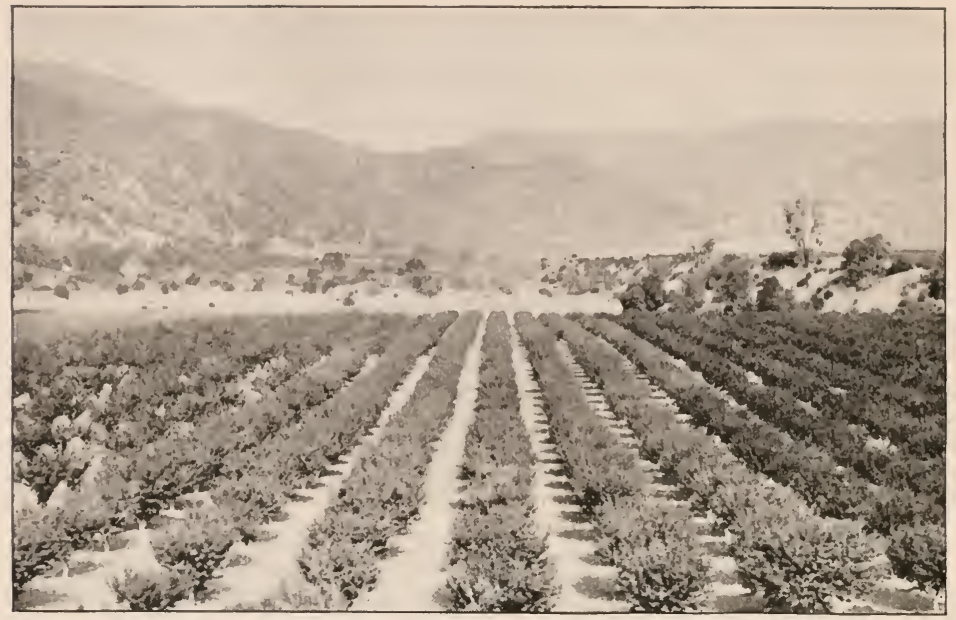

U.S. Dept. of Agricullure

Fig. 46. An orchard in California. The excess food of the trees is accumulated in the fruits.

bage, food is stored in the cluster of leaves at the top of the stem. In corn and cereals, the excess food finally accumulates in the grain. In the century plant, a considerable part of the excess food is stored in the thick, fleshy leaves; the process of accumulation may go on from 20 to 30 years, and the total quantity of food stored may amount to many pounds. In nature such accumulated foods are used for another season's growth of the plant or in starting the growth of its offspring.

Before insoluble foods are transferred in the plant, they are digested or made soluble by enzymes. When these soluble substances accumulate in the cells of storage organs, they frequently are transformed again into an insoluble form. For example, starch formed in potato leaves is transferred through the plant to the underground tubers in the form of glucose, 


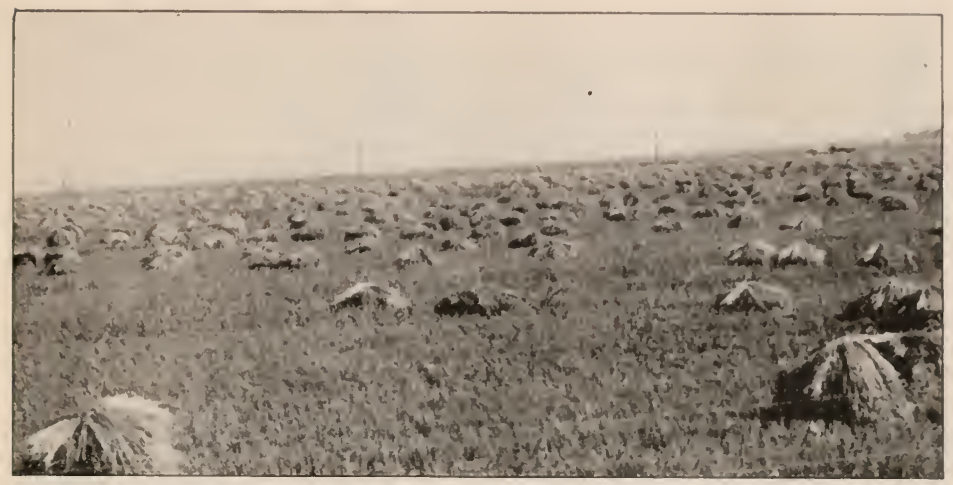

U.S. Dept. of Agricullure (E. L. Adams)

FIG. 47. A field of shocked rice in California. The surplus food of the rice plant accumulates in the seeds. These are more used than any other one article of diet by man.

and there it accumulates in the cells in the form of starch. It is believed that the same enzymes which change the starch to glucose, under suitable conditions change the glucose back again to starch, and that, in general, the enzymes that digest foods are the agents that build them up again into the more complex insoluble forms.

Kinds of food accumulated. In any given plant in which food is accumulated, protein, carbohydrate, and fat are all present. Depending on the plant, however, the amount of any one of these may be very great or it may be so small as to be practically negligible. In the sugar cane and sugar beet the excess food occurs mainly in the form of cane sugar (sucrose). In the potato it is almost wholly starch. The grains of wheat, oats, and rice contain mostly starch, but also some protein. In sweet corn there are both sugar and starch; in field corn there is mostly starch. In both kinds of corn there are measurable quantities of protein and oil. In the soy bean 


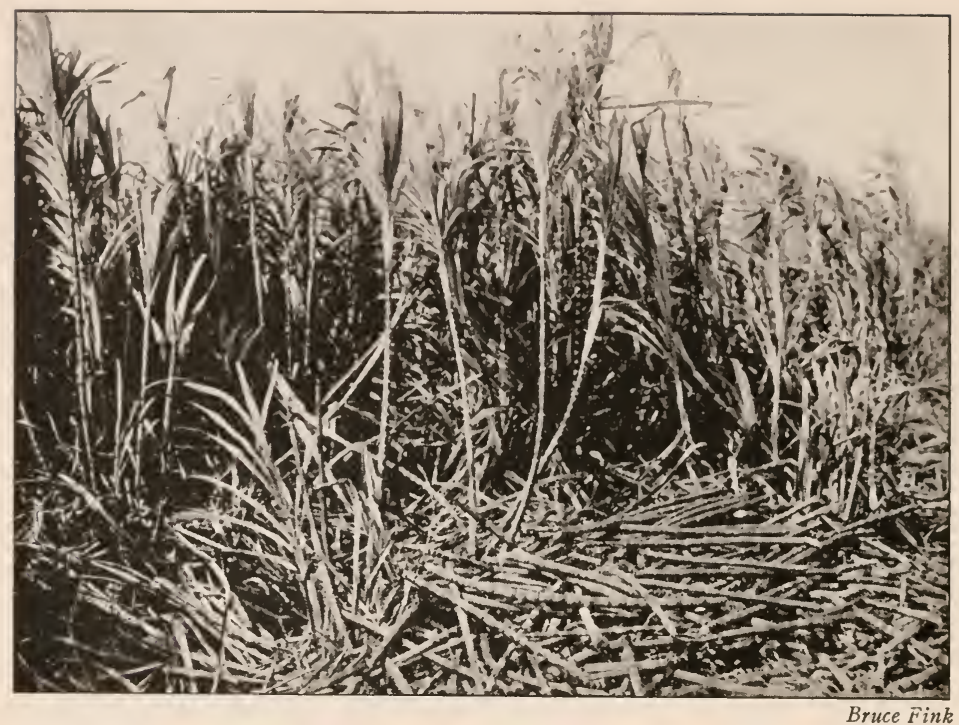

FIG. 48. A sugar-cane field in Porto Rico. The excess food is accumulated in the stems in the form of sugar.

and peanut, there are large quantities of both protein and oil. In the seeds of the coconut, flax, and cotton there is a large proportion of oil.

Food-accumulating plants and agriculture. Throughout the long history of agriculture the principal purposes of agriculturists have been: (I) the discovery of plants that accumulate large amounts of food; (2) the improvement of these plants by selection of seed from the most productive or otherwise most desirable individuals; (3) improvement of the methods of cultivation to provide conditions of growth that will cause the largest possible amounts of foods to be accumulated in the plants. Sweet corn was developed through the selection of seeds with a view to securing plants having a 


\section{Digestion, Transfer, and Accumulation of Foods 79}

large sugar content; field corn was developed through the selection of seeds for starch content. The original sugar
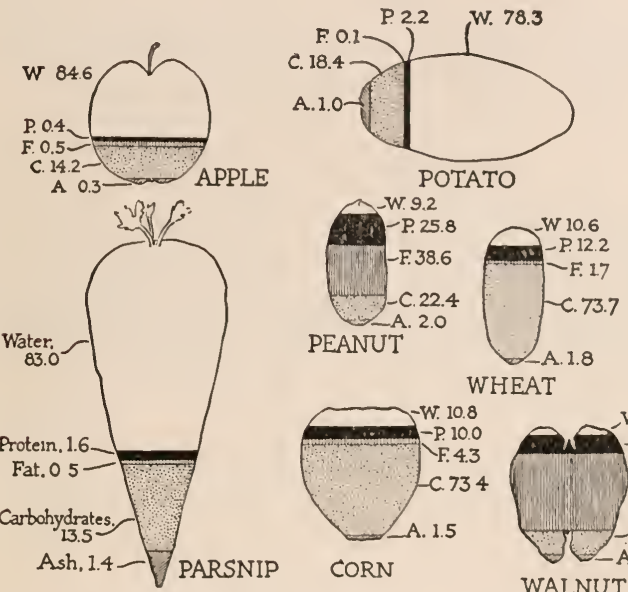
WHEAT

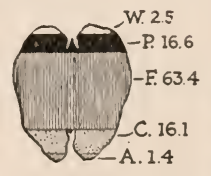

WALNUT

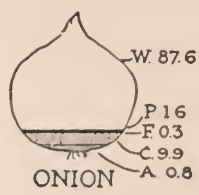

FIG. 49. Diagrams showing percentages of water, protein, fat, carbohydrate, and ash in various plant organs. Note the low percentage of water in seeds as well as the similarity of content of the potato and the banana.

beets contained less than 5 per cent of sugar; because of careful seed selection and intelligent fitting of the environment to the plants, the best quality of beets grown today contains as high as 22 per cent. The original potato tubers weighed about an ounce; potatoes weighing several pounds are now grown, and a plant may produce ten times as many tubers as are produced by the original plant.

The testing of wild species of plants for possible cultivation and use as sources of food, and the introduction of species cultivated in other countries, is being carried on by governments in all parts of the world. Through its agricultural explorers the United States has probably accomplished more 
in this particular field than have all other countries combined. Examples of plants that have been successfully introduced into this country through the efforts of government experts are the drought-resistant wheat, dasheens, figs, dates, guavas, kafir corn, milo, and new varieties of oranges.

\section{PROBLEMS}

1. In the recent Yearbooks of the Department of Agriculture, look up the accounts of new plant introductions.

2. Why is it important that the United States should grow within its own boundaries as great a variety as possible of cereals, fruits, and other foodproducing plants? 


\section{Suggestions for Laboratory Work to Precede Chapter Eight}

1. Generate some carbon dioxid by pouring hydrochloric acid on marble in a flask with a long delivery tube. Pass some of the gas through clear limewater in a small beaker. What is the effect?

2. Blow your breath through a tube into another small beaker containing limewater. Is the effect the same?

3. Arrange each of two small flasks with a two-hole stopper and two tubes as shown in Figure 50. In the first flask put flowers; in the second put clear limewater. After they have stood for a few minutes, draw air from the first flask through the limewater in the second. Note the effect. Does the respiration of plants produce the same gas as the respiration of animals?

4. Mark young leaves of fern, corn seedlings, and nasturtium as suggested in the text, and study the growth of the three kinds of leaves:

5. Show by experiment that oxygen is necessary for the growth of seeds. 


\section{CHAPTER EIGHT}

\section{THE UTILIZATION OF FOODS}

IN the preceding chapters we have seen how food is manufactured by the plant, how it is made soluble and is transferred, and how the excess food is accumulated in various organs of the plant. Food is finally utilized by the cells in respiration, assimilation, and growth. In this chapter we shall learn the meanings of these terms and study the changes that the foods undergo in connection with the production of energy, the making of protoplasm, and the growth of the cells.

Energy necessary to plant cells. In order to do work, each machine in a manufacturing establishment must be supplied with energy, and every living cell in a plant requires energy for carrying on its work of repair, growth, and movement. In manufacturing establishments the energy is usually generated at one place and is then transmitted by means of shafts and belts or wires and motors to all parts of the factory. The plant cannot transmit energy from one part to another, but it can and does send food to all its living cells, and from this food each cell generates within itself the energy that it needs.

Respiration. A steam engine is supplied with energy by the oxidation of fuel beneath the boiler that is connected with it. A cell is supplied with energy by the oxidation of food within it. The process by which the cells obtain energy through the oxidation of foods is called respiration. In the process oxygen is absorbed and carbon dioxid is given off. Respiration takes place in all living cells, and to carry on this necessary process all parts of the plant must be supplied with oxygen. The leaves and stems of land plants obtain their 


\section{The Utilization of Foods}

oxygen from the atmosphere, and the roots from the air that is in the soil. Wet soils are unsuited to the growth of many plants, not because of the water present, but because of the lack of a sufficient oxygen supply for the roots. Drainage is a valuable agricultural practice not only because it removes excess water, but also because it draws air (oxygen) into the soil. When the farmer breaks the crust

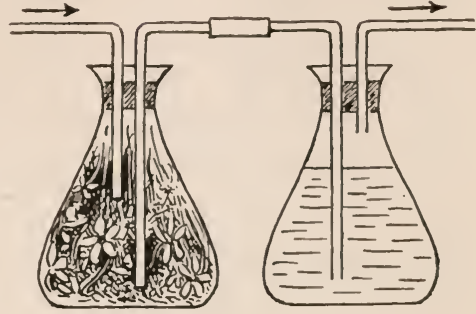

FIG. 50. Carbon dioxid is given off from the respiration of the flowers. on the surface, he is making it possible for more oxygen to reach the roots of his crop.

The plant and the process of respiration may be compared to a manufacturing establishment and the work that goes on in it.

The power stations are every living cell of root, stem, and leaf.

The machinery is the protoplasm.

The fuel is foods, especially carbohydrates.

The process

The product is the combining of food and oxygen.

The waste is energy.

is carbon dioxid and water.

The working hours are twenty-four a day.

Respiration and photosynthesis contrasted. In photosynthesis, carbon dioxid and water are combined to form the complex molecules of carbohydrates, and a large number of atoms of oxygen are set free in the process. When, in respiration, the complex carbohydrate molecules are again combined with oxygen, simple molecules of carbon dioxid 
and water are formed. In photosynthesis, the energy of the sunlight is used in building up the carbohydrates. The energy is stored in the carbohydrates, and it may be released by changing them back to the simple substances out of which they were made. When we wind up a clock spring, we put energy into the tightened coil. When the spring is allowed to uncoil, this energy is released and turns the wheels of the clock. So in photosynthesis the energy is stored in the carbohydrates, and this energy is released in the process of respiration and used in the life processes of the cell.

\section{In photosynthesis}

Oxygen is released.

Energy is accumulated.

Simple molecules are built up into complex ones.

Plants accumulate food and increase in weight.

\section{In respiration}

Oxygen is consumed.

Energy is released.

Complex molecules are broken down into simple ones.

Plants consume food and decrease in weight.

Comparative rates of respiration. The rate of respiration is greatest where there is rapid growth, as in germinating seeds, opening flowers, and ripening fruits. In some of these it is much more rapid, bulk for bulk, than in animals. The lowest rates of respiration occur in seeds and other dormant structures; and there is comparatively little respiration in woody stems and other hard parts in which there are only a few living cells.

Respiration and the shipping of fruits and vegetables. How important the recognition of the respiratory requirement of living cells is, may be illustrated by the difficulties that have been met with in shipping fruits and bulbs. Peaches, during shipment, sometimes develop brownish spots where they 
touch each other. These spots were formerly thought to be due to jarring in transportation, but they are now known to be caused by packing the peaches so closely that the air does not have full access to all the fruit. The respiration of the cells at the points of contact is in consequence interfered with, and these cells are suffocated and gradually die. Ships with specially ventilated holds are used in importing bulbs from Holland and fruits from the tropics. The building of ventilated holds came as a result of the death of several men who attempted to unload a cargo of bulbs from an unventilated bottom.

Assimilation. Another part of the food constructed by the plant is used for repair and for building additional protoplasm. A machine, if allowed to stand idle and uncared for, gradually goes to pieces. The cell is a very delicate mechanism, built of highly complex substances, and the protoplasm of the active cell requires constant repair. The foods that most nearly approach protoplasm in chemical composition are the proteins. Naturally these are the foods most readily changed into protoplasm and are the ones mainly used in the process of assimilation. Assimilation may be defined as the process through which the living protoplasm is repaired or new protoplasm built up by the use of foods. Assimilation takes place in all living cells.

Growth. The enlargement of plants or the development of new structures is called growth. The fact about plant life that is most familiar to all is that when a live seed is planted in the soil it germinates, and that from it there develops a seedling which continues to enlarge for a longer or shorter time, depending on the plant and the conditions of growth. The period of growth may be a month, as in the radish in mid- 
summer, or it may be hundreds of years, as in some trees. In the process of growth vast quantities of food are consumed. During the early stages of a plant's development most of the food it manufactures is used in this way. In order to grow, a plant must make new protoplasm, develop new cell walls, and thicken and strengthen old cell walls. Growth requires not only food, but energy as well. Indeed, a considerable part of the energy derived from respiration is used in growth. We might expect assimilation and food consumption to be most active in young growing parts, and that this is the case has many times been verified by experiment. Growth takes place through the enlargement of cells already present in the plant, through cell division, and through modification of cells without enlargement.

The making of the cell walls. The wall that surrounds each cell of the plant is composed largely of a substance called cellulose, which is secreted by the living protoplasm. When the cell is growing, its wall is exceedingly thin and it stretches as the cell enlarges. When a cell divides, a new wall is formed between the two parts. As the cell grows older, new layers of cellulose and allied substances are added. In some tissues, as in the shells of nuts, the walls become so thick as to occupy most of the volume of the cell. In other tissues, like the mesophyll of leaves, the cell walls always remain thin.

Chemically, cellulose is a carbohydrate, closely related to sugar and starch. Sugar and starch are the plant foods that are mainly used in its manufacture, just as the proteins are mainly used in the building of new protoplasm. Cotton fiber is pure cellulose, and exemplifies the strength, lack of color, and insolubility in water that are characteristic of cellulose. 
Conditions for growth. The conditions most favorable for growth are abundant water supply and warm temperatures,

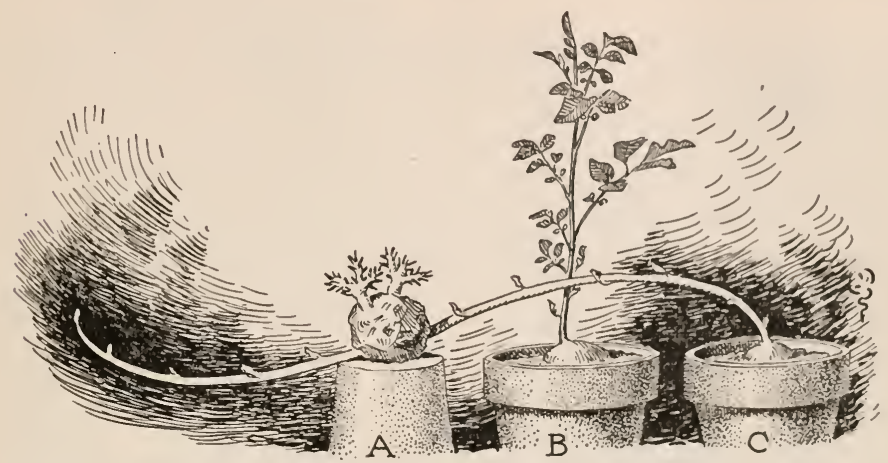

FIG. 5I. Results of an experiment to show effects of light and moisture on the growth of potato shoots: $A$, light but no water; $B$, light and water; $C$, water but no light.

such as normally occur in summer. For the growth of the plant as a whole, strong light is favorable because it increases the supply of food. For the growth of leaves in particular, medium light is generally most favorable. In darkness the blades of many plants do not expand, and in very intense light they do not expand fully because of excessive water loss.

The growing regions of leaves. By watching the development of leaves on any common herb, or on the trees in spring, we can see that growth takes place rapidly; also, that growth ceases when the leaves have developed to a certain rather definite size. After the leaf is mature, further enlargement will not take place, no matter how favorable to growth the external conditions may be. The question arises, do all parts of the leaf enlarge equally, or do some parts grow more than others? There is one characteristic of growing tissue that will 
help us in answering this inquiry: young tissue is very tender, and easily broken, while old tissue is stronger and firmer.

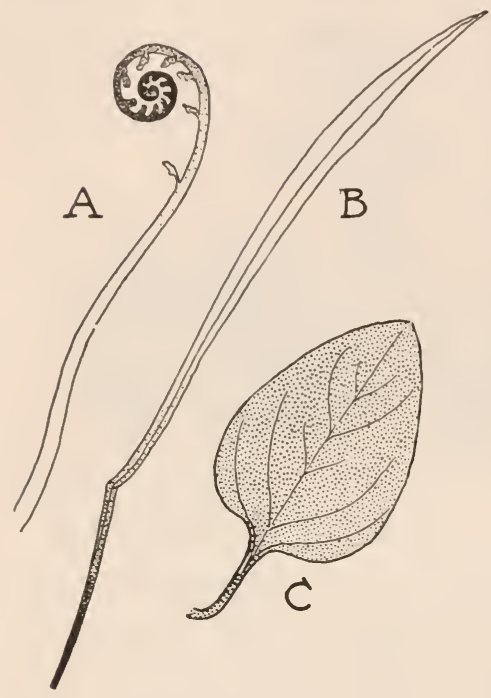

FIG. 52. Growing regions (shaded portions) of leaves: $A$, leaf of fern; $B$, grass leaf; and $C$, leaf of sunflower.

Fern leaves grow at the apex. The fern leaf is one that may be studied in this connection, for the growing portion is not only tender but coiled up, and its unfolding may be noted from day to day by marking with India ink the successive positions of the coil. In the Boston fern, which is so commonly cultivated as a window plant, the leaf may continue to unfold for weeks, if the water supply is adequate and other conditions are favorable. Evidently in the ferns the growing region is at the apex and the oldest part of the leaf is the base.

Growth in the leaves of seed plants. The flowering plants have either parallel-veined leaves or net-veined leaves, and the place of growth in these two types of leaves is different. In parallel-veined leaves, like those of the members of the grass family, the growth is at the base. What boy or girl, walking through a field of timothy or wheat, has not pulled the leaves from the stems? The leaves always break near the base. If you have tasted the broken end, you will recall that it was sweet and tender. The breaking near the base, and the sweetness there, indicate that the growing region of 


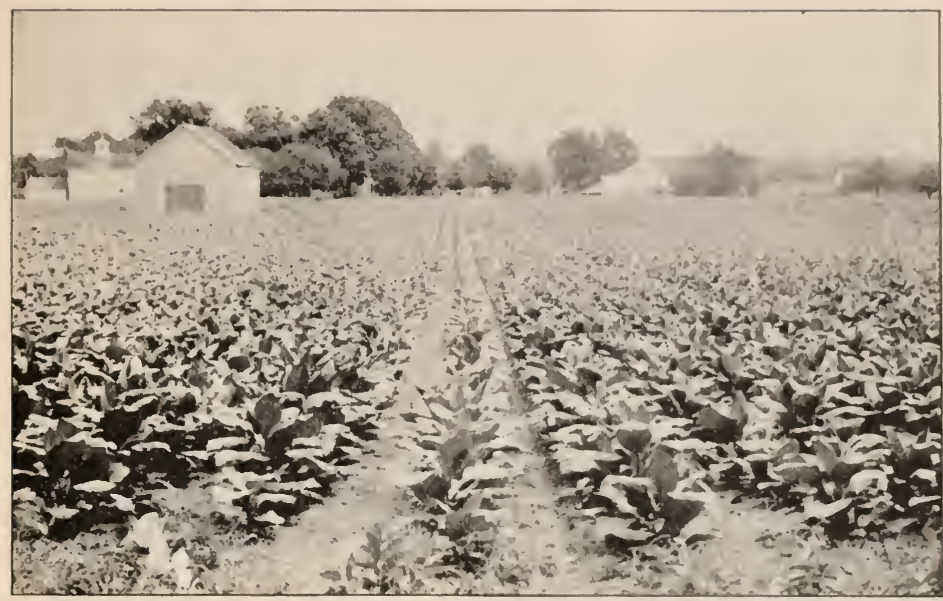

U.S. Dept. of Agriculture

Fig. 53. A tobacco field in Conneçticut. The plants are grown for their leaves.

the grass leaf is at the base. A more exact determination of the growing region may be made by marking a young grass leaf into equal spaces with India ink. This will show that as the leaf develops, it is continually pushed upward and outward from the node where it is attached. This mode of growth is characteristic not only of grasses but of many other plants having parallel-veined leaves.

Net-veined leaves. The net-veined leaves develop differently from the leaves of either ferns or grasses. An examination of a growing net-veined leaf will show that all parts are equally firm. The best method of study is to mark the young leaf into equal squares by means of two series of parallel lines at right angles to each other. A geranium or nasturtium leaf serves well for this purpose. After several days it will be seen that the only change has been an increase in size of the 


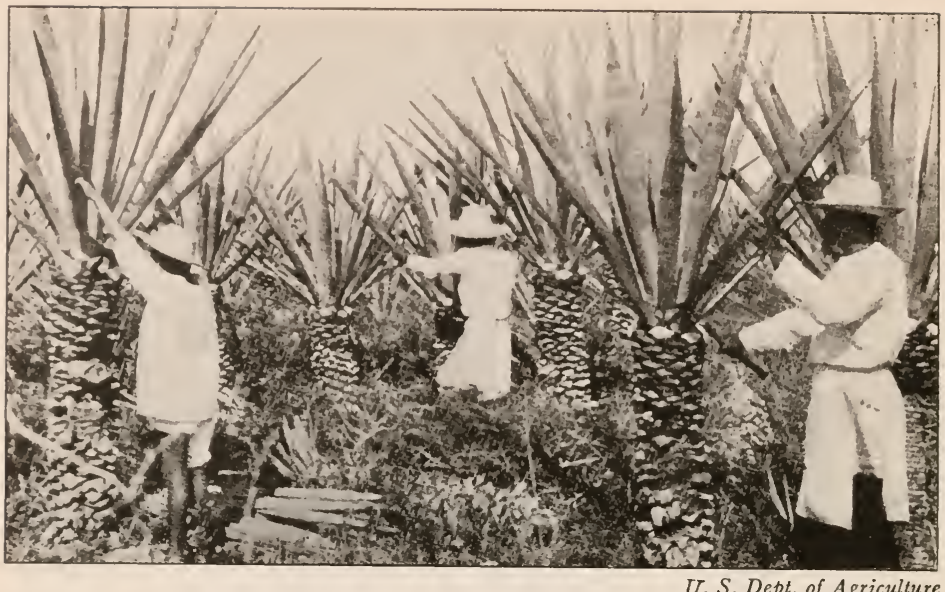

FIG. 54. Cutting leaves from the sisal (a form of century plant) for making the fiber used in the manufacture of binder twine in Yucatan.

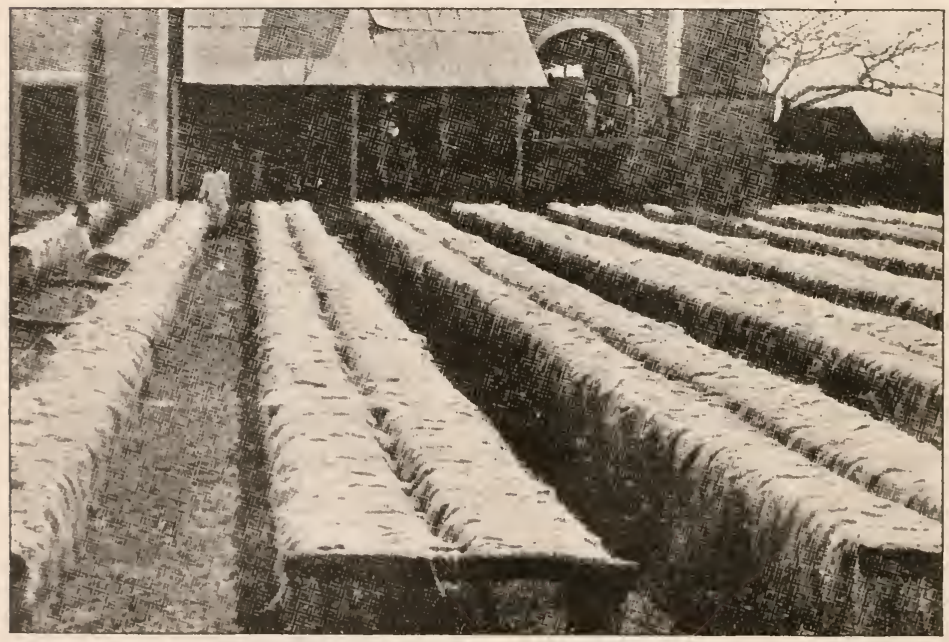

U.S. Dept. of Agriculture

FIG. 55. Drying sisal fiber in Yucatan. 
squares. The lines in each direction are still parallel. This indicates that all parts of the blade are growing equally.

These facts regarding the growth of leaves may be summarized in a somewhat different way. In the ferns the last part of the leaf to mature is the apex. In parallel-veined leaves a region near the base is still in a growing condition after the other parts are mature. In net-veined leaves all parts of the blade mature at the same time.

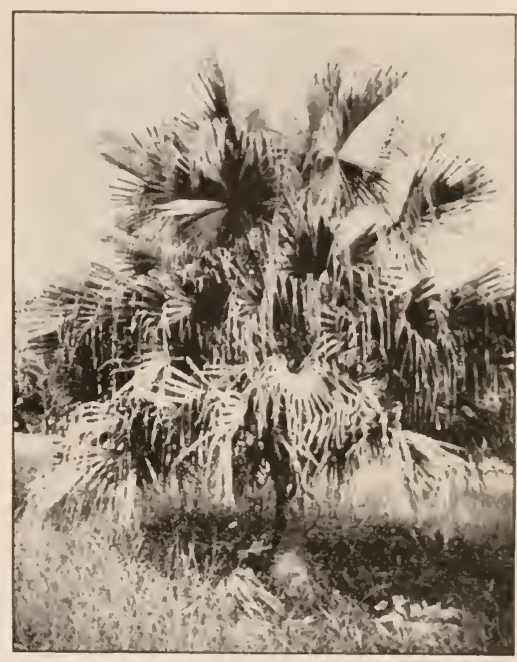

Bruce Fink

Fig. 56. Hat palm, Porto Rico. The leaves are split into strips and are used in weaving hats.

Leaves as sources of commercial products. Many plants are grown or collected for the sake of their leaves. The most nourishing part of forage crops like hay and alfalfa is the leaves. Lettuce, celery, and Swiss chard are important garden leaf crops. The leaves of the tobacco plant furnish the basis of a world-wide industry. The conductive bundles from the leaves of certain Mexican agaves furnish the sisal fiber used in the manufacture of binder twine. Manila fiber is made from the bundles of the leaves of a Philippine banana. The leaves of the tropical palm, raffia, are used by gardeners for tying up plants, and by others for the making of ornamental baskets. Other tropical palms furnish the fibers from which Panama hats are woven. The eelgrass, which 
grows in shallow water along our coasts, has been found to be one of the best materials for packing the sound-proof, fire-proof, and heat-proof walls of apartment houses, factories, and cold-storage warehouses. Cocain, caffein, digitalis, the oils of mint and wintergreen, and other substances used in medicine are derived from the leaves of plants. 


\section{Suggestions for Laboratory and Field Work to Precede Chapter Nine}

1. Examine the stem systems of an herb, a shrub, and a tree and make sketches of them, preferably in the field.

2. Field trip to study herbs, shrubs, and trees, noting the great variety of forms in each group. A visit to a greenhouse will permit the study of a variety of tropical species and of methods of propagating plants.

3. Field trip for the study of annuals, biennials, and perennials. Old fields, gardens, roadsides, and woods will show a variety of forms. In the case of perennials the underground parts are as interesting and important as the above-ground shoots. How does each of these types of plants pass the winter? 


\section{CHAPTER NINE}

\section{HERBS, SHRUBS, AND TREES}

EvERy one who has occasion to grow plants needs to know something about the length of life of the plants he is concerned with, and he must know also whether they have herbaceous or woody stems. For example, suppose a farmer wishes to determine whether it will be more profitable to grow sweet clover or alfalfa in a certain field. Before planting either of these crops, he should know that one of them is a biennial and the other a perennial, because all his plans for handling the crop will depend on this information. Or suppose that another man wishes to have a permanent border of flowering plants about his lawn to obstruct the view of some unattractive fields or buildings. He can choose wisely from among the hundreds of plants listed in nursery catalogs only when he has definite information about the longevity of the plants and as to whether they are herbs, shrubs, or trees. A clear understanding of the classification of plants on the basis of their length of life, their woodiness, and their tendency to form single large trunks or a number of stems is helpful also in any study of the structure and processes of stems.

Longevity of plants. Plants differ greatly in their length of life. To indicate the length of the natural life periods, the terms anmual, biennial, and perennial are commonly applied to plants. It is important that these terms be clearly understood before the subject of the tissues and their arrangements in stems is taken up, because in each of these length-of-life classes certain characteristics are associated with the form and development of the stem.

Annuals. Most of our common garden vegetables and field crops are started from seeds in early spring. The seeds 
germinate; roots and shoots develop; and by midsummer or autumn, flowers and fruits are produced and new seeds, which contain the beginning of another generation of plants, are formed. Then the plants die. The period from seed germination to seed production is called the life period. If it is completed within a single growing season, the plant is called an anmual (Latin : anmus, year). Corn, lettuce, radishes, beans, pumpkins, morningglories, and ragweeds are familiar annual plants.

Biennials. During the first season some plants develop only leaves and roots and a very short stem. The root is usually large and accumulates a considerable amount of food. In the second season growth is renewed, and there is developed an upright stem with leaves, flowers, fruits, and seeds. These plants which pass a winter season during their vegetative development, and whose life period includes two different growing seasons, are called biennials (Latin: bien-

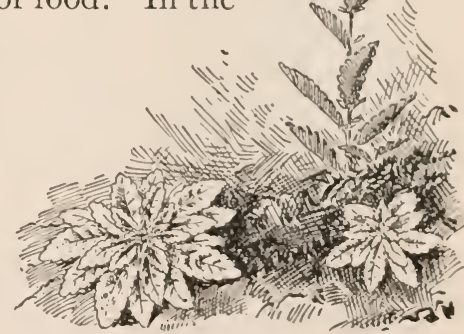

FIG. 57. Moth mullein, a biennial: first season rosettes (in foreground) and mature plant.

nium, space of two years). The seeds of some common weeds, like the shepherd's purse, evening primrose, and wild lettuce, germinate in August or September, and a little rosette of leaves is formed close to the ground. Food accumulates in the root until winter comes. The following spring the plants make rapid growth, and by midsummer they have blossomed, produced seed, and died. In spite of the fact that their whole 
life is passed within a twelvemonth period, these plants are called biennials, because their life period covers parts of two vegetative seasons.

The term annual or biennial as applied to plants, therefore, does not imply any definite length of life in months. Wheat may be grown either as an annual or as a biennial, depending upon whether it is planted in the spring or in the fall. ${ }^{1}$ Shepherd's purse and wild lettuce not infrequently live as annuals in nature. The commonest biennials of the garden are beets, carrots, parsnips, turnips, and cabbage. In the first four, large amounts of food are accumulated in the roots; in the cabbage the food is stored in the enormous terminal bud, the " head." These stores of food are used in the production of seeds the following year.

Usually biennials and annuals are herbs. Biennials, like annuals, are comparatively small in size, and die after flowers and seeds have been produced.

Perennials. Perennials (Latin: perennis, lasting through the year) are plants that live for a number of years. Some of them, as for example certain grasses, produce seed during the first and succeeding years. Other perennials, like alfalfa, form seed at the end of the second and succeeding seasons. Trees and shrubs usually require several seasons' growth before seeds are produced. The century plant of our southwestern deserts develops vegetatively for 25 or 30 years before it produces a flowering stem and seeds. Then it behaves like an annual or a biennial, for as soon as the seeds are mature the whole plant dies. This calls our attention to the interesting

${ }^{1}$ When wheat is planted in the spring and grown as an annual, it is called "spring wheat." When it is planted in the fall and grown as a biennial, it is called "winter wheat." The same variety may be grown either as spring or winter wheat, but in practice different varieties are grown. 
fact that in annuals, biennials, and a few perennials there is no well-marked period of senility or old age. They die suddenly at maturity, immediately after their period of greatest vigor. Trees and shrubs, on the contrary, have a distinct period of old age in which the physiological processes are slowed down gradually until the plants succumb to diseases and unfavorable conditions which they could have withstood in youth.

Perennials classified according to the persistent parts. All perennials add new leaves, new stems, and new roots each year; but they may be classified roughly according to the parts that persist from one season to the next.

Evergreen trees and shrubs are perennial in all parts of the plant body. Deciduous trees and shrubs are perennial in their stems and roots. Many herbaceous perennials, like the cat-tails, swamp mallows, peonies,

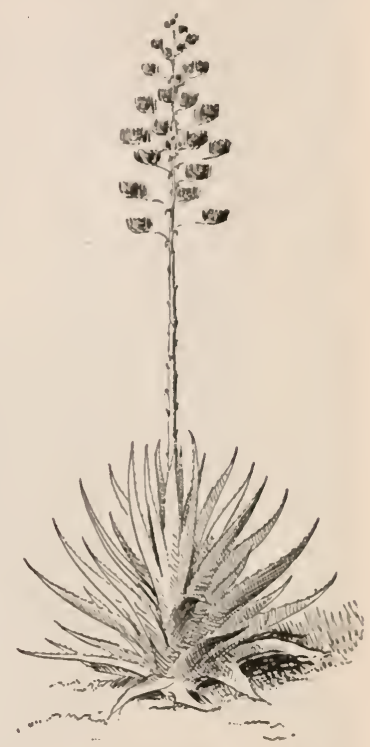

Fig. 58. Century plant (Agaic), showing rosette of fleshy leaves and flowering stem. It is a perennial, but, like an annual or a biennial, it dies when it flowers and fruits.

trilliums, and bananas, have annual above-ground stems but perennial underground stems and roots. Dahlias and sweet potatoes have perennial roots. Potatoes and the Jerusalem artichoke (a kind of sunflower) have perennial thickened underground stems (tubers). Tulips and hyacinths have perennial underground stems (bulbs). These examples show that perennial plants have many different ways of bridging 


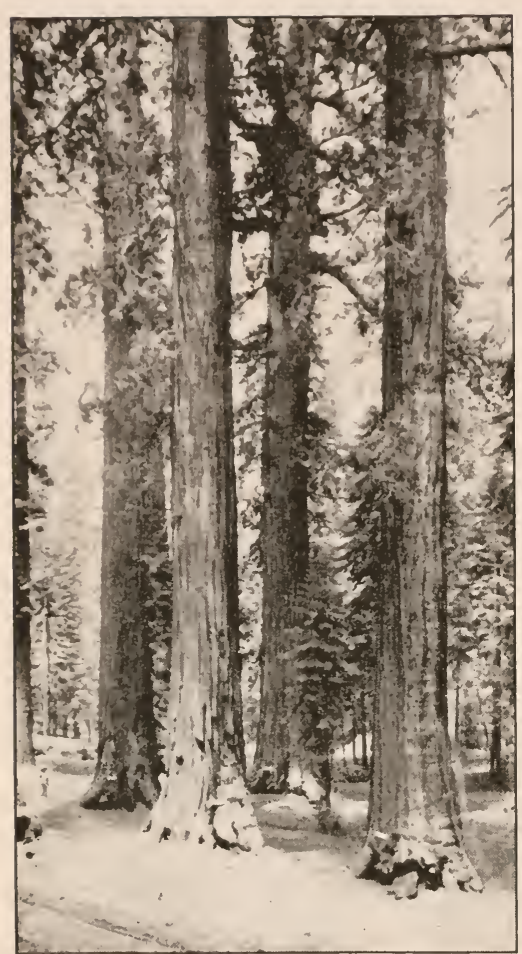

Fig. 59. Group of California Big Trees ( $\mathrm{Se}$ quoia gigantea). An idea of their size and height can be gained by comparing them with the man standing at the left of the picture. over unfavorable seasons like periods of cold or drought.

There seems to be no limit to the length of life of some perennial herbs, like ferns, the May apple, Solomon's seal, and certain grasses and mints. The older parts die each year, and new parts form at the other ends of the underground stems. The plants change their locations slightly each year, one end of the stem growing forward and the other end dying away. There is no apparent reason why such plants should not live indefinitely, perhaps longer than the oldest trees; but no one part of the plant lives for a long time.

Herbs, shrubs, and trees. Shrubs and trees have woody stems. The stems of herbs lack woody tissues. Our garden and field crops are all herbaceous plants. Their stems contain no woody tissue and, for this reason, in temperate climates the above-ground parts live but a single growing season.

The principal difference between shrubs and trees lies in 
the fact that shrubs develop numerous slender above-ground stems from a single base, while trees develop a single stem or trunk. This distinction may be expressed in another way by saying that shrubs branch underground, while trees branch only above ground. Most shrubs are less than io feet in height, but some, like the staghorn sumac, may reach a height of 20 feet. Most trees are between 25 and 200 feet in height, but the eucalyptus tree of Australia and the giant sequoias of California are over 300 feet in height, and the massive trunks of the latter may be more than 30 feet in diameter. However, the distinction between herbs,

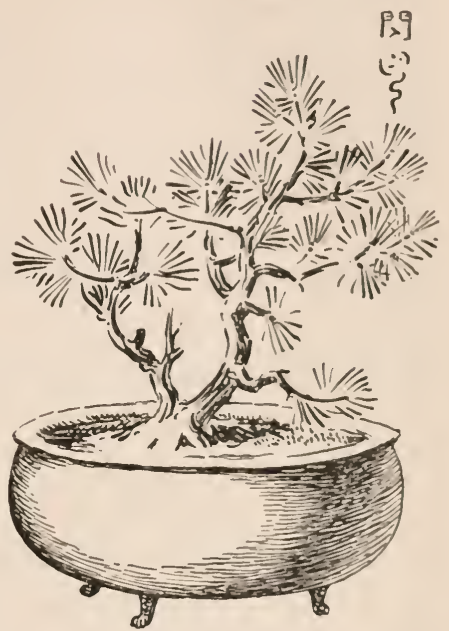

Fig. 6o. Japanese dwarf pine. Some of these small potted trees are a century old. shrubs, and trees is not one of size. Herbaceous plants, like the corn and sunflower, may reach a height of over I 5 feet and the banana a height of 30 feet, while some shrubs are only a few inches in height and some of the dwarf trees of Japan that are a century old are less than 5 feet in height (Fig. 60).

Plant characteristics and the plant-producing arts. The differences in the habits of growth, longevity, and materials stored by plants has led to specialization among those who grow plants. For many evident reasons the most important art of growing plants is agriculture. The farmer deals entirely with herbs and largely with annuals, though biennials and perennials may be grown for forage crops. He is for the 
most part concerned with plants that accumulate foods in a highly concentrated form.

The growing of trees to create forests for the production of timber, fuel, and pulp wood is the field of silviculture. The silviculturist specializes on those trees that accumulate cellulose in the most usable form.

Horticulture embraces a wider range of plants, but in actual practice a horticulturist usually specializes on plants having somewhat similar habits. The growing of food-producing shrubs and trees represents one division of horticulture. The object sought is the production of fruits containing pleasantly flavored substances stored in cells with the thinnest possible cell walls. The vegetable grower specializes on annuals and biennial herbs that accumulate both food and flavors, and to a less extent on perennials, like asparagus and rhubarb. Floriculture deals with all classes of plants and has for its object the production of attractive flowers and foliage. It reaches its highest development in landscape architecture, in which masses of vegetation are arranged to beautify a landscape. 
Suggestions for Laboratory and Field Work to Precede Chapter Ten

1. Make accurate drawings of small portions of herbaceous and woody stems, noting the various surface features. Goldenrod, sunflower, aster, gourd, buckeye, box elder, raspberry, elm, ailanthus, and hawthorn are particularly suitable. Label the terminal buds, lateral buds, leaf scars, bundle scars, lenticels, and bud scars.

2. Study branches of spruce and apple, to show growth of different years.

3. Place some twigs of soft maple, ailanthus, willow, and cottonwood in water. Make a series of drawings to show stages in the opening of the buds.

4. Make sketches of several trees to show the deliquescent and excurrent types of branching. 


\section{CHAPTER TEN}

\section{STEMS AND THEIR EXTERNAL FEATURES}

THE stem usually forms the axis of the plant and bears the leaves, flowers, and fruits. Plants showing all degrees of stem branching are found, from the unbranched palm and corn to the finely divided asparagus and elm. In most plants the stems are upright, aërial structures; but in some plants they lie on the surface of the soil, in other plants the main stem is underground and only the branches rise above the surface, and still other plants have the entire stem underground. The upright stem is the common type and has many advantages over a horizontal stem. At its lower end it bears one or more roots that connect the plant with the soil.

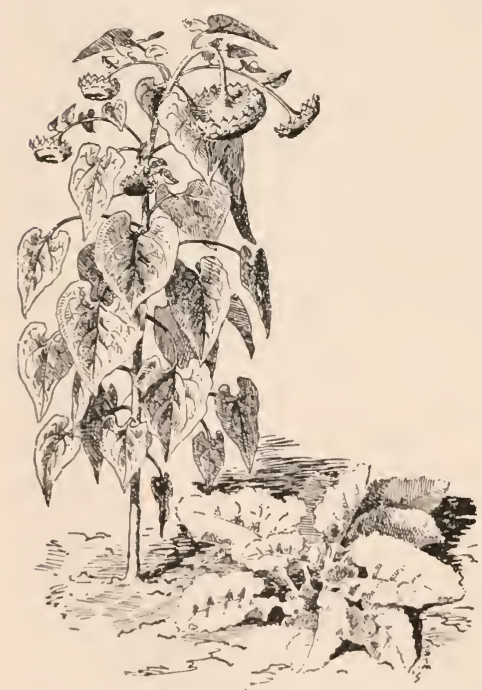

Fig. 61. Sunflower and burdock, showing advantage of upright stem in leaf display.

Advantages of upright stems. The photographer uses light to effect chemical changes in photographic papers and plates, and the plant uses light to bring about chemical changes in its green tissues. The photographer who uses sunlight for his work usually locates his studio at the top of a tall building, because there he avoids the shadows of near-by buildings and secures a more constant exposure to light. The same advantages come to the plant that has its leaves raised well above surrounding plants : the leaves are in less danger of 
being shaded, and each day they are exposed to the sunshine during a longer period.

The tall plant has an additional advantage in being able to expose to the light a greater leaf area over a given space of ground, because it can display several or many layers of leaves one above the other. The rosette of leaves formed by the burdock illustrates the possibilities of leaf display near the soil. A large sunflower plant covers no greater soil area than a burdock, but it is able to expose to the sunlight several times as great a leaf area, because

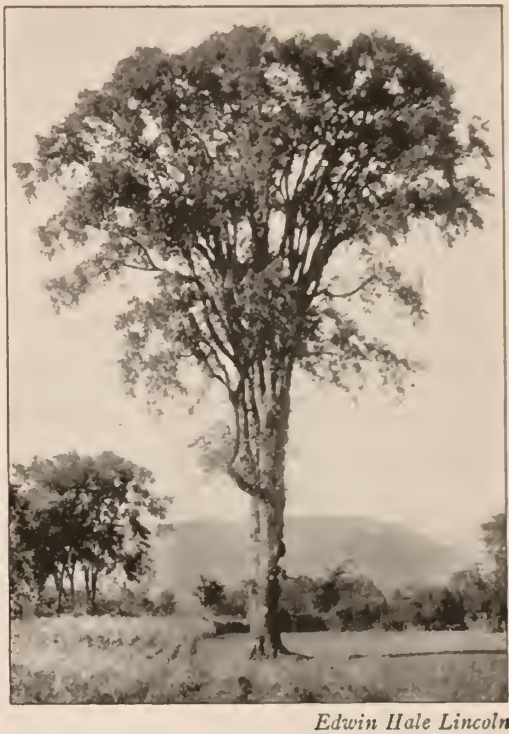

FIg. 62. An American elm in the Berkshire Hills, Massachusetts. The tall stem of such a plant makes possible the display of a large number of leaves to the light and facilitates the production and dispersal of seed. the sunflower leaves are placed at several different levels (Fig. 6I). Trees have the greatest stem development and the greatest leaf display. Rosette plants, like the dandelions and plantains, represent the opposite extreme of slight stem development, small leaf area, and a poor leaf display. One adiantage in a tall, upright stem is that it holds the leaves up to the light and thereby makes possible a greater leaf display.

Plants with upright stems have advantages also in connection with reproduction and seed dispersal. Wind-pollinated flowers, like those of corn or the pine, are better exposed to 
air currents when they are borne on an upright stem, and the display of insect-pollinated flowers high up on a stem is advantageous because the flowers are more readily found by insects. Moreover, seeds are likely to be distributed more widely when they fall from tall plants. For example, a maple seed dropped from a height of 50 feet is exposed to air currents during its fall and is almost sure to reach the ground at some distance from the point directly below the starting place. A second advantage in an upright stem is that it facilitates the production and dispersal of seed.

The advantages of the upright stem are all dependent on its capacity to support other organs. The stem must be strong enough to support leaves, flowers, and fruits. The city skyscraper needs first of all a strong framework about which the building is constructed. The stems of tall, erect plants must be correspondingly strengthened by a mechanical structure. The base of a tree is much smaller in proportion to its height than that of the tallest and narrowest building, and it is possible for trees to reach great heights only because their stems are composed in large part of supporting tissues that have great strength. Mechanical or supporting tissues are necessary in upright stems.

Advantages of horizontal stems. Horizontal stems have little or no mechanical tissue, and they display leaves to the light advantageously only when they grow in the open. There are advantages in stems of this type, however, because by growing horizontally on the soil or beneath the surface of the soil they spread the plant; because they are in contact with the soil and may take root at frequent intervals; and because they are better protected than upright stems during the winter and other unfavorable seasons. 
Conductive tissues necessary in stems. The simplest land plants are very small and grow flat on the soil in wet places. They are constantly in contact with the moist soil, and their cells can be supplied almost directly with water and mineral salts. In such plants a conductive system is not necessary; but if the leaves of a plant are to be raised into the air, water for transpiration must not only be supplied to them continuously, but at times it must be supplied in great quantity. Because of this fact, a plant that raises its leaves even a few inches above the soil must possess conductive tissues, and when large numbers of leaves are raised 200 or 300 feet into the air, a very extensive water-conducting system is necessary. The water-conducting tissues are of vital importance in the stems of complex plants.

The roots and stems require a continuous supply of food for repairing old cells and for building new ones. Since the foods are manufactured primarily in the leares, there must be foodconducting tissues that are adequate to carry them to all parts of the stem and roots. The food-conducting tissues also transfer food from the leaves to the seeds and growing parts, and when food has accumulated in the stem or roots it may pass up through the conductive tissues of the stem to other parts of the plant. Food-conducting tissues are necessary in stems to transfer food within the plants.

The stem as a place of food accumulation. Because of the volume of the stem it is natural that excess food should accumulate in it. Under favorable conditions, foods for which the plant has no immediate need are continuously passing from the leaves into the stem. Consequently, in our larger plants the stem is the place of temporary storage and the center from which foods are distributed as needed. In some plants 
the process of accumulation becomes one of the most important functions of the stem, and it may include the accumulation of water as well as of food (page 75).

Stems as photosynthetic organs. In plants with little or no leaf display, the stems may do all or most of the photosynthetic work. The night-blooming cereus and other cactuses, and asparagus and equisetum, have no leaves. The green stems of most herbaceous plants contribute at least a part of the carbohydrates, and the young twigs of many woody plants are green and carry on photosynthetic work.

Physiologically, then, the stem is an organ that supports and displays leaves to the light; aids reproduction by elevating the flowers and seeds; conducts water to the leaves for transpiration and photosynthesis; carries food to its own living cells and to those of the roots; is a place for the temporary accumulation of food materials; and may carry on photosynthesis.

External features of woody stems. On a woody stem nodes, leaf scars, buds, and lenticels may be seen. The nodes are the places where the leaves arise, and they are the most prominent external feature of stems. The arrangement of leaves at the nodes has already been discussed (page 37 ). In addition to the leaf, the node gives rise to one or more buds, just above the place of leaf attachment, in the so-called axil (Latin: axilla, armpit) of the leaf. The leaf scars are markings on the stem where leaves have fallen. The part of a stem between two nodes is called an internode. The lenticels are small, dotlike elevations scattered over the surfaces of the internodes.

Buds. Stems and branches produce leaves only once. We are accustomed to speak of deciduous trees clothing themselves with a new set of leaves each spring, as though the branches 
of the previous year put forth a new set of leaves to replace those lost the preceding autumn. As a matter of fact, when we look at a deciduous tree in winter, we see branches and twigs, all of which have borne leaves and none of which will ever bear leaves again. The possibility of producing new foliage lies in the development of new branches and twigs. This is the function of the buds; from them the new growth of each year takes its rise.

The buds of many tropical plants are like those we see at the tops of the stems of garden vegetables. Such a bud consists of the stem's growing point and the undeveloped leaves, with no special coverings of any kind. These naked buds occur also on the underground stems of some of our Northern plants. A simple sort of bud covering, which is common in the tropics, is made by the folding together of the stipules. This type of bud covering

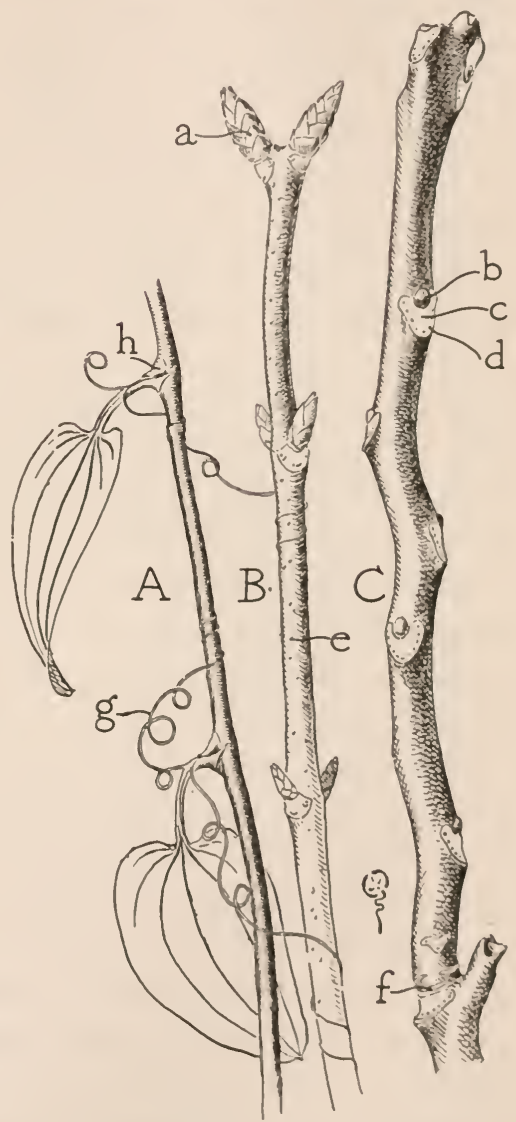

Fig. 63. Twigs of smilax (1), buckeye (B), and tree-of-heaven (.tilanthus) (C). The bud scales are designated by $a ; b$ and $h$ are buds; $c$ is a leaf scar, $d$ a bundle scar, $e$ a lenticel, $f$ a terminal bud scar, and $g$ a tendril. 
may be seen in the tulip tree and the magnolias of temperate climates. The buds of most temperate perennials are covered with scales. Not infrequently the scales are further covered with matted hairs and secretions of wax and resin. These all tend to make the bud coverings impervious to water. In this way the tender growing parts are protected from excessive loss of water during the winter and during the still more critical stage in early spring when the buds are opening.

We are likely to think of buds as being formed at about the time when the leaves fall from the trees. A good observer, however, will have noted that the buds begin to develop when the leaves unfold in spring, and that they grow all summer long. Because of the prominence of the leaves, the buds are obscured somewhat during the summer months, and become conspicuous only after the leaves are gone.

The opening of buds. When the warm weather of springtime comes, the innermost bud scales begin to grow and expand. Sometimes the outer scales are pushed off; sometimes they elongate and grow like the inner ones. But the scales quickly reach their full growth, and soon they are cut off by the formation of an abscission layer at the base of each. In the buds of a few plants all the scales are dead and are pushed off by the growth of the stem and leaves inside. The expansion of bud scales and leaves takes place almost wholly through the enlargement of cells already formed. Within the bud the minute leaf cells absorb water and develop large vacuoles. The expansion of these cells results in the enlargement and spreading of the leaves. Material for the study of the different habits of bud expansion may be secured in winter by bringing branches of different kinds of trees into a warm room and placing them in water until the leaves expand. 
Kinds of buds. Every bud contains the growing point of a stem. In addition, most buds contain the beginnings of foliage leaves; that is, the leaves have already begun to develop on the sides of the young stem within the bud. Some buds, as for example many of those on the maples and elms, contain the beginnings of flowers. Other buds, like some of those of the catalpa and the horse-chestnut, contain both leaves and a flower cluster. Bulbs are really a special underground form of bud, and they are similar in structure to other buds. We shall consider bulbs when we come to the study of underground stems.

Bud development and plant form. Buds which occur at the ends of stems are called terminal buds; those which occur at the nodes are called lateral buds. This classification is useful because only a part of the buds on a stem ever develop and because the form of a plant depends on which set of buds develops more freely and grows more rapidly. In most plants, the terminal bud simply extends a stem or branch; the lateral buds produce new branches. Plants with very strong terminal buds tend to become columnar in form, like the large, unbranched sunflowers of the garden or like the spruce and palm among trees. Plants with strong lateral buds tend to branch continually and to become bushy in form, like the lilac and hydrangea. There are all gradations between these extremes in the development of the terminal and lateral buds, and in the resulting plant forms.

In many roses the shoots from the base of the stem develop only through their terminal buds the first year. The shoot is thus extended to great length by the first season's growth. The following year the lateral buds develop, and the long shoot becomes highly branched. As these lateral branches 


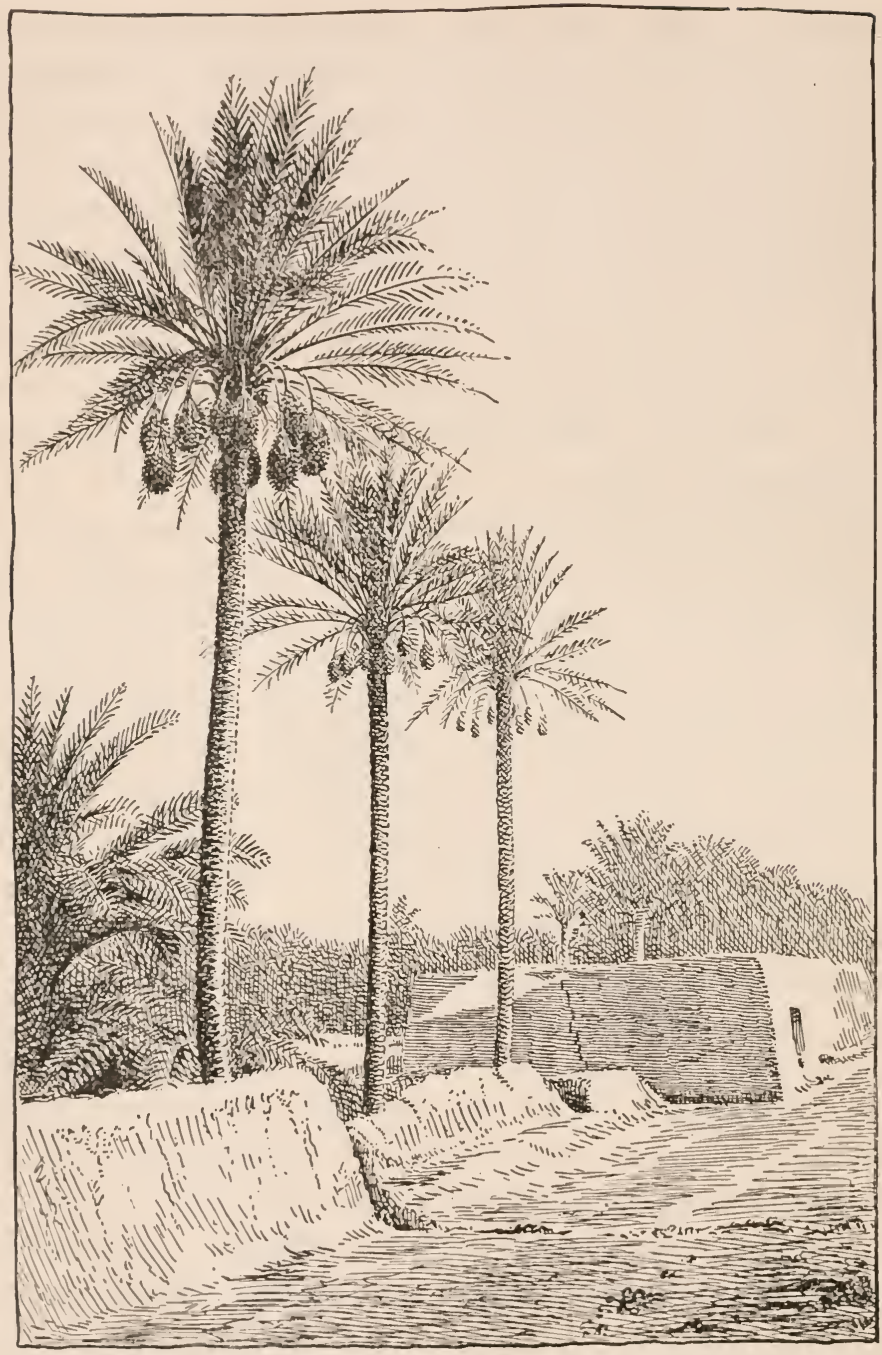

Fig. 64. Date palms in fruit, on an oasis in an Algerian desert. The terminal bud continues its development year after year and builds up the long, unbranched stem of the tree. (From photo U.S. Depl. of Agriculture.) 


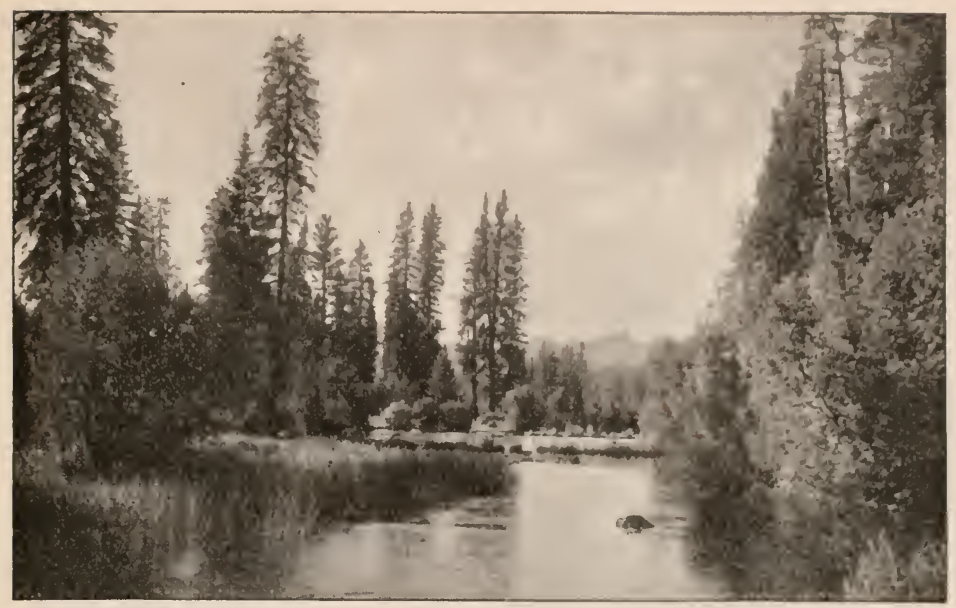

FIG. 65. Pine trees on Wood River in Oregon. The strong terminal bud continues its development, and the excurrent stem is the result.

bear the flowers and produce them abundantly only once, we can promote flowering in these roses by trimming away each year all but the long, unbranched shoots. In many other shrubs, as spiræa, barberry, and privet, a few strong lateral buds at the surface of the soil develop each year. This accounts for the basal branching of these plants.

Excurrent and deliquescent stems. When trees have strong terminal buds, the main stem extends to the top and is called excurrent (Latin: excurrens, running out). The spruce has a strong terminal bud, and just beneath it several smaller lateral buds. The terminal bud grows upward, and the lateral buds grow outward, forming a whorl of branches at the base of the season's growth. 'This is repeated each year, the terminal shoot lengthening the stem, and the lateral buds adding a new whorl of branches. Consequently each 


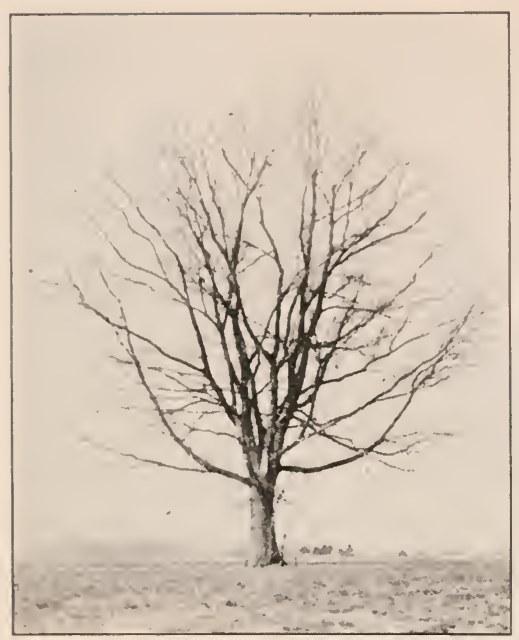

FIG. 66. A hackberry in Illinois. The development of the lateral buds results in the formation of a deliquescent stem.

year's growth is marked by a whorl of branches, and the age of a tree may readily be estimated by counting the number of whorls on the stem. Since the oldest branches are nearest the ground they are the longest, and the tree becomes cone-shaped as it grows.

The terminal buds of the elm tree seldom survive the winter. The lateral buds develop, and the main stem divides and subdivides until it is lost in the crown of the trees. This gradual dissolving of the trunk into a spray of terminal branchlets suggested the name deliquescent (Latin: deliquescens, dissolving) for this type of stem. We see, therefore, that the excurrent type of stem depends on the continual development of terminal buds, while the deliquescent type depends on the growth of lateral buds. Consequently we may modify the forms of plants in cultivation by trimming them and so forcing the growth of certain buds. Lawn trees and shrubs are grown either for shade or for ornamental effects. We secure shade by trimming off the terminal buds and so causing many of the lateral buds to develop into branches and thus form a denser crown. Ornamental effects are secured by trimming plants so that they will be in artistic harmony with their surroundings. 


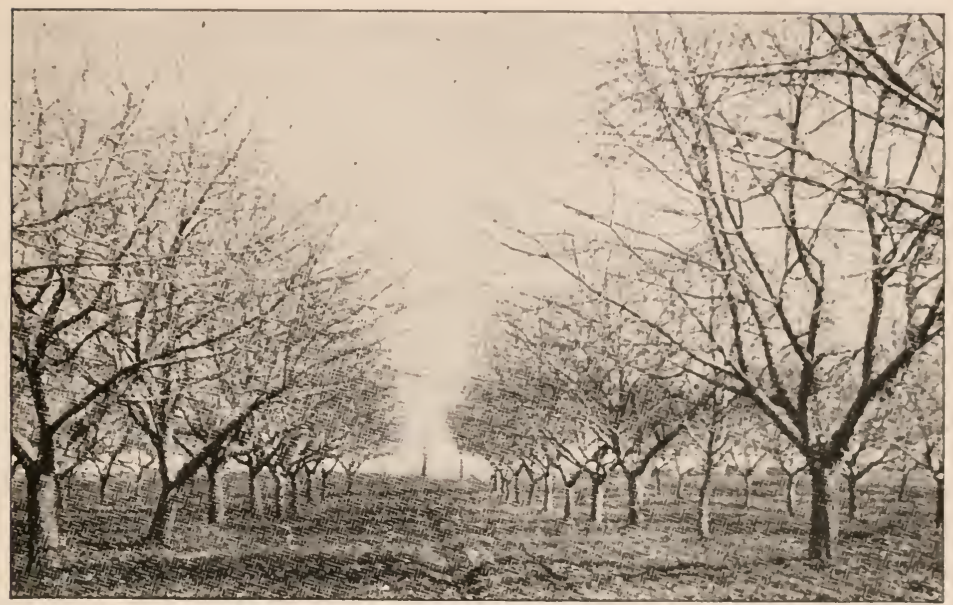

U.S. Dept. of Agricullure (J.Craig)

Fig. 67. Baldwin apple orchard, showing trees with the branches thinned to increase the production of fruit.

Fruit trees and grapes have been found to produce more fruit, and fruit of a better quality, when the number of branches is small. A smaller number of branches on a tree secures an open crown and permits the sunlight to penetrate to every leaf, and the removal of some of the branches forces the development of flower buds which might remain dormant if the terminal and branch buds were allowed to grow uninterruptedly. In grape culture, only four or five branches are allowed to remain on a vine each year, and these branches are shortened. This insures full development for a few of the flowering branches and the production of the best quality of fruit.

Leaf scars and bud scars. The leaf scars on some plants are round; on others they are narrow lines; on most plants they are crescent-shaped. Usually they are smooth, except 
for small, dotlike markings. These markings are bundle scars; they show where the bundles of conductive and mechanical tissue extended outward from the stem into the petiole. The shape of the leaf scar and the arrangement of the bundle scars are so characteristic for many kinds of trees that they may serve to identify the tree in winter.

The bud scales also leave scars when they drop. These scars are usually numerous and so closely crowded that they form a roughened ring about the stem. The terminal-bud scars occur at intervals, surrounding the stem or branch. The lateral-bud scars occur only at the bases of the branches and twigs.

Determining annual growth of shoots from terminal-bud scars. Since the terminal bud marks the end of each year's

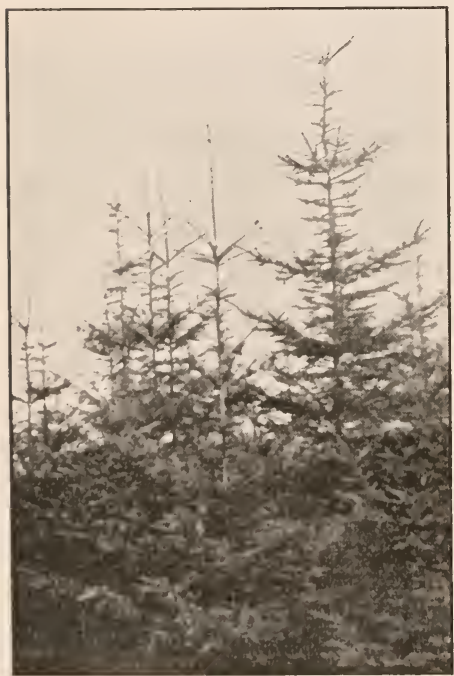

FIg. 68. Norway spruce, showing whorls of branches at end of each year's growtb. growth, the terminal-bud scars mark off a perennial stem into segments, each of which represents the growth of a single year. Often an interesting life history is suggested by the varying length of the intervals between the bud scars on a particular stem. By a study of these intervals we can determine the seasons that were favorable and those that were unfavorable on account of drought, excessive rain, attacks of insects, or some other cause.

In the pines and spruces the year's growth is marked off 
not only by the bud scars, but also by whorls of branches. Differences in the color of the bark and in its texture will also help to distinguish successive annual stem segments in most trees.

Lenticels. All living cells require energy. This is largely obtained from respiration. Therefore, in addition to a constant food supply, the cells of the stem must have access to oxygen. As in the leaves the oxygen is supplied through the intercellular spaces, so in stems there must be sufficient intercellular spaces to permit oxygen to diffuse inward and carbon dioxid to diffuse outward. There must also be openings through the epidermis or bark to connect these intercellular spaces with the outside atmosphere.

The young green stems of all plants have stomata. Perennial stems, however, soon develop a corky layer beneath the epidermis, which cuts the cells in the interior of the stem off from the stomata. While this layer is developing, masses of round, loose cells form beneath some of the stomata, pushing out and tearing the epidermis above them. These open places are the lenticels. They permit gas exchanges, and in older stems take the place of the stomata. The lenticels of most trees and shrubs are closed in the late autumn by the growth of a thin layer of cork beneath them. The following spring loose cells are again formed at the same point, the cork is burst open, and the lenticels again permit gas exchanges.

In the cherry and birch the lenticels persist for many years and become elongated transversely, forming granular rings part way around the stem. In the trunks of thick-barked trees, the lenticels occur in the furrows of the bark. 


\section{PROBLEMS}

1. What advantage in resisting wind have tall, columnar tree trunks over equally tall smokestacks or monuments? What disadvantage?

2. What are the perennial food-producing plants of your locality?

3. Find out how your local gardeners trim their grapevines, berry bushes, and fruit trees. Secure definite information for five of these plants, and determine the reasons underlying the practices.

4. What are the best trees for street planting in your locality? What trees now planted there are objectionable? Why?

5. Compare a tree growing in an open field with one of the same species growing in the woods. Account for the differences in arrangement of branches and leaves.

6. Which will furnish the better lumber, a tree grown in the open, or one grown in the forest? Why? 


\section{Suggestions for Laboratory Work to Precede Chapter Eleven}

1. Sketch cross sections of some monocot stems like corn, bamboo, asparagus, lily, or wheat. Note particularly the arrangements of the bundles. Cut a longitudinal section through a node, and note how the bundles unite in the node.

2. Sketch a cross section of a peach branch that is an inch or two in diameter. Note pith, wood, bark, cortex, cortical parenchyma, cork, cambium, annual rings, and pith rays.

3. Sketch a cross section of a pine stem and note the parts, as in the peach.

4. With a microscope, examine thin sections of monocot, dicot, and conifer stems, and note differences in the structures of the bundles.

5. Examine sections of tree trunks and determine the number of annual rings in the sapwood and in the heartwood. What fraction of a large tree trunk is alive?

6. Bring a branch of a tree to the laboratory and try to set up cleft and whip grafts. Also try to set a bud. Repeat the operation on trees out of doors and see whether or not the cions will live.

7. Show the region of growth by marking the upper end of a stem with transverse lines at equal intervals.

8. Show the effect of gravity on the direction of growth by changing the position of a growing stem with reference to gravity.

9. Show the effect of light on the direction of stem growth by placing a plant where light can reach it from only one direction. 


\section{CHAPTER ELEVEN}

\section{THE STRUCTURES AND PROCESSES OF STEMS}

IF we study the development of a stem from a bud, we find that the growing point is made up of very minute cells, all of which are practically alike. These cells divide to make other cells like themselves, and the lower ones begin to enlarge. In this way the growing point is pushed forward and the diameter of the stem increased. Upon these two processes, cell division and cell enlargement, the growth of the stem depends. Then certain groups of cells begin to take on special forms. The cells that are to form the bundles elongate; some of them develop woody walls. Others elongate but remain thin-walled, and these form the food-conducting tissue. The other tissues of the stem are composed of cells which have enlarged and have become rounded or variously angled, and which have their walls more or less thickened. These cells form the pith or soft inner part of the stem, and the cortex or outer portion. In this way the various tissues of stems arise from the small uniform cells of the growing point.

Stem structures and plant groups. There are three groups of seed plants that we wish to distinguish at this time because the stems of the plants that belong to these groups differ fundamentally. These groups are: (I) the conifers, or conebearing trees, like pines, spruces, firs, and cedars, that have scale or needle leaves and are for the most part evergreen; (2) the monocotyledonous plants (monocots), or plants with parallel-veined leaves, like the grasses, lilies, cannas, orchids, and palms; and (3) dicotyledonous plants (dicots), or plants with net-veined leaves, like oaks, maples, sunflowers, asters, and clovers.

The stems of the plants belonging to these three groups II 8 


\section{The Structures and Processes of Stems}

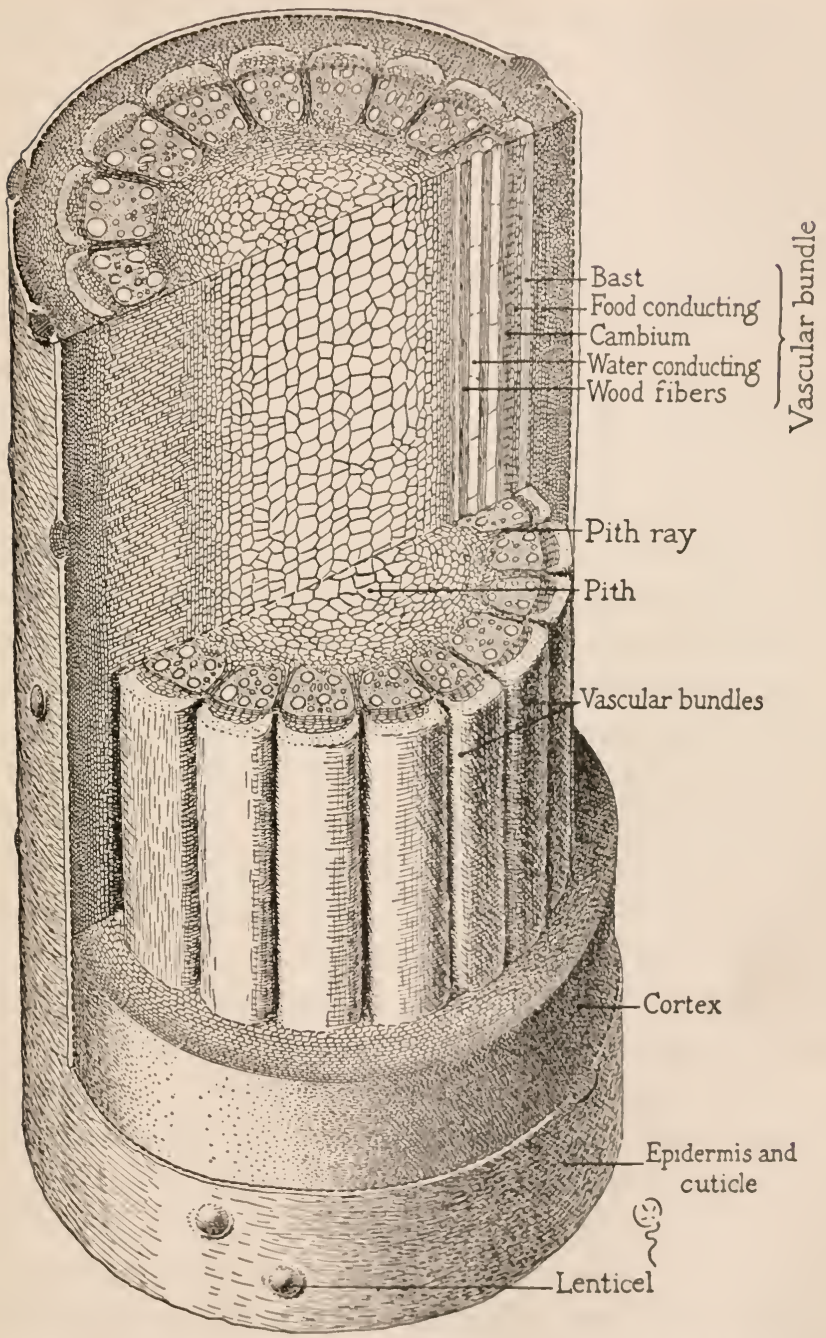

Fig. 69. Stem of moonseed vine, showing tissues and their arrangement. 
differ in ( $\mathrm{I}$ ) the kinds of tissue making up the bundles, and (2) the arrangement of the bundles in the stem. We shall first study the bundles and the arrangement in a dicot stem, and then we shall learn how the stems of monocots and conifers differ from those of dicots.

The structure of a dicot stem. When a dicot stem is cut across, the bundles are seen to be arranged in a ring. The cylinder of tissue lying inside the bundle cylinder is the pith; outside the bundle cylinder is the cortex; and covering the cortex is an epidermis very similar to that of leaves (Fig. 69). In older and harder stems the outer cortical cells have thick walls and form a corky or hard outer covering that replaces the epidermis. The pith and the inner part of the cortex are made up of rounded, thin-walled cells called parenchyma. In annuals and young perennials the cortical parenchyma contains chlorophyll and resembles the mesophyll of the leaf in appearance and function. It is this tissue that forms the inner "green bark" of twigs and gives the green color to the stems and branches of herbaceous plants.

There are, then, four distinct layers in dicot stems: (I) on the outsicle is the epidermis; (2) from the epidermis to the bundles is the cortex; (3) inside the cortex is the hollow bundle-cylinder; (4) the pith forms the axis of the stem, filling the space inside the cylinder of bundles (Fig. 69).

Between the bundles of the dicot stem there are strands of parenchyma cells that connect the pith parenchyma with the cortical parenchyma. These are the pith rays. They convey food across the stem, and with the other parenchyma cells form a complex tissue system in which excess foods accumulate and from which they later move to other parts of the plant. 


\section{The Structures and Processes of Stems}

General structure of the dicot bundle. The bundles in a plant stem terminate above in the veins of the leaves, and below they connect with the bundles of the roots. In the dicot stem these bundles contain four tissues: (I) the waterconducting tissue, (2) the food-conducting tissue, (3) the cambium, and (4) the mechanical tissue. The cambium is a layer of thin-walled cells that lies lengthwise in the bundle and separates the inner water-conducting tissue from the outer food-conducting tissue.

Tissues of the dicot bundle. The water-conducting tissue contains long, tubelike vessels made up of cylindrical cells joined end to end, often for considerable distances without end walls between them. These tubes (tracher) usually have heavy walls marked by spiral and lattice-form thickenings. When mature they are empty of protoplasm. In other words, they are the coverings of dead cells joined together to form tubes usually several inches, more rarely several feet, in length. Mixed with them are smaller and shorter tubes, and cylindrical cells that retain the cell contents. All together these tissues form the passageway for the movement of water and mineral salts, and sometimes sugar, to all parts of the plant. The general direction of the water movement in this tissue is upward, because the lifting of the water is brought about principally by transpiration from the leaves (page 134).

The food-conducting tissue differs from the water-conducting tissue in being composed of smaller, thin-walled cells, all of which retain their living protoplasm. The largest of these cells are set end to end, and the end walls have holes in them like the top of a salt shaker. These rows of cells, therefore, form tubes with sievelike cross walls in them, and on this 


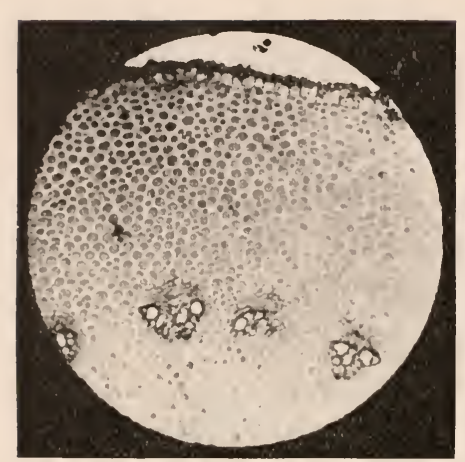

FIG. 70. Cross section of a portion of rootstock of calamus, photographed through a microscope. The circular areas are the cells which are filled with starch.

account they are called sieve tubes. Through the openings in the sieve plate the protoplasm is continuous from cell to cell, and through these tubes the foods pass from one part of the plant to another. Because the cells of the stem and root are supplied with food manufactured in the leaves, it is often said that the movement of foods is downward in a plant. In reality, the direction of the food current is not so fixed as is that of the water current. Food moves toward any part of the plant where it is being used or is being accumulated. For example, in midsummer when a tree is in full leaf and the season's growth has practically been completed, food moves out of the smaller branches into the larger branches and the trunk. In the spring, when leaves and blossoms are developing, food is being used in the twigs, and the direction of the movement of food materials is reversed.

The mechanical tissue is made up of cylindrical or spindleshaped cells with very heavy walls. Indeed, the walls at maturity may be so thick as to render the cells almost solid. Ordinary cellulose is not very hard, but the walls of the mechanical tissue are hardened and thickened by a deposit of a substance called lignin. The difference between hard and soft woods is for the most part due to the thickening of the walls of the mechanical cells; 
secondarily it is due to changes in the walls themselves (lignification).

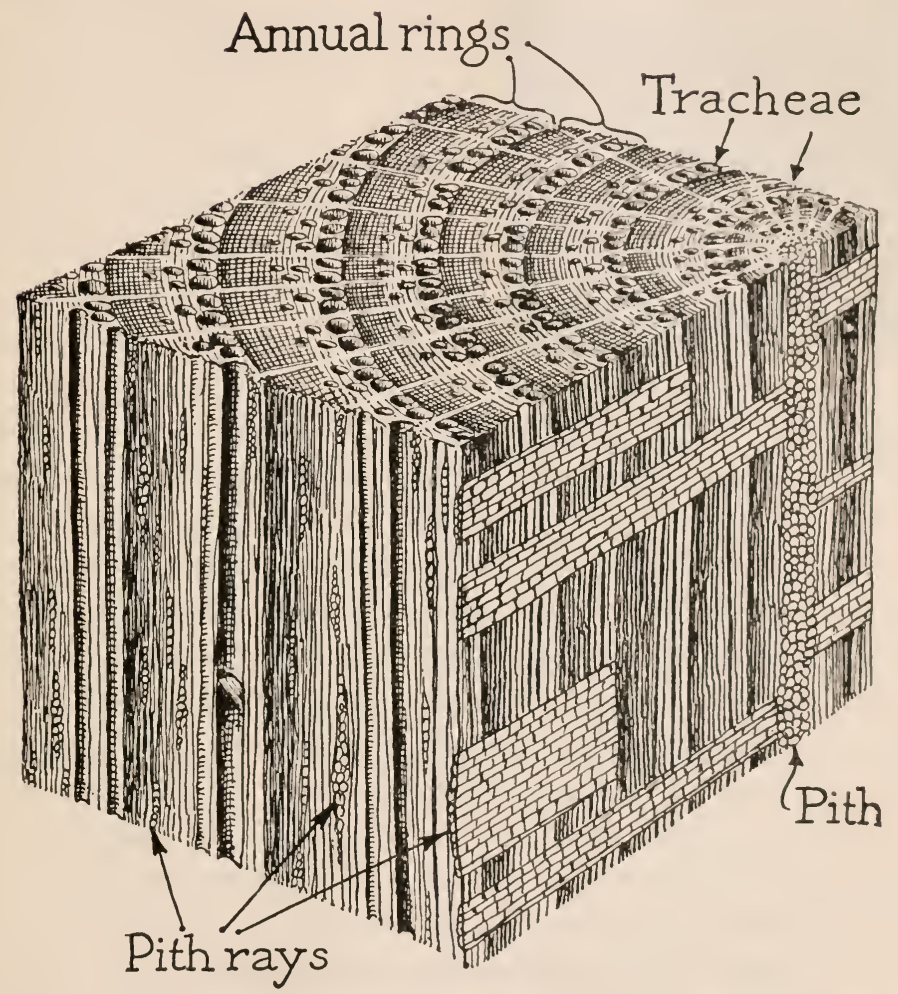

FIG. 71. Block of oak wood magnified to show the arrangement of the various tissues which produce the patterns on polished wood surfaces. (Diagrammatic.)

Mechanical tissue is found on both the water-conducting and food-conducting sides of the bundle. On the food-conducting side it lies outside the food-conducting tissue, and is made up of long, exceedingly slender, nearly solid, spindleshaped cells. These cells are called bast fibers, and the tissue 


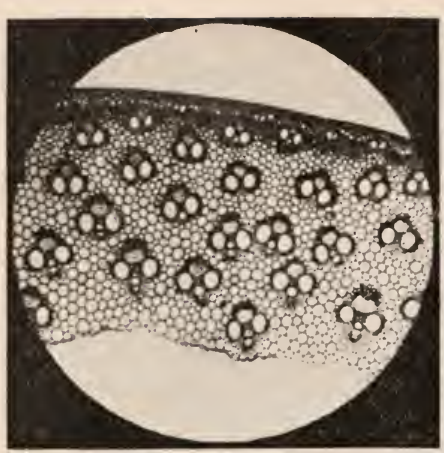

FIG. 72. Cross section of a portion of bamboo stem photographed through a microscope. The large openings in each bundle are the water-conducting tubes.

that is made up of them is called the bast. Bast may be seen in the stringy fibers on a grapevine or in the bark of trees. It is the bast fibers from flax, hemp, jute, and other dicotyledonous plants that are used in the manufacture of thread and cordage.

The cells of the mechanical tissue on the water-conducting side of the bundle are somewhat shorter and thicker than the bast fibers. They are known as wood fibers and make up what is properly called the wood, although in most dicots the wood fibers are mixed with the water-conducting vessels, and the whole inner part of the bundle is known as wood. In woody plants this mechanical tissue is present in abundance and forms the bulk of the stem. The lumber that is obtained from dicotyledonous trees is derived from the inner parts of the bundles and is made up of wood fibers and water-conducting tissues.

The cambium is a layer of soft tissue between the two sides of the bundle. It is the principal growing tissue of the dicot stem. Growth takes place in it by the longitudinal division of the cells. On its inner face the cells of the cambium layer change into water-conducting cells or wood fibers; on its outer face they change into food-conducting cells or bast fibers. In this way the bundles of perennial dicots enlarge from year to year, and this causes the stem to increase in thickness. In a tree the cambium cells form a continuous 
layer between the wood and the bark, and the diameter is increased by the addition of successive layers of tissues built by these cells.

Every one who has made willow or hickory whistles has become acquainted with the cambium. In early spring the cambium cells are dividing actively, and the cambium layer can be broken by tapping on the bark. The whole bark can then be readily stripped from the wood.

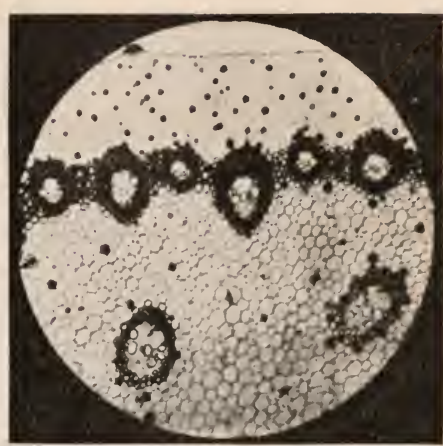

FIG. 73. Cross section of portion of a rattan stem photographed through a microscope. Note the ring of bundles near the outside, with the heavy-walled mechanical tissue and the scattered bundles within.

The monocot stem. The monocot stem, like dicot and conifer stems, is bounded externally by an epidermis which closely resembles that of the leaf. The groundwork of the stem is made up of parenchyma, which is commonly called the pith. The parenchyma is usually composed of thinwalled cells, and is the principal tissue for the temporary accumulation of foods; from it the sugar solution is obtained when the stems of sorghum and sugar cane (Fig. 48) are crushed. In a monocot stem the bundles are scattered, instead of being arranged in a cylinder as they are in a dicot stem. In the hollow stems of grasses they are scattered through the cylinder of parenchyma tissue; in a cornstalk, a shoot of asparagus, or the trunk of a palm they are distributed through the whole stem. As in the dicot and conifer bundles, the water-conducting tissue is on the side next the center of the stem, and the food-conducting tissue is on the side toward 
the epidermis. The scattered arrangement of the bundles in the pith may easily be seen in a stalk of corn.

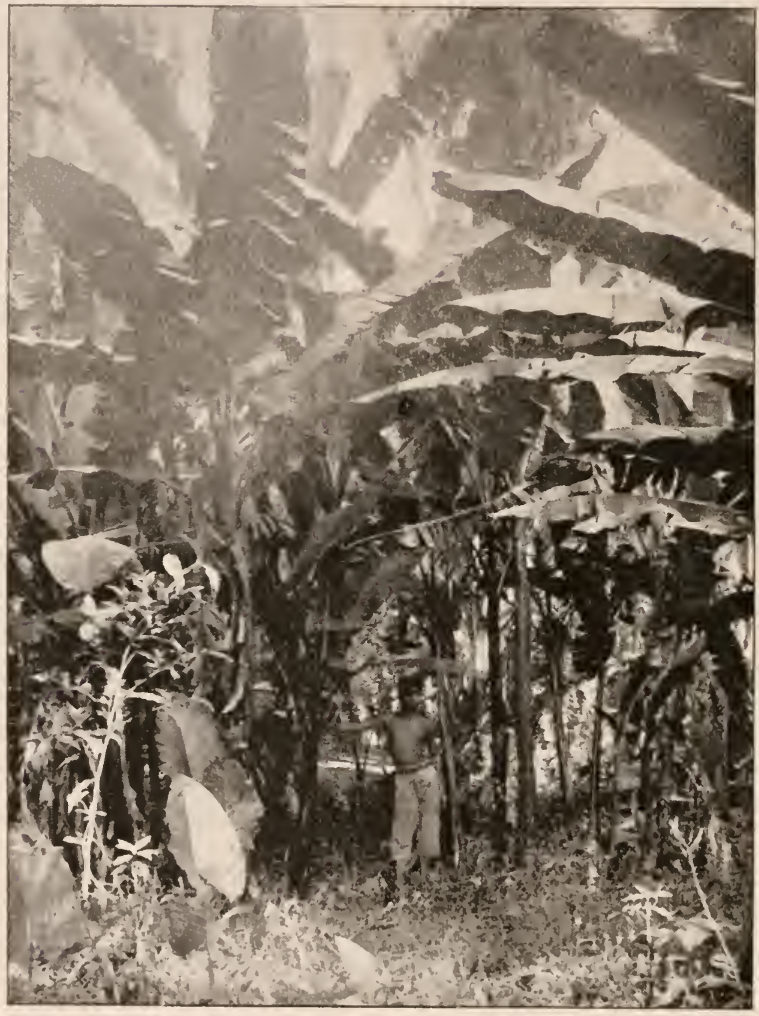

FIg. 74. Plantation of abacá, a form of banana, from the petioles of which Manila fiber is obtained. Abaca flourishes only in the Philippines. The fiber is used chiefly in the manufacture of ropes.

The monocot bundle. The monocot bundle differs from the dicot bundle in that it lacks a cambium layer. It is frequently called a closed bundle, because in the absence of cambium 


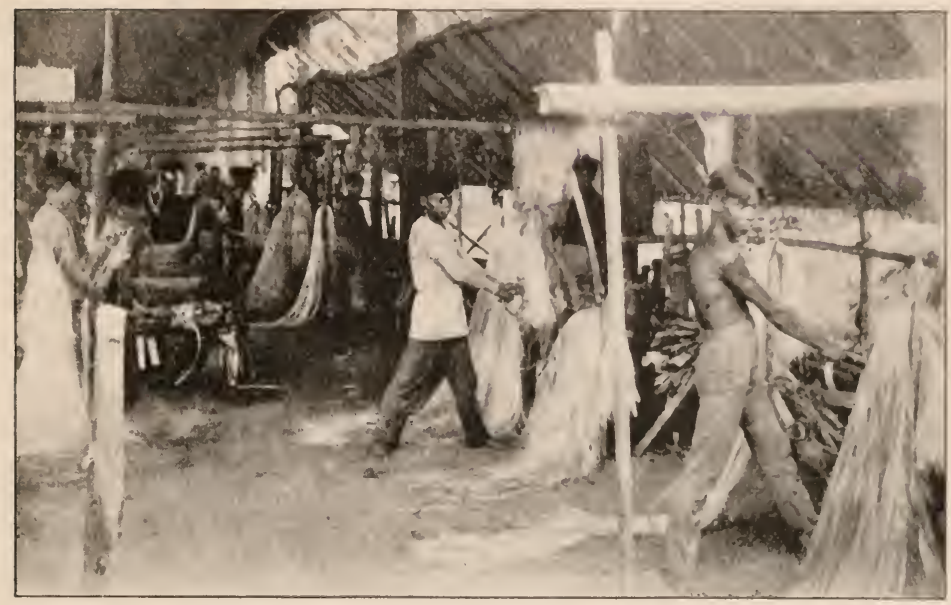

Buresu of Agriculture, $P . I$.

Fig. 75. Stripping abacá for fiber. The long ' petioles are pulled under toothed knives which scrape the soft tissues from the bundles. Abacá is a monocot, and the fiber is composed of an entire bundle.

tissue the bundle cannot increase in size, and there can be no growth of the monocot stem through the multiplication of cambium cells. The dicot bundle, on the other hand, is spoken of as open, because there is a cambium layer between its water-conducting and food-conducting tissues and the bundle can increase in size. The monocot bundle differs further from the dicot bundle, in that its mechanical tissues form a complete sheath about the food and water conducting parts. It is as though the bast of the outer part of the dicot bundle and the wood of the inner part were joined at the sides of the bundle to make a sheath about the conducting tissues.

The fibers like sisal and Manila hemp, that are derived from the monocots, are usually coarser than the fibers derived from dicots, because the monocot fibers are entire bundles, 
while the dicot fibers are made up of only the strand of bast cells from the food-conducting side. The bundle sheaths are usually thicker in the bundles near the outer part of the monocot stem. In fact, in some monocots like rattan and bamboo, the sheaths of adjacent outer bundles may join each other and thus form a hard layer beneath the epidermis (Fig. 73).

The structures of conifer stems. The conifers, like the dicots, have their bundles arranged in a hollow cylinder. In structure these bundles are somewhat similar to those of dicots, except that the wood and water-conducting cells are not distinct. The wood cells form the water-conducting tissue as well as the mechanical tissue. In keeping with their double function, the cells (tracheids) are thick-walled and spindle-shaped, with numerous thin places, or pits, in two of the walls. Because of this structure, the stem retains its rigidity and still permits the ready passage of water and mineral salts.

Growth of stems. The limit of growth of a stem is not so definite as that of leaves. The length and the diameter of a stem depend largely upon the conditions under which the plant lives, the available water supply, amount of light, temperature, and quality of the soil. Along a dry roadside a ragweed may complete its development with a stem less than 6 inches long, while in a rich bottom-land field the same plant might have reached a height of ${ }_{5} 5$ feet.

The growth in length takes place at the apex of a stem, the growing point being located in the terminal bud. The growing region extends back from the tip, sometimes for only a fraction of an inch, more rarely, as in rapidly growing vines, a foot or two. If we mark the upper portion of a growing 


\section{The Structures and Processes of Stems}

stem into equal spaces, we may observe on the following day that the uppermost space has elongated the most. The adjoining spaces below are less and less elongated. This indicates that the greater part of cell division and enlargement takes place very near the tip (the growing point), but that some growth takes place in the cell layers for a certain distance below the end of the stem (the growing region).

Annual stems increase in thickness until the plant matures. This increase in size is brought about by the enlargement of cells and by the formation of additional cells. Shrubs and trees increase in thickness each growing season. This is often called secondary growth; as we have seen, it is brought about by the continued growth of the cambium. This layer of cells produces new water-conducting tissue and wood fibers on its inner side, and it produces food-conducting tissue and bast fibers on its outer side. As growth proceeds from year to year, annual rings mark the successive additions to the wood. The bark also develops annual layers, but in most woody plants these are much thinner and less conspicuous than the annual layers of the wood. Further, since growth takes place inside the cortex, the cortex is continually being split and broken. The outer layers may die and after a few years will be gradually weathered off. The ridges and grooves of the bark show how much too small the outer bark is to cover the more recently formed wood. Smooth, thin-barked trees lose their bark very rapidly. Trees with bark that is thick and has large ridges are the ones that hold their bark more tenaciously. But in all large trees the bark contains only a part of the cortical layers that have actually been formed; much material has scaled off and fallen away. It should be noted that as a tree increases in diameter, the annual rings of wood 
in the stem are each year farther removed from the corresponding annual layers of the bark.

Annual monocots increase in thickness through the enlargement of the bundles and by the multiplication and enlargement of the pith cells. Perennial monocots, like the bamboo and asparagus, have underground stems to which new and thicker stem segments are added each year. The aërial, erect branches never increase in size after they are once mature; but the erect branches from old underground stems are from the beginning much thicker than those from young plants. Consequently, no little bamboo rod could ever grow into a bamboo beam. No large bamboo beam was ever a slender rod. These aërial branches come out of the ground nearly as thick as they will be when mature. Asparagus plants are several years old before the underground stems send up thick, upright branches suitable for marketing.

Heartwood and sapwood. As the trunks of trees increase in thickness, all the living cells toward the center of the stem gradually die. The wood usually changes in color after the death of these cells. In a peach tree only the outer three or four annual rings may be alive. In a walnut trunk 2 feet in diameter, all but the outer 2 inches may be dead. The dead wood still helps to support the enormous weight of the tree top, but it has nothing to do with the conduction of water and substances in solution. This inner dead wood is called the heartwood; the outer living wood is called the sapwood. The heartwood in many species of trees is much more valuable than the sapwood for lumber, because of its color and greater durability.

Stems in relation to gravity. The direction of growth of stems is for the most part determined by gravity. The erect 
type of stem grows upright even in darkness. If these stems are laid horizontally, the younger parts will grow faster on the lower side and the stem will again become erect. This response of a plant organ to gravity is called geotropism. ${ }^{1}$ If the response is in the direction of the pull - that is, toward the earth - as in the case of a primary root, the organ is said to be positively geotropic. If the response is in the opposite direction, as in most stems, the organ is said to be negatively geotropic. If the response is sidewise, as in many branches, the organ is said to be transversely geotropic.

Stems in relation to light. Light affects also the direction of growth of stems, as the plant grown at a window will show. Most stems grow toward the strongest light. Response to light is called phototropism, and most stems are positively phototropic. The stems of some prostrate plants are held close to the ground by their response to light, as is proved by the fact that if a shade is placed over them, the stems become erect. Some of the common doorweeds of paths and waste places are examples. There are some prostrate stems, of course, that lie flat on the ground because of a lack of mechanical tissue to hold them upright.

The direction of growth in branches is a compromise between the response to light and the response to gravity. In some trees, like the spruce, the direction of growth in the branches is in some way controlled by the main stem. If the top of the main stem is cut off, one or two of the lateral branches become negatively geotropic instead of transversely geotropic.

${ }^{1}$ The responses of organs to external influences like gravity and light are called tropisms (Greek: trope, turning). "Geotropism" means literally a turning toward or away from the earth; "phototropism," a turning toward or away from light; "hydrotropism," a turning toward or away from water. 
This means that they will grow erect instead of horizontally and will take the place of the main stem.

Grafting and budding. In the propagation of many varieties of fruit trees it has been found that seeds are not satisfactory. Most of our cultivated fruit trees are so highly variable that their seedlings are not like the parent plants in quality of fruit. Horticulturists long ago learned to overcome this difficulty by grafting a twig from the desired variety of tree on a seedling of a similar tree. The grafted-in branch then becomes the top of the tree, and the fruit it bears is like that of the tree from which it came.

In grafting, the plant that furnishes the root is called the stock. The twig that is attached to it is called the cion (Fig. 76). In cleft grafting, the top of the stock is cut off. The stock is then split and two cions with chisel-shaped ends are placed in the cleft, one on either side, so that the cambium of the cion is in close contact with the cambium of the stock. The wound is covered with wax to prevent the drying out of the tissues. If the cambium tissues are in perfect contact, they will soon unite. New tissue will grow under the wax and finally cover the wound. If both cions grow, the weaker one is removed.

Whip grafting is the common method of uniting cions to small seedlings. Usually this is done at or below the surface of the soil. Both cion and stock are cut obliquely, and each is split. The upper half of the oblique end of the cion is pushed into the cleft of the stock and is bound firmly in place with raffia or twine (Fig. 76). Again, the success of the graft depends upon the contact bctween the cambium of the cion and the cambium of the stock.

In budding, a T-shaped cut is made on the side of the stock, through the cortex, down to the cambium. A bud from a 
tree of the desired variety, with a small oval piece of wood and bark attached, is slipped down inside the cortex of the

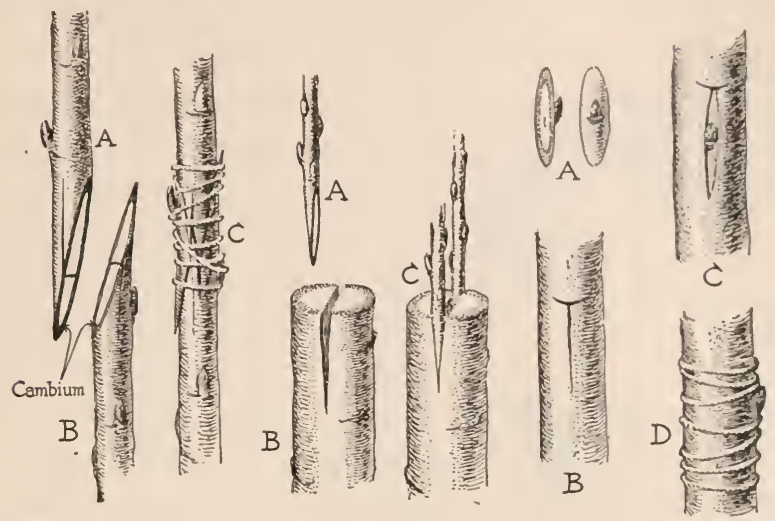

FIg. 76. Methods of grafting and budding. At left, whip grafting; in middle, cleft grafting; at right, budding. $A$ is the cion, and $B$ the stock. $C$ shows the cion and stock joined.

stock and tied firmly in place (Fig. 76). This places the two cambium layers in contact; the two pieces unite, and the bud develops into a branch. The stock is then trimmed, so that only the branch from the cion bud remains.

Grafting is commonly done in the spring; budding, in the early fall. The fruit produced on grafted or budded trees is usually like that of the cion, regardless of the variety of stock. However, there are cases in which the cion is modified by the stock. Discussions of these cases may be found in books on horticulture. Grafting is usually possible only between closely related species of plants. Sometimes, however, plants that are more remotely related may be grafted on each other, as for example tomato, tobacco, potato, and nightshade, or the pear, apple, and quince. 
The lifting of water in stems. Nothing concerning the physiology of plants has interested more people than the

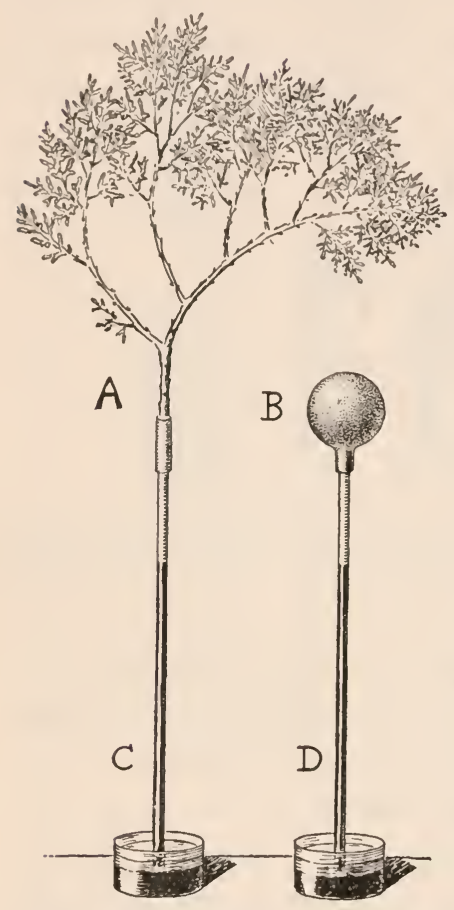

Fig. 77. Experiment to show the lifting power of transpiration and evaporation. Both tubes were filled with boiled water and placed in a dish of mercury. In $C$ the mercury has been drawn up by transpiration from a branch of arbor-vita $(A)$; in $D$, by evaporation from a porous cup $(B)$. transport of water from the soil to the topmost leaves of trees. Yet in spite of much observation and experiment, the process is still only partially explained.

There can be no doubt that one of the principal factors in the rise of sap is the evaporation of water from the leaves. As the water evaporates from the cells of the mesophyll in transpiration, water is drawn from the adjoining water-conducting tissue of the veins into these cells to take its place. Water inclosed in tubes has a high cohesive power; that is, it holds together like a solid. If a pull is exerted on the upper end of a column of water in the vessels of a tree, the column holds together like a cord or wire, and the whole column is pulled upward. As the water at the upper end of the waterconducting tissue moves into the mesophyll cells, additional water is pulled upward into the blades, petioles, and stems. Transpiration is greatest and the largest amounts of water 
are being lifted in trees during the summer. If at this season a hole is bored into the trunk of a tree and an air-tight connection made between this hole and a tube that has its lower end in a vessel of water, the water is drawn into the stem, not forced out. This indicates that there is more pull on the water from above than there is pressure from below. It is known also that there may be currents moving downward in one layer of the wood and upward in another, although the general direction of water transport is upward to the leaves. It is certain that the roots do not force the water up into the tops of trees.

The primary factor, then, in the rise of sap is transpiration; the second factor is the drawing of water from the waterconducting tissue by the mesophyll cells to replace that lost through transpiration; the third factor is the cohesion of water columns in the long strands of water-conducting tissue, which makes it transmit the pull from the mesophyll cells all the way down to the roots. In the chapter on roots we shall learn how the water passes from the soil into the roots, and to what extent the roots aid in the lifting of water.

The pulling up of water by transpiration is exemplified when cut flowers are placed in a vase containing water. That water is drawn up into the flowers may be shown by placing the stems of white flowers in water colored with red ink.

The flow of maple sap. The water in stems always contains a certain amount of sugar in addition to mineral salts. In the maple, in the early spring when the days are warm but freezing still occurs at night, great quantities of sugar pass into the water-conducting tissue. This sugar comes from the pith rays and other tissues where it accumulated in the form of starch during the preceding growing season. With the 
coming of warmer weather the starch is digested, and the sugar formed from it diffuses into the water-conducting vessels.

The earlier sap is the richest and apparently comes largely from the upper parts of the tree. The last sap is more dilute and probably comes from the roots. The positive pressure that produces the flow occurs only during the day; at night it becomes negative and the sap flow ceases. The causes of the pressure are only partly known. A portion of it is due to the expansion of gas bubbles within the tree, but this gas expansion accounts for only a small part of the pressure.

Whether the flow shall continue for weeks or stop after a few days is determined by weather conditions; but just how the several weather factors like changes in temperature or rainfall bring about the increase and decrease of pressure, is unknown. Even under the most favorable conditions it is not possible to draw out of a tree more than 5 per cent of the food that it contains.

A flow of sap somewhat similar to that in the maples occurs in many species of trees, as in the birch, butternut, and hornbeam. Sugar and sirup are made from the hard maples.

\section{PROBLEMS}

1. A tree increases in height at the rate of 2 feet a year. When the tree is 5 years old, a nail is driven into the trunk 2 feet from the ground. How far from the ground will the nail be when the tree is ro years old?

2. Why is the timber from monocot stems less useful for building purposes than that from dicot stems?

3. What are the woods principally used in your locality for interior finishing and for making shingles, posts, and flooring? What properties do these woods have that fit them for these special uses?

4. What kinds of wood are used in the making of furniture? Why?

5. How is a $\log$ quarter-sawed? Why is quarter-sawed lumber more valuable than that cut otherwise? 
6. Why is lumber seasoned by piling it in lumber yards for months or years before it is used?

7. What is charcoal? How is it manufactured? What are its uses?

8. Why is charcoal made from peach and apricot pits and the shells of nuts preferred as an absorbent in gas masks?

9. What commercial products are made by the distillation of wood?

10. What substances are used to preserve railroad ties and posts from decay? From what are these substances derived? 
1. A field trip to a greenhouse will help to make clear the important factors of the environment. Observe how the water, light, temperature, soil, animal, and plant factors are taken care of. (Animal factors: scale, aphids, mealy bugs, and white flies. Plant factors: overcrowding, bacterial and fungous diseases.)

2. In the field, compare the environmental factors in a lake or swamp with those on a hilltop or slope. What are the notable effects of these factors on leaves, stems, and roots? Write the results of your observations in the form of a table.

3. Examine trees growing in the open to see how the wind affects the shape of the crown. Is the trunk in the center of the crown? What is the direction of the prevailing wind in your locality? In what direction are the branches of trees generally longest in your locality? Shortest? What is the relation of this branch development to the direction of the prevailing wind?

4. Field trip to a dense wood. Study (I) the environmental conditions of the large trees; (2) of the young trees; (3) of the climbing plants; (4) of the low herbs; (5) of the mosses, lichens, or ferns on the tree trunks; and (6) of the mosses, lichens, or ferns growing on the soil. Write your notes in the form of a table showing relative amounts of light, water, and mineral salts available to plants belonging to each of the above groups, and relative dryness of air to which they are exposed. 


\section{CHAPTER TWELVE}

\section{THE ENVIRONMENT OF PLANTS}

Even the most casual observation suggests that plants are greatly affected by the conditions under which they grow. The grasslands, the forests, and the deserts of North America are occupied by different plants because of the difference of conditions in these areas. The white oak growing in the open has broad, spreading branches and a large crown, while in the forest it is more columnar and has a crown at the upper level of the forest. The sugar maple becomes a great tree or remains a mere shrub according to whether it grows in rich soil or in a crevice of a rock. The internal structure of a plant is also modified by the external conditions under which it grows; the leaves of many plants which are thin and tender when there is an abundant water supply, become thick and leathery when grown under conditions of drought. Since conditions of growth show so great an effect upon the form, size, structure, abundance, and distribution of plants, we should know the principal factors that make up a plant's environment before going further in the study of the plant itself. It is especially important to understand these factors, because the purpose of a great part of agricultural practice is to modify the environment of the plants that are being grown.

Definition of environment. By the environment of a plant is meant the complex of all those influences outside the plant which directly or indirectly affect its physiological processes, its structures, and its development and propagation. These influences are numerous and are usually spoken of as faclors. The natural habitat of a plant is a combination of environmental factors favorable to the complete development of the plant. The factors include the chemical and physical prop- 
erties of the soil and the air surrounding the plant; also light, gravity, and the influences of animals and other plants (Fig. 78).

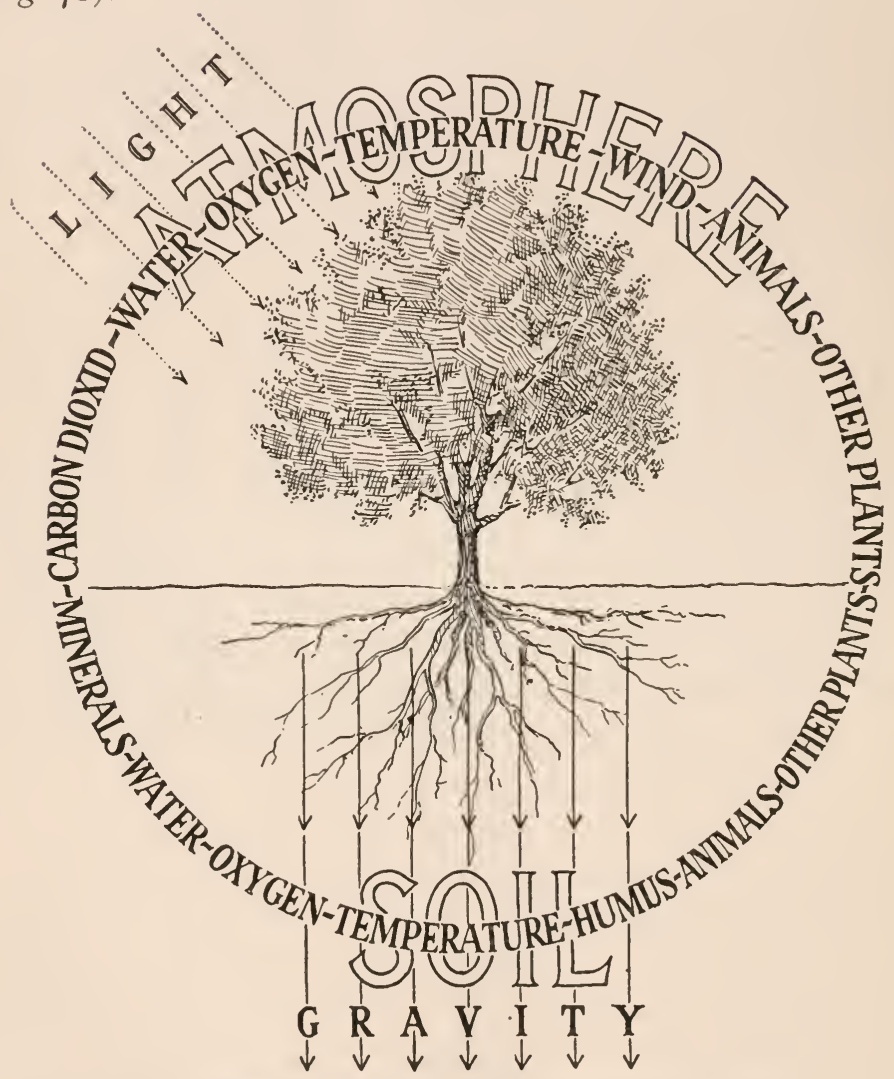

Fig. 78. Diagram illustrating the environment of land plants.

The soil factors. If a plant is to grow in a soil, the soil must furnish it with sufficient water for transpiration and the manufacture of food. At the same time, the soil must not be 


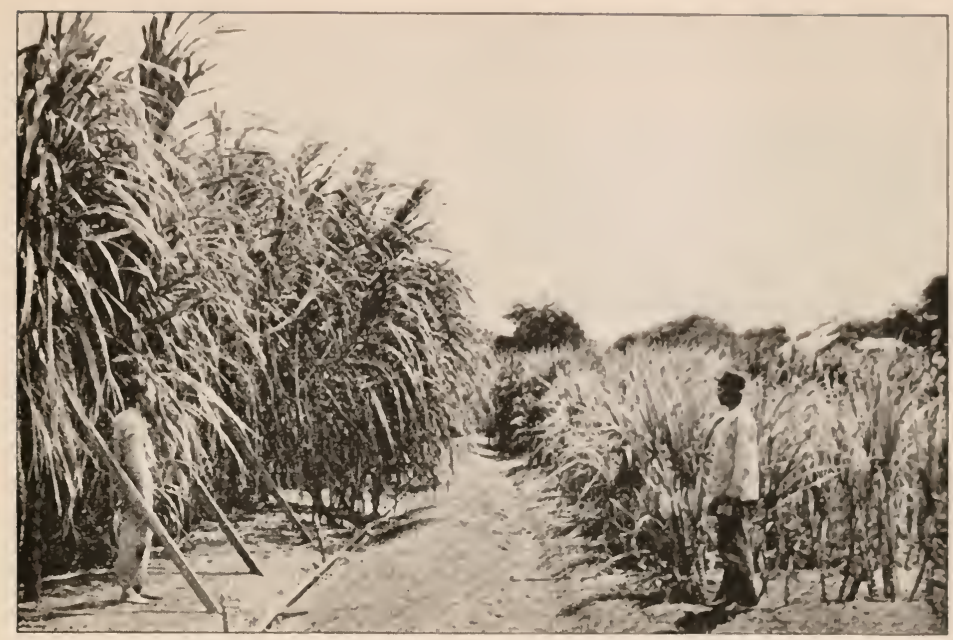

Irrigation Division, U.S. Depl. of Agriculture

FIG. 79. Irrigated and unirrigated sugar cane, showing the value of sufficient water in the growing of this crop.

so filled with water as to exclude air from the roots. In order that the roots may penetrate the soil readily, it should not be too resistant; but it should be compact enough to afford the plant a firm anchorage.

The soil must supply also certain indispensable chemical elements used by plants in the manufacture of food. These elements are potassium, calcium, magnesium, phosphorus, nitrogen, iron, and sulfur. In soils that contain insufficient amounts of any of these substances the growth of plants is hindered, and certain plants are excluded from such a soil. One of the purposes in using chemical fertilizers is to add to soils or to liberate in them sufficient quantities of all the elements essential to the vigorous growth of crop plants. It should be remembered that in addition to the 
seven elements mentioned above, plants use, for the manufacture of food, carbon, hydrogen, and oxygen, which they derive from water and carbon dioxid.

Most plants grow best when the soil is neutral or slightly alkaline. Red clover, alfalfa, and blue grass, for example, cannot withstand an acid soil. By the addition of lime, acid soils may be neutralized or made alkaline. This explains the common practice of putting lime or wood ashes on lawns where a growth of blue grass is desired. Some plants are favored by an acid soil. Cranberries, blueberries, and redtop grass are examples of such plants. In arid regions, the evaporation of water may cause salts to accumulate in the surface layers of the soil to such an extent that most or all plants are excluded.

Another soil factor of great importance is humus. This

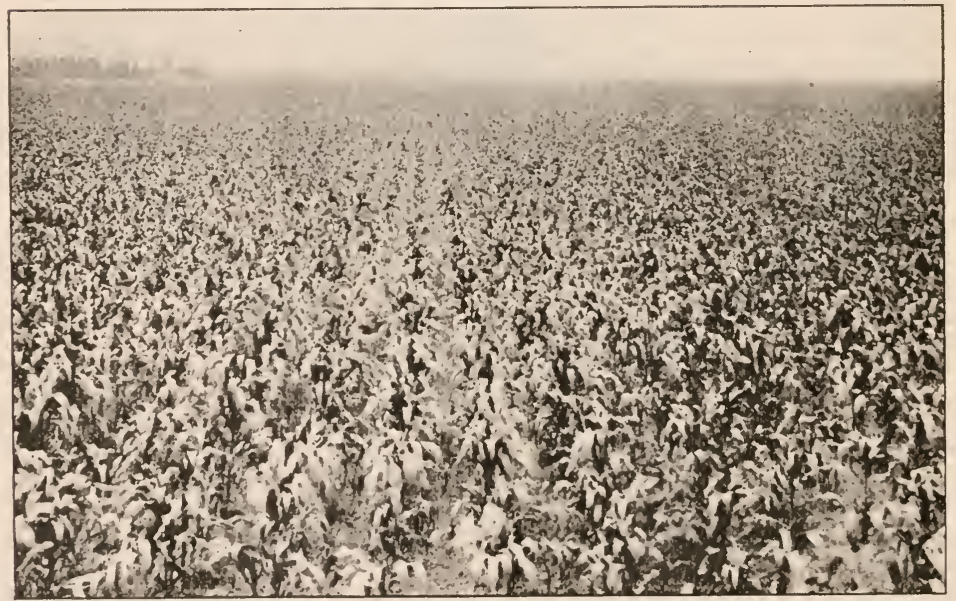

U.S. Depl. of Agricullure

FIg. 8o. A Kansas cornfield. The soil is rich in humus, and the plants attain a height of $\mathrm{I}_{2}$ to $\mathrm{I} 4$ feet. 


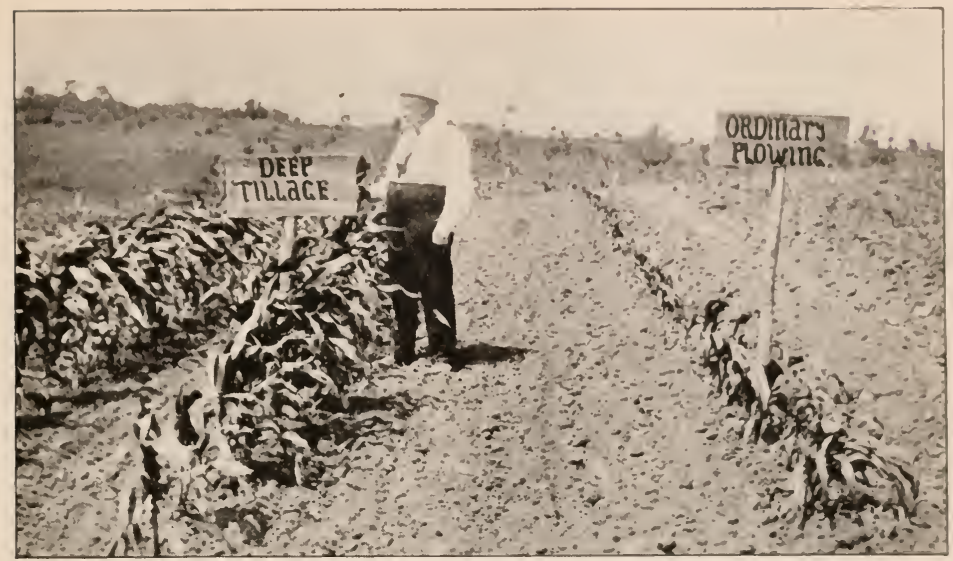

Fig. 8I. The results of deep tillage and shallow tillage.

material, which gives the brown and black colors to rich agricultural land, is composed of the partially decayed remains of plants. Leaves and other plant organs that fall to the ground are slowly changed and broken up by bacteria and other agencies until only the brown, powdery humus remains.

Humus favors plant growth by increasing the water-holding capacity of the soil and so rendering the water supply more uniform throughout the growing season. It improves the physical properties of the soil by making it mellow. Humus also makes it possible for bacteria and other organisms that increase fertility to live within the soil.

In agricultural literature the importance of the soil factors is emphasized. Plowing, harrowing, disking, and cultivating are methods of keeping the soil in good physical condition. Adding manures to increase the humus, and adding nitrates, phosphates, and other salts as fertilizers, are methods of im- 
proving the chemical composition of the soil and to a less extent its physical condition. Irrigating the land where the water supply is inadequate, and underdraining it where the soil moisture is excessive, are further means of improving soil conditions for the growth of crops. The soil requires these special attentions for the growth of domesticated plants because they must not only live, as do wild plants, but they must, in one form or another, yield a profitable return.

Atmospheric water. The water in the air affects plants directly in several ways. The moistness or dryness of the air determines whether less water or more is required for transpiration, and the amount of water precipitated from the air in the form of rain determines to a large extent the amount of water available in the soil. Atmospheric water condensed in the form of fog and cloud reduces transpiration and also lessens the amount of light that reaches the plant.

The distribution of rainfall through the year is of the greatest importance to vegetation. When the period of heaviest rainfall coincides with the hottest part of the year, the conditions are best for the rapid growth of plants. If the rain-
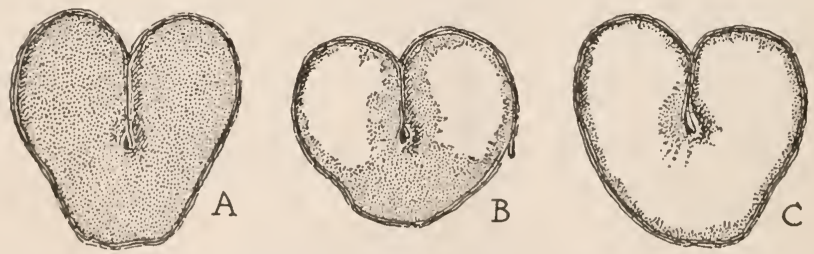

FIG. 82. Cross sections of kernels of hard or macaroni wheat. This wheat is grown in dry regions and is valued because of its large content of protein. In the figures the flinty or high protein parts are shaded and the soft or starchy parts are white. When the wheat is grown under the conditions of dry farming, the protein content is highest $(A)$; when regularly irrigated, the same wheat produces soft, starchy grains $(C)$. An intermediate condition is shown by $B$. This exemplifics the effect of the water balance un the composition of a grain. 


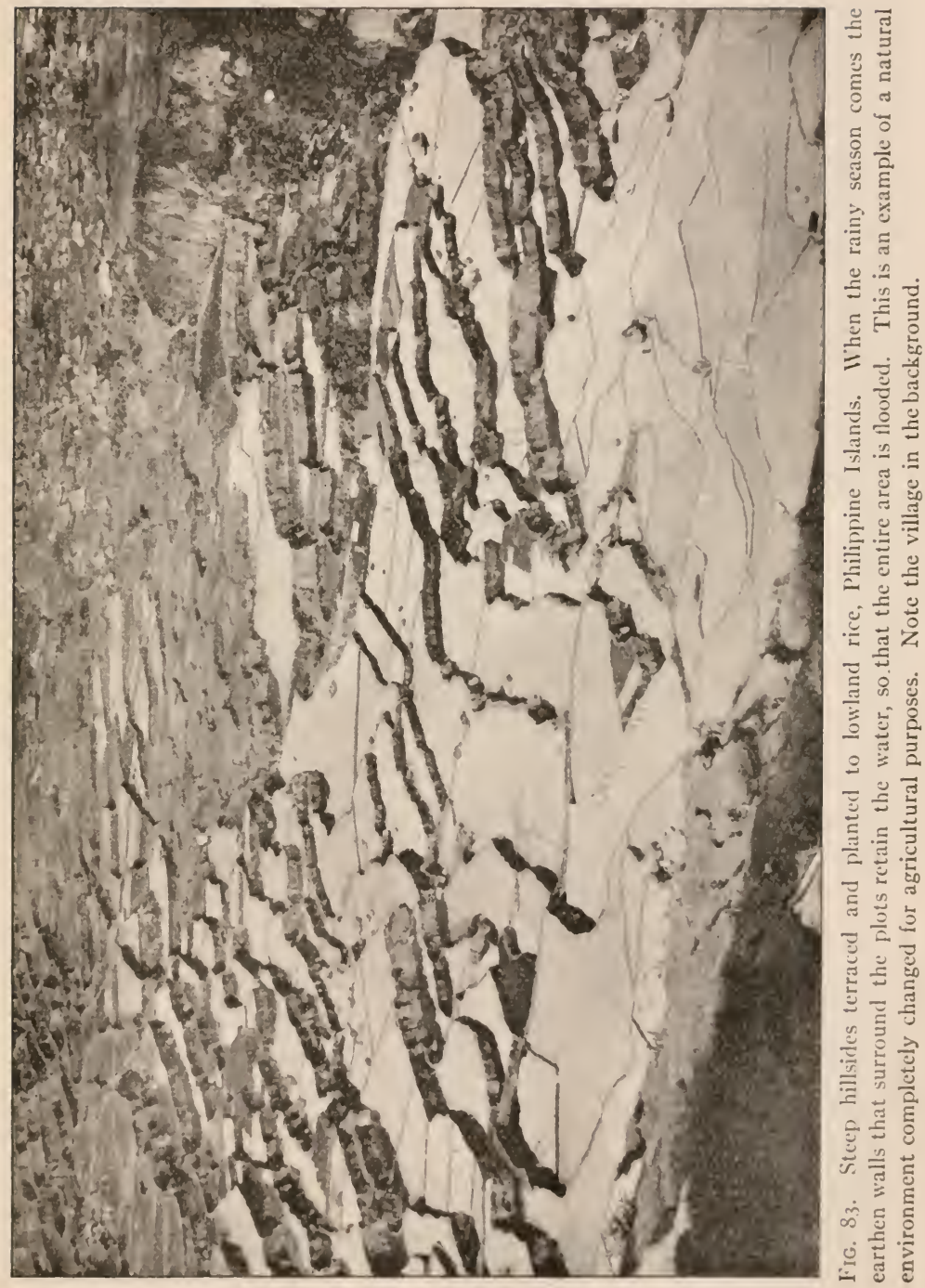


fall is scanty during the time of highest temperatures, plants are hindered in their growth, and only xerophytes may be able to withstand the conditions.

The temperature factor. As one goes north or south from the equator, the temperatures of the soil and air decrease. Increasing altitude in mountains brings about the same effects. Temperature directly influences the rate of all plant processes, and most plants grow best under certain rather fixed temperature conditions. For tropical plants, air temperatures above 90 degrees $F$. are most favorable. Temperate plants develop best at between 60 and 90 degrees F. Arctic and alpine plants grow at temperatures but little above the freezing point.

Air temperatures are greatly influenced by air drainage. Cold air is heavier than warm air ; consequently it accumulates in low grounds and reduces the temperature there. Frost occurs later in the spring and earlier in the autumn in low places than on hills. Crop plants like beans, that are easily injured by frost, can be planted earlier and grown later on uplands. Peach orchards are more profitable on uplands than in valley bottoms, because on the uplands they are more likely to escape late spring frosts.

The time during which the temperature remains above the freezing point is the growing season. In the tropics this extends throughout the year. In arctic and alpine regions it may be reduced to 2 or 3 months. The temperature of the air and the length of the growing season determine the amount of food a plant may manufacture, and consequently the amount of growth.

Soil temperatures also are important. Dark-colored soils are warmer than light-colored soils, because they absorb the sun's rays more readily. Well-drained soils are warmer than 


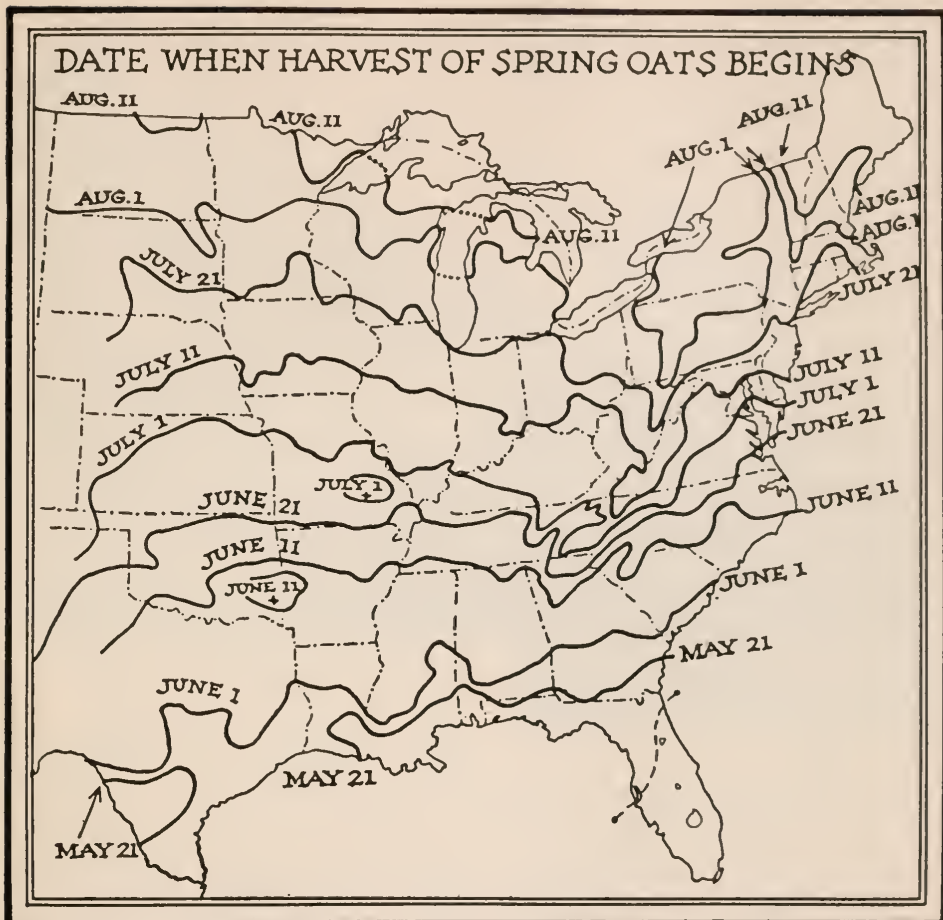

FIG. 84. Map showing date of oat harvest in different parts of the United States; an example of the effect of temperature on the maturing of plants.

wet soils, (I) because less heat is required to raise their temperatures, and (2) because the temperature of a wet soil is lowered by the constant evaporation of water. The most valuable farm lands are those with dark-colored, well-drained soils. On north slopes, soils do not warm up so rapidly in the spring, and plants growing there start their growth later than do those on the south slopes of the same hills. Peach growers prefer not only uplands but north slopes. Why? 


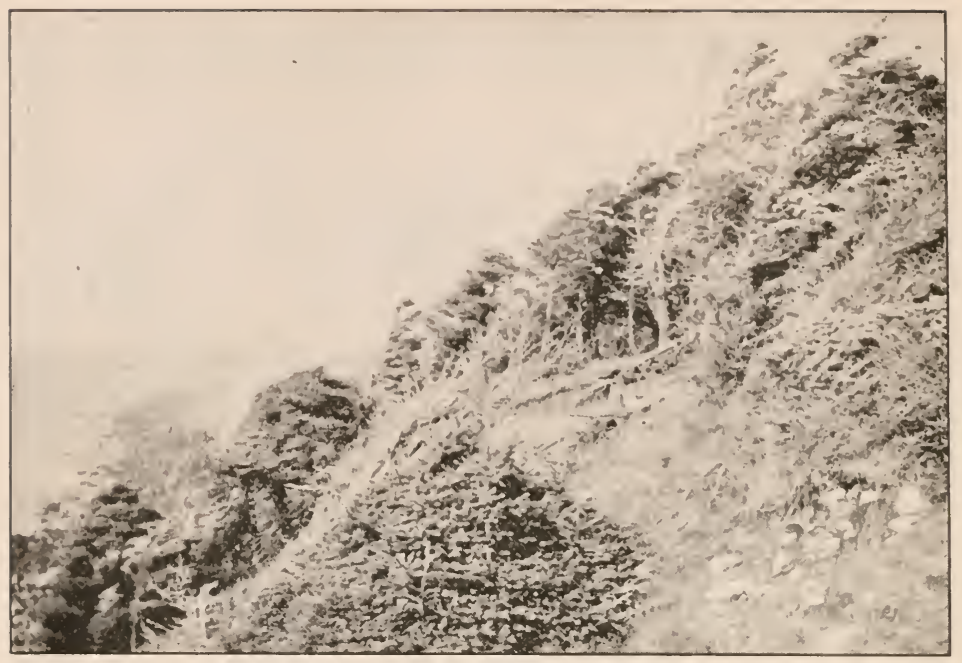

FIG. 85. Effects of wind on trees along the Bay of Fundy, Nova Scotia.

The light. The amount of light available to a plant depends primarily upon the intensity of the sunshine. This is greatest in the tropics and least at the poles. The total amount of light is influenced also by the length of the day. At the equator the daylight lasts $\mathrm{I} 2$ hours; at the poles the light continues all summer. So tropical plants have intense light during half of each day, while arctic plants have weak light continuously through the growing season.

Locally the light is modified by clouds and fogs. These are much more prevalent along the seacoast than inland, and are particularly common along the Pacific coast from Alaska to California. The slope of the land, especially in mountain regions, may increase or decrease the intensity and the length of daylight. Finally, plants may have their light reduced or cut off by trees or other objects. 
Gravity. Gravity is an important environmental factor, largely because of its influence on the direction of growth in stems, roots, and other organs (page I3I). Light influences also the growth of the various parts of the plant. Consequently the position of the aërial organs of plants is to a large extent determined by the combined influences of light and gravity.

Wind. Winds and air currents are of importance, as they affect the rate of transpiration or modify the temperature. It may take Io minutes for your wet hands to

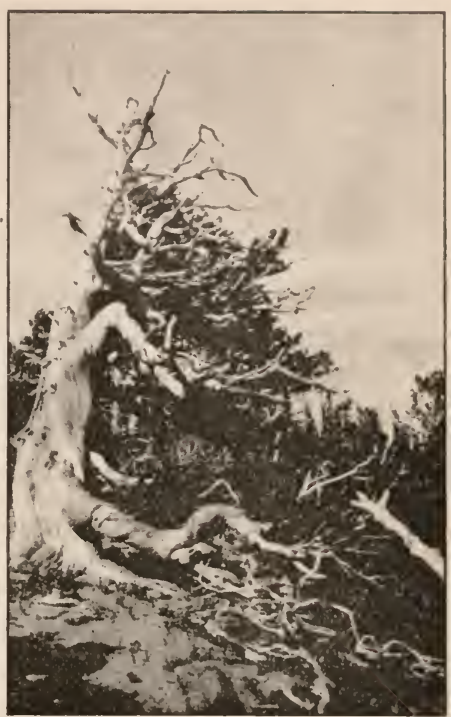

W. S. Cooper

Fig. 86. Western white pine on Long's Peak, Colorado, showing the effects of violent winds and of wind-driven snow. dry in still air, but if you hold them before an electric fan they will be dry in 2 or 3 minutes. The passing of an increased volume of air over a wet surface increases evaporation, and wind affects the transpiration of plants in the same way. In drying your hands before a fan, notice also the cooling effect of the breeze. Leaves are cooled by transpiration in the same way. Winds also may cause important modifications in the forms of plants, and occasionally violent winds may destroy large areas of timber and crops.

Animals. Leaf-eating insects, such as the potato beetle, injure the plant by destroying the food-making apparatus. 
It is estimated that grasshoppers and leaf-hoppers often eat as much of the grass in a pasture as do the farm animals. Plant lice and scale insects remove the sap from the cells of the tender growing parts and may kill the entire plant. Other animals, like the earthworm, favor the growth of plants by loosening the soil and promoting the change of fallen leaves to humus. Herbivorous (Latin: herba, herb, and vorare, to eat) wild animals, like the rabbits, squirrels, and deer, markedly affect natural vegetation, while the domesticated cattle, sheep, and hogs to a large extent determine what plants can survive in pastures and grazing lands. Man, more than all other animals put together, has modified the natural vegetation of the earth. In some cases he has destroyed it; in other cases he has encouraged and protected it. Most of all, he has selected certain plants and made of them the food supply of the world.

Other plants as an environmental factor. Other plants, such as weeds growing among cultivated crops, may modify the environment of plants by shading them, by removing water from the soil, and possibly by producing poisonous substances in the soil. Or a plant may directly affect another plant by growing on it and taking its nourishment from it. For example, the mistletoe grows on trees and injures them. Corn smut and wheat rust live on corn and wheat and decrease or prevent the production of grain.

The complexity of the environment. The environment of plants is made up of many factors, and the factors themselves are more or less dependent upon each other. Consequently it is often difficult to determine definitely the cause of a particular effect that is undoubtedly produced by something in the environment. But as our knowledge of botany 
advances, we are able to relate more and more of the effects that we observe in plants to definite factors in their environment. The farmer, gardener, or forester is often able to use this knowledge in making the environment more favorable for the plants which he grows.

Subdivisions of botany. Three of the great subdivisions of botany are morphology, physiology, and ecology. The study of the structures of plants is plant morphology (Greek morphos, form, and logos, study of). The study of the processes of plants such as transpiration and photosynthesis is plant physiology (Greek: physis, nature, and logos, study). The study of plant structures and processes in relation to the environment, or as they are modified by the factors that make up the environment, is called ecology (Greek: oikos, home, and logos), or ecological botany. Since the environment determines what plants can live in a particular place, ecology includes also the study of the distribution of plants on the earth's surface and attempts to account for that distribution. For this reason the environmental factors that affect plants are also spoken of as ecological factors; and the changes in structure that adjust plants to particular habitats may be called ecological modifications.

\section{PROBLEMS}

1. What is the principal factor that limits the growing of oranges in this country to Florida and southern California?

2. Why are beans planted a month later than peas?

3. What environmental factor determines that melons and squashes should not be planted until late spring?

4. What factors in the environment make it necessary to spray potatoes?

5. What is the principal factor limiting the production of crops on the Western plains?

6. Why are plants absent from the larger sand dunes? 
7. Why are plants absent from sea beaches and from the beaches of large lakes?

8. Why do trees along streams have their longest branches out over the water?

9. Why do trees along streams frequently lean outward over the water?

10. Why do trees on steep hillsides have their shortest branches toward the hill?

11. What are the most favorable environmental conditions for the growing of rice, celery, onions, dates, bananas, sugar cane, guayule, sisal, tulips, and pecan trees?

12. How do the plants and fruits of blackberries and dewberries grown in bottom lands differ from those grown on dry hillsides? Why? 
Suggestions for Laboratory Work to Precede Chapter Thirteen

1. Sketch a few twining stems. Note the twist of the stem as shown by surface markings.

2. Sketch examples of tendrils. The Boston ivy, gourd, pea, sweet pea, and grape are readily obtainable. Is the spiral continuously coiled in one direction? Why?

3. Dissect a cactus stem. Note the nodes, internal waterstorage and food-storage tissue, and green tissue.

4. Make drawings of a rootstock, corm, bulb, and tuber. Divide each of them into halves by cutting through the longitudinal axis. Compare their advantages as organs of propagation and storage.

5. Examine stems of water hyacinth, bulrush, and pondweed, noting air chambers.

6. Examine a cross section of a grapevine or a rattan stem. Note the large size of the water tubes. 


\section{CHAPTER THIRTEEN}

\section{ECOLOGICAL GROUPS OF STEMS}

IN the tenth chapter we discussed the normal structures of the upright stems of land plants. It was pointed out that each of the three great groups of seed plants has a characteristic arrangement of its tissue systems. The essential tissues, like the water-conducting, food-conducting, storage, and mechanical tissues, are present in all.

Stem structures and habitats. Plants growing in different habitats, as ponds, swamps, and deserts, have very different stem structures. The stem of a leafless desert plant must of necessity be different from that of a leafy submerged plant. The tropical climber has a stem quite unlike that of a plant -whose main stem is underground. These differences consist not so much in the arrangement of the several tissues as in modifications in their amounts and proportions.

Stems of mesophytes. The native plants of the eastern United States grow under medium conditions of moisture, light, and temperature; and they are characterized by large leaf area, leaves of soft texture, and much-branched stems. The vegetation culminates in the forests of the rich, wellwatered soils of the river valleys. Here may be found oaks, walnuts, elms, and sycamores from roo to i 50 feet in height and with trunks from 4 to 14 feet in diameter.

In the moist cañons of the Sierras of California, the giant sequoia reaches heights of from 250 to 320 feet above the ground, with extreme trunk diameters of 35 feet. This tree is the largest and is perhaps the oldest of all living things. The redwood, its near relative, grows in the fog-abounding ravines of the Coast Ranges. Its trunk does not attain a diameter of more than 28 feet, but it surpasses the giant 
sequoia in height. Really to appreciate the size of these trees you should pace off a distance equal to the diameter of the trunk and calculate how many times the height of your school building a giant sequoia is. Then try to imagine how one of the Big Trees would look if it stood in your school yard.

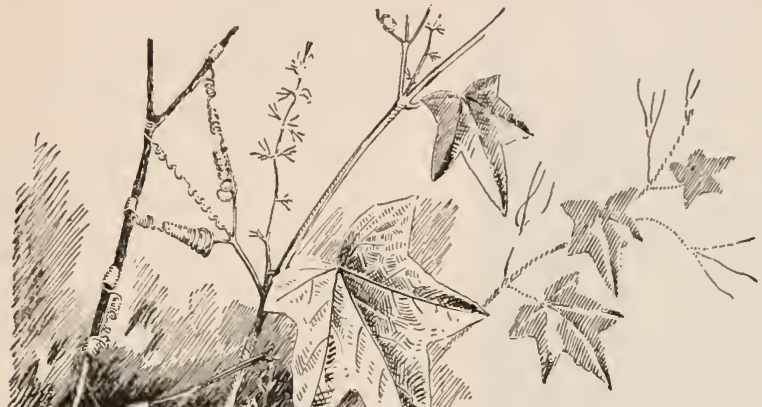

\section{Stems of climbing plants.} Among mesophytes are many vines with exceedingly long, slender stems. The Virginia creeper, wild cucumber, and grape have stems from 50 to 300 feet in length. These long stems enable them to spread their leaves over the tops of large trees. Climbers may attach themselves to their support by twining about it by ten-

FIG. 87. Tendrils of wild cucumber. Note the coiling of the tendril by which the plant is drawn nearer the support, and the reversal of the spiral in different parts of the tendril. Is there always a reversal in coiled tendrils? drils, or by supportive roots. Tendrils are specialized organs developed in place of 


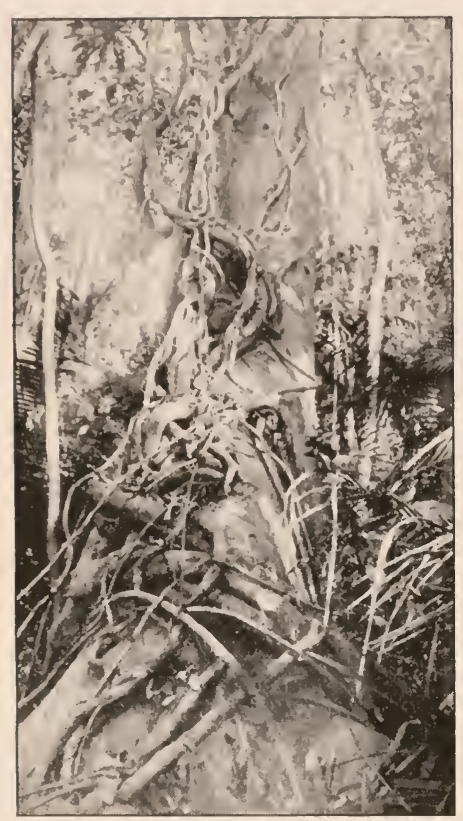

FIg. 88. Climbing stems on a tree trunk in a tropical forest.

branches or leaves. They respond to contact with a support by coiling tightly about it. After attaching themselves, they develop mechanical tissue which gives the plant a firmer support. In some vines, like the Boston ivy, the tendrils have at their tips sensitive disks which become cemented to the support. This type of tendril is especially effective in taking hold of the bark of trees, rock cliffs, and walls (Fig. 87).

In the tropics, climbing stems may attain a length of more than rooo feet. Thus the water transpired by the terminal leaves has to be carried for about a fifth of a mile within the plant. This suggests the need of an efficient conductive system in a climbing plant, and explains why the bulk of its slender stem is made up of conductive tissue.

Stems of hydrophytes. We have seen that submerged leaves have distinctive forms and characteristic internal structures. Under-water stems also differ from those of land plants. In floating plants like duckweed, water hyacinth, and Salvinia, the stems are short. Their conductive systems are poorly developed, and they are practically without mechanical tissue. 
Other hydrophytes, like the pondweeds and water lilies, are rooted in the soil, and their stems bear submerged or floating leaves. The stems have little or no mechanical tissue. As compared with land plants, the conductive system is much reduced. Many of these hydrophytes develop underground rootstocks and tubers. For this reason the plants commonly grow in masses.

A third group of hydrophytes are those like the cat-tails, rushes, bulrushes, and sedges, whose roots and stem bases may be under water, while the upper parts are exposed to the air. These plants have both the conductive and mechanical tissues well developed. This is in keeping with the fact that such plants are exposed to the action of wind and wave and to the conditions that bring about normal transpiration.

The most distinctive feature of submerged stems is the presence of large air chambers extending throughout their length. When the stems are broken open, the tissues are seen to occupy much less space than the air cavities. We may properly speak of " intercellular spaces" in mesophytic stems; in describing hydrophytes, the term "air cavities" is more appropriate. They buoy up the plant and provide an internal atmosphere for gas exchanges between the leaves and roots.

Stems of xerophytes. The xerophytes are the characteristic plants of deserts and dry plains. They occupy sand dunes and sand plains along the Atlantic coast and on the shores of the Great Lakes. They may be found locally on rock cliffs and on dry, exposed hilltops, situations in which a reduced water supply in the soil is accompanied by atmospheric conditions that promote rapid transpiration and in which the plants are periodically or continuously subjected to drought. Plants that thrive in these habitats show a re- 


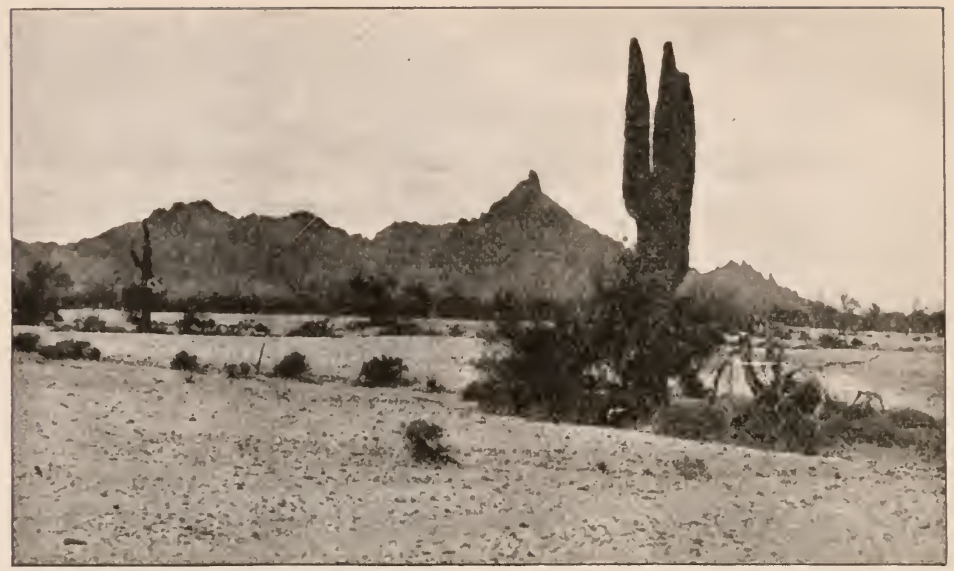

Fig. 89. A desert scene in Arizona.

Caspar W. Hodgson

duced leaf area or a complete absence of leaves. The stems also may be reduced in size and amount of branching.

The cactuses represent extreme examples of this type of plant. Leaves are wanting; and the stems are columnar, often ridged and fluted, and always thick and fleshy. The photosynthetic work in cactuses is done by the cortical tissue. As the green surface is small compared with the green surface in mesophytic plants, food manufacture is slower and growth is correspondingly less. Some of the cactuses of Mexico attain heights of 60 feet. The cactus form points clearly to one of the most characteristic features of desert plants; namely, water storage. A single plant may contain from 15 to 20 gallons of water. As the plant loses moisture so slowly, it may continue to live for several years without an additional supply of water. Other desert plants that accumulate water in the leaves were mentioned on page $5^{8}$. 
Underground stems. Many plants belonging to each of the three ecological groups, xerophytes, mesophytes, and hydrophytes, possess underground stems. Underground stems are particularly useful as storage places for accumulated food and water, and as organs for propagating the plant (page 21 7 ).

The commonest type of underground stem is the rootstock. Rootstocks are horizontally growing stems, from which the aërial stems arise. They may be slender, or thick and fleshy. Usually they have small scale leaves and buds at the nodes, and roots that arise from the nodes or from the entire under surface. The presence of nodes is the external feature of underground stems that distinguishes them from roots.

In many of the grasses and grasslike plants rootstocks develop rapidly in all directions, sending up erect branches at short intervals. The rootstocks and their accompanying roots soon become mixed with those of adjoining plants, finally forming a closely interwoven mat which is the "turf " of lawns and meadows. Turf-forming grasses are often of great value for holding in place the soil of embankments, dikes, and levees. In these plants the rootstocks are mainly useful in spreading or extending the plant. Bermuda grass and Johnson grass are sometimes troublesome weeds because of their extensive rootstock system. The sand-reed grass has been planted extensively in Europe and in America to hold drifting sand in place, and to prevent the sand from invading towns and cultivated fields.

In plants like the May apple, Solomon's seal, and yellow water lily, the rootstock' not only causes the plant to spread, but it also accumulates a part of the food manufactured each season and thus serves as a storage organ. It is this store of food and the readiness with which the rootstock sends up 
shoots, that make the bindweed so difficult to eradicate from cultivated fields, gardens, and hedgerows.

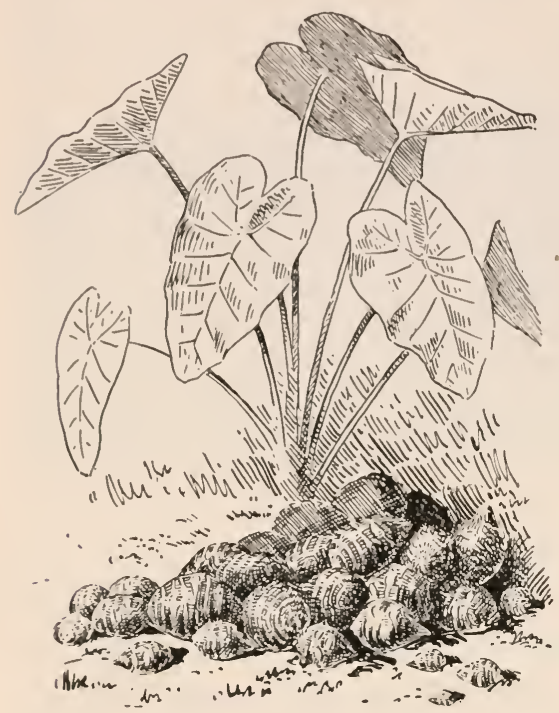

Fig. 90. Dasheen and edible corms produced by it. The dasheen is related to the common "elephant's ear" or Caladium, and is extensively grown in the tropics for food. In the states along the Gulf Coast it is being introduced as a food plant.

of a short stem covered with several layers of thick scales in which food is stored. Tulips, hyacinths, and onions are commonly propagated by means of bulbs.

By planting bulbs of the tulip in autumn, we can have flowers early in the following spring, whereas if we planted the seeds, we should have to wait several years for flowers. Furthermore, tulips do not grow well except in a very moist climate, and the development of large, vigorous bulbs is im- 
possible in most parts of the United States. For this reason nearly all our tulip bulbs are brought from Holland. The importation of bulbs from countries where they grow particularly well is an important industry and enables us to have many flowers which cannot be so successfully propagated in our climate.

Tubers are the enormously thickened ends of short underground stems. The potato, the Jerusalem artichoke, the dahlia, and the common white water lily develop tubers. The scale leaves of the ordinary

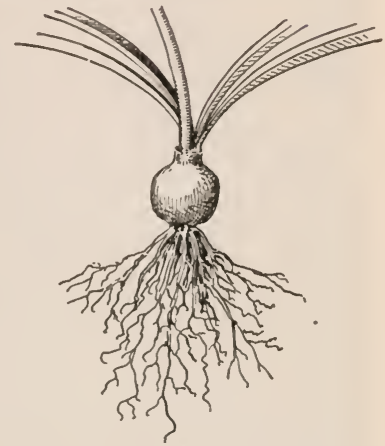

FIG. 91. Amaryllis bulb. rootstock are in tubers reduced to ridges, and the buds themselves to mere points. The scales and buds together form the eyes of tubers. Tubers serve the same purposes for the plant as do other fleshy underground stems: surplus food accumulates in them, and by them the plant is multiplied. The potato tuber has become one of the most important sources of food for man.

Commercial products derived from stems. We are all familiar with the important products derived from the trunks of trees. Lumbering is one of the most important industries of the United States. Closely associated with it are the furniture industry, which uses the hardwoods, - walnut, oak, maple, sycamore, and birch, - and the wood-pulp industry, which utilizes soft woods - such as spruce and poplar - in the making of paper. The Southern pines furnish rosin and turpentine ; the bark of oaks and hemlocks supplies tannic acid for the manufacture of leather; and Span- 


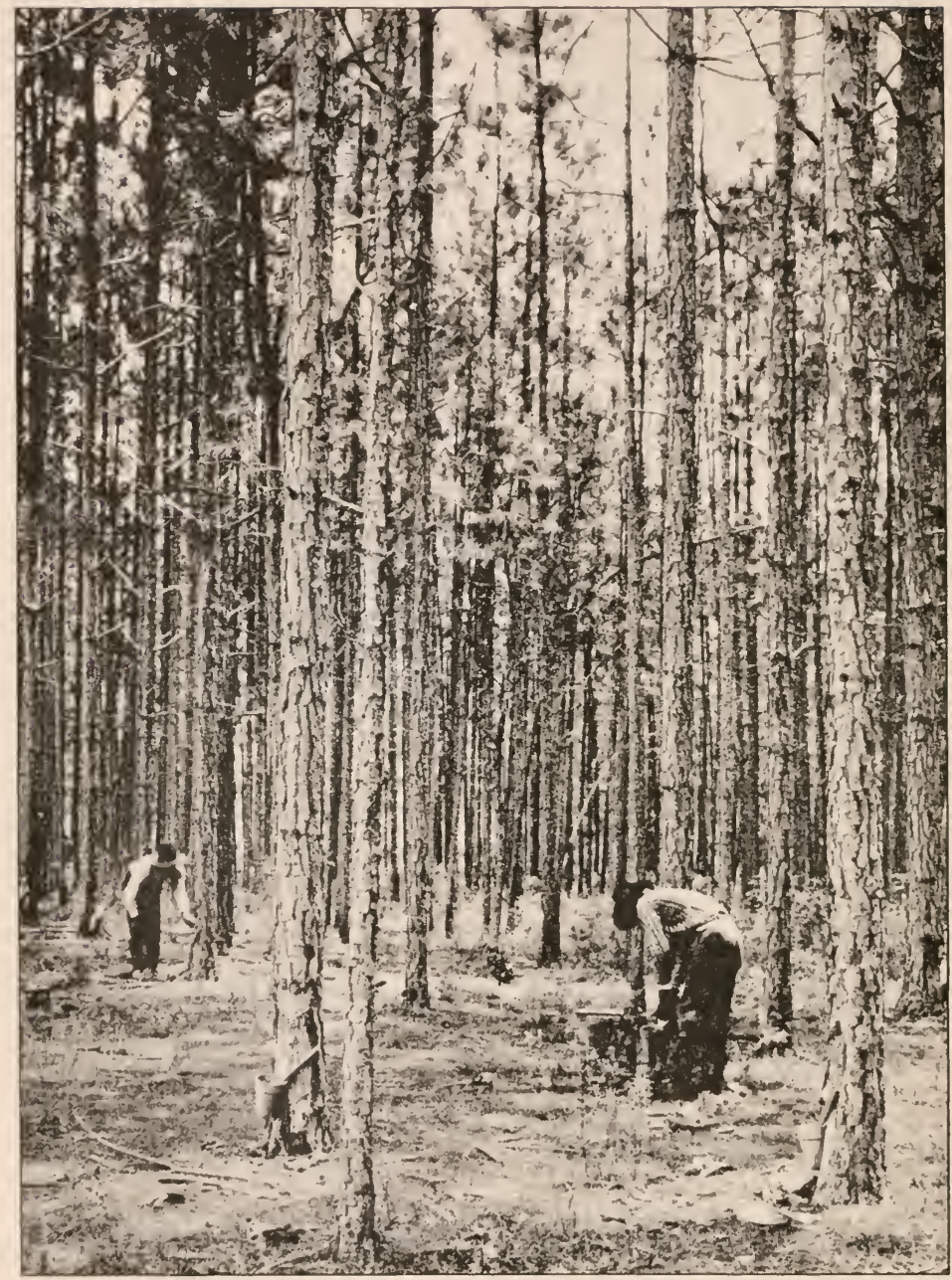

U. S. Furest Service

FIG. 92. Southern long-leaf pines tapped for resin. 
ish oak bark provides the cork of commerce.

The stem of the rattan palm, which is one of the very longest of tropical climbers, furnishes the cane for chairs and materials for basketry and wicker furniture. In this country baskets and furniture are made from shoots of the osier willows.

Stem vegetables of importance as food for human beings include the potato, Jerusalem artichoke, asparagus, dasheen, and kohl-rabi.

Sorghum and sugar cane furnish a considerable part

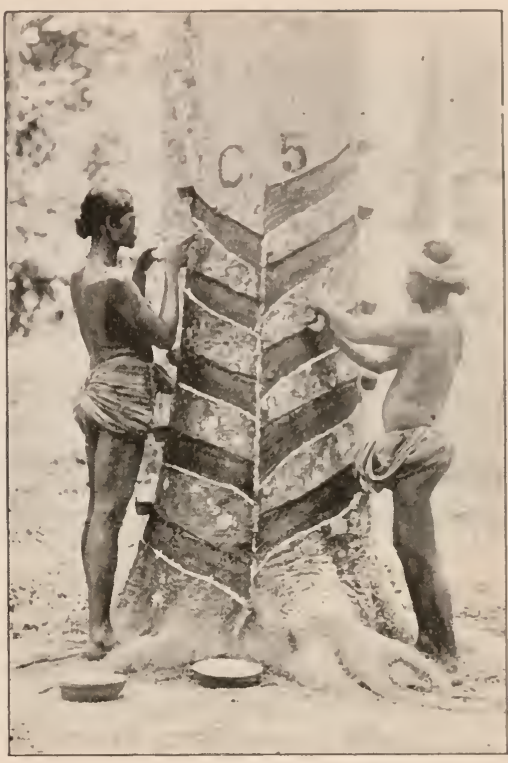

Bureau of Agricullure, P.I.

Fig. 93. Tapping para rubber trees, in the Malay States, to obtain the milky juice from which crude rubber is made.

of the sugar and sirup of commerce. The maple is the source of a delightfully flavored sugar.

The crude rubber used in the manufacture of shoes, garments, and tires is furnished by the stem of the desert plant, guayule, and the sap of various tropical rubber trees. Many substances used in medicine are derived from stems directly or by distillation. Wintergreen oil may be obtained from the twigs of the sweet birch, and camphor from the stem and branches of the camphor tree.

The bast fibers of flax, jute, and hemp furnish material for the manufacture of linen, cordage, coarse fabrics, and rugs. 


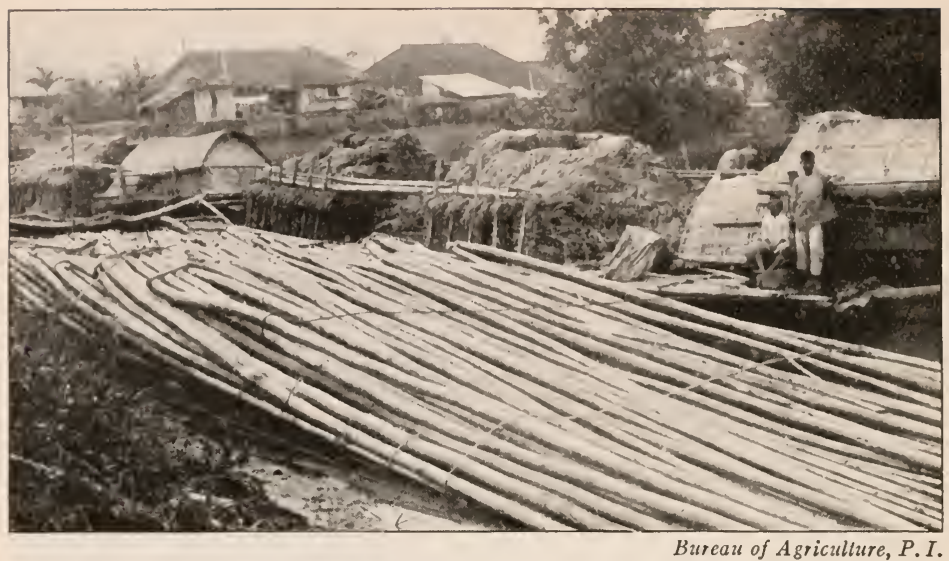

Frg. 94. Marketing bamboo, Philippine Islands.

Cornstalks not only furnish food (ensilage) for cattle, but from them is made the packing used inside the armored walls of war vessels.

\section{PROBLEMS}

1. What tree is most valuable to the natives of the tropics? Why?

2. Where are the principal forest reserves of the United States located? May trees be lumbered on forest reserves?

3. What kinds of work are carried on by the United States Forest Service?

4. Will twining stems twine about a horizontal wire?

5. For your vicinity, make a list of the plants that climb (I) by twining; (2) by means of tendrils; (3) by means of roots. 
Suggestions for Laboratory and Field Work to Precede Chapter Fourteen

1. Demonstration of imbibition with gelatin, wood, and a dry leaf.

2. Demonstration of osmosis with thistle tube and animal membrane; or with diffusion shell or porous cup; or with carrot root and glass tube.

3. Study the root system of a seedling or weed. Note primary, secondary, and adventitious roots. Make a drawing of the root system.

4. In the field, study the roots of some plants growing in dry sand; in clay; and in swampy low ground.

5. Study distribution and development of root hairs in seedlings. Wheat and oat seedlings are very satisfactory for this purpose.

6. With a microscope examine a young root. Try to make out the root cap; the epidermis; the cortex; the vascular axis.

7. Longitudinal sections of a root tip will show stages in cell division and cell enlargement. Note changes in nucleus, cytoplasm, and vacuole. 


\section{CHAPTER FOURTEEN}

\section{THE STRUCTURES AND PROCESSES OF ROOTS}

IN preceding chapters we have learned that leaves manufacture food in the presence of light; that their exposure to

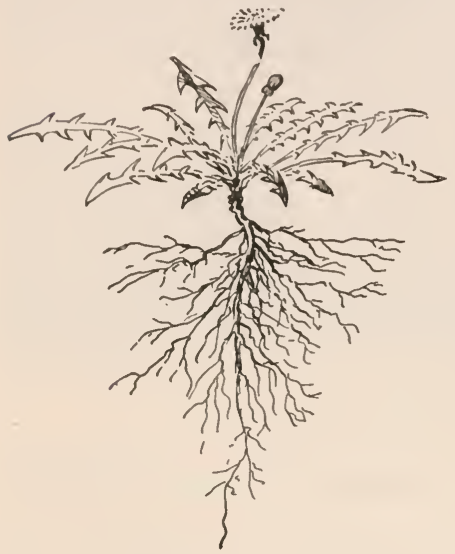

FIG. 95. Dandelion plant, showing the primary tap root and its branches, the secondary roots. air facilitates the entrance and exit of carbon dioxid and oxygen; and that by being raised and displayed on erect stems their efficiency is increased.

The support of leaves by stems makes necessary the development of mechanical tissue in the stems. The display of leaves high above the water supply of the soil requires a conductive system capable of raising water and mineral salts from the roots and of carrying food away from the leaves. Consequently plants that expose great numbers of leaves to the light must develop large and strong stems. The stems, in turn, must be firmly anchored in the soil, and they must also be supplied with the water and mineral substances that press up through them to the leaves. Anchorage and absorption are the particular functions of roots, though they carry on other processes also, such as conduction of water, transfer of food materials, accumulation of food, respiration, and growth.

Classification of roots. The root of a well-developed bean seedling will show the essential features of roots. There is the primary root, extending downwards from the base of the 
stem. On its sides are numerous secondary roots which extend at right angles, or grow obliquely downwards. Unlike stems, roots possess no definite nodes from which branches arise. A secondary root may originate at any point on the primary root.

In many seedlings there are also roots that develop from the first node of the stem. All roots arising from stems and leaves are called adventitious roots. The "prop roots" that develop from the lower nodes of corn stems and the roots that grow from "cuttings" are familiar examples. Adventitious roots develop also from the stems of many plants like the poison ivy and trumpet creeper and act as holdfasts in supporting these climbers on trees and walls. Adventitious roots may arise also

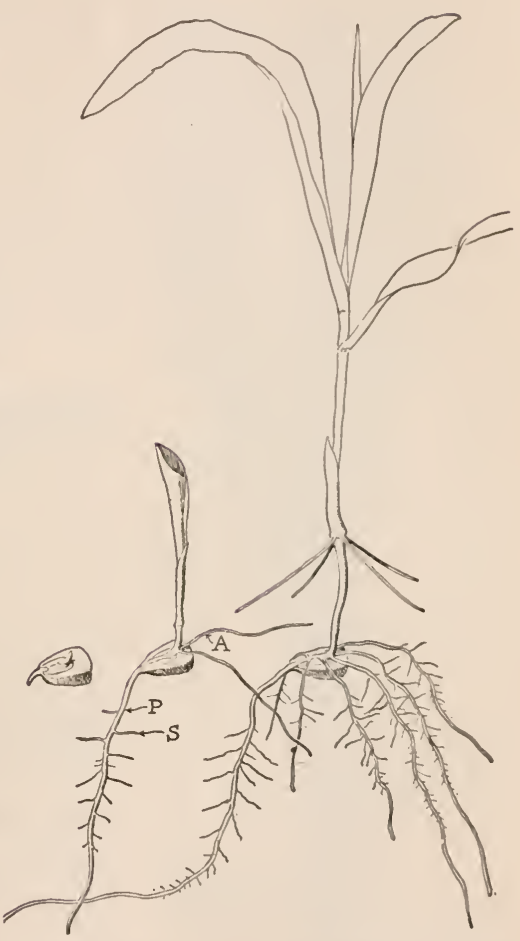

FIG. 96. Stages in the development of a corn seedling. $P$ is the primary root, $S$ a secondary root, and $A$ an adventitious root from the first node of the stem.

at any point on a primary or secondary root, following injuries. For example, when we plant pieces of horseradish or dandelion roots, adventitious roots develop. During the dry season in deserts the younger parts of the root systems 
of some plants like the cactuses are killed, and when the next wet season comes, many adventitious roots develop from the parts of the root system still alive. In desert plants these new adventitious roots do most of the absorbing work during the moist season.

Root hairs. The young roots of land plants generally bear root hairs. These are delicate elongations of the epidermal cells of the root. They are especially concerned with the absorption of water and mineral salts, and their presence increases the absorbing surface of the root from two to fifty times. Since the rate of absorption depends in part upon the surface area in con-

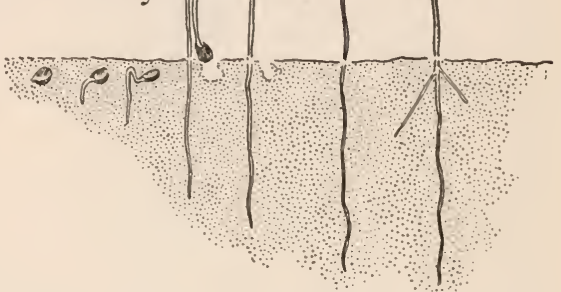

FIG. 97. Stages in the growth of an onion seedling, showing the lifting and shedding of the seed coats and the development of the primary and secondary roots.

tact with the soil water, the advantage in root hairs is evident.

Root hairs are usually short-lived structures, their duration being best measured in days. They begin to develop at a short distance from the tip of the root. Farther back they have attained full length, and beyond this they are in a dying or dead condition. Thus from day to day the zone of root hairs moves forward with the growth in length of the root. This brings the root hairs continually in contact with new supplies of water and food materials in the soil. As a plant enlarges, its root system becomes more complex through repeated branching and the elongation of the branches. Most 
of the absorption occurs in the root-hair zone, and this is continually moved farther and farther from the base of the stem. In large trees this zone may be many feet from the base of the trunk.

Advantages in spreading roots. The spreading of the root branches in all directions not only enables the roots to come in contact with more water and mineral salts, but as the woody tissue develops, it helps to anchor the plant more firmly. It is an interesting fact that when stems are subjected to bending by winds or other agencies, the mechanical tissue of the root develops to a greater extent than ordinarily.

The principal tissues of roots. In the root, the water-conducting tissue and the wood form the central axis. Surrounding this is a layer of food-conducting tissue. In perennial roots there is a cambium layer between the central axis and the food-conducting tissue. Outside the food-conducting tissue

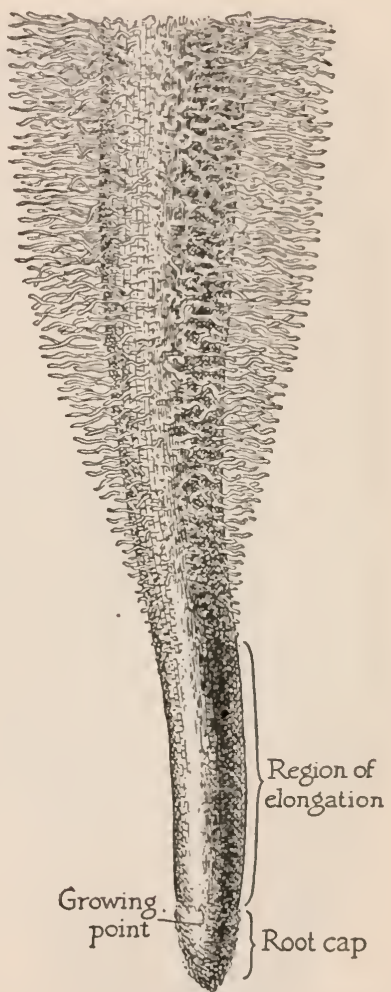

Fic. 98. Enlarged siew of the end of a root, showing root cap, growing region, and root hairs. is the cortex, extending to the epidermis. Perennial roots like those of trees soon lose their epidermis; later the cortex also disappears. The continued thickening of the wood and of the water-conducting and food-conducting tissues results 
in the death of the outermost layers of the root and the formation of a bark very similar to that of tree trunks.

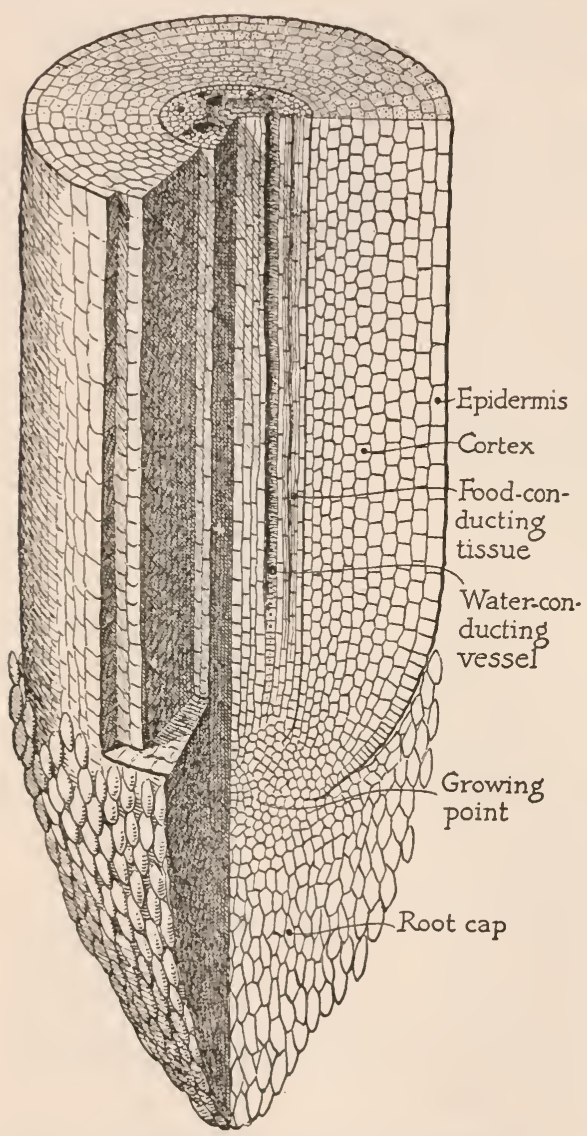

FIG. 99. Diagram of a root tip, showing the tissues and their arrangement.

Absorption. The passage of water and other substances into a body is called absorption. Of all the processes that take place in plants, absorption is the one most commonly associated with roots. In addition to water, roots absorb the mineral substances found in plants, and they absorb a part, or all, of the oxygen needed for respiration by their own cells. Water and other substances not only enter the external cells of a plant by absorption, but they pass from cell to cell within the plant by the same process. A dead root in the soil may take up water and become saturated; but only a living root can absorb water rapidly enough to furnish an adequate supply to the living parts above the soil. The 


\section{The Structures and Processes of Roots}

water supply of plants, therefore, depends upon the presence of living cells in the roots.

Three physical processes are involved in absorption in plants. These processes are diffusion, imbibition, and osmosis. Their action may be demonstrated to a large extent by the use of physical apparatus.

Diffusion. If a small dish of ether is exposed in a room, in a few minutes the odor of the ether may be noticed in all parts of the room. Even if there were no air currents, the ether would evaporate; that is, particles of ether would rise from the surface of the liquid, pass out of the dish, and move through the room in every direction. This is an example of the diffusion of a vapor. The vapor is concentrated in the dish and the particles move outward into the room where there is none; that is, the particles move from the place where the concentration is greatest to where it is less. After the ether has evaporated, the vapor tends to become evenly distributed throughout the room.

Similarly, if a few crystals of copper sulfate are placed in the bottom of a vessel of water, particles of the copper sulfate diffuse through the water. The crystals are blue in color, and as diffusion proceeds, the water in the vessel gradually becomes blue. The direction of the movement is again from the place where the diffusing substance is most concentrated to where it is less concentrated. The particles pass from the place where they are most abundant to where there are fewer of them, and this process is continued until they are evenly distributed throughout the water.

Diffusion of a gas or vapor is very rapid. Diffusion of a dissolved substance is slow, but the distances that substances must travel in plant cells are very small. Oxygen and carbon 
dioxid, when once dissolved in the water of cells, move about partly by diffusion.

Imbibition. The process of imbibition may be illustrated by placing a sheet of gelatin in water. Dry gelatin is a hard, brittle, partly transparent solid. After it has been in water for a few minutes, it will be found to have increased in weight and in length, breadth, and thickness. The gelatin, instead of being brittle, is now soft and pliable; it is also more transparent than it was.

The increase in size and weight is explained by the fact that particles of water have forced their way between the particles of the gelatin, spreading them apart. Since the gelatin particles have been forced farther apart, the gelatin is more pliable and the particles cling to one another less firmly. Hence when a piece of dry wood is put into water, it imbibes water and swells. The cell walls of a root, like wood, are largely composed of cellulose and they take up water in the same way. When dry seeds are placed in water, they imbibe water and increase in size. Indeed, most organic substances have the property of imbibing water and swelling. Imbibition is a form of diffusion that results in swelling. Compare the size of a sponge when dry with its size after it has been soaked in water and squeezed as dry as possible.

When a piece of wood becomes saturated, it stops taking up water. If, however, the water were being removed from the inside, more would continue to pass into the wood. This is exactly what happens in the root of a living plant. The external cells of the root are in contact with the water of the soil. Inside the root the water is being used and removed by being drawn up through the stem to the leaves. More water then passes into the cell walls and protoplasm to take the place 
of that which is drawn away, and this keeps the amount of water in the cells of the root nearly constant.

Osmosis. The third physical process that aids in the absorption of water is osmosis. If an animal membrane, as a piece of bladder, is tied over the broad end of a thistle tube and the bulb of the tube is immersed in water, the water will gradually pass through the membrane. The membrane is permeable to water; that is, it allows water to pass through its minute pores. The water continues to move through until its level is the same inside and outside (Fig. I00).

When the water level is the same inside and outside the tube, one might think that the water particles were at rest. This is not the case. Water particles are still passing both into the thistle tube and out of it through the membrane. The rate is the same in both directions, however, and so the water level within the tube remains unchanged.

If we put a little sugar into the thistle tube, something different happens, as is shown by the fact that the liquid in the tube begins to rise. Evidently, more water is passing through the membrane into the tube than is passing out, and this change has been brought about by the presence of the sugar. Perhaps we can get a mental picture of what causes this difference from the diagram in Figure IоI. The membrane $(C)$ allows water molecules to pass through it freely, but it permits scarcely any of the sugar molecules to pass. The outer side of the membrane is completely covered with water molecules $(B)$, tending to diffuse through the membrane. The inner side $(A)$ is only partly covered with water molecules, since part of the area is occupied by sugar molecules. Consequently there are fewer water particles on the side $A$ tending to diffuse outward than there are on the side $B$ tending to 
diffuse inward. We may say that the water is more concentrated outside the tube than inside, so water passes from

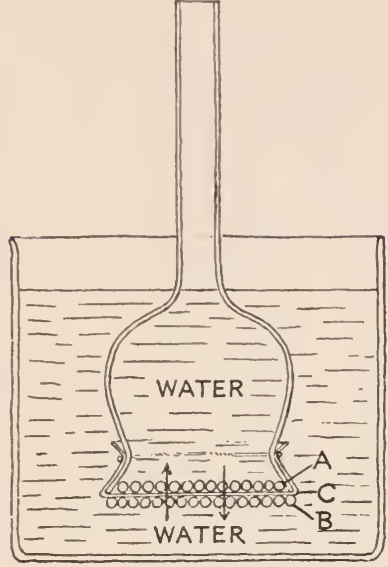

FIG. Ioo. Diagrams to illustrate the passage of water through a membrane: $A$, molecule of inside water; $B$, molecule of outside water; $C$, membrane.

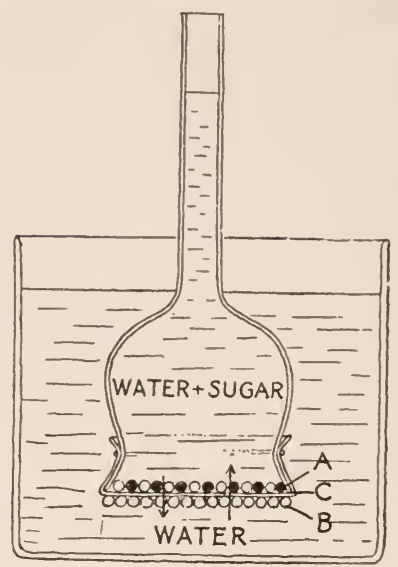

FIg. ror. Diagram to illustrate osmosis: $A$, sugar molecule; $B$, water molecule; $C$, selectively permeable membrane.

the place of greater concentration to the place of less concentration. Moreover, sugar is a highly soluble substance; that is, it has a great affinity for water, and the sugar particles tend to hold the water particles in contact with them inside the thistle tube. The sugar, like the water, tends to pass from the place of greatest concentration but is restrained by the membrane from moving outward.

If we close the upper end of the thistle tube, the water will continue to rise and compress the inclosed air. The pressure developed under these conditions is called osmotic pressure. If a large amount of sugar is put inside the tube, the water will rise rapidly and exert great pressure. If only a 
small amount of sugar is present inside the tube, the water will rise slowly and exert but little pressure.

When a membrane permits water or other substances to pass through, it is said to be permeable to that substance. For example, animal membranes are permeable to water and to various dyes. A membrane that allows one substance to pass through it, but retards the passage of another substance, is said to be selectively permeable. The membrane on the thistle tube is selectively permeable, because it allows the passage of water but restrains the sugar that is dissolved in the water. The membranes in root cells are permeable to water, but they do not allow sugar and many other substances found inside the cells to pass out.

The conditions for osmosis as it occurs in plants, then, include a selectively permeable membrane between two bodies of water, one of which contains a dissolved substance that does not pass through the membrane readily.

Osmosis in roots. The cellulose walls of plant cells are permeable to water and to most of the substances that dissolve in water; but the layer of cytoplasm inside the cell wall forms a selectively permeable membrane about the cell contents. The cell sap in the vacuole may contain sugar and other dissolved substances, just as the water in the thistle tube contained sugar. The outer cells of the root are in contact with the soil water. Hence the water passes into these cells in the same way as into the thistle tube. In a similar manner water may move from one cell to another and replace the water that is being carried to the stem and leaves through the conductive tissue. The path of the water from the epidermal cells is through the cells of the cortex to the water-conducting vessels in the interior of the root. 
Absorption and rise of sap in plants. Attention was called to the fact that transpiration exerts a pull on the water in

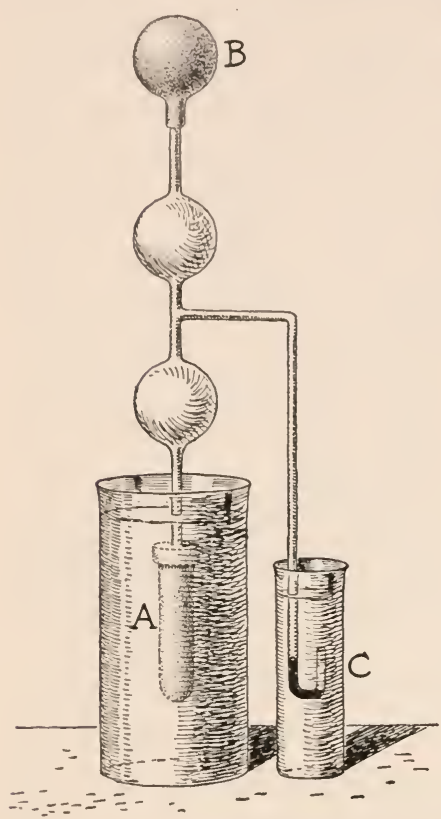

FIG. 102. Experiment to illustrate the water balance in a plant. The entire apparatus is filled with water, and $A$ and $C$ are immersed in water. The water is absorbed by osmosis into the porous cup $A$, and evaporated from the cup $B$. The rate of evaporation is faster than the rate of absorption, as is shown by the fall of the mercury in the outer end of the tube $C$. ment of water into them. Air bubbles already in stems that have been cut in the air may sometimes be removed by cutting off an inch or two of the lower ends of the stems under water. the conducting tissue of the leaves (page 134). This pull is transmitted to the water-conducting tissues of the stem and root. So a fourth factor enters into the absorption of water by the roots: the pull on the water in the cells of the root is indirectly due to transpiration from the leaves. .Large trees have been kept alive for days by placing the cut-off trunks in water. This shows that sufficient water to maintain the water balance of the plant for at least several days may be lifted in a plant by the pull of transpiration without the aid of roots. It is of practical interest to know that cut flowers will last much longer if the ends of the stems are bent over into a vessel and cut under the water. If cut in the air, air bubbles get into the water-conducting tubes and prevent the subsequent move- 
Root pressure. If a number of well-watered plants are cut off just above the soil, some of them will exude water for a day or two. Experiments have shown that the sap may in some cases be forced out with pressure sufficient to raise water 30 or 40 feet. This pressure is called root pressure. When such pressures exist in plants, they probably aid in the lifting of water in stems. Under these circumstances transpiration pulls on the columns of water in the water-conducting vessels from the top, and root pressure pushes on them from below. Extensive experiments have shown, however, that root pressure is intermittent. It may exist at one time and not at another, and when transpiration is most active and the largest volumes of water are being raised in a plant, root pressure is wanting entirely. Because of all these facts, it is generally believed that root

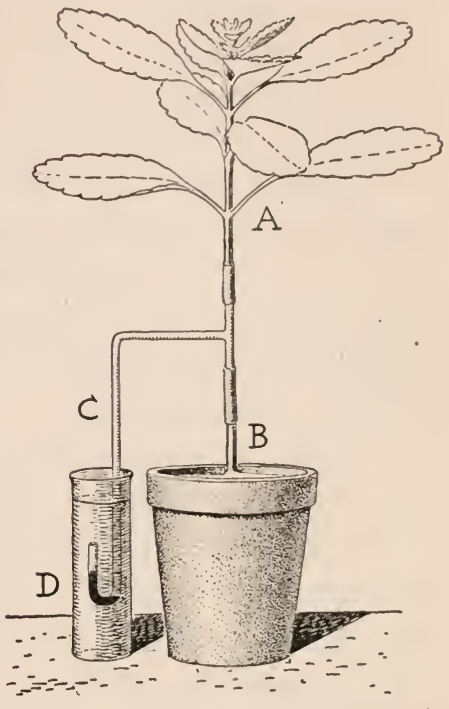

FIG. 103. A plant with its stem cut in two and connected again with a tube similar to that shown in Figure 102. In this case the roots are absorbing water more rapidly than the leaves are transpiring it, since the mercury at $D$ is pushed away from the plant. By setting the plant in bright sunshine, the transpiration may be increased. The mercury is then almost immediately drawn toward the plant.

pressure is not a necessary factor in the raising of water in stems.

Imbibition and osmosis lead to the development of root pressure, and they are partly responsible for the flow of maple sap (page I35). Grapevines pruned in the spring exude 
water for days afterward as a result of root pressure. On a small scale the same thing may sometimes be seen when wellwatered begonias and fuchsias are cut off near the soil.

Food conduction. The transfer of food takes place in the food-conducting tissue of roots in the same way as in stems and leaves. Substances that are to be transferred must be in a soluble form, and they are usually in a comparatively simple form. Starch, for example, is transferred as glucose, and protein and fats are broken down into simpler compounds before they are moved from one part of the plant to another. Diffusion and osmosis are the principal processes that bring about food conduction.

The movement of a substance into or out of a cell depends upon the permeability of the cell protoplasm to that particular substance; if the cytoplasm will not permit the substance to pass through, it cannot enter or leave a cell. The direction of the movement of foods may change from time to time, as is shown by the fact that sugar and soluble proteins may move down into the root during one season and up out of the root at another season. For example, in the turnip or beet the excess food made by the leaves during the first summer passes downward into the roots; the next year, food passes upward from the roots to the developing stems and leaves. This may be due to changes in the permeability of the cells or to changes in the foods stored in the cells.

These changes in the behavior of organs, tissues, and cells are clear evidences of life. In physical apparatus the behavior is fixed and a process soon comes to a standstill. In living things changes are continually taking place in the living matter itself, and these bring about continual changes in the processes that are going on. 


\section{The Structures and Processes of Roots}

Accumulation of food in roots. Food accumulates in the roots of many plants, notably in those of biennials like the beet, carrot, turnip, and salsify. The sweet potato and the dahlia are examples of perennials with large storage roots. The most common forms in which carbohydrates accumulate in roots are starch and sugar. Starch as a storage material has the advantages of being insoluble and more concentrated than sugar. When growth begins anew, starch is readily converted (digested) into sugar (page 74).

Respiration in roots. Respiration must go on in the living cells of the roots just as in the other living parts of the plant. This process requires a constant supply of oxygen. In obtaining oxygen as well as in obtaining water, the division of the roots into numerous fine branches is an advantage, because it exposes a large surface to the soil air and the soil water. Some plants are easily injured by the lack of oxygen in the soil; if water stands on the soil and excludes the air, the roots gradually suffocate. Suffocation of a part of the roots interferes with other root processes besides respiration, and the whole plant suffers. For example, you may have seen yellow, sickly corn in low fields where water has stood for some time. Such plants may recover if the soil is drained. Water plants and swamp plants can grow in poorly aërated soils because the roots are able to secure oxygen through the internal air spaces of the plants.

Under normal conditions the energy liberated by respiration in roots is largely used in growth and in overcoming the resistance of the soil. During the life of a plant the roots, like the stem, continue to develop new branches.

The growth of roots. In growing through the soil, the tip of a root is continually pushed against and between sharp- 
angled soil particles. If a root tip or a longitudinal section of one is examined under a microscope, it may readily be seen that the growing point is not at the very end, as in stems, but is covered by a root cap. The growing region of the root extends a few centimeters back from the growing point (Fig. 98). Therefore, as the root elongates, the root cap is pushed forward and is abraded by the soil particles. This injures the outer cells of the cap, but as they are being renewed from within, the cap is always present as a protection for the growing point.

At the growing point the cells are small, similar in form, and filled with protoplasm. They are constantly dividing and forming new cells. As the cells grow older and enlarge, they assume the mature cell form of the particular tissue to which they belong. The protoplasm of mature cells is merely a lining inside the cell wall. Most of the cell space is occupied by a water solution of sugar, soluble proteins, salts, and acids. Sometimes starch grains are present (Fig. 99, page 100).

The three stages of growth are characterized by cell division, cell enlargement, and the fixation or thickening of the cell walls. They are very similar in all plant organs. But nowhere can they be seen so readily as in the longitudinal section of a young root. 


\section{Suggestions for Laboratory Work to Precede Chapter Fifteen}

1. Grow seedlings on blotting paper or cotton, between two glass plates. Keep the plates in one position until the roots are 2 or 3 inches long. Then set the plates at right angles to the previous position. Note the change in the direction of growth of primary and of secondary roots.

2. Replace the bottom of a cigar box with mosquito netting, and place on the netting mustard or radish seeds that have previously been soaked in water. Then fill the box with wet moss or cotton. Suspend the box so that the bottom rests at an angle of 45 degrees. Note the direction of growth of the roots as they develop. Do they respond more to gravity or to moisture?

3. Study roots of floating or submerged plants. Note air chambers.

4. Study aërial roots of climbers like Boston ivy and trumpet creeper. Study the prop roots of mature corn.

5. Sketch and study roots of carrot, parsnip, or radish. Test for starch.

6. Sketch and study root nodules and roots of either clover or beans.

7. Study the arrangement of roots on a bulb or corm. Onion, hyacinth, gladiolus, or crocus may be used. 


\section{CHAPTER FIFTEEN}

\section{ROOTS AND THEIR ENVIRONMENT}

Roots commonly develop in soil. Floating plants, however, develop roots in water; and many plants in the moist tropics

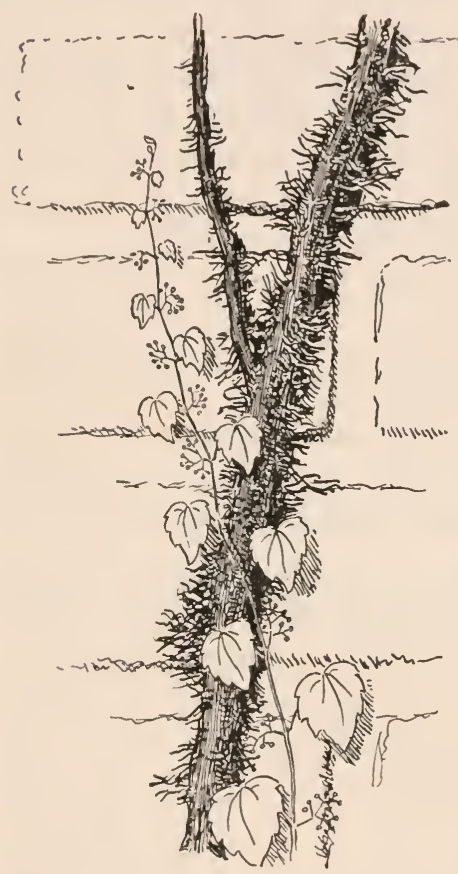

Fig. 104. Young and old stems of Boston ivy. The young stems are held by means of tendrils, the older stems by means of adventitious aërial roots.

the root. Gravity merely determines the direction of growth. The penetration of the soil is due to growth pressure; the cells of the root multiply and enlarge, forcing the tip downward. Secondary roots also respond to the pull of I 82 
gravity, but they tend to grow at right angles to its direction rather than directly toward it, as do primary roots. Secondary roots are transversely geotropic.

The response of roots to light. Roots tend to grow away from strong light. They are negatively phototropic. This tendency may be observed in the aërial roots of ivies and other climbers. No matter from what surface on the stem they arise, they curve around away from the light. This is advantageous to a climbing plant, for it brings the root to the supporting tree or wall.

The response of roots to water. Particles of water, in diffusing from wet places in the soil to places that are drier, also affect the direction of root growth. A root in drier soil will turn toward the direction from which water particles strike it. Continued growth will then bring the root into the moister soil. This response of a root is of great advantage to the plant. It is sometimes stated that roots "seek" the water. In reality, roots grow toward moist places only when water diffusing from the moist places reaches them and so controls the direction of growth. They do not seek the water, but they are turned to the moist soil by the water itself.

The distribution of roots in the soil. Another factor that determines the distribution of roots in soil is the oxygen supply. Various plants have different requirements, but all roots doubtless require oxygen for growth. Those who have seen stumps pulled from the land know that the roots go deep in upland sandy soils; that they do not go so deep in heavy clay soils; and that they are just beneath the surface in swamp and bog land. The principal reason why one finds the roots near the surface in swamps is that these roots were the only ones that continued to live and grow. The roots that in times 
of drought penetrated to greater depths were killed off suffocated - when the water stood at higher levels. The distribution of roots in the soil, therefore, is determined principally by the combined influences of gravity, water, and oxygen. Water and gravity control the direction of growth, and the oxygen supply determines whether or not growth can take place or the roots survive.

In the plains of eastern Kansas, the roots of plants may penetrate certain soils to depths of from I 5 to 20 feet. The absorbing parts of these roots actually reach the water table; that is, they reach the level at which the soil is saturated, or the level to which water would rise in a well.

Two or more species of plants are sometimes found associated in dry regions, and locally in dry habitats, because their roots get their water at different levels and hence do not compete with each other. For example, in our Southern deserts the giant cactus commonly grows with the creosote bush. The former plant obtains its water from the superficial layers of the soil, while the latter obtains its water at deeper levels. The roots of lawn grass are very superficial, and lawn grass suffers from drought much sooner than do the deeper-rooted dandelion and English plantain that occur with it as weeds.

In dry regions where plants compete with one another, success comes mostly to those that secure a sufficient water supply. In moist regions success in competition between plants depends chiefly on ability to reach the light or withstand shade.

The pressure of growth. The pressure exerted by roots in penetrating the soil may be very great, amounting to hundreds of pounds to the square inch. This is readily appreci- 
ated when one sees cement sidewalks broken and large rocks moved by the growth of roots under them. Growth pres-

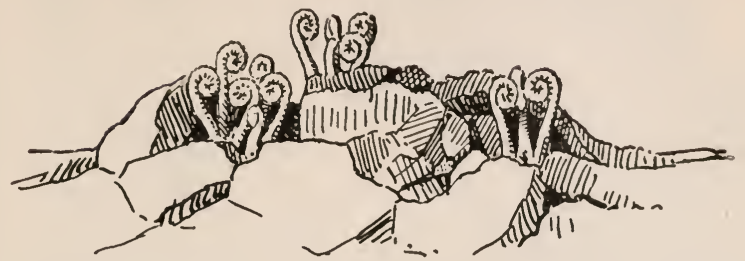

FIG. 105. Fern leaves pushing upward through a cement sidewalk. (After G. E. Stone.)

sure is just as powerful in stems and other growing parts. Fleshy roots like those of the radish and turnip sometimes force themselves partly out of the ground by the thickening of the upper portion.

Root contraction. As roots mature, they may contract in length and so draw the base of the stem a slight distance into the soil. In this way crevice plants on cliffs are continually held firmly in place, in spite of the wearing away of the cliff face by erosion. In the same way the crowns of clover and plantain roots that have been lifted up by frosts may be drawn into the soil, and small bulbs and tubers, many of which are formed at higher levels than the parent bulbs, may be pulled deeper into the soil by root contraction.

Root duration. The roots of various plants are annual, biennial, or perennial. Perennial plants may have either annual or perennial roots, just as they may have either annual or perennial aërial stems. Plants with bulbs, tubers, or corms grow a new set of roots each year. Plants with rootstocks, like the May apple and Solomon's seal, generally have roots that last for several years. Shrubs and trees also have perennial roots. We must be sure to understand, how- 


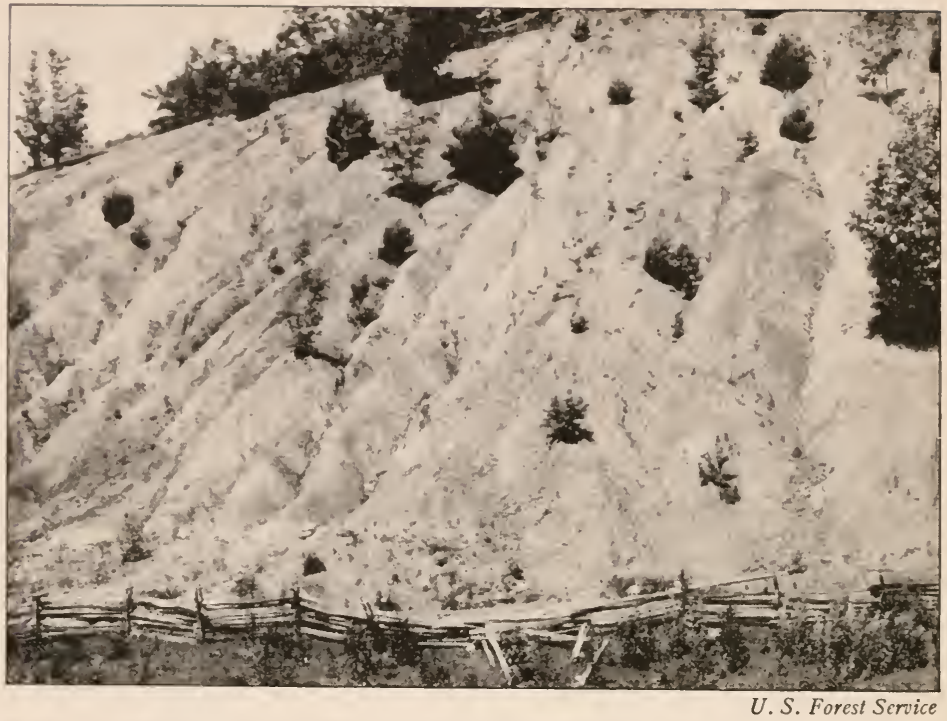

FIG. I06. Typical section of a mountain slope in western North Carolina, after removal of forest. The binding effects of the roots have been removed, and the erosion of the soil is so rapid that it is difficult for seedlings to take hold. When the forest was cut, enough young trees should have been left to hold the soil and start a new lumber crop.

ever, that even in perennial roots the work of absorption is for the most part done by the new roots which are added each year. Most biennials, like the common evening primrose and wild carrot (page 3 I5 $_{5}$ ), have fleshy roots in which food accumulates during the first year. This food is used in the rapid development of the plant during the second season.

Ecological types of roots. Most of the root characteristics thus far described are those of the roots of mesophytes. In hydrophytes, or water plants, the roots are notably smaller and less branched than in mesophytes. They absorb water and mineral substances from the soil even when the plants 
are totally submerged. The roots of hydrophytes, like the leaves and stems, are remarkable for the presence of internal air cavities (page 156 ).

When the roots of $\ldots$. land plants (mesophytes) extend into well-aërated water, they develop innumerable branches, differing in this respect very markedly from the roots of hydrophytes. On account of this fact, roots of trees, especially those of willow and cottonwood, that enter drain pipes and tiles often develop masses of fine branches that obstruct the flow of the water even when the entering root is not Frg. ro7. Holdfast roots of trumpet creeper, dethicker than the lead in veloped from the nodes. These roots are perennial a pencil. The banks of and may lengthen and branch for several years.

streams are often protected from erosion by the mat of roots developed along the water's edge. This is why willows are planted on levees.

In moderately dry regions the roots of xerophytes may penetrate to considerable depths, but in deserts many of the largest plants have only small root systems, spread in the upper layers of the soil (page I84).

Climbing plants, like the Virginia creeper, poison ivy, 


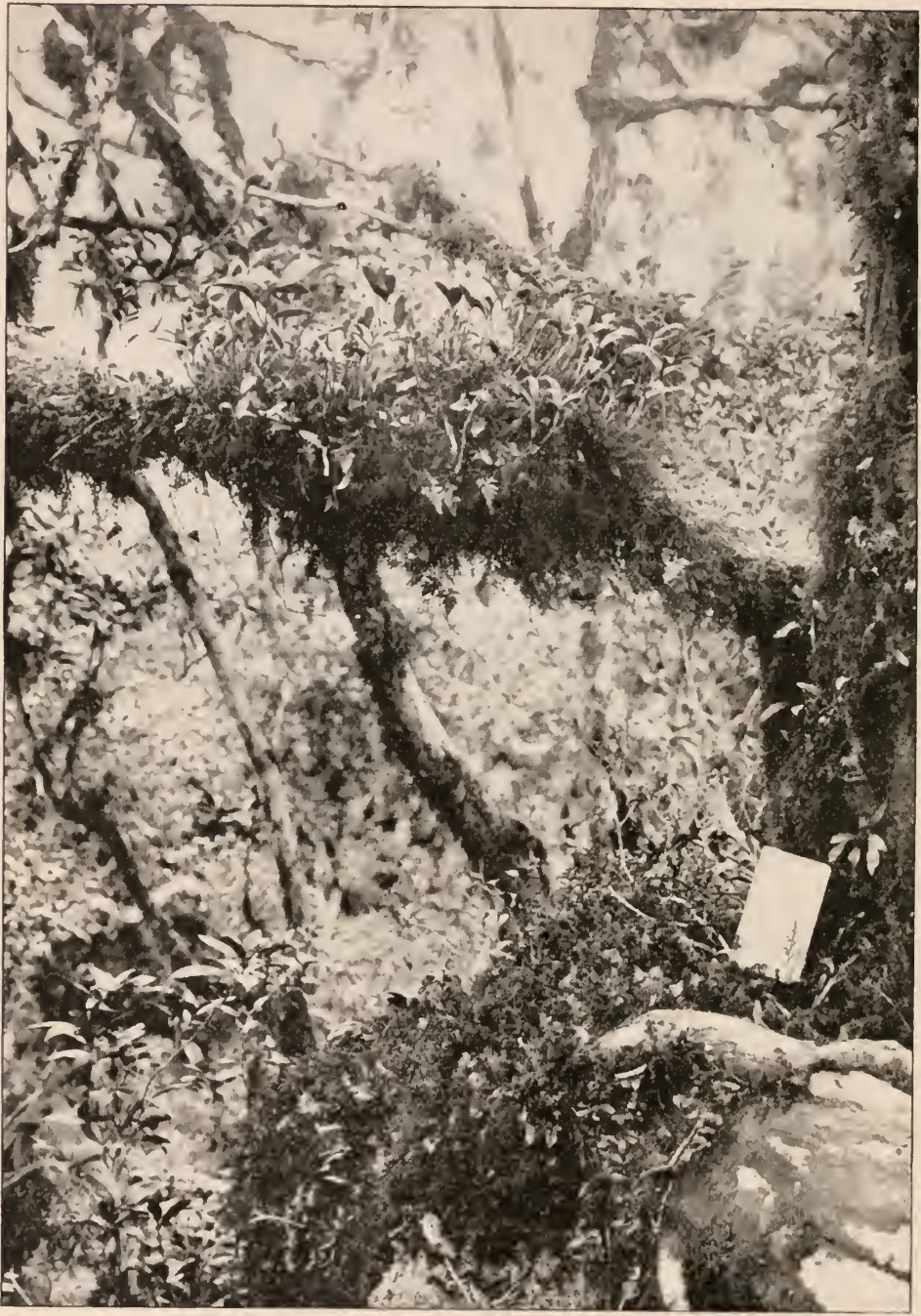

Bureau of Scicnce, P. I.

FIG. 108. Epiphytes on the branches of trees in the rainy tropics. 
Boston ivy, and trumpet creeper, develop holdfast roots which help to support the vines on trees, walls, and rocks. By forcing their way into minute pores and crevices, they hold the plant firmly in place. Usually the roots die at the end of the first season, but in the trumpet creeper they are perennial. In the tropics some of the Iarge climbing plants have holdfast roots by which they attach themselves, and long, cordlike roots that extend downward through the air until they strike the soil and become absorbent roots.

Epiphytes. A plant that lives perched on another plant is an epiphyte (Greek: epi, upon, and phyton, plant). Mosses and lichens are the most common epiphytes in temperate regions, but in the rainy tropics and along our own Southern coast many flowering plants live attached to the branches of trees. They usually have leathery leaves and a low transpiration rate. Many have water-storage tissue in fleshy stems or in thickened leaves. Others are called tank epiphytes, because they catch water in the axils of the leaves or in pitcher-like leaves. Epiphytes cling to the supporting tree by means of roots that act both as holdfasts and water-absorbing organs. They do not take their nourishment from the

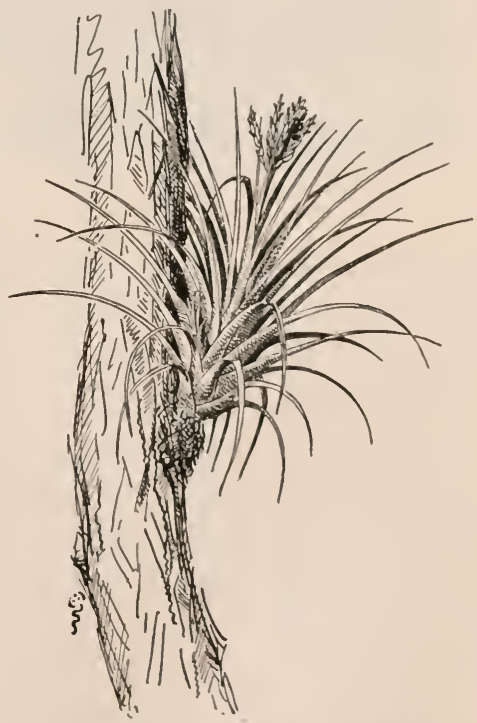

Fig. Io9. Florida epiphyte (Tillandsia). It belongs to the Bromelia or pineapple family. 


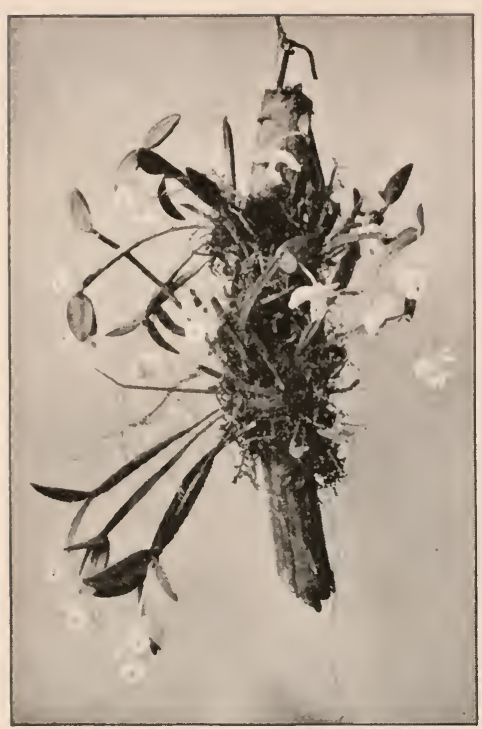

FIg. I ro. An epiphytic orchid.

plants on which they grow (page 249), but depend for their water upon the evenly distributed rainfall and for their mineral substances upon dust and the decay of the bark on which they live.

Epiphytes are pronounced xerophytes, for there is probably no habitat in which it is more difficult to maintain a water balance than the one in which they live. It is not surprising, therefore, to find that among the epiphytic plants of the West Indies there are several species of cactus. Among epiphytes there are many species of ferns, and many species belong to two families of flowering plants, the Bromelias and orchids. The Bromelias are related to the pineapple and have leaves of the same type. The orchids have flowers remarkable for their shapes and colors, and have the distinction of being the highest priced of all flowering plants. The long moss of Florida, a flowering plant, is perhaps the best known of American epiphytes. It is an extreme form and is devoid of roots. The roots of many epiphytes contain chlorophyll and assist in the manufacture of food.

Roots and transplanting. Only a few years ago it was thought impossible to transplant large trees or even mediumsized conifers. Today trees of large size are dug up, trans- 


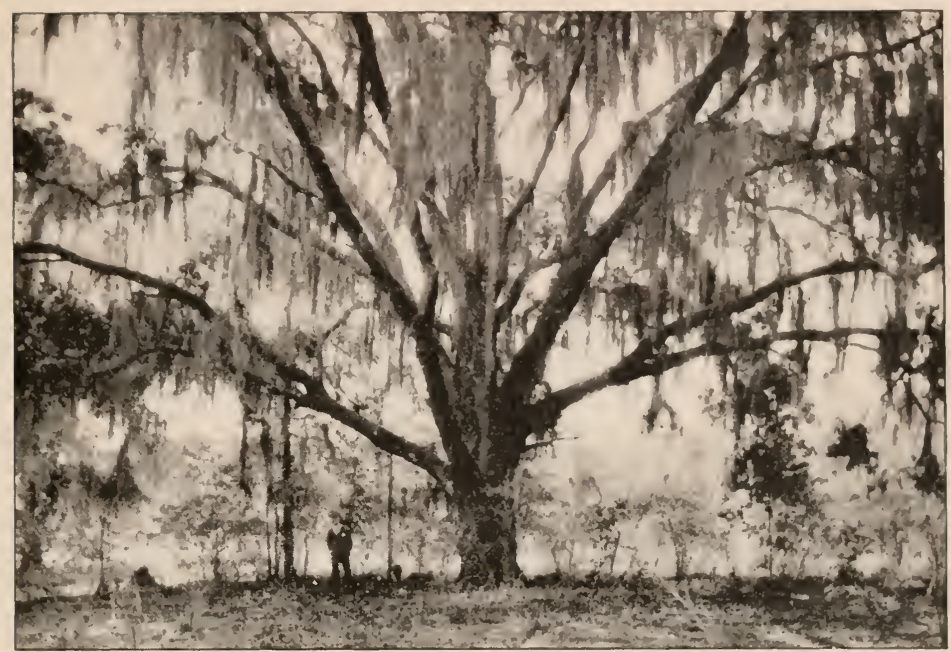

U. S. Forest Service

FIG. III. Live-oak tree draped with Spanish moss. This epiphyte, which is common along the Gulf Coast, has no roots. It is a flowering plant belonging to the Bromelia family.

ported many miles, and replanted successfully. Even whole hedgerows several feet in height are transplanted without injury. This advance in the art of tree moving is a fine example of the application of a knowledge of root physiology to practical problems.

We have learned that the absorbing part of the roots is mostly in the root-hair zone near the root tips. Formerly when a tree was dug up for transplanting, all the roots were cut off 3 or 4 feet from the base of the stem. This operation destroyed practically all the absorbing organs, and the tree could not absorb water from the soil until a new set of roots had developed. Meanwhile it suffered from extreme drought and not infrequently died. 


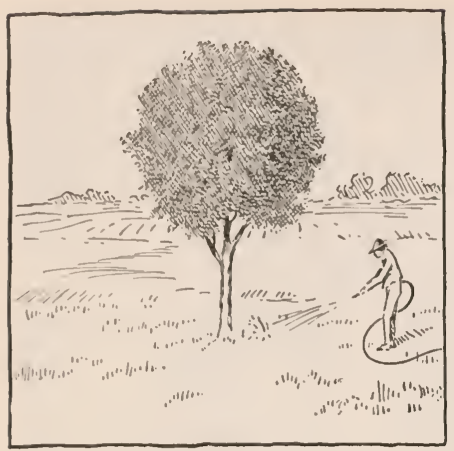

FIG. II2. By using great care to preserve the root system a tree may be transplanted even when in leaf. Some hours before the tree is lifted it is thoroughly watered in order that the leaves and other parts may have in them as large a supply of water as possible.

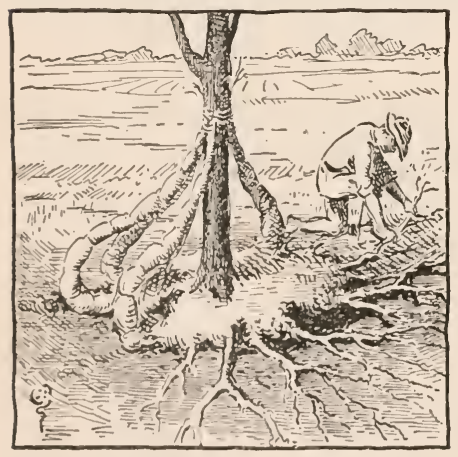

Fig. II4. The roots are wrapped to keep them from drying, and tied to the trunk of the trec. The natural environment of the roots is the moist soil, and it is very important that they be kept moist; even a few minutes' drying may be fatal to the delicate rootlets.

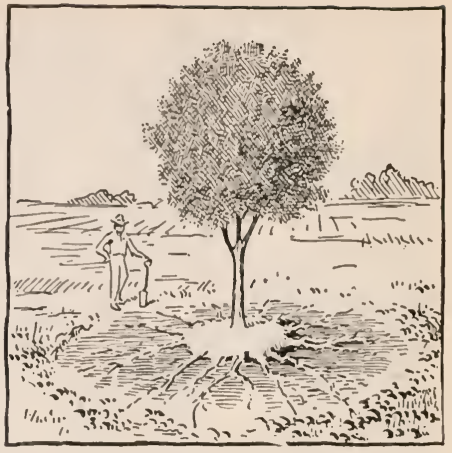

FIG. II3. The long roots are carefully laid bare, leaving a ball of earth close to the trunk of the tree. Before this is done the hole where the tree is to be planted should be made ready. It should be so dug that the tree will not be set deeper than it was in its original location.

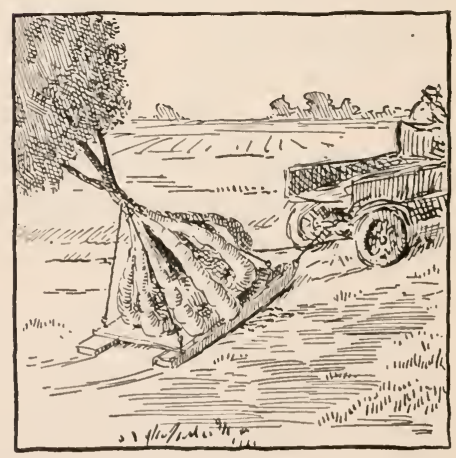

FIG. II5. The tree is placed on a sled and securely fastened. It is then hauled to the new location, where the roots are carefully spread out and covered with soil. Fertile topsoil and not the raw subsoil should be used for covering the roots, 


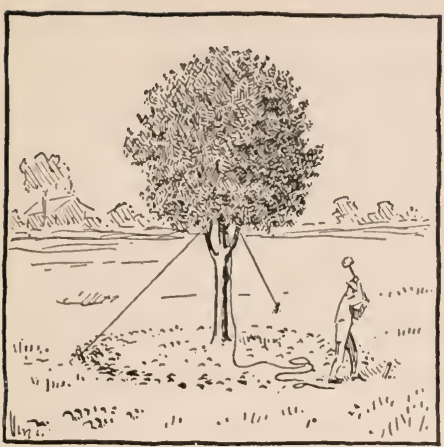

FIG. II6. The newly planted tree is supported by ropes or wires until the roots can take hold and anchor it securely. The soil should be packed firmly about the roots to facilitate the absorption of water and allow the quick development of rootlets and root hairs.

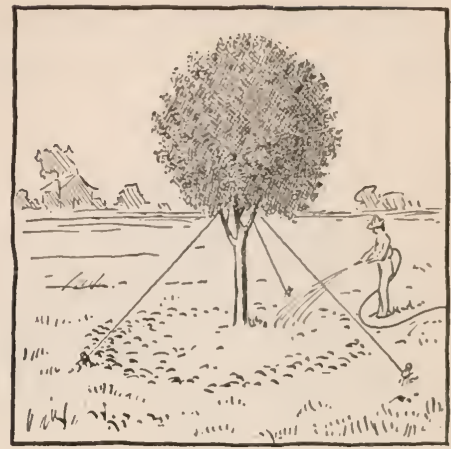

Fig. II7. The tree must be kept well watered (but not flooded) for a time, for many of the absorbing rootlets have been lost and there is danger that the leaves will not receive an adequate water supply. By this method large trees are successfully transplanted when in full leaf.

Success in transplanting is attained by gradually trimming the roots months before the tree is moved, and by loosening the soil near the tree so as to develop a mass of absorbing roots near the base of the stem. When the tree is lifted, the roots are not cut off, but as many as possible of them are carefully removed from the soil. The small roots of trees are killed by drying, and for this reason they are protected from wilting by being bound up in wet moss. Sometimes the trees are loosened somewhat in the autumn and moved during the winter, together with much of the frozen soil surrounding the roots. Successful transplanting depends upon reducing temporarily the loss of water by trimming the top, preserving the absorbing roots, and exercising care in handling both roots and stems so that they may not be injured. (See also page 55 .) 
Roots in relation to bacteria and fungi. The roots of many plants have bacteria or fungi growing about them or inside

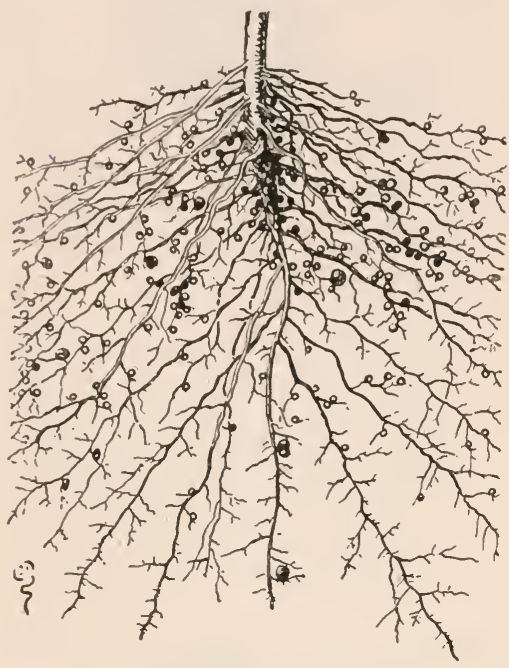

FIG. I 8. Roots of soy bean, showing nodules containing nitrogen-fixing bacteria. them. The best-known crop plants belonging to this group are the clover, cowpea, and alfalfa; their roots develop small nodules in which certain kinds of bacteria change nitrogen of the air into nitrogen compounds which may be used by the plants. More information about these bacteria will be found in a later chapter (page 258).

Many of our trees and shrubs have fungi surrounding their roots. The beech tree, for example, flourishes only when it grows under such conditions. The difficulty in transplanting azaleas, laurels, and rhododendrons from the woods to our lawns lies largely in supplying conditions favorable to the fungi that invest the roots. It is easy to supply the proper shade and water conditions for the shrubs, but it is difficult to furnish soil conditions favorable to the life of the fungi. The transplanting of these shrubs is therefore most frequently successful when they are planted in large bodies of soil brought with them from their natural habitat. Just how the fungi aid the plant is not understood; that they are essential is very clear.

Commercial uses of roots. The fleshy roots of the sweet potato, yam, turnip, carrot, beet, celeriac, and salsify are 
important sources of food. The sugar beet is the most important domestic source of sugar in the United States. The roots of sassafras, rhubarb, ginseng, aconite, and ipecac are used in medicine. In the past many other roots were collected for the same purpose. The roots of plants are used by man much less than are stems and leaves. Perhaps roots are in general less useful; but the failure to utilize them more generally is in part accounted for by the difficulty of harvesting them and by our lack of knowledge concerning uses that might be made of them.

\section{PROBLEMS}

1. What states produce sugar from the sugar beet?

2. What states produce sweet potatoes?

3. How are roots made use of in the jetties at the mouth of the Mississippi River?

4. Why do trees along city streets frequently die when the street is paved or cement walks are laid inside the curb?

5. Why does the filling in of wooded land with a 3 or 4 foot layer of soil kill trees?

6. What flood-plain trees will continue to live in an area that is flooded with water for a year or more, as by the building of a dam? Why? Why do other trees die? 
1. Examine and make diagrams of several types of flower clusters, such as spike, catkin, umbel, raceme, and panicle.

2. Draw several flowers of different types. Label pistil, stamen, corolla, calyx, petal, sepal, receptacle, peduncle, anther, filament, ovulary, style, and stigma. Note differences between monocot and dicot flowers.

3. Examine pollen under a microscope, and germinate grains in sugar solutions. Try various strengths from 5 to ro per cent. Place pollen in a drop of the solution on a micro slide, cover with cover glass, and keep in a moist chamber. The pollen tubes develop by the following day.

4. Examine the stigmas of flowers for pollen that has germinated.

5. Soak different kinds of seeds in water and study them, noting embryo, endosperm, seed coats, cotyledons, hypocotyl, and plumule.

6. Study mature pine cones with seeds in place, noting the number of the seeds and their relation to the scales. Dissect a seed and note the seed coats, endosperm, and embryo.

7. Germinate some seeds and follow the stages in germination.

8. Collect as many kinds of fruits as possible. Study them from the standpoint of their contents, their origin from the flower, and their methods of dispersal. Draw as many as convenient.

9. Field trip to study the variety of flowers and flower clusters.

10. Methods of pollination may best be studied in the field. Note the kinds of insects that visit a particular kind of flower. Compare these insects with those that visit another kind of flower. Is there a noticeable difference in the forms of the two flowers? in the location of the pollen? in the location of the nectar? Does this account for the difference in the kinds of insect visitors?

11. Examine several varieties of flowers and note whether or not the stamens shed their pollen when the stigma is ripe, before it is ripe, or after. Does the relative time at which the stigma and pollen mature favor self-pollination, insure it, make it difficult, or prevent it? 


\section{CHAPTER SIXTEEN}

REPRODUCTION IN FLOWERING PLANTS: FLOWERS, FRUITS, AND SEEDS

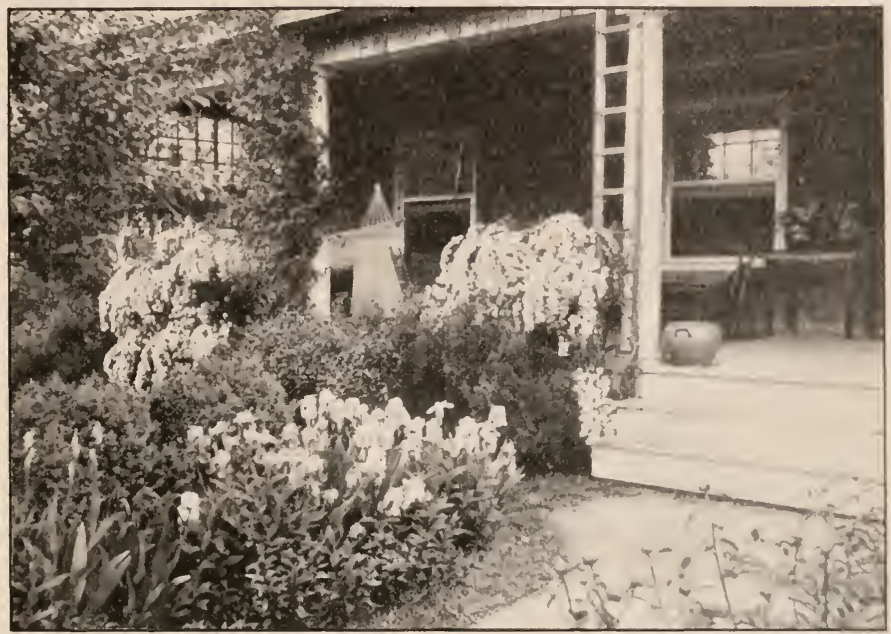

FIG. II9. The plants in flower have reached the reproductive phase of their life.

THE development of roots, stems, and leaves makes up the first period of the life of a flowering plant. These parts form the vegetative body of the plant, and are all primarily concerned, as we have seen, with the production, distribution, and accumulation of food materials. The period of growth of the vegetative parts and of activity in connection with the food supply is the mutritive phase of the plant's life.

The development of flowers, fruits, and seeds takes place during the second phase of the plant's existence, the reproductive phase. The foods that have previously accumulated in various parts of the plant are, to a large extent, transferred; they are used in the building of the reproductive structures 
and in supplying the seeds with the store of nourishment needed for germination and for the early growth of the seedlings. The reproductive phase of the plant's life is essentially a food-transferring and food-consuming one; it begins with the production of the flower and ends with the maturing of the seeds. In perennials these phases are not distinct as they are in annuals and biennials.

The flower. The flower is a specialized shoot, whose end is the production of seed. Commonly the word "flower" is associated with the brightly colored parts that make many of our garden and house plants so attractive. But here we shall include under the term the simple structures associated with seed production in plants like the grasses, poplars, and birches, that have merely scalelike leaves and bracts inclosing the reproductive parts. In the conifers the seeds are produced on scale leaves arranged spirally in cones. These cones may be looked upon as a lower type of flower, structurally very different from the flowers of the monocots and dicots.

Flower clusters. The arrangements of flowers on stems are so varied in different plants that it is quite beyond the scope of this book to describe the many kinds of flower clusters. In many plants the flowers occur singly at the ends of stems or lateral branches, as in the tulip and in some varieties of roses. In other plants they are arranged in groups, as in the spike of the common plantain and cat-tail ; the catkin of the willow, alder, and oak; the umbel of the carrot, onion, and milkweed; the raceme of the snapdragon, spring beauty, black locust, and larkspur; and the composite head of the sunflower and chrysanthemum. The head of wheat and the ear and tassel of corn are other forms of flower clusters. Plants like the yucca, curly dock, rhubarb, broom corn, and hy- 
drangea furnish examples of large and much-branched flower clusters. A stem which bears a single flower or flower cluster is the flower stalk or peduncle. The branches of the peduncle

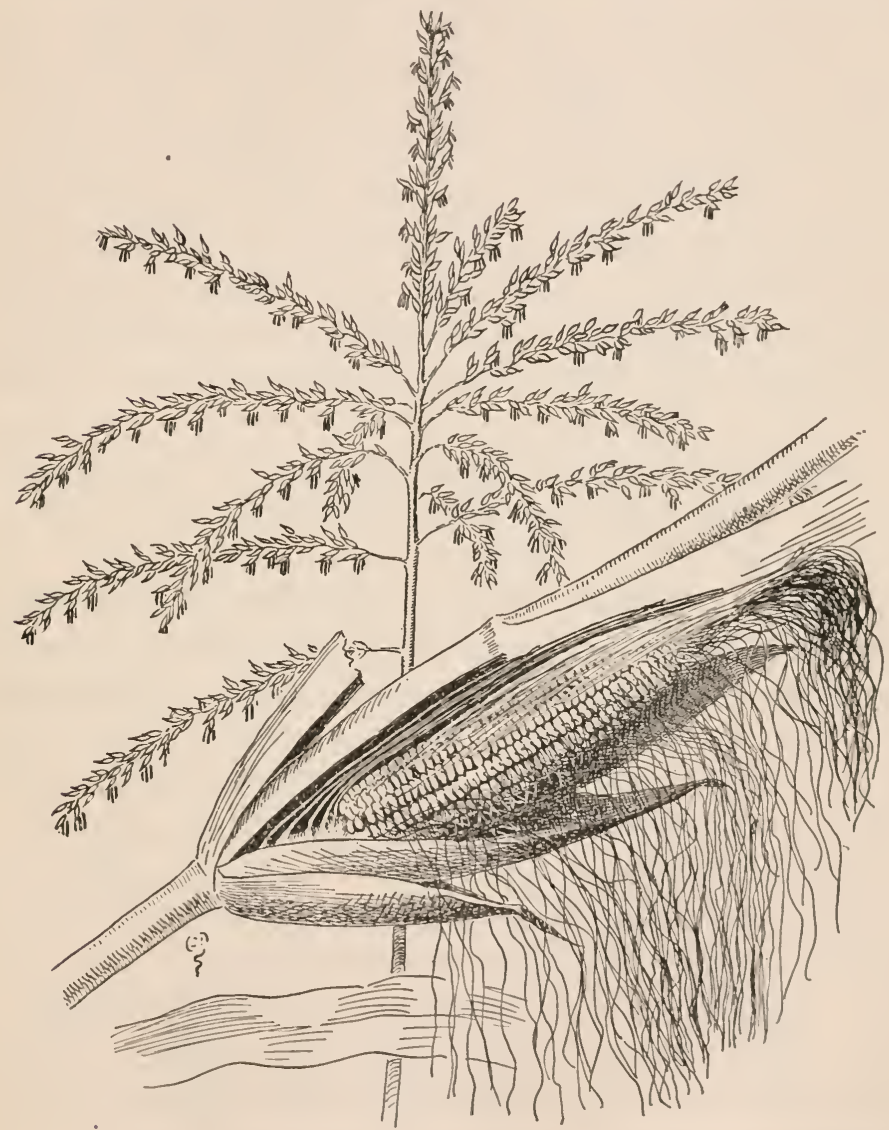

Fig. 120. Flowers of the corn plant. The panicle of staminate flowers (tassel) is shown above. Below are the pistillate flowers arranged in a spike (ear) inclosed by sheathing leaves. The only part of the pistillate flowers exposed to the air is the long style (silk). 
which bear the individual flowers in a flower cluster are called pedicels.

The.parts of the flower. The apex of the flower stalk is called the receptacle. It is often enlarged and serves as a place of attachment of the various floral organs. The outer whorl of scales or leaflike organs is the calyx. It usually is green in color, and in the bud stage it completely incloses the flower. The individual parts of the calyx are called sepals. Next inside the calyx is a whorl of white or brightly colored leaves that make up the corolla. The several parts of the corolla are called petals. The corolla is usually the attractively colored part of the flower; but in some flowers, as in the tulip and clematis, the sepals have the same coloring as the petals. The calyx and corolla are often spoken of as the floral envelopes, because in the bud they form a wrapping, or envelope, for the inner parts of the flower.

Inside the corolla is a group of stamens, each composed of a stalklike filament and an anther that contains the pollen. The center of the flower is occupied by one or more pistils, each made up of an ovulary, style, and stigma. The ovulary is the enlarged part of the pistil that contains the ovules, which develop into the seeds. The style is the stalk above the ovulary that bears at its summit the stigma. The stigma is usually an enlarged surface, which secretes a sticky, sugary solution in which the pollen grains are caught and germinated. The pistils and stamens are called the "essential organs" of the flower, because they produce the ovules and pollen which are the two elements necessary for the production of seed.

The variety of floral structures. The above is a description of a typical flower; but in the plant world we find an 
almost endless variation in the number, form, size, color, and arrangement of these parts. In some flowers the calyx or the corolla may have their parts united into a tube, or one or both may be wanting. Or the flowers may lack either pistils or stamens. For example, the soft maples bear pistillate flowers on some trees and staminate flowers on others, and the corn has staminate flowers in the tassel and pistillate flowers on the lower lateral branches or ears. It is not our purpose to name and describe here the many different variations in floral structure; a visit to a conservatory or a tramp through the near-by fields and woods is a far more effective way of securing an idea of the great diversity of flowers.

Pollination. If the stamens of a lily or nasturtium are examined, the pollen is found to be a fine yellow powder, which under a microscope will be seen to be composed of a multitude of small grains. For the production of seed it is necessary that the pollen grains shall be carried to the stigma. This transfer is called pollination. In some plants the pollen

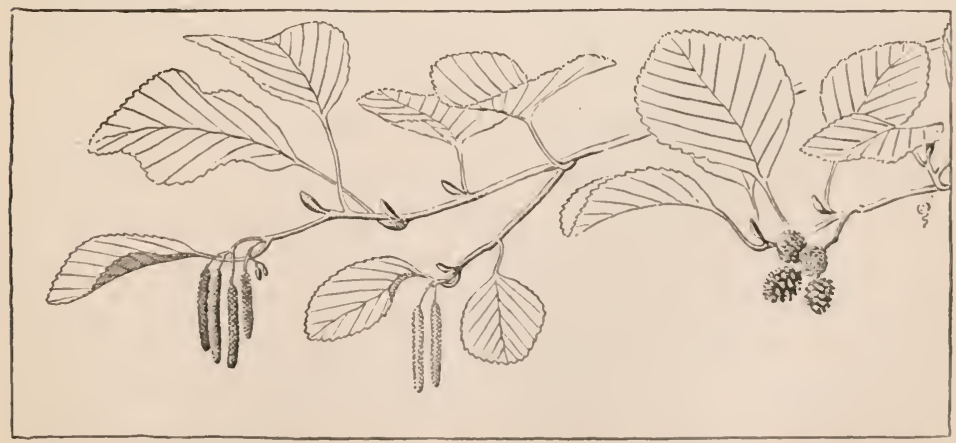

FIG. I21. Flower spikes of the alder. The two clusters on the left are staminate spikes; on the right the mature pistillate spikes are shown. 
merely falls by gravity on the stigma. Wheat and oats are examples of plants that are pollinated in this way. In other plants, like the pines, elms, birches, oaks, rye, and corn, the pollen is carried by the wind. It is an interesting fact that the stigmas of wind-pollinated flowers are usually roughened by hairs, which probably make them more effective in holding the pollen.

In the case of most plants with conspicuous flowers, the pollen is carried by bees, flies, butterflies, and moths. As the body of one of these insects is rough or hairy, pollen grains become attached to it when the insect enters a flower. Then when the insect passes to another flower, some of the pollen from the first flower is brushed off on the stigma of the second. Thus pollination is brought about by the insects in the course of their visits to successive flowers. It is an advantage to the plant to have its pollen carried by insects directly from flower to flower instead of being blown about and reaching a stigma by mere chance. If the amounts of pollen produced by the pine, corn, ragweed, and other wind-pollinated plants are compared with the amounts produced by plants that are pollinated by insects, it will be seen that insectpollinated plants generally produce less pollen.

Why insects visit flowers. Insects do not visit flowers to carry pollen for the plants. They eat the pollen or feed their young on it, and they also secure nectar from the flowers. The nectar is a watery solution containing sugar, which is secreted by glands called nectaries. One or more of these nectaries is usually located near the base of the corolla, inside the flower. The insects visit the flowers, therefore, to secure food for themselves, but as they make their visits they brush against the stigmas and leave grains of pollen adhering 
to the plants, and in this way perform a service for the plants. The perfumes of flowers aid the insects in finding them, and conspicuous white or brightly colored parts of flowers may serve the same purpose. The massing of many small flowers in clusters and heads certainly makes them more conspicuous.

Cross-pollination. When a flower is pollinated with its own pollen or with that from another flower on the same plant, it is said to be self-pollinated. If the pollen comes from another plant, a flower is said to be cross-pollinated. In many plants it makes no difference whether the pollen comes from the stamens of the same plant or from those of another plant. In the common tobacco plant the pollen may be transferred to the stigma of the same flower, and seeds will be produced. In some plants, however, it is only when the flowers are cross-pollinated that sceds are formed. The sunflower is a good example of this kind of plant. In still other plants seeds that are formed after self-pollination are less vigorous than those formed after cross-pollination.

From the above statements it will be seen that cross-pollination is an advantage to some plants, and we find in flowers many arrangements that help to bring this about and to prevent self-pollination. Often the anthers do not shed their pollen at the time when the adjoining stigma is in condition to receive it. The pollen may be shed either before or after the ripening of the stigma. In such plants there is little possibility of the stigma's being pollinated from the stamens of the same flower. So, as insects go from one flower to another they transfer pollen from flowers in which the pollen is ripe to flowers in which the stigmas are ripe. This favors cross-pollination.

It is exceedingly interesting to study the various other 
mechanisms that favor cross-pollination, but it should be done in the field or with the flowers in hand. In the white lily the stigma is out of reach of the insects when the pollen is shed. In other plants the pistillate and staminate flowers may occur on different individuals, or on different branches of the same plant. In primroses and bluets the stigmas and stamens each have two different lengths; the flowers on one plant have long styles and short stamens, while the flowers on another plant have short styles and long stamens.

The most remarkable cases of cross-pollination by insects are those in which a particular species of insect is necessary for the pollination of a plant. Such relations exist in the yuccas and in some orchids. In the absence of the particular insect, pollination and seed production fail. Yuccas may be grown in our Northern states, but in certain localities they fail to produce seeds because the moth (Pronuba) needed to pollinate the flowers does not live there.

Formation and growth of the pollen tube. A second step essential to the production of seed is the germination of the pollen and the formation of the pollen tube. After a grain of pollen is placed on the stigma, a microscopic tube develops from its side and grows downward among the cells of the stigma and style. At the time of shedding, the pollen grain of most flowering plants contains three cells. One of the three is active in the formation of the pollen tube; the other two are the sperms or male cells.

The stigma, as we have seen, secretes a sticky fluid containing sugar, acids, and other substances. The pollen germinates best in the fluid secreted by the stigmas of the same kind of plant, and it usually germinates imperfectly or not at all on the stigma of a different kind of plant. Perfect 
pollen tubes sometimes develop, however, following pollination from related species. The seeds produced by such crosses

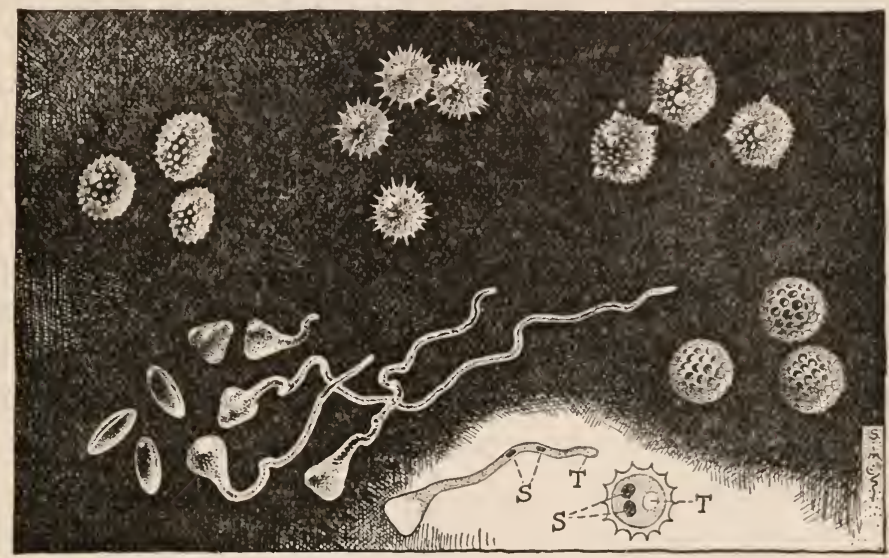

Fig. I22. Pollen grains and pollen tubes. $S$ is the two sperms or male cells, and $T$ the tube nucleus.

often give new forms of plants that are different from both parents.

After germination of the pollen, the pollen tube grows downward through the stigma and style to the ovule, or young seed. Usually this is but a short distance. In corn, however, the silk is the style and stigma, and the pollen tube must grow several inches or a foot down the silk to the ovule below. As the pollen tube lengthens, the sperms pass down the tube.

Fertilization. Inside the ovule there is an oval, saclike body which contains several cells. One of these is the egg cell, or female cell. At the beginning of fertilization the pollen tube grows into the ovule and discharges the two sperms into the sac in which the egg cell lies. One of the sperms unites with the egg cell. This union of the sperm, 
or male cell, with the egg, or female cell, is the act of fertilization.

The fertilized egg immediately begins to develop ; that is, it grows and divides into a large number of cells, and from it eventually comes the embryo or young plant that is found within the seed. Fertilization is the essential part of sexual reproduction both in plants and animals, and it marks the actual beginning of a new generation. After the egg is fertilized, it is able to develop into a new plant or animal of the same kind as its parents. It should be understood that the sperms from one pollen tube fertilize the egg in only one ovule, and that to fertilize all the eggs, as many pollen tubes must
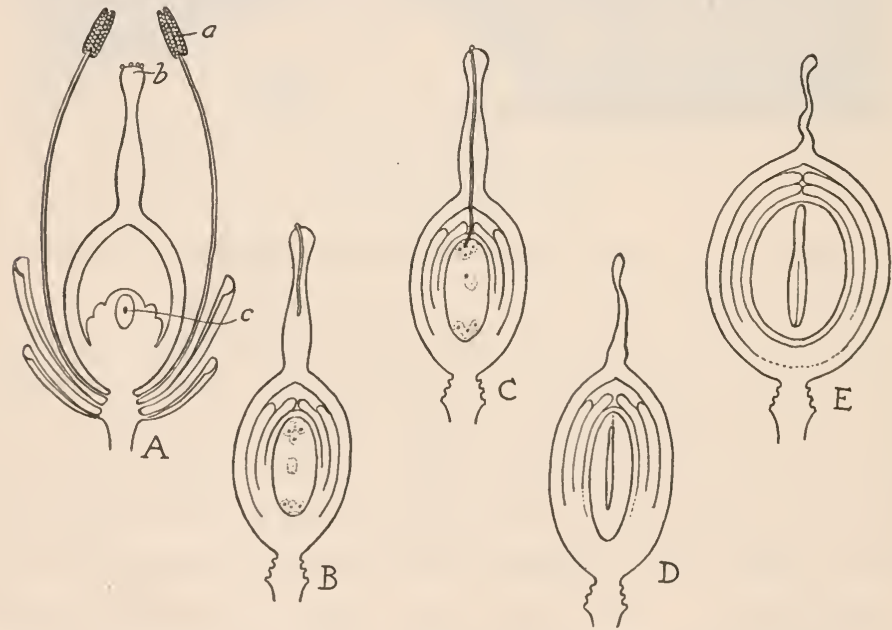

FIG. I23. Diagram to illustrate stages in the reproduction of a seed plant. $A$ shows pollen grains $(b)$ from anther $(a)$ on top of stigma; $B$ shows a stage in the growth of the pollen tube and the formation of the egg cell; $C$ is the stage when the pollen tube has reached the egg and sperm and egg unite; $D$ shows the formation of the embryo plant within the seed; and $E$ shows the further development of the embryo and the maturing of the seed coats. The young plant thus formed and incased may remain alive for years within the seed. 
grow down through the style as there are ovules in the ovulary below.

The seed. The seed is the final product of pollination and fertilization. Its complete development ends the rôle of the flower. The essential part of the seed is the embryo, for it is the embryo that will later produce the seedling; and in order to supply the embryo with nourishment during the early stages of growth, food from the parent plant is accumulated in the seed. This may either be stored inside the embryo itself, as in the bean; or it may be stored in the tissue surrounding the embryo, as in the castor bean and corn. The food-containing tissue surrounding the embryo in many seeds is called the cndosperm. Since the seed carries the plant over the winter or through an unfavorable season, the embryo with its food supply is protected by the seed coats, one of which is usually hard and resistant.

The three constituents of a seed, then, are (I) the embryo or young plant, (2) the food supply, either inside the embryo or in the endosperm, and (3) the seed coats or protective covering.

The structure of seeds. Although seeds vary as much in form as do other plant organs, the different arrangements of the three essential parts may be illustrated by a castor bean, a bean, and a grain of corn.

In the castor bean the seed coats consist of a hard outer layer and a thin inner membrane. These inclose an endosperm, which is a mass of cells containing food in the form of starch, oil, and protein. Within the endosperm lies the embryo, ready to grow when favorable conditions for germination come. The embryo consists of the hypocotyl and two cotyledons, with a small bud between the cotyledons, called 
the plumule. The cotyledons are the first leaflike organs of the plant. The hypocotyl is the first stem, and the plumule

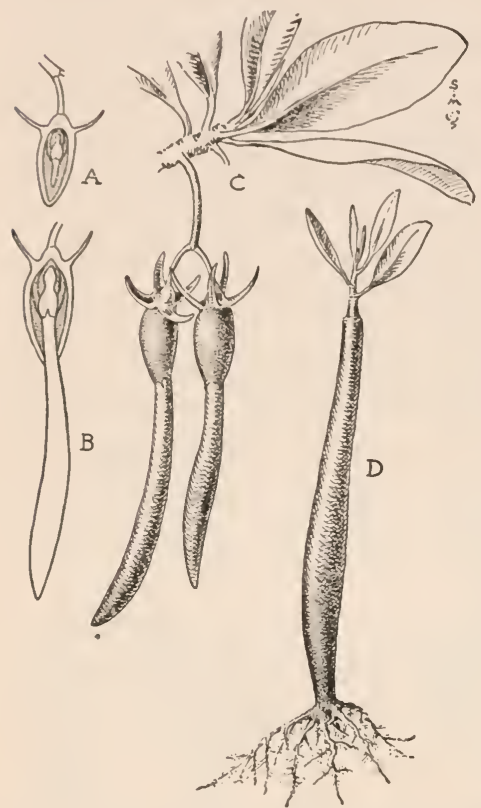

FIG. I24. Development of mangrove seedlings. This small tree grows on soft mud flats in the tropics and semi-tropics. The seed $(A$ and $C$ ) germinates while still attached to the tree and forms an embryo a foot or more in length. The embryo finally drops endwise like an arrow into the mud and starts a seedling $(D)$. is the first bud. No root is found in the embryo; but when the seed germinates the hypocotyl elongates, and from its end the primary root develops. The cotyledons at first absorb food from the endosperm and later expand into photosynthetic organs, which become green when exposed to the light. The plumule grows upward to form the stem. All these early changes are made at the expense of the food in the endosperm.

The bean seed consists merely of the embryo with a seed coat about it. The food in this seed has already been absorbed into the embryo and stored in the greatly thickened cotyledons; that is, the young embryo has continued its growth in the seed until it has all the food inside itself. The parts of the embryo are the same as in the castor bean, but the cotyledons are thick and contain a great supply of food for the young plant. The bean is an example of a large class of plants, including the pea, squash, 


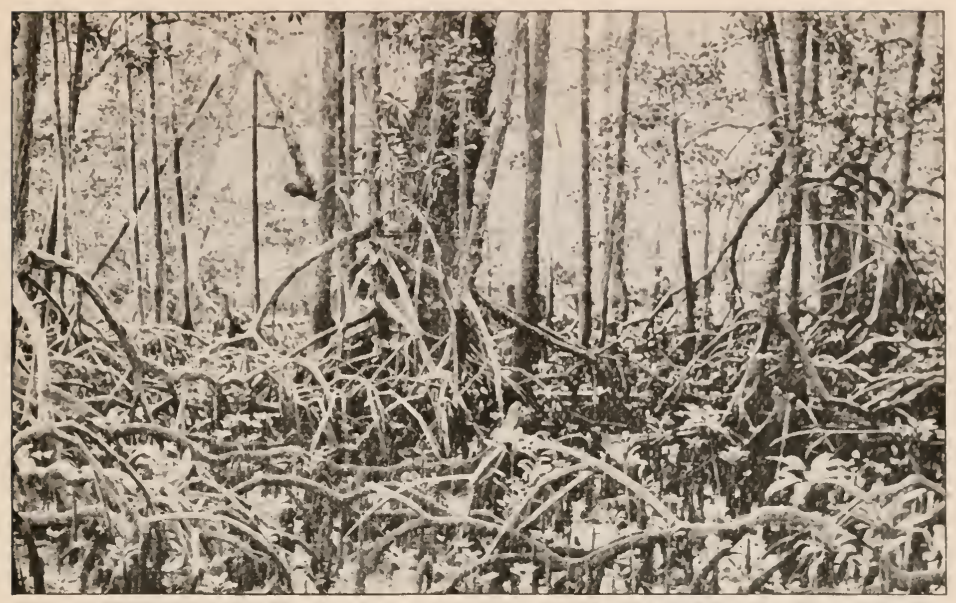

Bureau of Scicnce, P.I.

FIG. I25. A mangrove swamp. Note the prop roots which support the trees, and the young plants in the foreground which have dropped from the overhanging branches.

and pumpkin, in the mature seeds of which the endosperm is lacking.

A grain of corn is an example of a third kind of seed. In it there is a large endosperm with a small embryo placed at one end of it. The embryo differs from the embryos of the bean and the castor bean in that it has only a single cotyledon, wrapped more or less around the hypocotyl and plumule. In germinating, the hypocotyl grows downward, and the primary root develops from its tip. The plumule grows upward to form the aërial shoot. As in the castor bean, the cotyledon is the absorbing organ through which the foods in the endosperm enter the young plant.

The flower and embryo in monocots and dicots. In discussing the subject of stems, attention was called to the fact 


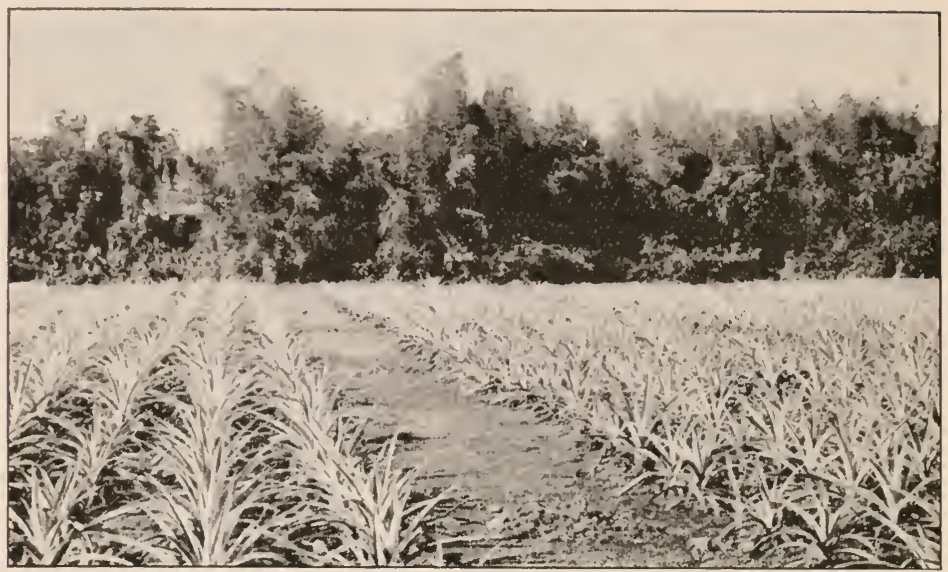

Bureau of Agriculture, P.I.

FIG. i26. A pineapple field. The pineapple fruit is an enlarged fleshy flower cluster.

that flowering plants are divided into two great groups, the monocots and dicots. The monocots have parallel-veined leaves; the bundles of the stem are closed (have no cambium); and the bundles are not arranged in a circle. The dicots include forms with net-veined leaves; the stem bundles are open (have a cambium); and they are arranged in a circle.

The terms "monocot" and "dicot" (or, as they are frequently written, "monocotyledon " and " dicotyledon") are based on the apparent number of cotyledons in the embryo, whether there are one or two. Any one who has watched plants beginning to grow in a garden will recall the two cotyledons of the bean, pumpkin, sunflower, and radish, raised above the soil. It will also be recalled that these plants have net-veined leaves. The cotyledon of a monocot is usually an absorbing organ that remains below the ground in contact with the endosperm. 
The two groups differ in their flowers also. In the monocots the number of parts of the calyx and corolla is usually three, and the stamens and divisions of the pistil are three or some multiple of three. In the dicots the parts of the flower are typically in fives or fours, or in a multiple of these.

Thus the names "monocot" and "dicot" relate to the form of the embryo; but the two groups are further distinguished by differences in leaf venation, bundle structure, bundle arrangement, and flower plan.

The gymnosperms and angiosperms. We have previously learned that the conifers bear their seeds on scale leaves arranged in cones. A study of one of these cones shows that the seeds are formed on the upper surfaces of the scales and are

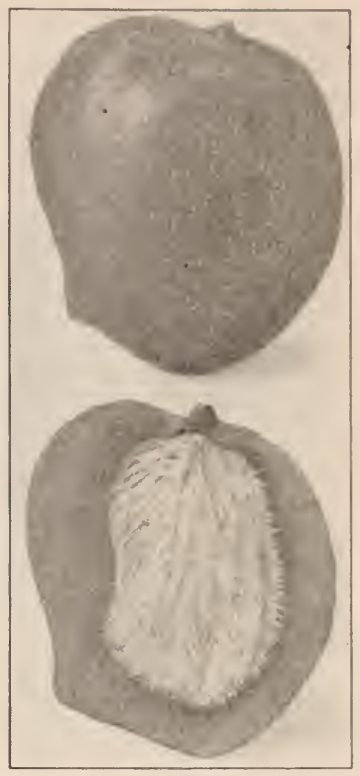

U. S. Dept. of Agriculture

FIG. 127. Fruit of mango. This much-prized fruit has hitherto been grown only in the tropics, but recently it has been introduced into southern Florida. not inclosed in capsules. When the scales mature and become dry, the cone opens and the seeds fall out. The word "gymnosperm " means " naked seed," and this is the group name for the conifers and all other plants whose seeds are not inclosed.

The angiosperms are what we usually call the flowering plants, although some of them, like the grasses and forest trees, do not produce flowers with colored parts. The seeds 


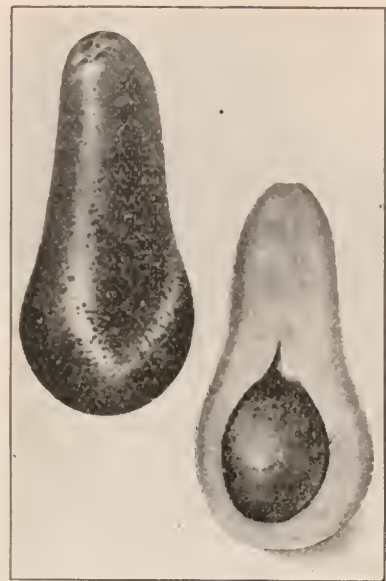

U. S. Dept. of Agriculture

FIg. I2S. Avocado, or alligator pear, a salad fruit now being grown in southern Florida and California.

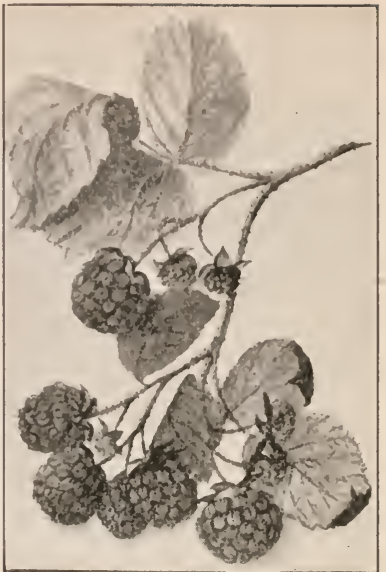

U.S. Dept. of Agriculture

FIG. I29. Raspberries, a fruit which is made up of a collection of fleshy pistils.

of an angiosperm, in contrast to those of a gymnosperm, are inclosed in an ovulary commonly called a pod or capsule, as in the bean, horse-chestnut, hickory nut, and watermelon. The term "angiosperm" means "hidden or covered seed," referring to the fact that the seeds are inclosed by a pod, fleshy fruit, or other covering.

The fruit. The term "fruit" is commonly used to designate a great variety of organs that are developed as a result of the flowering and pollination of plants. The direct result of pollination and fertilization is the production of the seed. The indirect effect of pollination is the further development of adjacent structures. Primarily the fruit is the enlarged pistil or ovulary; but in many cases the calyx and the receptacle also enlarge and form a part of the fruit - sometimes most of it. 
In the cucumber, watermelon, yucca, and tomato the fruit is the enlarged ovulary. In the okra, wild geranium, maple, hickory, and elm the entire pistil is involved. In the haw, apple, blueberry, and pear the calyx forms part of the fruit. In the strawberry, lotus, rose, and fig the fleshy part of the fruit is the enlarged receptacle. It is a remarkable fact that the fertilization of the egg in an ovule not only causes the egg to develop into a new plant (the embryo), but also causes other parts of the flower to enlarge and become fruit.

The grains like wheat and corn are both seeds and fruits, for the outer coat contains the ovulary wall as well as the seed coats proper.

Economic importance of flowers, fruits, and seeds. The economic value of flowers lies chiefly in their use for decorative purposes, but certain flower clusters like the artichoke and cauliflower are used as food. The fruit industry needs only to be mentioned to call to mind the vast scale upon which plants are grown for their fleshy edible fruits. It should be

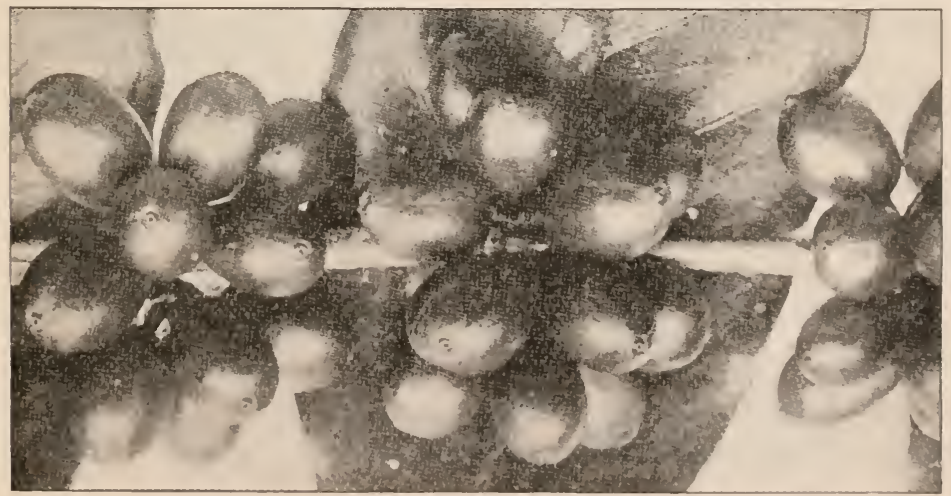

U.S. Dept. of Agriculture

Fic. I30. Coffee berries, natural size. Each contains two seeds. 


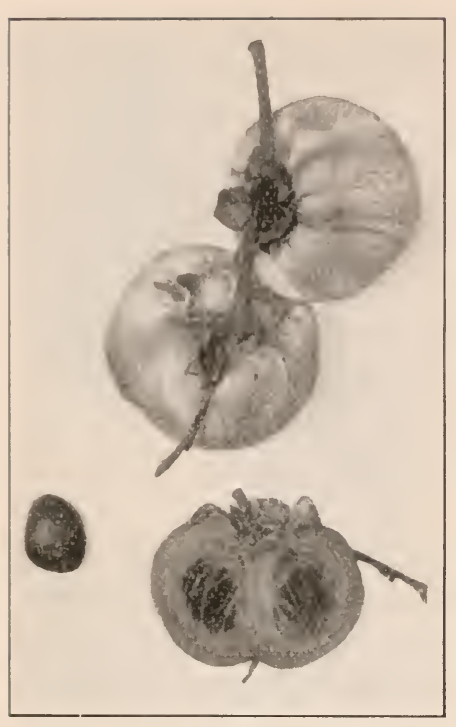

U. S. Dept. of Agriculture

FIG. I3I. Persimmon fruits. The persimmon grows wild over a large part of the Southeastern states, and improved varieties are now cultivated.

noted that ripe fruits are made up largely of water pleasantly flavored with sugar, dilute acids, and aromatic substances. The amount of food actually present is usually small. Fruits are valuable chiefly for the variety which they add to our diet. Through canning, preserving, and drying they are made available at all seasons of the year.

Seeds and grains supply the most concentrated foods derived from plants. They provide the larger part of the food of all human beings. Seeds of cotton, corn, and coconut furnish enormous quantities of oils used in the manufacture of various fats and soap, and nuts of various kinds are coming to be used more and more extensively as foods. Corn oil is widely used in the making of rubber. Flaxseed is the source of linseed oil, which is used in the manufacture of paints. From the grains we derive also starch, glucose, alcohol, ether, and many related organic substances. The seeds of the coffee and cacao plants supply pleasant and mildly stimulating drinks. The hairy covering of the cottonseed is the most important fiber used in the manufacture of cloth. 


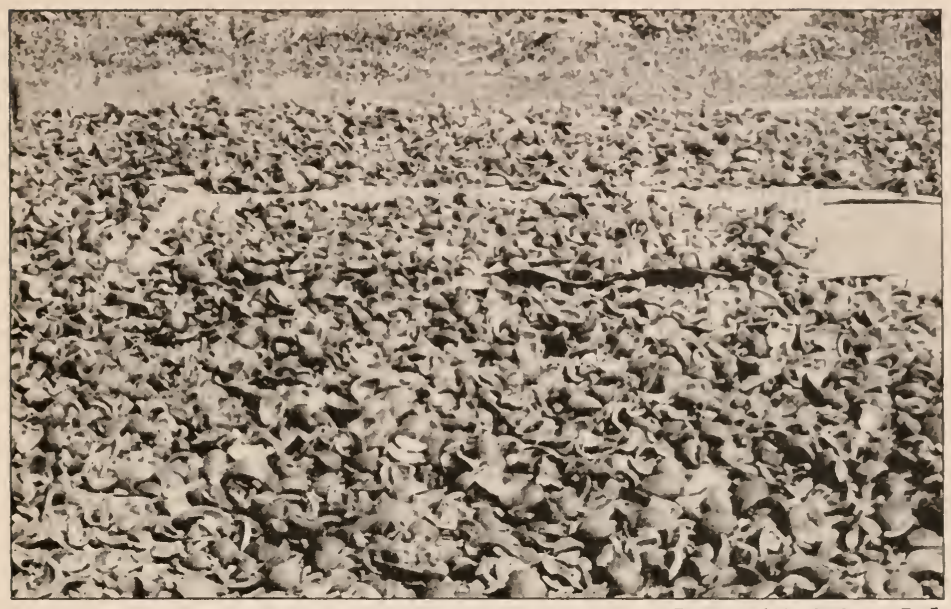

Bureau of Agricullure, P.I.

FIG. I32. Drying copra, the fleshy portion (endosperm) of the coconut seed. The coconuts are split and set in the sun, and the meats, after they shrink and become loose, are removed from the shells and placed on mats to dry. Copra is the source of coconut oil.

\section{PROBLEMS}

1. Why does a corn plant growing alone produce imperfect ears?

2. When cucumbers are grown in commercial greenhouses, how is pollination accomplished?

3. Why are large, heavy seeds of agricultural plants more desirable for planting than small, light seeds?

4. What common market "vegetables" are included in the botanical term "fruit"? 
Suggestions for Laboratory and Field Work to Precede Chapter Seventeen

1. Review and as far as possible illustrate with specimens the various methods of propagating plants vegetatively. Here may be included :

$a$. Bulbs, tubers, corms, and rootstocks.

$b$. Cuttings, as in the geranium and grape.

c. Runners and horizontal stems, as in strawberry and blue grass.

d. Leaf cuttings, as in Begonia and Bryophyllum.

$e$. Small lateral branches (suckers), as in carnation, pineapple, and banana.

2. Make a field trip to a commercial greenhouse or nursery to see how plants are propagated.

3. Report on the origins of some of the common garden vegetables and field crops. Information may be obtained in encyclopedias and in agricultural and horticultural textbooks.

4. Study a few weeds in the field, trying in each case to determine why the plant is successful in growing where it is not wanted. List the weeds, and put the results of your study in the form of a table:

\begin{tabular}{l|l|l|l|l}
\hline \hline Name of Weed & Propagated by & Reproduced by & Seeds Carried by & $\begin{array}{c}\text { Why Difficult } \\
\text { to Exter minate }\end{array}$ \\
\hline & & & & \\
\hline
\end{tabular}

5. What are the five commonest weeds of lawns? of cornfields? of pastures? of gardens? Why do different kinds of weeds occur in these several habitats? 


\section{CHAPTER SEVENTEEN}

\section{REPRODUCTION IN RELATION TO AGRICULTURE}

ThE reproduction of plants is of particular interest in agriculture because the reproductive structures themselves have an economic value. In a former chapter the importance of seeds and fruits as sources of food has been discussed. In this chapter we shall consider the relation of reproduction to three important phases of agriculture: plant propagation, plant breeding, and weed control. Propagation and breeding furnish better crop plants; weed control provides more productive fields.

Vegetative multiplication. In the discussion of stems (page I59) attention was called to the fact that one of the advantages in underground stems lies in the facility with which the plant may be multiplied. From rootstocks arise new terminal and lateral buds that later form new aërial shoots, and through the death of the older parts of the underground stems these branches become separate plants. Bulbs,

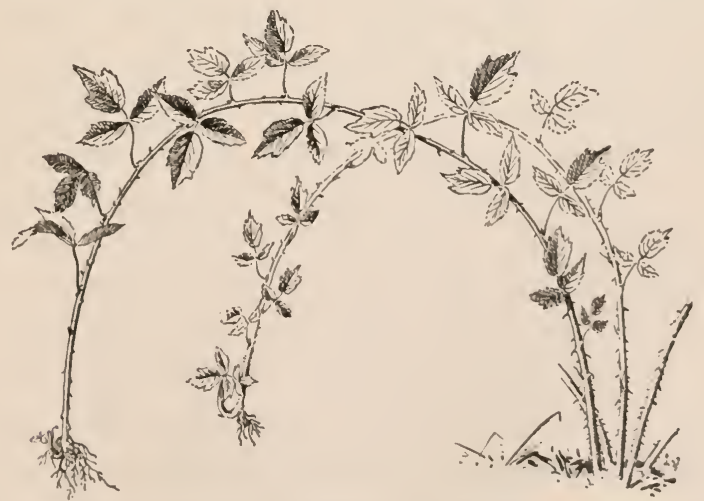

Fig. 133. Multiplication of the raspberry. The stems arch over and take root where they touch the ground, thus starting new plants. 
corms, and tubers bring about vegetative propagation in a similar way.

Plants may multiply from the aërial vegetative parts also.

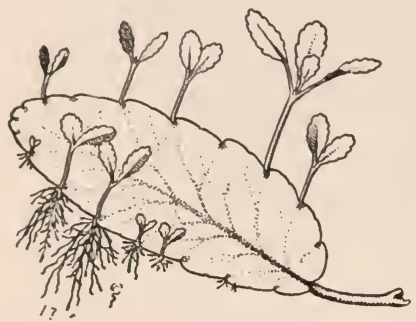

FIG. I34. Bryophyllum leaf, with young plants starting from the notches in the margin. The stems of the raspberry commonly bend over, and where they touch the ground they form buds from which adventitious roots and new upright stems develop. A grapevine will take root where a node comes in contact with the soil. In the walking fern (page 283) the tips of the leaves develop buds, roots, and new plants when in contact with the soil. The strawberry is an example of certain plants, including many grasses, which have horizontal branches (runners) on the soil surface that take root at intervals and produce new plants. In Bryophyllum, a weed in cultivated fields of the West Indies, the leaves when they fall to the ground develop new plants from the notches in their margins (Fig. I34).

These illustrations, which might be multiplied, show the importance of vegetative propagation in the increase and spread of plants. Among wild plants it is entirely possible that vegetative multiplication is as effective in spreading the plants as is reproduction by seeds. By the former method the young plant is able to start more vigorously than a seedling, because it is able to draw water and food materials from the parent plant until its own root and leaf systems are well developed.

Vegetative propagation of cultivated plants. In agriculture and horticulture, vegetative multiplication is relied upon for starting many cultivated plants. Potatoes, mint, horseradish, sugar cane, sweet potatoes, and certain varieties of 


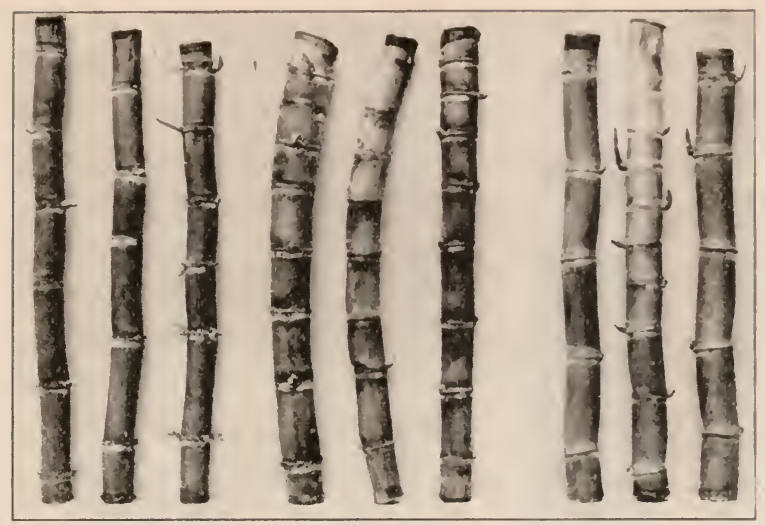

Bureau of Science, $P, I$.

FIG. 135. Sugar-cane cuttings. The plants are started in the fields from cuttings and not from seeds.

onion are examples of crop plants started in this way. Geraniums, coleus, willows, currants, grapes, and most ornamental shrubs are grown from cuttings. These cuttings are pieces of stem containing two or more nodes. Propagation by bulbs, corms, or rootstocks is the method commonly employed in starting lilies, tulips, hyacinths, irises, cannas, Caladiums, and chrysanthemums. Many of our fruit trees are multiplied by budding and grafting, which are specialized forms of vegetative propagation (page I32).

Vegetative propagation has been found advantageous in crop plants wherever its use is possible, (I) because the variability of the plants produced is much less than when they are propagated by seeds, (2) because some plants, like the sugar cane, banana, and horseradish, do not produce seed, and (3) because it saves time in securing the product, as a longer period is required for the maturing of plants started from seeds. In practical plant production, vegetative multiplication is as important as reproduction by seeds. 
Plant breeding. Reproduction in plants is the 1) foundation upon which the important industry of plant breeding is being built. Plant breeding is concerned with the improvement of economic plants and with the production of new plants of economic value. The activities of plant breeders are being directed toward four principal objectives: (I) the breeding of plants with more desirable products, as flowers, fruits, leaves, and fibers; (2) the breeding of new varieties which will increase the yield per acre; (3) the securing of varieties better fitted to particular climates and soils; and (4) the producing of varieties capable of greater resistance to diseases.

Plant breeding with these purposes is possible and profitable because (I) variations naturally occur among plants; (2) some variations are inherited and may be preserved by selection; and (3) different varieties and species may be crossed to produce hybrids having a still larger

FIG. 136. Timothy spikes. The heads show great variation in length and number of seeds produced, and by selecting seed from only the plants with long spikes the yield of seed may be increased several fold. range of variations than the parent plants or possessing new combinations of desirable qualities. 


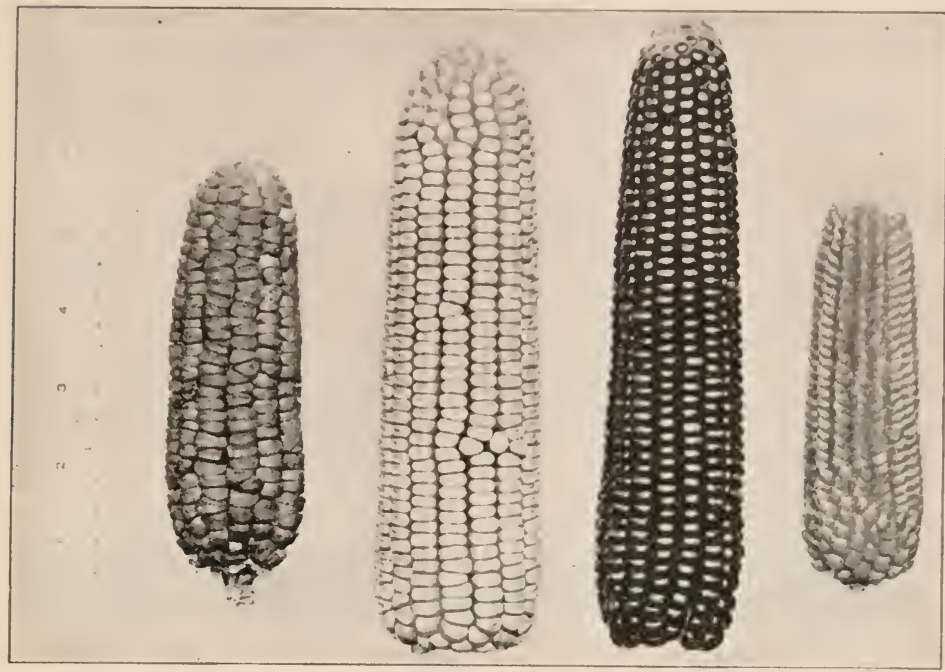

Bureau of Agriculture, P.I.

FIG. I37. Four types of Indian corn. From left to right: Sweet corn, which has a high sugar content and shrivels when dried; dent corn, which has a depression in the crown of each kernel due to the shrinking of the endosperm; flint corn, which has a hard endosperm and rounded kernels; and popcorn, which is a small, extremely flinty variety.

The methods used by the plant breeder depend upon the reproductive structures and habits of the particular plants with which he is working. For example, the means by which a plant is naturally pollinated will determine how it must be handled at the time of flowering to secure self-pollinated seed or cross-pollinated seed. Methods of vegetative propagation may be used to multiply the plant after a desirable variety has been produced. In this way the plant grower avoids cross-pollination and the variations that appear when many cultivated crops are grown from seed. The best ways of propagating particular crops vegetatively may be found 
described in recent publications devoted to plant production and plant breeding.

Variations. No two fruits, flowers, or other plant organs are exactly alike. The variations may be small or large, and there may be every gradation between the extremes of any character. The several thousand sunflowers that might be grown from a pound of seed would vary in height of stem, amount of branching, and size of flowers. Not only may there be variations in the structures of plants, but there may also be variations in the composition of the plant organs. For example, the great variety of colors, flavors, and other qualities in apples is due to variations in the composition of this fruit. The variation in each of these characters is quite independent of variations in the others. It is possible, there-

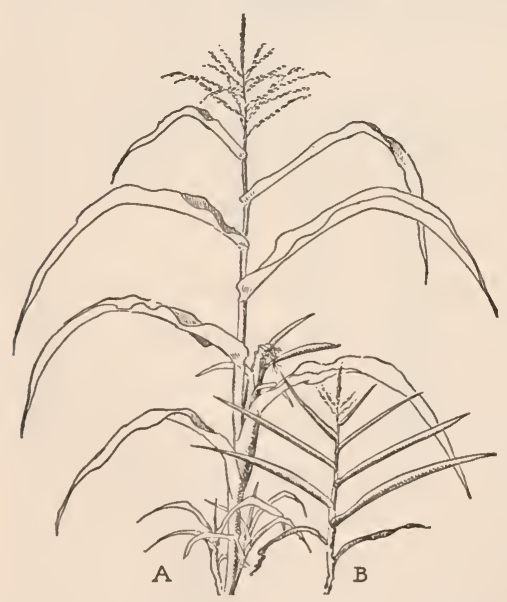

FIG. I38. Two plants of sweet corn of the same variety, one grown in poor soil and one in soil to which fertilizer was added. The differences in the plants are due to the environment. fore, to get all kinds of combinations of different characters, and by careful breeding and selection to combine many desirable qualities in a single plant. The Shasta daisy, for example, was made by breeding together the English, American, and Japanese daisies, and combining in one plant the pleasing foliage of the English species, the free-blooming habit of the American daisy, and the waxy luster of the petals of the Japanese plant. 


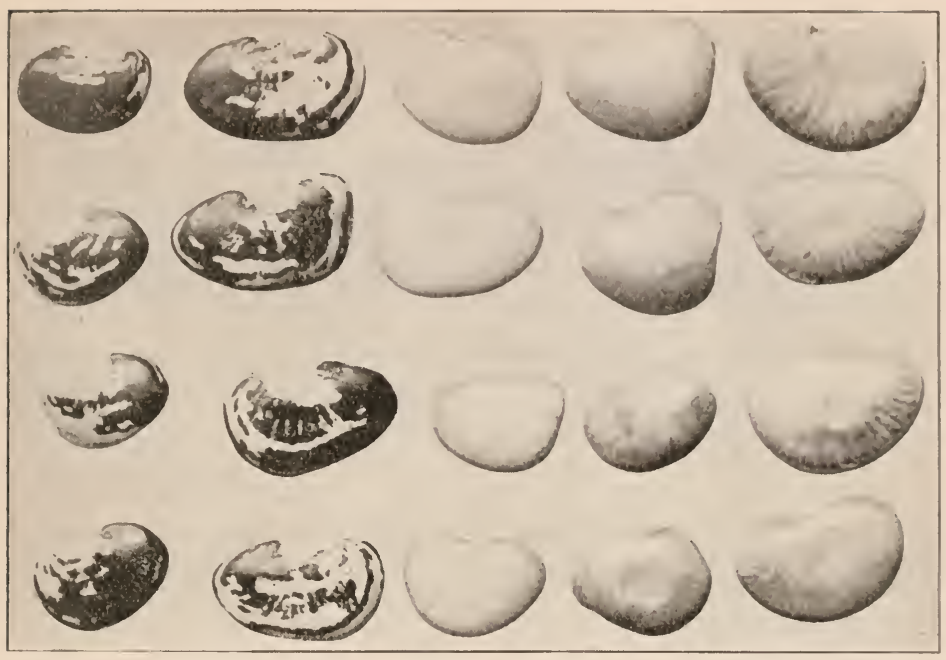

Bureau of Agriculture, P.I.

FIG. I39. Five varieties of lima beans, all grown in the same soil. The differences are due to differences in the plants.

Two kinds of variations. When a crop plant like corn is grown in rich soil and in poor soil, there are great differences in the size of the plants and in the yield per acre. These variations in size and yield are due to the environment. Even though the seed planted in each kind of soil is exactly the same, there will be a wide difference in the plants.

On the other hand, there are variations that are due to innate differences in the plants themselves. If dwarf sweet corn and large field corn be planted in the same soil and given the same treatment in every way, they will still be very different. It is a natural quality of sweet corn, as compared with field corn, to produce a smaller stalk and to have more sugar in the grain; and these differences will appear even when the environments are the same. We have, therefore, 


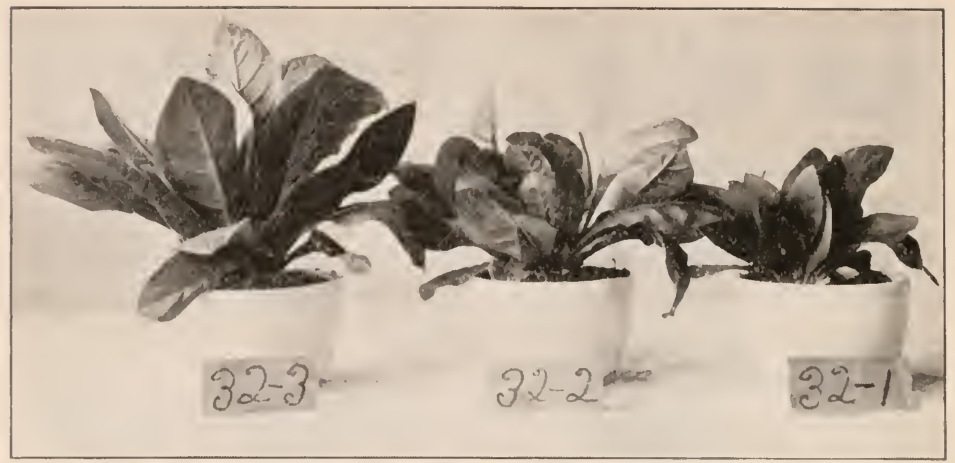

U.S. Dept. of Agriculture

Fig. I40. Tobacco plants of the same variety grown from large, medium, and small seeds, showing the relation between the size of the seed and the size and vigor of the seedling. Is the difference in size in the plants due to environment or to differences in the plants themselves?

two kinds of variations in plants: variations due to environment and variations due to differences in the plants themselves.

All variations are of interest to the plant breeder; but since he is trying to produce new plants that may be perpetuated, he is most interested in those variations which are inherited, - that is, variations which may be carried over from one generation to another. There is little or no evidence that variations produced by environment may be inherited; a variety of corn grown for many generations on rich soil would develop no larger plants on poor soil than would corn of the same variety that had always been grown on poor soil.

Mutation. Sometimes, among many thousands of individuals, a single plant appears which is markedly different from all the others. For example, a few years ago a sunflower was discovered that had some red pigment near the base of the otherwise yellow corollas. Among the millions of sunflowers 
that have been seen, this was the first one in which a red color was noticed. In some unknown way there was produced in this plant a red pigment not formed in other sunflowers. From the seeds of this plant there were developed other plants having red pigment in their flowers. Evidently the new character is inherited and these sunflowers have a chemical constitution which enables red pigment as well as yellow to be formed. The sudden appearance of the sunflower with the red pigment is an example of mutation. Individuals that first show new characters are called mutants (Latin: mutare, to change).

What the plant breeders have long known as "sports" are the rare mutants in which notable changes have occurred. They show new characters, and these characters are inherited. Consequently, their discovery is of the greatest importance.

The Concord grape was a mutant selected from among many seedlings, the others of which showed only the usual variations. The many modern varieties of tomato have been developed

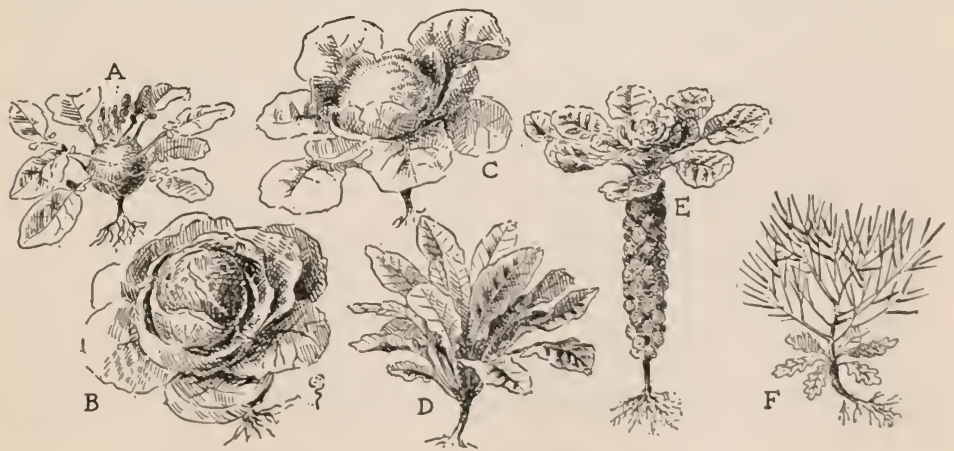

Fig. I4I. Varieties derived from the wild cabbage $(F)$, a native plant of Europe. $A$ is kohl-rabi, $B$ cabbage, $C$ cauliflower, $D$ kale, and $E$ Brussels sprouts. 
from mutations that occurred among the currant tomatoes or love apples grown for ornament in our great-grandmothers' gardens. The original fruits resembled large red currants. Today single tomato berries may weigh a pound. In color they may be red, yellow, or pink, and in shape they may be spherical, plum-shaped, pear-shaped, or flattened. They exhibit at least three types of leaves and two types of stems. The characteristics due to mutation are inherited, no matter what the soil and climatic conditions may be.

Mutations occur not only among plants grown from seed, but also among plants, or plant parts, developed from buds. These are called bud mutations, or bud sports. On fruit trees, one branch will occasionally produce fruit that is of different quality from the fruit produced on other branches. If the quality of the fruit is superior, these branches may be used in budding and grafting to preserve the new variety. Bud sports are comparatively rare, but it is estimated that at least several hundred horticultural varieties have originated from them. In this country the improved varieties of navel oranges have been secured entirely by this method. The Boston fern and its forty or more varieties originated in bud mutations from a wild tropical fern. In the potato and some other plants that are usually propagated vegetatively, bud variations are known to occur; but they are so rare and so difficult to discover in plants of this kind that they have not been of much practical value.

Hybridization. The crossing of two species or varieties of plants is known as hybridization. It is brought about by transferring the pollen from one to the stigma of the other. The plants grown from seed produced in this way are called hybrids. Hybrids may resemble one of the parents, or they 


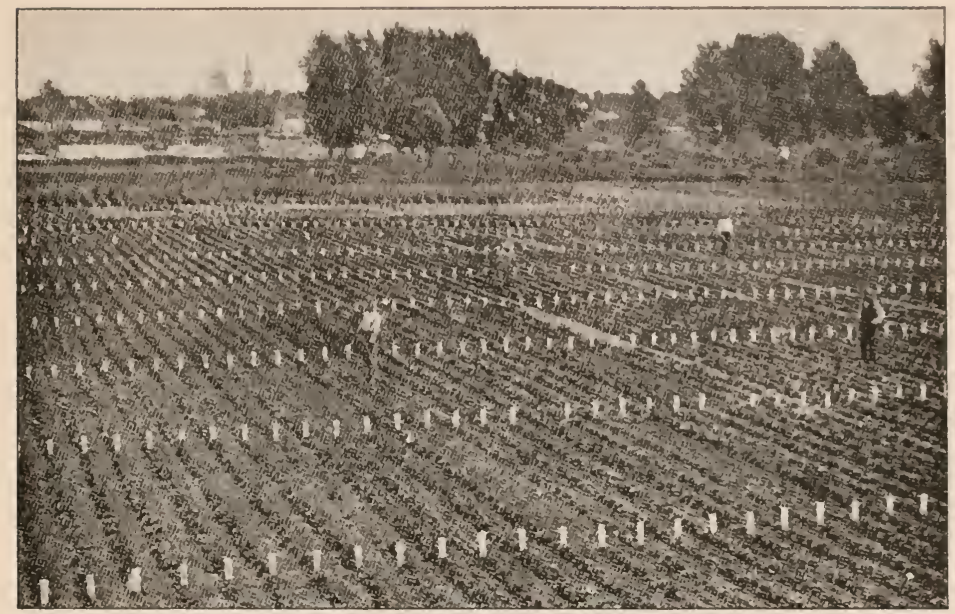

U.S. Dept. of Agriculture

FIG. I42. Vegetable trial grounds of the Office of Seed and Plant Introduction, United States Department of Agriculture, Washington, D. C.

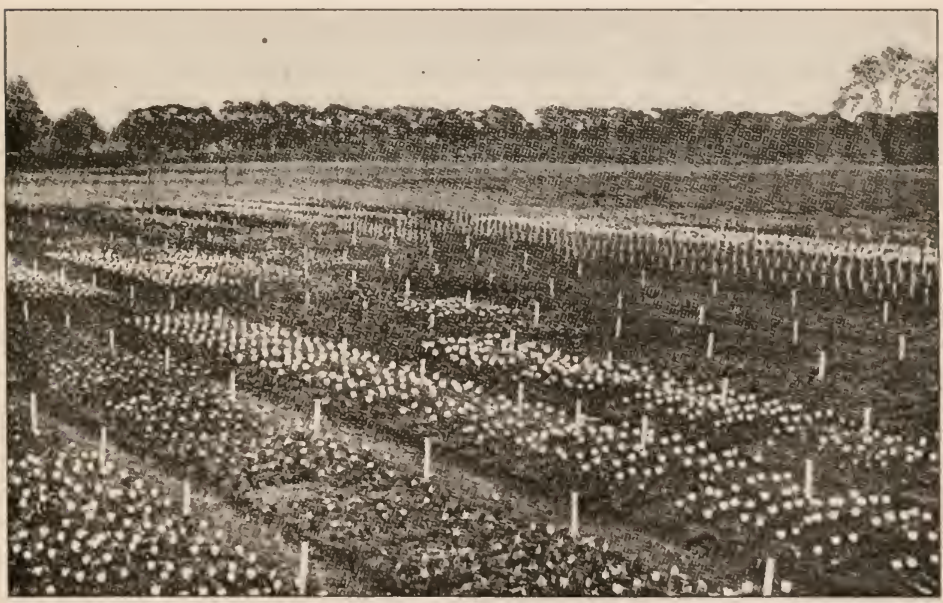

U. S. Dept. of Agricullure

FIG. 143. Bulb trial grounds of the Office of Seed and Plant Introduction, United States Department of Agriculture, Washington, D. C. 
may show some characters of each. In the second generation derived from crosses some show a wide range of variation, with all possible combinations of the characteristics of the parent plants. Successful hybridization, therefore, frequently increases the number of variations available for selection by the plant breeder.

In many plants hybridizing has a physiological effect which is of importance, in that it increases the vigor of the offspring. In sunflowers, for example, the hybrids secured by crossing the American sunflower and the Russian sunflower, neither of which was over ro feet in height, grew under the same conditions to a height of $\mathrm{I}_{5}$ feet.

Selection. Variations, mutations, and the results of hybridization furnish the material from which valuable new varieties of animals and plants may be selected. The plant breeder selects from among the hundreds or thousands of plants grown' in trial grounds those individuals that most nearly approach the form or quality desired. The seeds of these, plants are kept separate and are planted the following season. This process of selection may be repeated year after year until a large part of the progeny or all of. them show the quality aimed at in the selection. Some variations can be maintained only by continual selection of the best individuals. Others may soon become stable in character, and the plants are then said by plant breeders to breed true. In fruit trees, desirable varieties may be maintained by grafting and budding; and in other plants that can be propagated vegetatively, varieties may be perpetuated by cuttings, bulbs, tubers, and corms.

Weeds. Another way in which agriculture is affected by reproduction in plants is through the multiplication of un- 


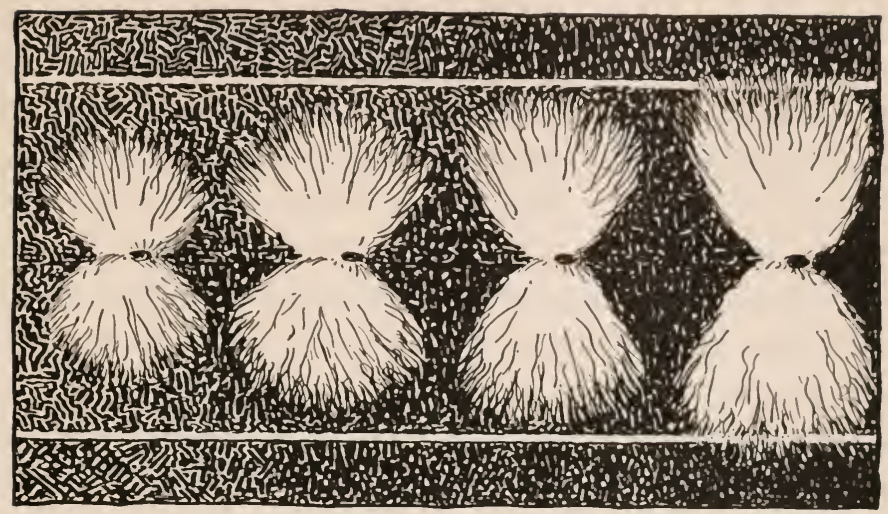

FIG. I 44. Fiber from new varieties of long-fibered cotton at the right, obtained by hybridizing and selecting progeny from the two forms producing the shorter fibers at the left. The hybrid offspring excel both parents in the length of fiber produced.

desirable plants. Weeds as a class are plants in which reproduction has reached the highest degree of efficiency. The sequoia may stand for the culmination of vegetative efficiency, the dandelion for efficiency in reproduction and dispersal. The dandelion produces good seed without pollination; if the stem is cut, the plant develops numerous new sprouts; if the root is cut into small pieces, each piece may sprout from either end or from both ends at the same time. The dandelion can thrive in a swamp, and it can withstand the droughts of a sand plain. The sequoia still occupies the comparatively small area in which it existed several thousand years ago. It reproduces very slowly, and it is restricted to a single habitat. The dandelion has in recent times spread to all parts of the world, and it occurs in most habitats, from the seashore to the alpine summits of mountains. In other words, it becomes adjusted to many environments. 
In the ordinary sense the term "weed " applies to any undesirable plant that reproduces abundantly and that adjusts itself to diverse habitats. In its broadest sense the term is applied to any plant growing out of place. Rye may become a weed in wheatfields. Red clover is very desirable in a field on the farm, but it becomes a weed when it springs up in a lawn. The most pernicious weeds, like the dandelion, cockle bur, Canada thistle, bindweed, and sand bur, are not desirable plants anywhere.

Weeds interfere with crop production. Weeds are undesirable and harmful, (I) because they use soil water needed by crop plants, (2) because they interfere with the growth of crops by shading them and by occupying the land, (3) because some weeds promote the spread of diseases and injurious insects, and (4) because some of the species found in pastures and grazing lands are poisonous, or harmful to cattle, or spoil the quality of milk, butter, and cheese by their persistent and unpleasant flavors. It is estimated that the average American farmer loses annually one dollar on every acre of his land through the damage done by weeds.

Weeds spread rapidly. How rapidly a weed may spread is illustrated by the history of the Russian thistle. It was introduced into South Dakota in imported flaxseed, in 1874 , and it had become a common weed by 1888 . In 1894 it had spread as far as Chicago. In 1900 it was reported in all the states and provinces east of the Rockies, from the Gulf of Mexico and Atlantic Ocean to Saskatchewan.

The control of weeds. In crops that are cultivated at intervals, most weeds can be controlled by turning under the seedlings as fast as they develop. In fields of wheat and other small grains the problem of weed control is more dif- 
ficult. By changing the crop from year to year so as to follow or precede the crop of small grain with a crop like corn, that is cultivated at intervals during its development, the weeds may to some extent be held in check. Grazing animals, particularly sheep, may aid greatly in removing weeds from pastures.

In grainfields, pasture lands, and meadows some success in weed control has recently been attained by the use of solutions of poisons, particularly copper sulfate and iron sulfate. The fields are sprayed with the poisonous solution while the plants are young. Grasses are not greatly injured by the spray and recover quickly, while weeds like the dandelion, wild mustard, and corn cockle are killed.

In order to control the weeds in sugar-cane fields, some fields are now covered with paper. The strong, spearlike shoots of the sugar cane break through the paper, but the weed seedlings do not. The paper is made from the pulp left after the sap has been pressed out from the cane. Formerly this pulp was wasted, but now it has been put to good use in the form of field paper.

Weeds should not be allowed to ripen seeds. The state laws which require that weeds be cut along the roads aim not so much at the removal of the unsightly plants from the roadsides as at the protection of farmers from the seeds.

Seed that is to be planted on any farm should be examined for weed seeds. If they are present, the seed should be either cleaned or rejected. Many a farmer plants his weeds with his grain. 


\section{PROBLEMS}

1. How much of the potato must be planted with each eye in order to get normal growth?

2. In what plants would it be profitable to select varieties for increased size of the flower cluster?

3. Why should field corn and sweet corn be widely separated when grown on the samę farm?

4. What are the most important things to know about seed, when buying it for the farm?

5. In a row of radishes a few will develop bulbous roots before the others. Would seed from these produce an earlier maturing crop than seed taken at random from the row?

6. In what plants would it be profitable to select for increased height of stem? 


\section{Suggestions for Laboratory and Field Work to Precede \\ Chapter Eighteen}

1. Make a field study of Protococcus to determine (I) where it grows, (2) its relation to light, moisture, gravity, and roughness of the substratum, and (3) how it is disseminated.

2. Make a field study of pond scums in a pond or small stream. In a jar, collect material for laboratory study; cover the bottom of the jar with mud from the bottom of a pond or stream. The amount of algx should be very small compared with the volume of water. If these algx are collected in late autumn, they may be grown in winter at a north window.

3. The forms of the cells and the methods of reproduction may be studied from fresh or preserved material. Particular attention should be given to the differences between vegetative multiplication, sexual reproduction, and asexual reproduction.

4. Dried specimens of Fucus, Laminaria, Sargassum, Polysiphonia, and Dasya will give an idea of the Brown and Red Algæ.

5. In early spring place some algæ in an aquarium with snails and young tadpoles. Note the rate at which the algæ disappear. If you can find frog or toad eggs, the experiment may be started with them. The water should be changed occasionally. 


\section{CHAPTER EIGHTEEN}

\section{THE ALGÆ}

THE plants that we have discussed in the preceding chapters are all seed plants, - plants with well-developed roots, stems, leaves, flowers, and seeds. In these plants the physiological processes - photosynthesis, digestion, absorption, conduction, accumulation, and reproduction - are carried on in tissues and organs that are specialized to varying degrees, and the plant body is a complex structure in which all the organs are mutually dependent. The seed plants make up by far the largest and most conspicuous part of the earth's vegetation, and it is with them that the word "plant" is ordinarily associated.

There are thousands of other plants, however, that are far simpler in structure. They usually pass unnoticed among the larger plants that crowd the landscape; but this does not imply that they are unimportant in the world of plants and animals. Indeed, quite the reverse is true. They play a very definite rôle in nature : they modify the earth's surface, supply food, and produce other effects which are of great consequence to the seed plants, to animals, and to man. In this and the succeeding chapters we shall make a brief study of these simple plants in order that our conception of the plant kingdom as a whole may be more complete, and also that we may gain some appreciation of the relations of man, of the animals, and of the complex plants to the lower forms of plant life. The first group that we shall study are the alge, small green plants that are very common in ponds, brooks, and pools, but which are found in other habitats also. The algae occur in all parts of the earth.

The simple structure of the algæ. The algæ are simple plants that consist of single cells, groups of cells, or masses of 
cells. In the lowest algæ the cells are quite independent of one another, and in most of them dependence among the cells of the plant body is very slight. That is, in most forms, organs corresponding to the roots, stems, leaves, conducting systems, and reproductive parts of higher plants are not found, and all the cells in the plant body are much alike. Under these conditions each cell must carry on for itself the processes of absorption, photosynthesis, digestion, assimilation, and respiration. So, when we speak of the algæe as simple plants, we mean only that they are simple in structure; in their physiological processes they may be very complex. They all contain chlorophyll and are therefore capable of manufacturing food. Some of them, however, grow better in water that contains organic matter, and these forms doubtless get a part of their food directly from the organic substances in solution in the water. A good type with which to begin a study of algæ is Protococcus, a very common and extremely simple form.

Protococcus. On the partly shaded, moist sides of trees, rocks, buildings, and fences everywhere, there occur patches that look as if they had been stained green. If a little of this stain is scraped off and examined under a microscope, it is seen to be made up of little rounded green cells. Each cell has a cell wall, cytoplasm, and nucleus. In the cytoplasm is a large green plastid which almost fills the cell.

When the cells are examined, certain of them will be found to be elongated; some of these may be dividing into two. Sometimes there are two or more cells still clinging together, showing clearly that they have just been formed by division. These groups separate readily when the cover glass is tapped, and each single cell may go on living quite independently of 


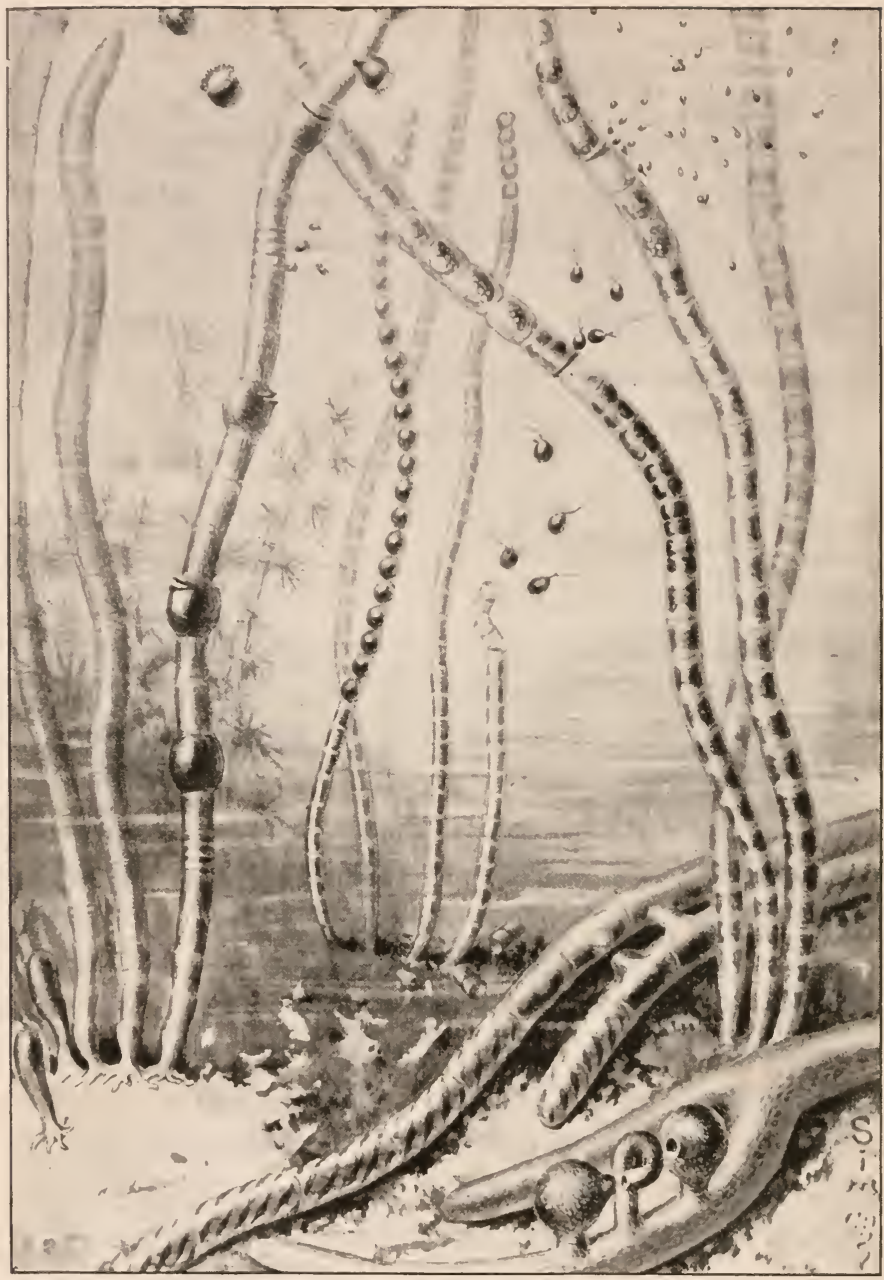

FIg. I45. Freshwater algx. The upright filaments are, from left to right: Edogonium, producing swimming spores, eggs, and sperms; Microspora, forming resting spores and swimming spores; and Ulothrix, forming swimming spores and gametes. The horizontal filaments are Spirogyra (left) and Vaucheria (right). 
the others. The plant, therefore, consists of a single cell which carries on all the essential processes of life and is able to reproduce itself. Moreover, it is a highly successful plant, for Protococcus occurs in all parts of the world, from the tropics to the polar regions, in habitats of many different kinds.

The pond scums. If examined in the spring or fall, almost every pond and little stream will be found to contain many kinds of algæ. Some of these are merely masses of rounded cells like the cells of Protococcus. Others have the cells arranged in rows, forming simple filaments. In still others the filaments are highly branched and the plant body may be several feet in length. Some of the forms are imbedded in a gelatinous matrix. All these various kinds of algæ taken together are called the "pond scums." They are the algæ that a person who has not studied botany is most likely to know.

Many of the pond scums are at first attached to underwater objects, but during warm weather they break loose and come to the surface. All cells carrying on photosynthesis give off oxygen, and the bubbles of oxygen that come from the filaments cling to them and help to buoy them up. Furthermore, bubbles of air which are given off from the water when it becomes warm collect under the masses of algæ and cause them to come to the top of the water, where they form a green or yellowish-green surface layer. The pond scums are generally considered unsightly, and not a few persons think them poisonous. In reality, they are quite as harmless as lettuce. The danger in drinking from ponds lies not in the green scums, but in the presence of certain diseaseproducing bacteria that may have been carried into the ponds 
by surface water. Several thousand different species of algæ are concerned in the formation of pond scums. Microspora may be studied as an example of the more simple filamentous forms.

Microspora. . The Microspora plant is a filament made up of cylindrical or barrel-shaped cells placed end to end. Each cell carries on all its own food- and energy-producing processes. During early spring, as food is manufactured, the cells enlarge and divide. The division is always in the same direction, however, and the cells remain attached to each other, so that the growth and division of the cells causes the filament to increase in length. This long, slender line of cells is easily broken, and the plant may be multiplied by the breaking of the filaments into parts.

Spores in Microspora. Microspora produces swimming spores and resting spores. These are special cells that reproduce the plant. A swimming spore is formed by the contents of a cell in the filament contracting into an ovoid body. At one end of this body two cilia, which are small, hairlike propellers, are developed. The wall of the original cell then breaks and the swimming spore is set free. After swimming about in the water for a short time, it becomes attached to some object under water, loses its cilia, and grows into a cylindrical vegetative cell. This cell then continues to grow and divide until a new filament is formed. The advantages of swimming spores are that they multiply the plant, and by their ability to swim they enable the plant to spread to new locations that it might not reach without these motile cells.

The resting spores are usually formed in the spring after the active period of vegetative growth has passed. At this 


\section{The Algæ}

season the cells in the filament stop dividing and food accumulates in the form of starch and protein granules. The protoplasm in each cell then contracts into a spherical form and secretes a heavy cell wall about itself inside the original cell wall. In this way the cells of a filament form a row of ovoid or spherical heavy-walled resting spores. Usually the walls of these spores become yellow or brownish. The resting spore remains dormant until the late fall or early spring. Then, like a seed, it germinates, or begins to grow. The wall that incloses the spore breaks and the protoplasm pushes out and forms a cylindrical vegetative cell which continues to grow and divide until a new filament is formed.

Microspora, then, in addition to the vegetative multiplication of the cells shown by Protococcus, has specialized swimming spores that multiply and spread the plant, and resting spores that undergo a dormant period, after which, when favorable conditions for growth appear, they produce a new plant. Its life cycle and that of other similar algæ includes (I) an active chlorophyll-working period, during which the plant grows and enlarges its body and accumulates food; (2) a reproductive phase, which closes with the production of resting spores; and (3) a period of dormancy, during which only the resting spores are alive. The length of the dormant period for a particular alga is practically the same, whether it lives in a permanent pond or in a pool that dries up in summer.

The living conditions of the pond algæ. Curiously, the ponds in which the algx are most abundant are the ones that dry up in the summer. Yet these plants are among the most delicate of all living things; you may readily discover, by putting the green masses in a dish and letting the water 
evaporate, that the vegetative plants are killed by drying. How, then, do they withstand the dry period?

It is resting spores that enable the plant to be carried over the dry season. These spores are produced in large numbers and, being heavier than water, sink and become a part of the mud bottom. When the pond dries up, the spores are incased in the dried mud. At intervals they are watered by rains, but they do not germinate for weeks or months after their formation. No doubt a large part of the spores that were formed perish during this period, but enough survive a drought to start the plant the following season.

Ulothrix. Another green alga occurring on the margins of lakes, in running streams, and in clear springs is Ulothrix. It has a filamentous body similar in many respects to Microspora, and like that form it is attached to rocks and other objects. Its methods of reproduction, however, are more numerous and more complex than those of Microspora, and they will serve to exemplify the reproductive processes of many other forms of algæ. When the filaments are mature, the protoplasm within some of the cells divides into two, four, or eight parts, each of which contains nucleus, cytoplasm, chloroplast, and vacuole. Each of these parts becomes oval in shape and develops into a swimming spore with four cilia. An opening appears at one side of the original cell wall, and a few minutes later the swimming spores pass out from the cell cavity and swim away. Sometimes all the cells in a filament produce swimming spores at about the same time, and hundreds of these small green bodies may be found moving about in the water. At the end of from I 5 to 30 minutes the swimming spores settle down on some object and become attached. By the end of a day the cell formed 
from each spore has divided and produced the first two cells of a new filament.

The protoplasm of other cells of the same or other filaments continues to divide until $16,32,64$, or more bodies have been formed. These are called gametes. They are similar to the swimming spores but much smaller, and each possesses two cilia for swimming. Like a swimming spore, each of them leaves the old cell through an opening in the wall. The gametes swim about for some minutes and then unite in pairs. They are attached at first only by the ciliated ends, but later the two gametes fuse. The body thus formed may grow directly into a new filament, or it may produce swimming spores from each of which a new filament is formed.

Asexual and sexual spores. Spores of Microspora and the swimming spores of Ulothrix are formed directly from vegetative cells or by the division of the contents of these cells. The spore which is formed by the two gametes of Ulothrix is produced by the union of two cells. Since cell division takes place in all parts of plants while cell union occurs only in the sexual process, it is plain that we have in Ulothrix a simple type of sexual reproduction. The spore that is formed by the union of the gametes is, therefore, a sexual spore. The swimming spores and the resting spores are formed without the union of cells, and these are called asexual spores. The gametes of Ulothrix look alike, but physiologically they are probably different. One of them corresponds to the male reproductive cell of the higher plants, and the other to the female reproductive cell (page 205).

Edogonium. Edogonium is another filamentous alga that flourishes in ponds and streams. In early life the filaments are attached, but large masses of them will often be 
found free in ponds and stagnant pools. From the cylindrical vegetative cells, large swimming spores are formed. Gametes also are produced. These are of two distinct forms, male and female. Plants belonging to the Edogonium group may be used to exemplify reproduction in many other algx, whose gametes are essentially like those of more complex plants.

At the time of production of the gametes, some of the cells in the filament enlarge, become rounded, and accumulate starch and other food material; also, a small opening is formed in the cell wall. The content of this cell is the female gamete or egg, which like other eggs has in it a store of food.

Other cells of the filament are cut up into very short cells by the formation of transverse walls. In each of these short cells there are formed two small gametes, which escape from the filament and swim out into the water. These are the male gametes, or sperms. Fertilization.takes place when one of the sperms enters through the opening in the cell wall that surrounds an egg and unites with the egg. The egg and the sperm may be of the same filament or of different filaments. The product is a sexual spore, usually called an oöspore (egg spore). After a dormant period this produces swimming spores that start new filaments.

In Edogonium, therefore, the sex cells are of two kinds quite distinct in structure and function. The egg is a large, stationary cell filled with food. The sperm is a small, swimming cell that moves to the egg and accomplishes fertilization by uniting with it. The product is an oöspore which may start a new generation of plants like that which produced it. This condition is essentially like that in the seed plant, where the egg is produced inside a complex structure called the ovule and the sperm reaches it through a pollen tube (page 
205). When the two unite in fertilization, the product in a seed plant also is an oöspore, or unfertilized egg, which immediately divides and forms the embryo within the seed.

Reproduction among the algæ. The methods of reproduction among the algxe that we have studied are representative of those found in the entire group. The three general types are:

(I) Vegetative multiplication. By means of cell division cell masses, filaments, or highly branched plant bodies are produced. If the individual cells separate from each other after division, as in Protococcus, many new individual plants are produced; and when filaments and branched forms are broken, as in Microspora, a new individual plant is produced by each part.

(2) Reproduction by asexual spores. Vegetative cells form thick-walled resting spores which carry the plant over to the next season. Another kind of asexual spore is the swimming spore, by means of which the plant secures immediate reproduction and spreads to other parts of the pond or stream. These spores are formed directly from vegetative cells or by the division of vegetative cells. There is no union of cells as there is when sexual spores are formed.

(3) Sexual reproduction. A sexual spore, or oöspore, is formed by the union of two gametes. The gametes may be similar in size and appearance, as in Ulothrix, or they may be unlike, as in Edogonium, where one gamete accumulates a large food supply and the other is small and motile. In either case, the one gamete corresponds to the sperm and the other to the egg that is found in higher plants. The union is the process of fertilization. The oöspore may germinate immediately, but more often it remains dormant for a period of 


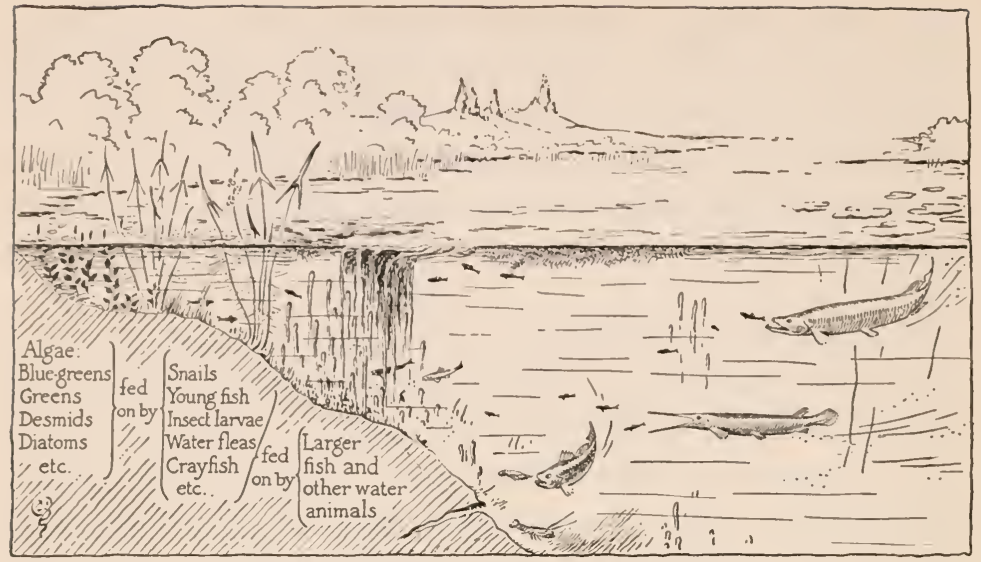

Fig. I46. Food relations of aquatic life.

weeks or months. Essentially this same process occurs in the sexual reproduction of all plants and animals.

Other algæ found among pond scums. Great numbers of different kinds of algx are found growing in fresh-water ponds and pools, and when these are examined under the microscope they are seen to be composed of the most beautiful and the most varied cells found in the whole plant kingdom. Some have intricate star-shaped and latticelike chloroplasts; in other forms the chloroplasts wind about within the cells like spiral green ribbons. Some forms have no cell walls in the filament, but all the living matter of the plant, with hundreds of nuclei in it, lies together in one mass. A great group of one-celled forms (Diatoms) have siliceous cell walls that are like delicate cases of glass and that are sculptured and marked with lines in a highly complex way. Some of these forms are stationary, while others move slowly through the water by invisible means. Still other forms swim about 
rapidly by means of little hairlike appendages, seeming more like animals than plants.

The pond scums include many blue-green algx, which are much simpler in structure than the green plants that we have studied. These contain, in addition to chlorophyll, a bluegreen pigment which gives them the color from which the group takes its name. The cells are generally smaller than those in the green algæx, and distinct nucleii and chloroplasts are absent. These small blue-green forms are common in a!l kinds of water habitats and also in the upper layers of the soil. Sometimes during wet weather they become sufficiently abundant in fields to give a blue-green color to the soil.

The importance of the pond scums. Both green and bluegreen algæ are generally considered a nuisance in ponds and streams, and they are commonly thought to have no economic importance; but the fact is that these despised pond scums are the primary food supply of all the water animals. They bear the same relation to aquatic animal life that the herbaceous plants bear to animal life on the land. Nearly all the water animals, from minute insects and crustaceans to the largest fishes, ultimately depend upon them for their supply of food. For, like the land plants, these small water plants manufacture food, and the animals that live in the water must feed either on them or on other animals that get their living from the plants. Without the pond scums the fish would soon disappear from our waters, because their food supply would be cut off. A decrease in the number of fish in a lake frequently follows the draining of its swampy margins, for the algæ thrive best in shallow water, and it is from the algæ that the small animals on which the fish feed secure their food. The time is not far distant when fish will be 
more highly prized as food than they are now. When that time comes, the cultivation of algx will probably be undertaken as a first step toward greater fish production.

But while the pond scums are a source of food for water animals, they are also a source of annoyance in reservoirs in which drinking water is stored. When they accumulate in large quantities and die, they "cause the so-called "fishy taste" of water. This trouble has been to some extent controlled during recent years by the exclusion of light from small reservoirs, and by the addition of small amounts of copper sulfate to the water in large reservoirs. Copper sulfate is very poisonous to algæ, even in quantities of one part to a million parts of water. Since animals are not injured by such small amounts, the water may be used without harm for drinking purposes.

The seaweeds. The brown and red algæ, commonly known as seaweeds, grow attached to rocks in the shallow water along our coasts. They are generally from a few inches to several feet in length. Some of the brown kelps grow in deep water and attain lengths of 100 feet or more. In texture the seaweeds vary from the most delicate filaments to broad, leathery expanses, with stalks so tough that they are used for making ropes.

In China and Japan, seaweeds have long been used for food. They are cooked with fish and take the place of vegetables. Along our northern coasts the "Irish moss" and "dulse" are collected in considerable quantities for food purposes. The agar used in laboratories for growing bacteria and fungi is made from certain kinds of red algæ that grow abundantly on the coasts of Asia.

The brown kelps are an important source of iodin, and also 


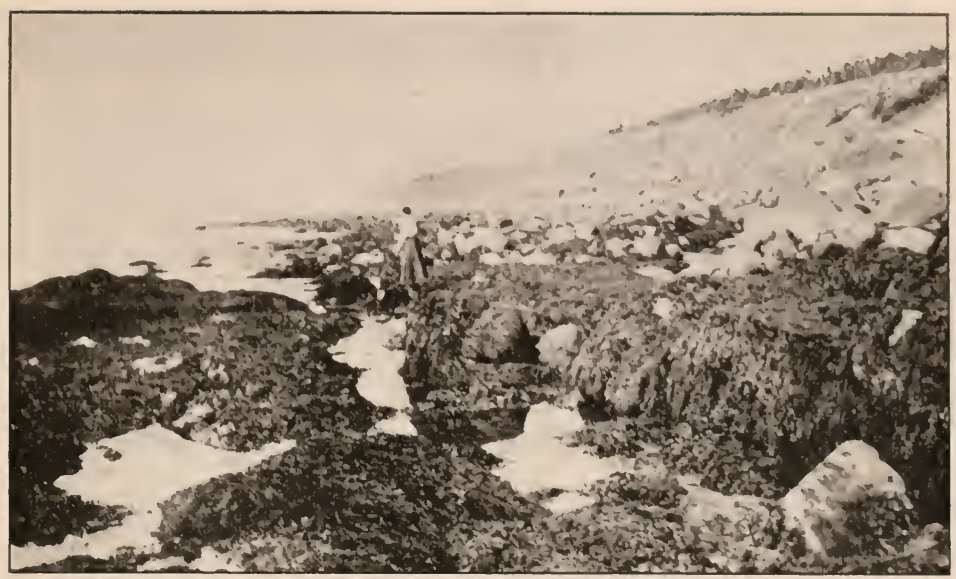

FIG. 147. Seaweeds on the rocky coast of Nova Scotia.

of the potassium salts which are required in large quantities for the manufacture of commercial fertilizers. The great kelp beds of the Pacific coast are being harvested on a large scale in order to secure these products. The kelps are dried and burned, and the potassium and iodin are obtained from the ashes. 
1. Bacteria and molds may be grown for study by placing bread and slices of boiled potato in moist chambers (tumblers inverted in saucers).

2. Place cultures under different temperature conditions and note the effect of temperature on the rate of growth. Dry a part of the bread and potato slices somewhat, and compare the growth of bacteria and fungi on the dry slices with the growth of those on the moist and wet slices. What do these experiments suggest regarding methods of a voiding bacteria and molds?

3. In test tubes, yeast may be grown in sugar solutions from commercial yeast cakes. The formation of carbon dioxid and alcohol should be noted. The cells, buds, and filaments may be seen with a microscope.

4. From grainfields in the summer, specimens of rusts and smuts can be obtained, and they may be preserved by drying. The cluster-cup stage of rusts is common on elder, crowfoot, barberry, and Indian turnip. In the laboratory the spores may be examined and injuries to the leaves noted.

5. Mushrooms and toadstools may be collected in the woods at all seasons. Study the relation of the fruiting body to the vegetative part of the plant. Dried material and specimens preserved in strong alcohol will serve to show the variety of these plants. 


\section{CHAPTER NINETEEN}

\section{BACTERIA AND FUNGI}

THE seed plants and alga which have been described manufacture their own food. Both of them are independent of other plants and both are self-supporting. 'They are called autophytes, since they make their own food and can live without the assistance of other plants. There are many other plants, including a few of the seed plants, which lack chlorophyll and are unable to manufacture their own food. There are two groups of these dependent plants, saprophytes and parasites.

Saprophytes live on organic substances which have been manufactured by other plants or animals. The mold that develops on bread is a good example of a plant of this kind. The starch, sugar, and protein in the bread were made originally by wheat plants; and the mold, therefore, derives its nourishment from substances previously manufactured by a green plant. It grows as well in the dark as in the light, because its food is already prepared. It needs merely to digest the food and absorb it into its own body. The mushrooms are mostly saprophytes, living on fallen leaves, tree trunks, and humus. The Indian pipe is an example of a flowering plant that secures its food in the same way.

Parasites take their food directly from other living plants, or from animals. The mistletoe is a common parasite on various trees in the Southern states. Its seeds are sticky and adhere to the bark of trees. When a seed germinates, the hypocotyl penetrates the bark and grows inward to the cambium and the food-conducting tissue. There it reaches the food made by the tree and appropriates some of it to its own use. The plant on which a parasite lives is called its 
host. The yellow dodder, which lacks chlorophyll altogether, is a common parasite related to the morning-glory. It twines about green plants and sends small roots into them to obtain its food. Some parasites may take all their food from the host plant, as does the dodder; others, like the mistletoe, which contain some chlorophyll, may secure only a part of their nourishment from the host.

The bacteria and fungi form a great group of simple plants which resemble the algæ in structure, but which differ from the algæ in having no chlorophyll. They must, therefore, live as saprophytes or parasites. Either they grow on or in living plants or animals and draw their food directly from them, or they feed on organic matter.

The bacteria. The best known and the most discussed of all the simple plants are the bacteria. They are so intimately related to human welfare that most persons, even though they have never seen bacteria, know something about them. Bacteria constitute a group of one-celled plants, at once the smallest in size, the simplest in structure, and the most abundant of all plants. They live in immense numbers in the water and in the upper layers of the soil, and they are blown about in dust in the air. Some are too small to be seen except with the highest powers of the microscope. Others may be seen with an ordinary laboratory microscope. They make up for the small size of the individual by their rapid multiplication, and by the formation of colonies containing countless numbers of individuals. Bacteria are responsible for many of the diseases of men, animals, and plants, and bacteria affect our lives in almost countless other ways. All our modern methods of sanitation, quarantine, surgery, water supply and sewage disposal, and much of our personal 
hygiene, are primarily based on our knowledge of the behavior of this group of plants.

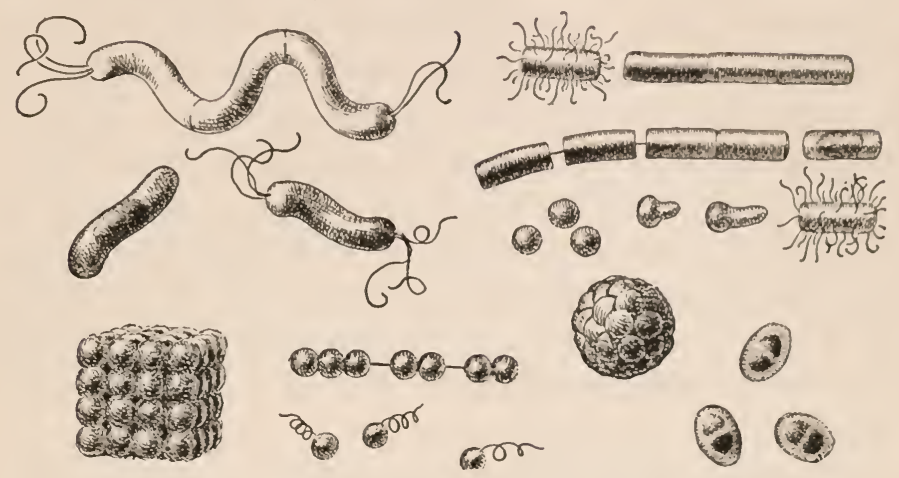

FIG. I48. Various forms of bacteria.

Economically the bacteria are of the greatest importance. Together with the fungi they are the principal cause of decay. Bacteria bring about the ripening of milk in butter and cheese making, and they produce both the pleasant flavors in these products and the unpleasant flavors that develop in them with age. The bacteria are also the source of much of the available nitrogen in agricultural soils (page 32). The drying of hay, vegetables, and fruits, the canning and pickling of vegetables, fruits, and meats, and refrigeration and cold storage, are methods of avoiding or making impossible the growth of bacteria. Thus a knowledge of these plants is fundamental to our understanding of thousands of details of our daily life.

Growth and reproduction of bacteria. Bacteria grow best and reproduce most rapidly in the presence of organic food materials, in the absence of light, in the presence of moisture, and at moderately high temperatures like those of the mid- 
summer months and of our own bodies. They reproduce by simple cell division, the cell simply pinching in two to form new plants. Many forms produce spores, similar to the resting spores of the algæ, by the contraction of the protoplasm in the cell and the secretion of a new cell wall. Spores are very resistant to drying, to high and low temperatures, and to poisons which readily kill the ordinary bacterial cells. It is because the spores of certain forms withstand the temperature of boiling water that steam pressure is used in sterilizing cans of corn, beans, peas, and other vegetables. Most of the common disease-producing bacteria, however, do not produce spores.

Bacteria and sanitation. The bacteria of decay help to keep the surface of the earth clean. They change the highly complex organic substances that form the bodies of plants and animals into simple substances that may be used again by other plants in building foods. When plants and animals die, their bodies are gradually transformed by the bacteria into carbon dioxid, water, and mineral salts. The sewage that is turned into our rivers is chemically changed and disposed of in the same way by these minute plants. The great increase in the number and size of our cities has made it necessary to build large sewage-disposal plants where the bacteria can act more rapidly and more efficiently. This prevents the pollution of streams and keeps the water suitable for city water supplies.

The modern processes of filtering and sterilizing the water supplies of cities are carried on partly to remove sediment and partly to remove disease-producing bacteria. Adding minute quantities of alum and chloride of lime to the water and then filtering it through sand not only renders the water 
clear, but removes from it disease-producing bacteria. The most dreaded of all the water-borne diseases is typhoid fever, and the cities are now much freer from this disease than are the country districts where people depend upon well water. Surveys in some of the Middle Western states showed that from one fifth to one third of the wells examined contained large numbers of bacteria derived from surface drainage. In such wells there is always danger that the surface waters may bring in disease-producing bacteria, especially typhoid germs derived from human sources.

Other sanitary practices, such as quarantine, disinfection, admitting plenty of sunshine into living rooms, cleaning walls and floors, removing dust, cooking food, washing and scalding dishes, pasteurizing milk, and keeping food supplies in refrigerators, are all related to the control or elimination of bacteria.

Bacteria and disease. When certain bacteria grow in the body, they produce poisonous substances called toxins. These toxins interfere with the normal working of the bodily processes and cause illness. The body under these circumstances produces substances called antitoxins, which protect the tissues until the bacteria are destroyed by leucocytes (colorless blood corpuscles) or in other ways. Not all persons are equally susceptible to infectious diseases. A person may be immune to a disease because his blood contains the corresponding antitoxin or is able to produce it or because his blood contains substances that kill the germs. Habits of personal cleanliness, sleeping in the open air, and careful diet help to increase immunity against many of the common diseases to which we are subject.

Some of the commoner bacterial diseases are tuberculosis, 


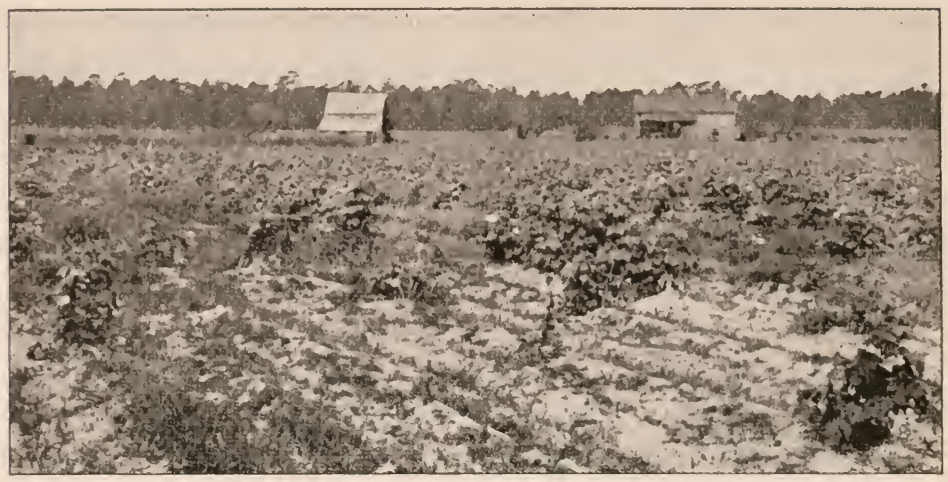

U.S. Dept. of Agriculture

Fic. I49. A field of upland cotton, in South Carolina, attacked by the wilt disease. The fungus that causes the wilt remains in the soil for many years.

pneumonia, grip, diphtheria, typhoid fever, colds, lockjaw, and blood poisoning. With the exception of lockjaw and other infections through wounds, these diseases are largely communicated by one person to another. Typhoid is carried also by means of water and milk supplies which have been contaminated, and by flies that have visited infected matter.

A fundamental fact that should be learned in this connection is that no one can contract a bacterial disease unless he comes in contact with the particular bacterium which causes that disease.

The natural means of defense against disease are somewhat similar in the higher plants and in animals. The plant, in addition to protective chemical substances within its cells, has an epidermis which renders the entrance of bacteria difficult. Bacteria are able to enter, however, if the epidermis is bruised or broken. Plants probably suffer from bacterial diseases as much as do animals. Most of the well-known 


\section{Bacteria and Fungi}

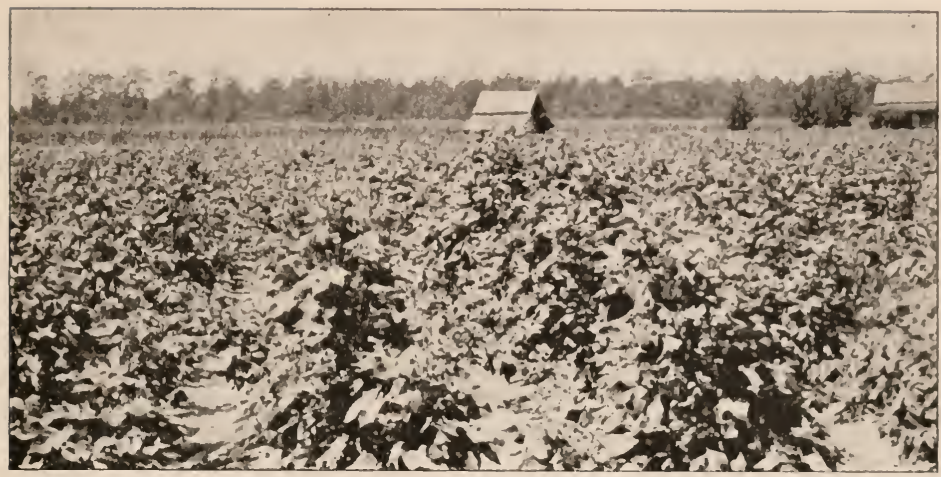

U.S. Depl. of Agriculture

Fig. I50. The same ficld shown in Figure I 49 planted with seeds from plants that survived the attack of the disease.

plant diseases, however, are produced by fungi. Of the bacterial diseases of plants, the twig blight of pear and apple, the cucumber wilt, and the crown gall of various plants are perhaps best known.

In crop plants subject to disease, it has been found possible in some instances to breed varieties that are immune to a particular disease. By selecting seed from plants that were least affected, or not at all injured, in a diseased field, the characteristic which gave that plant immunity may be preserved. In this way wilt-resistant cotton was bred in the South. In fields where the wilt disease had killed nearly all the cotton, it was noticed that an occasional plant suffered scarcely at all. Seedlings grown from these plants were found to be highly resistant.

By hybridizing with related species or varieties that are immune, and then selecting the desired offspring for producing seed, it is possible to transfer the immunity to the crop plant 
which possessed the other desired qualities but which was not immune. Such desirable combinations are possible because most of the qualities of plants are inherited independently of one another. For example, the watermelon wilt threatened to make the profitable growing of watermelons in certain regions along the Atlantic coast impossible. It was discovered, however, that a closely related plant, a small African citron, was immune to the disease. The problem then was to cross the watermelon with the citron and out of the hybrid progeny to select those plants that possessed all the good qualities of the watermelon and the immunity of the citron. This was accomplished, and hybrid watermelons could then be grown in the infected fields.

Bacteria in the dairy. Milk is an ideal medium for the growth of bacteria. This makes necessary the most careful handling of milk, especially when it is used directly as food. The bacteria get into the milk from the cow, from the stable, from the vessels into which the milk is put, and from the persons who handle it. Evidently the cows should be kept clean, and the stable should be as clean and free from dust as possible. The vessels with which the milk comes in contact should be sterile. The dairymen should have clean hands and clothes, and above all they should be free from infectious diseases. Because bacteria multiply very rapidly at high temperatures, the milk should be chilled at once and kept on ice. To make butter and cheese of fine flavor, pure cultures of desirable bacteria are added to the milk and allowed to develop for a time.

In order to avoid the danger that lies in the use of milk contaminated with disease germs, milk that is shipped into the larger cities is usually pasteurized before being sold. This treatment kills most of the bacteria, destroying all the kinds 
that produce disease in human beings. By "pasteurization" is meant the heating of the liquid to 150 degrees or 160 degrees F. for from ro to 30 minutes. This does not kill the spores, but they are to a large extent prevented from developing by the subsequent cooling that the milk receives.

The preservation of foods. The greatest losses that occur in the utilization of crops are connected with the distribution of the products to the consumer. Much of the food produced never reaches the consumer, because bacteria and molds render it unfit for use before it can be distributed through the markets. There are four methods of preventing this loss: (I) cold-storage warehouses and refrigerator cars are used to keep foods below the temperature at which bacteria grow appreciably; (2) fruits, vegetables, or other foods are packed in cans, and the cans are then sterilized by heat and are sealed so that they are bacteria-tight; (3) food products are dried to make it impossible for bacteria to grow in them; and (4) foods like meat and fish are treated with salt or with some other chemical that will prevent the growth of bacteria. Refrigeration enables us to preserve foods for weeks and months. Canning and drying make foods available after months and years.

Soil bacteria and humus. In the process by which the bacteria of decay destroy animal and vegetable bodies, the brown organic matter represents the products of partial decomposition. This matter is called humus, and it is one of the important soil factors in crop production. Humus is of importance in light soils because it helps to hold the water and so to keep the soils moist. In heary clay it mellows and loosens the soil and promotes aëration and drainage. Humus may also contribute something directly to the nu- 
trition of the crop, for among the multitude of substances it contains are simple carbon and nitrogen compounds which the higher plants may absorb and use in small amounts.

Soil bacteria and nitrogen. In order to manufacture proteins, seed plants must have a supply of nitrogen. This they secure principally in the form of nitrates. There may be other nitrogen compounds in the soil, but they are unavailable until certain nitrifying bacteria change them to nitrates. Ammonia is one of the nitrogen compounds produced in the process of humus formation. The ammonia may be acted upon by certain bacteria and changed to nitrites, which in turn are changed by other bacteria into nitrates. These nitrates are used by the green plant. The nitrifying bacteria are of great importance to the seed plants, because they break down the nitrogen compounds in humus and other soils, and convert the nitrogen into an available form.

Still other soil bacteria bring about a process known as nitrogen fixation, by which nitrogen is actually taken from the air and built into compounds which are added to the soil. The nitrogen-fixing bacteria are, with a few exceptions, the only plants that can take nitrogen from the air and combine it to form nitrogen compounds. They require rich, welldrained soil in order to flourish. They are of great importance in agriculture because nitrogen is one of the elements that is most commonly lacking in soils, and because it is the most expensive of all the elements that are purchased for fertilizers.

Bacteria and legumes. Clover, alfalfa, beans, soy beans, and peas belong to a family of plants called legumes. They increase the nitrogen in soils on which they are grown, and for many years they have been used in crop rotations, following wheat or corn. The practice of using legumes in 


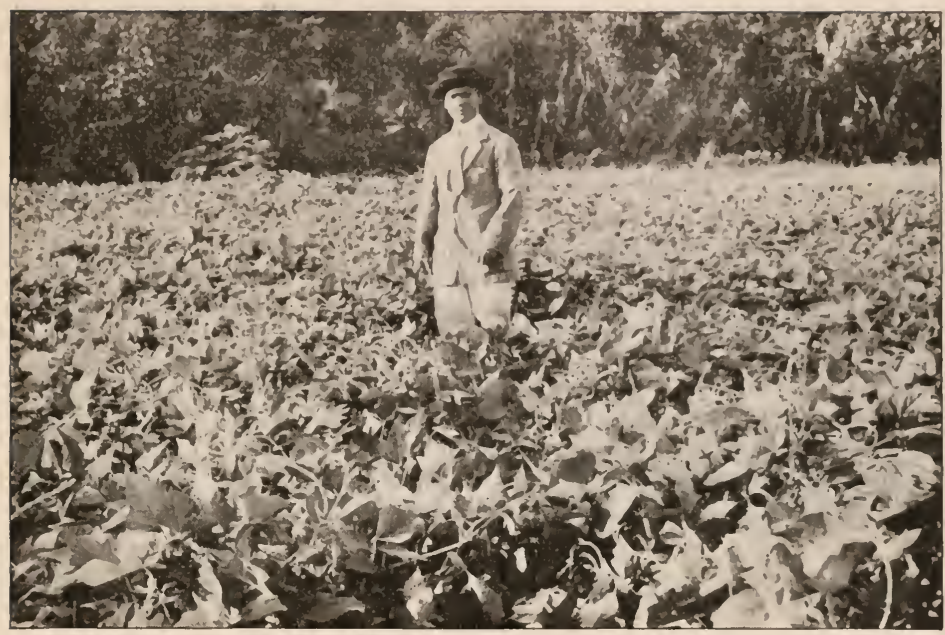

Bureau of Agriculture, P.I.

FIG. I5 r. A field of cowpeas. Like other legumes, cowpeas accumulate nitrogen compounds, and when plowed under they add nitrogen and humus to the soil.

crop rotations existed long before the real cause of the increase in soil nitrogen was understood, or even before it was understood how different elements in the soil contribute to its fertility. By experience it was learned that other plants flourish in land after leguminous plants have been grown in it, and for this reason the farmer included legumes in his scheme of crop rotation.

It is now clearly understood that nitrogen compounds accumulate in leguminous plants only because of the presence of certain nitrogen-fixing bacteria. These bacteria occur in many soils, and when the legume is planted and develops roots, they invade the cells of the root. This causes the infected parts of the root to enlarge, forming nodules. If a nodule from a clover or alfalfa root is crushed and examined under 


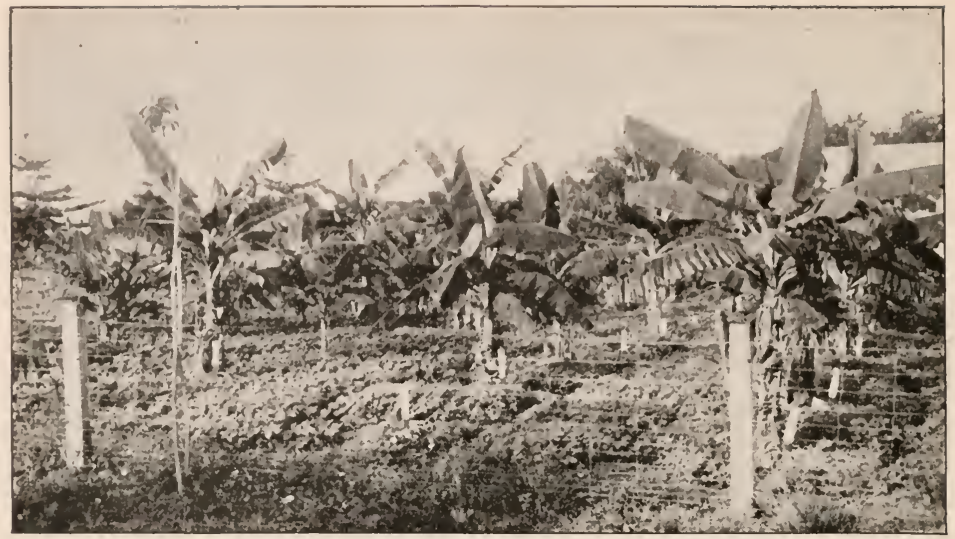

Bureau of Agriculture, $P . I$.

FIG. I52. A field of young bananas, with cowpeas planted between the rows to enrich the soil.

a microscope, it will be found to be filled with bacteria. These bacteria are parasites and take their food from the legume, but by the processes which they carry on in the nodules, they change nitrogen from the soil air into nitrogen compounds, just as the soil bacteria mentioned in the preceding section do. The nitrogen compounds thus formed are used by the host plant, and when the latter is plowed under and decays, the nitrogen compounds are made available for a succeeding crop of wheat or corn.

The fungi. The fungi form an exceedingly large and diversified group, ranging in size from microscopic forms of a single cell to the large, fleshy mushrooms and to the bracket fungi found on tree trunks and logs. Among the most important fungi are yeasts, molds, mildews, smuts, rusts, and mushrooms. We cannot here describe the many interesting forms and give their life histories. They all lack chlorophyll, 
however, and get their food either from organic matter or from living plants. The plant body is always made up of filaments like those of the algx. In the higher forms, like the mushrooms, the filaments are massed together into a compact, solid structure.

The yeasts and molds, and most of the mushrooms, are saprophytes; the smuts, rusts, and some of the. mildews are parasites upon the higher plants, and they cause serious losses to the farmer and gardener. A few of the mushrooms are edible and furnish small quantities of food for animals and man.

The yeasts. In the making of bread, yeasts are of primary importance. They are small, one-celled plants that multiply very rapidly, and when properly mixed with flour and water they develop in all parts of the dough. The yeasts have within them enzymes which change part of the sugar that is present into carbon dioxid and alcohol. The carbon dioxid accumulates in bubbles and makes the dough light. When the dough is put into a hot oven the alcohol is vaporized, and together with the carbon dioxid it is driven off into the air. The high temperature kills the yeast, bakes the dough, and changes some of the starch into its soluble form, dextrin, which makes it more readily digestible. Sour bread is produced when the yeast that is added contains acid-forming bacteria which change part of the alcohol into acetic acid.

Yeasts and bacteria are the organisms that change fruit juice into cider and vinegar. resting spores.

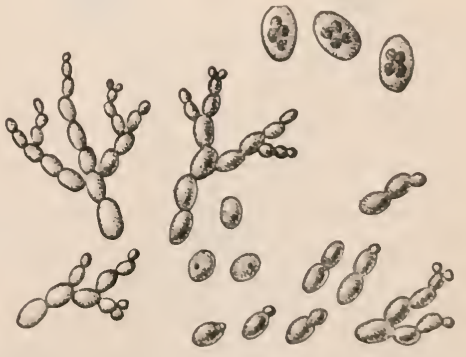

FIG. I53. Yeast cells and chains of cells. Above are three cells, each containing four 
Yeast first changes the sugar in apple juice to carbon dioxid and alcohol, and bacteria further oxidize the alcohol to acetic acid or vinegar. Yeasts are also used in the fermenting of beer and wines.

Yeast may readily be grown by adding a bit of yeast to a 5 per cent sugar solution in a test tube. The branching groups of cells may then be examined under the microscope. The manner of forming new cells among yeasts is unique, in that the new cells start as small protuberances (buds) from the older cells. These buds gradually enlarge until they attain their complete growth and separate. The alcohol formed in the test tube by the yeast may easily be detected by its odor.

The molds. The molds are usually white, filamentous plants that are of great economic importance because of the damage that they do to foods during storage or shipment. Like bacteria, the spores of molds are in the air and in the dust everywhere. If the temperature is warm and the food is moist, they germinate and, together with bacteria, soon

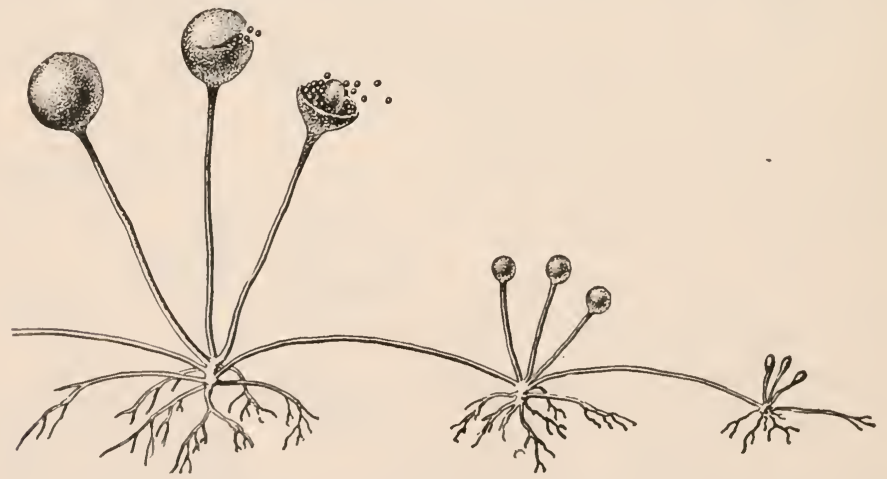

Fig. 154. Bread mold, showing the rhizoids which penetrate the material on which the mold grows and which absorb food, the horizontal filaments by which it spreads, and the vertical filaments which bear the sporangia and spores. 
destroy food. The same measures that will prevent the growth of bacteria in foods will prevent the growth of the molds, which are usuaily associated with them.

The molds exemplify one of the fundamental characteristics of the fungi; namely, their capacity for producing enormous numbers of spores. In some cases, as in the bread mold, these spores are produced in rounded sacs called sporangia; in other cases upright filaments of the mold develop spores by cutting off chains of little rounded cells from the ends of the filaments. These spores are of various colors, - brown, black, blue, green, or yellow, - and they give the characteristic color to the mold. In most molds the spores begin to develop at ordinary temperatures within 2 or 3 days after the parent spore germinates.

The rusts. Among the most serious diseases affecting wheat, rye, barley, and oats are those produced by the fungi known as the rusts. These fungi are called rusts because plants that are infected with them develop yellow and brown spots that have the appearance of iron rust. The rusts occur wherever grains are grown, and they cause millions of dollars' worth of damage to crops every year.

The rusts are parasites that live inside the host plants and injure or destroy the tissues which are concerned in food manufacture. Their life history is peculiar in that the fungus usually produces diseases on two different kinds of host plants. The stem rust of wheat, for example, produces patches of red spores which will infect other wheat plants. It produces also black spores which live over winter on the stubble, and which germinate the following spring and produce a third kind of spore that infects the barberry. On the barberry leaves the fungus produces a cuplike depression within which a fourth 
kind of spore is formed. This spore will not germinate on the barberry, but it will infect wheat. Thus the stem rust

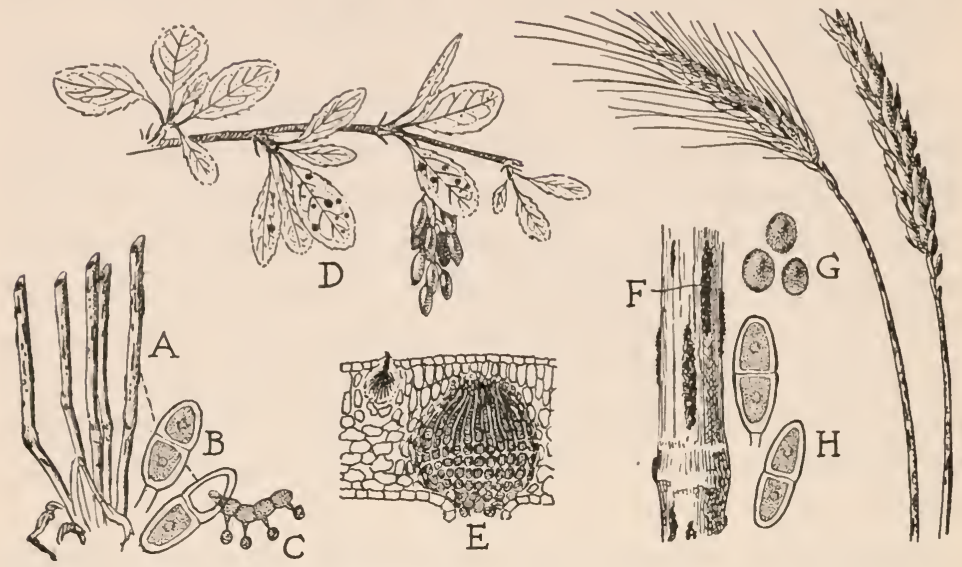

FIG. I55. Life history of the stem rust of wheat. In fields where wheat has been grown, the stubble $(A)$ carries over the winter black spores $(B)$, that germinate in early spring, producing smaller spores $(C)$. These infect the leaves of the common barberry $(D)$. In the leaves of the barberry the fungus grows and produces cup-shaped cavities filled with spores $(E)$ that are carried by the wind to wheatfields and infect the wheat plants. After growing in the wheat a short time, the fungus produces first the red spores $(G)$ that spread the disease to other wheat plants, and later the two-celled black spores that carry the disease over the winter again.

of wheat spreads from one wheat plant to another by means of red spores, from wheat to the barberry by spores that are produced the next spring, and from the barberry back to the wheat by still another kind of spore.

In the Northern states, from the Dakotas to New England, the barberry stage is of special importance in the life history of the rust. In the central United States where winter wheat is grown, the red spores produced during the summer drop to the ground and infect the wheat planted in the autumn. In this way the rust may be perpetuated from year 
to year without the intervening barberry stage. In the Northern states the destruction of all barberry plants has

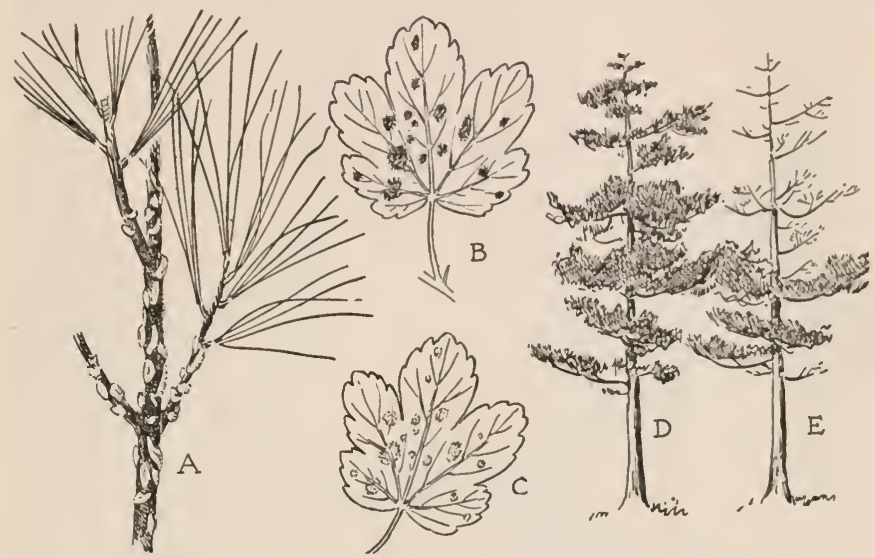

FIG. 156. The white pine blister rust. The fruiting bodies on the white pine $(A)$ produce spores that infect the leaves of the gooseberry ( $B$ and $C$ ). On the gooseberry leaves the fungus produces at first yellow spores that will infect other gooseberry plants, and later brown spores that carry the disease back to the pine. When a pine $(D)$ is infected by the disease, the younger parts soon die $(E)$.

been undertaken, and this work will doubtless reduce the amount of infection. The hope of effectively controlling wheat rust, however, probably lies in breeding new varieties of wheat that are immune to the disease.

Other rusts also live on two host plants, and because of this double life and the fact that the fungus grows on the inside of its host, they are very difficult to control. The rust on the red cedar produces the so-called "cider apples," the spores from which infect the leaves of the apple tree and may do great damage to them. Recently the blister rust of the white pine has been brought to America, and it threatens to destroy what remains of our white-pine forests. In this case 
the alternate host plants are the wild and cultivated gooseberries and currants. Another common rust is frequently seen

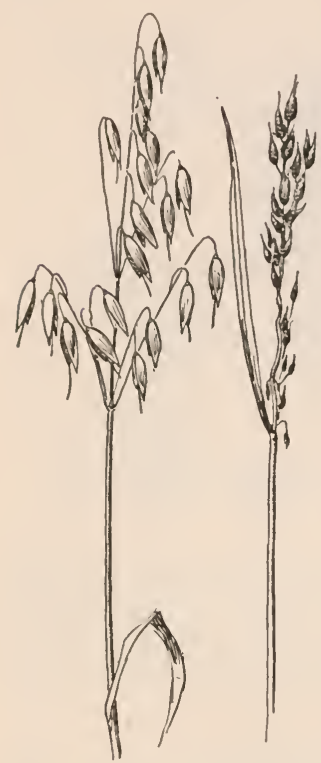

FIG. I57. A normal and smutted flower cluster of oats.

All smuts of the small grains may be prevented from germinating by soaking the seed in hot water for a short time before planting. It is easier, however, to wash the grain with a weak solution of formalin, and this treatment is effective in preventing the growth of those smuts whose spores are carried over the winter on seed. Detailed information concerning seed treatment for the prevention of the several kinds of smuts may be obtained from State Agricultural Experiment Stations. The corn smut is controlled by removing 


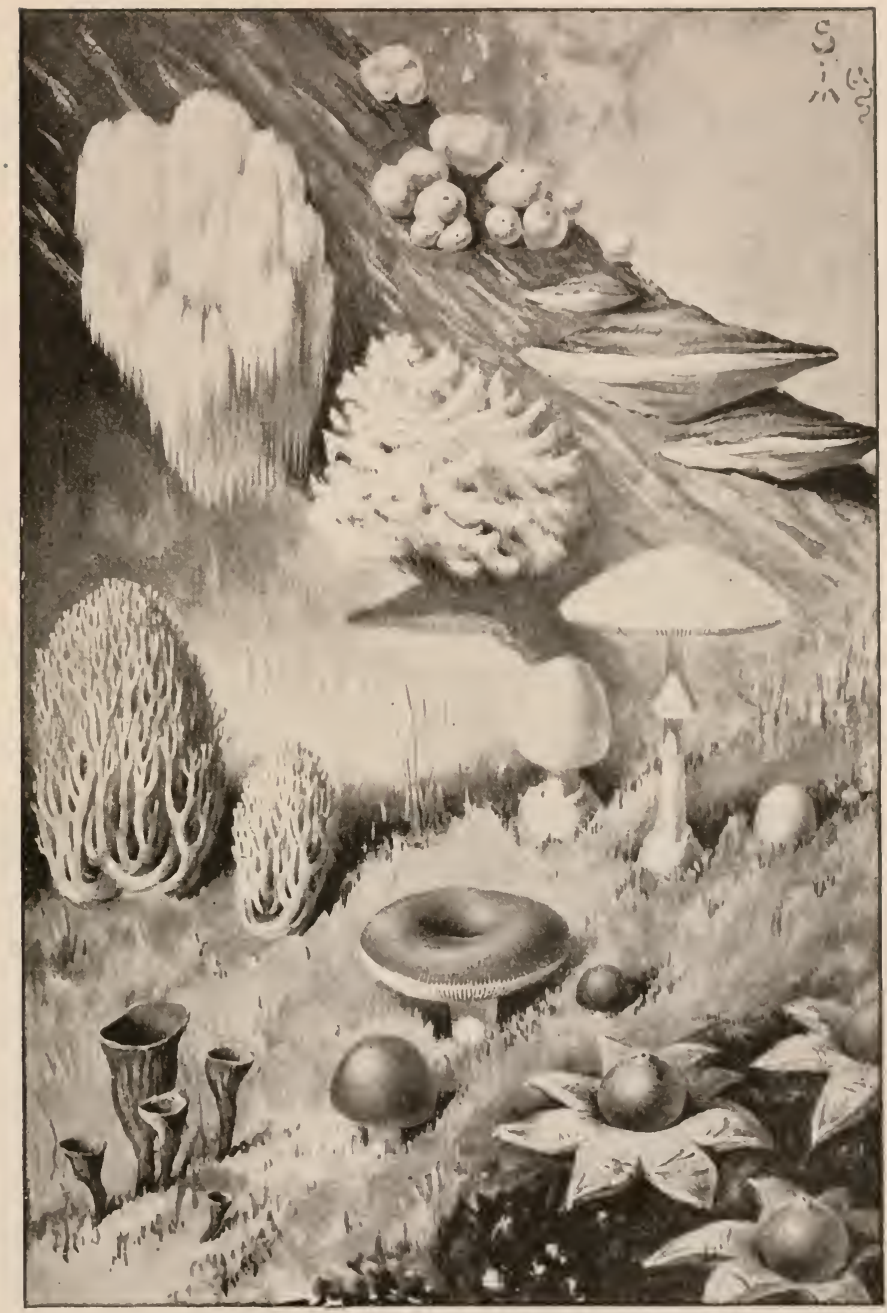

FIG. I58. Various forms of mushrooms. At top : puffballs in center, bracket fungus (Fomes) at right, Hydnums to left. Center: coral fungus (Clavaria) on left and poisonous Amanila on right. At bottom, left to right: cornucopia fungus (Cralerellus), Russula, and earthstars (Geaster). 
and burning the plants as soon as evidence of the disease appears.

Mushrooms and toadstools. The largest and most complex of the fungi are the mushrooms and toadstools. They are common in fields and woods and for the most part live on decaying wood and on humus in the soil. There is no real distinction between mushrooms and toadstools. Some of them are edible, others are indigestible, and some are deadly poisonous. Edible forms are cultivated on a large scale in caves and abandoned mines, and on a smaller scale in cellars. Wild forms should not be eaten unless they are gathered by persons competent to distinguish the different species, many of which are similar in appearance but very different in their effects when eaten.

The mushrooms as they are gathered are only the fruiting bodies of the fungi. The real plant consists of bundles of filaments extending in all directions throughout a large mass

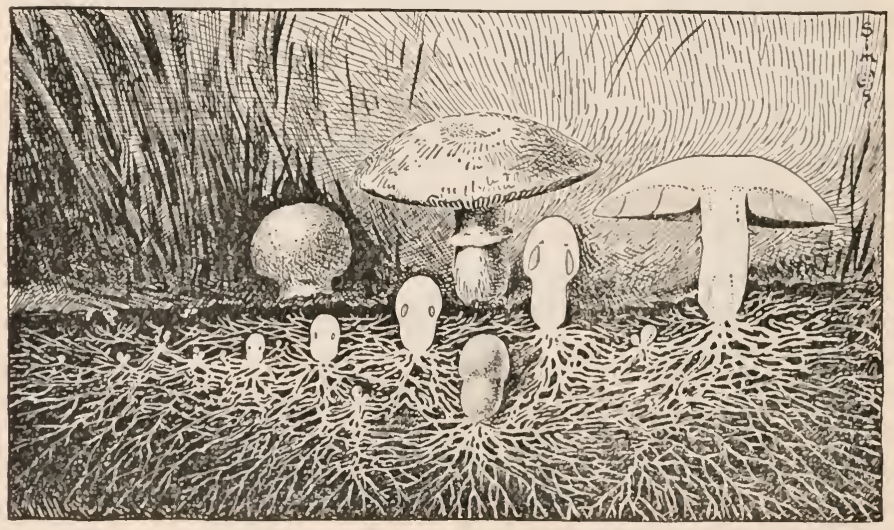

Frg. 159. Stages in the development of the common edible pink-gilled mushroom. Note the underground vegetative body of the plant. 
of soil on which the fruiting bodies appear. It may take several years for the underground vegetative part of the fungus to develop, while the fruiting bodies may develop in a few days. It is the enlargement of the fruiting bodies that persons have in mind when they speak of " mushroom growth." This expression leaves out of account the months or years of growth during which the materials were accumulated for the sudden production of the fruiting body. The spores of mushrooms are produced in unthinkable numbers either inside the fruiting body (puffballs), on the upper surface (morels), or on the under side of the umbrella-shaped cap (mushrooms) (Fig. I59).

Lichens. Among the parasitic fungi are some that live on such one-celled algæ as Protococcus. The fungus forms the plant body, and the algal cells are completely enveloped. These forms constitute the lichens, which are gray-green, irregular-shaped plants that are common on the bark of trees,

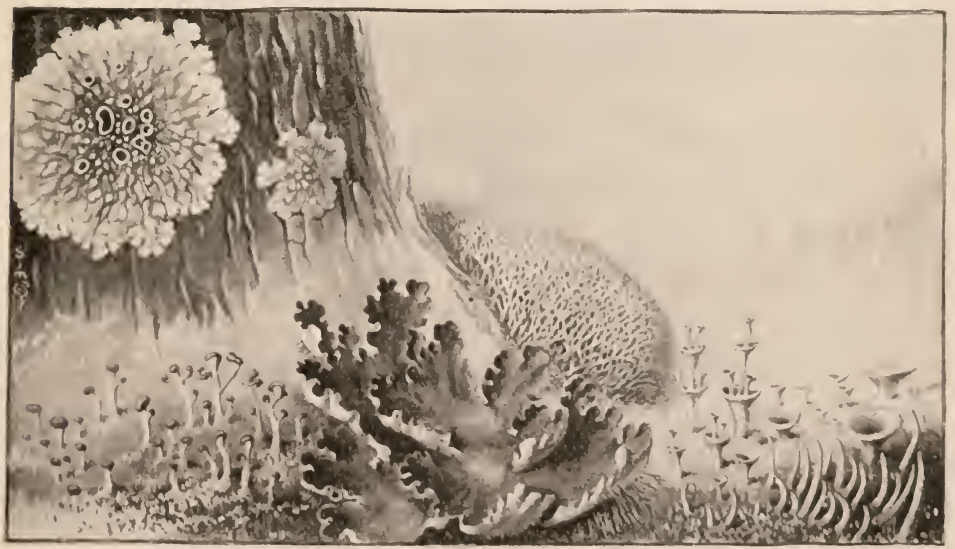

Fig. I60. Several common lichens. The form on the tree is Purmelia; the one in the middle foreground is Peltigcra; the other forms are species of Cladonia. 
on rock surfaces, and occasionally on the soil (Fig. I60). Like other fungi they produce fruiting bodies, - small cup-shaped or disklike elevations, - in which asexual spores are produced in great numbers.

Summary of the simple plants. The simplest forms of plant life include three great groups that are of the highest importance to man :

(I) The algæ constitute the primary food of fishes, and they will become increasingly important as the cultivation of ponds, lakes, and streams (aquaculture) for the production of fish becomes more necessary to augment our food supplies.

(2) The bacteria have a most important and intimate bearing upon the lives of all of us. They have made necessary our various food-preserving industries. Their existence everywhere is the chief factor that must be considered in personal hygiene and in the making of our sanitary laws. Some kinds of bacteria aid other forms of life by destroying the bodies of dead organisms and improving the fertility of soils; other bacteria are responsible for many diseases of both plants and animals.

(3) The fungi also are destructive agents, causing injury to our crop plants, the loss of much valuable food, and the destruction of timber. Forms like the yeasts are valuable aids in certain food industries. A very few of the fungi are themselves sources of food. The fungi are notable for the enormous number of spores which they produce.

Algæ are autophytes, while the bacteria and fungi are saprophytes or parasites. The algæ are of world-wide distribution, but they are chiefly confined to aquatic and marine habitats. The bacteria and fungi are also world-wide in their distribution, but they are most numerous on land. 
Suggestions for Laboratory and Field Work to Precede Chapter Twenty

1. Make a field study of liverworts and mosses, noting especially conditions most favorable to them. Examine underground parts as well as above-ground parts.

In winter a visit to a conservatory or greenhouse will enable students to see these forms in a growing condition.

2. Specimens of liverworts may be secured in spring from moist rocks along streams, from the soil in clover fields, and from trees in moist woods. In Marchantia, study particularly the thallus, rhizoids, growing region, cupules, gemmæ, and reproductive branches.

3. Of the mosses, Mnium and Polytrichum are particularly good to show protomena, rhizoids, stem, leaves, and reproductive structures. Compare the vegetative plant body of a moss with that of a liverwort in its relation to water, light, and air. 


\section{CHAPTER TWENTY}

\section{LIVERWORTS AND MOSSES}

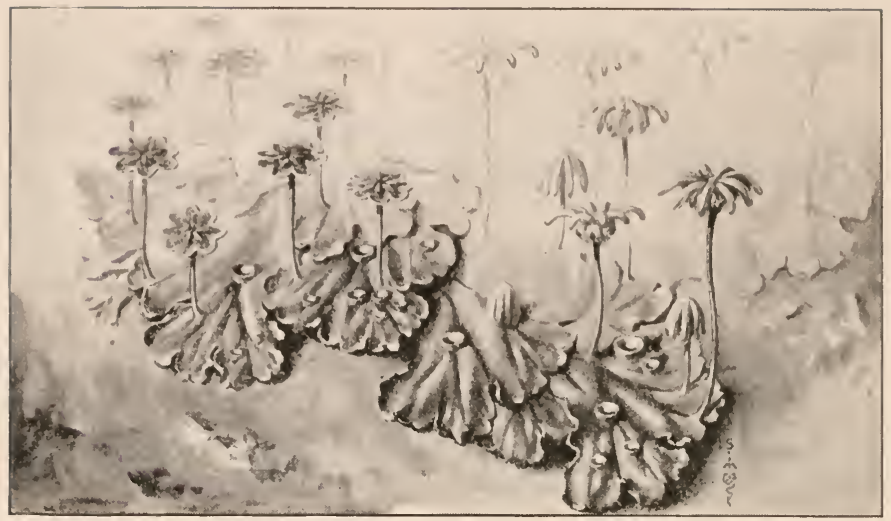

Fig. I6I. A common liverwort (Marchantia), showing thallus, cupules, and reproductive branches.

THE largest of the mosses and liverworts never attain a height or length of more than a few inches, and they are of very simple structure in comparison with the flowering plants. In contrast with the algæ, which on the whole are water plants, mosses and liverworts for the most part live on land. The passing of plants from a water to a land habitat is one of the notable steps in the development of the plant kingdom, and in connection with the study of this group we shall contrast the environments of land and water plants and consider the modifications in structure that accompany the passing of plants from the water to a land habitat.

The liverworts. The body of a liverwort is flat and leaflike and is called a thallus (plural, thalli). It may be from one to several cell layers in thickness. It grows at the tip, and usually branches by forking at intervals. Liverworts do not 
stand erect, but usually have their thalli in close contact with the substrata on which they grow. In most forms the thallus is a continuous plate of cells, but some forms have prostrate stems with small leaves on either side. All of them have chlorophyll and manufacture their own food. All the forms have on their under surfaces small, hairlike rhizoids that anchor the plant and absorb water and minerals.

Liverworts are widely distributed but are most numerous in the tropics. A few of them are found on trees and rocks and a few are found floating on water, but as a whole they live on moist soil and in shaded situations.

Reproduction among the liverworts takes place by means of spores, produced either directly on the thallus or on special branches. In many liverworts there are produced also special bodies called gemme (singular, gemma), which propagate the plants vegetatively.

The liverworts are supposed to be descended from plants like the green algæ, for it is thought that the simplest plants existed first and that plant life as well as animal life had its origin in the water. The liverworts may be considered, therefore, as a group of simple plants that exhibit some of the stages through which plants pass in going from the water and taking up their life upon.the land. In this respect they can be compared to the amphibious (Greek: amphi, double, and bios, life; i.e., life both on land and in water) frogs and salamanders of the animal world. Just how a plant becomes adjusted to its new environment, when it is forced to live on land because of the drying up of the pool in which it grew, is a most interesting question to consider.

Living conditions of water and land plants contrasted. The algx probably represent the remnants and derivatives 
of the first plants that grew on the earth, and the shallow water in which the fresh-water algæ live is the most favorable of all habitats for plants. Because the plants are of about the same weight as water or are lighter, they are supported by the water and do not need to use their foods for building mechanical tissues. In the shallow water there is sufficient light for photosynthesis, while the plants are protected from the heating and drying effects of the intense sunshine to which land plants in many situations are exposed. An abundant supply of the carbon dioxid and oxygen needed for photosynthesis and respiration is in solution in the water, and mineral salts sufficient for the needs of the plants are washed in with every rain. Furthermore, the temperature is more uniform than on land, and this permits the processes of growth and reproduction to go on almost uninterruptedly throughout the entire twenty-four hours. The length of the growing season in temperate and cold climates is longer under the water than on land, because the water protects the plants from the sudden changes of temperature to which land plants are subjected in the spring and fall. The shallow-water plants, therefore, live under the conditions most favorable for plant life. Even the deep-water plants like some of the marine algæ, although they are under the great disadvantage of having little light, gain many advantages through their water environment.

The environment of the land plant provides a supply of carbon dioxid and oxygen directly from the atmosphere, and mineral salts may be secured from the soil water with which the plants are in contact. But if the plant grows in full sunlight, it is subjected to much more intense illumination and heating than are water plants, and it must withstand the 
drying effects of the air. In aquatic plants the cells are never without an adequate supply of water, while in land plants

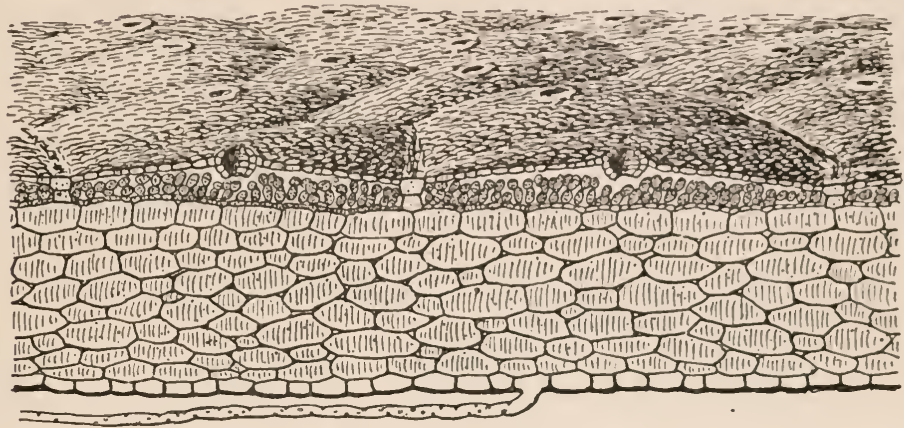

Fig. 162. Cross section of Marchantia thallus, showing rhizoid (below), waterstorage tissue, the air chambers containing the principal photosynthetic cells, and the epidermis which forms a transparent roof over the air chambers.

transpiration may reduce the water content of the cells to such an extent that they may be injured or even die. A study of the amphibious liverworts shows that they have become adjusted only to a medium light and a moderate amount of drying. These plants, therefore, grow in shaded and moist situations. During wet periods many individuals start in intensely illuminated places, only to be killed off by the light and its secondary temperature and drought effects. The shaded situation where the water is near the surface of the soil is evidently the habitat where these plants suffer the least, and this explains why liverworts persist in moist situations and not in the open.

Responses of the plant to the aërial environment. The land liverworts show several changes in structure that are of advantage to the plants in an aërial life. The more important of them are: 
(1) Firmer, and in some cases thicker, cell walls and waterstorage tissue. The firmer cell walls are less permeable to water and reduce the rate of water loss. Furthermore, the plants grow flat on the soil in contact with the water supply, and some of the forms develop layers of water-storage cells on the side in contact with the soil (Fig. 162). This enables them to withstand short dry periods better than do those forms that have only the ordinary green cells. The development of firmer cell walls and water-storage tissue is the first adjustment to land conditions.

(2) The development of rlizoids. Land plants are liable to be washed away by rain and surface water, and on this account they need some anchorage; also, it is necessary for them to have structures that will bring them into contact with the soil-water supply. In the liverworts, rhizoids anchor the plant and to some extent absorb water and mineral salts from the soil. Rhizoids are elongated cells that develop on the lower side of the plant body and penetrate the soil. They resemble root hairs in form. The development of rhizoids, therefore, represents a second important adjustment of plants to the land environment.

(3) The development of an epidermis. The land liverworts are covered by an epidermis which helps to protect them against water losses. Since a ready access to carbon dioxid and oxygen is necessary for photosynthesis and respiration, the liverworts with thicker bodies have openings or pores in the epidermis. Through these pores the gas exchanges between the air and the cells within the body can take place. In the more complex liverworts, the epidermis is raised like a transparent roof on ridges of supporting tissues, leaving beneath it a series of small air chambers in which the 
chlorophyll-bearing cells stand up in short chains (Fig. I62). Each chamber is connected with the air by a pore in the center of its roof. In these rather simple plants, therefore, protection against water loss is accomplished in much the same way as in seed plants, but the epidermal pores in them are chimney-like openings and are incapable of closing as do the stomata of the higher plants. The development of an epidermis and of pores is a third adjustment of plants to the land environment.

(4) The ability to withstand drying. When the cells of water plants are dried, the protoplasm dies at once; but a few of the liverworts, like many mosses and like Protococcus and a few other algæ, do not die when water is lost from the cells. Just what quality the protoplasm possesses that enables it to withstand drying, it is impossible to say; but some of the liverworts that grow on trees and rocks possess this quality, and certain mosses have to a remarkable degree the ability to withstand drying. A fourth adjustment of plants to the land environment is the development of the ability to withstand drying.

The mosses. The mosses form a very large group found in all parts of the world. They usually have upright stems, though many live close to the substratum and have only horizontal or inclined stems. They possess very simple leaves, frequently only one cell layer in thickness, sometimes thicker toward the midrib.

The mosses, like the liverworts, are most abundant in moist, partly shaded habitats. A few, however, grow on rocks and trees where they are exposed to periodic drought. These latter forms, like Protococcus, have the power to withstand complete drying. When dry, they are in a dormant 


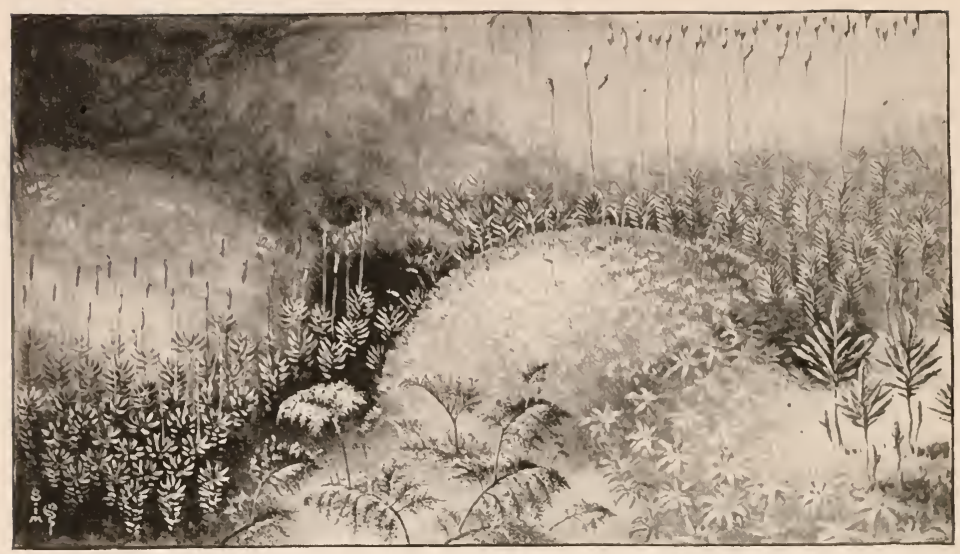

FIG. I63. Mosses, showing the compact grouping of the plants.

condition; and when wet, they go on with their normal processes of photosynthesis, respiration, growth, and reproduction.

Mosses also possess means of anchorage by rhizoids. The rhizoids of the liverworts are one-celled structures. . Those of the mosses are branching, many-celled structures which penetrate the soil, affording a firm hold and absorbing a part of the water used by the plant. The habit of growing in compact clusters gives the mosses a method of conserving water and maintaining the water balance, other than the methods spoken of in connection with the liverworts; the dense masses of plants take up water from rains and hold it for some time like a sponge.

Mosses, therefore, show some advances over the liverworts in their upright stems and branching rhizoids, in the regular occurrence of simple leaves, and in their ability to grow in drier habitats. The liverworts and mosses together show the 
successful adjustment of simple green plants to the land environment.

Life history of the moss. Mosses reproduce by vegetative propagation and by both sexual and asexual spores. A study of each of these methods will make clear the somewhat complicated life history of the moss plant.

Vegetatice multiplication. When a moss spore germinates on the soil, it produces a branching, filamentous

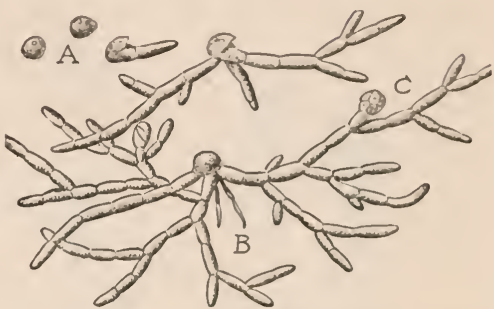

FIG. I64. Moss spores $(A)$ and protonema $(B)$, with a bud $(C)$ from which an upright stem develops. body, the protonema, which resembles some of the branchirg forms among the green algx. The protonema spreads over the soil for some distance and then develops numerous buds (Fig. I64). The buds give rise to the upright leafy branches which we commonly call the moss plant. Because of the numerous buds developed on the protonema, the moss plants stand in thick clusters or masses.

The upright leafy stems of the moss also have the power of producing protonema-like branches which spread still farther over the soil, thus serving to multiply the plants and to make the plant mass denser and larger. In some mosses with horizontal or inclined stems, the stem tips when in contact with the soil develop rhizoids and give rise to new branches, much as the stems of the raspberry develop new plants (page 2I7). These methods of regetative propagation are common among the mosses, and some mosses are not known to multiply in any other way.

Sexual reproduction. The upright stems of most mosses 
when mature produce gametes - egg and sperm cells - in special organs at the stem tips. The sperms are swimming

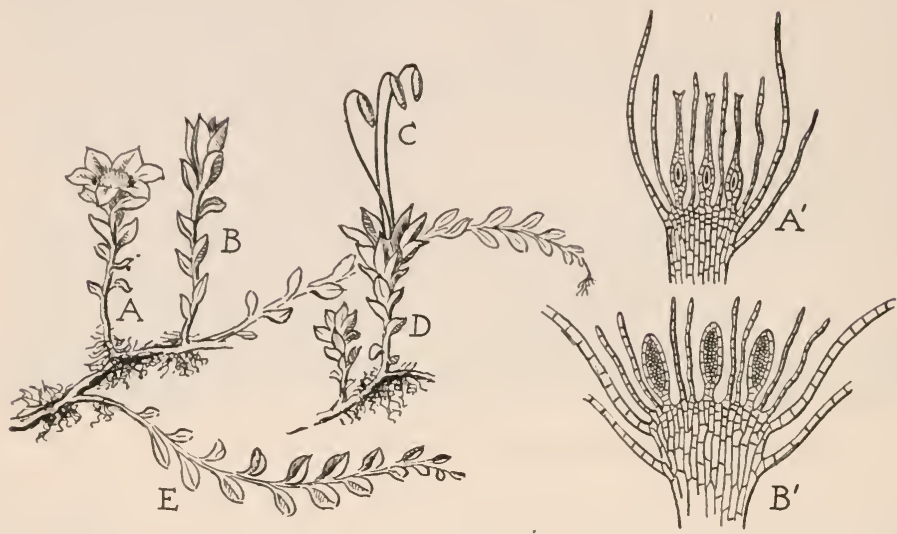

Fig. ${ }^{6} 65$. A moss plant (Mnium). $\quad E$ is a vegetative branch, $B$ a branch that produces eggs, and $A$ a branch that produces sperms. After fertilization, an upright stalk bearing a spore case $(C)$ develops from the egg. $A^{\prime}$ is a longitudinal section of a female branch, showing three egg cells in the cases in which they are produced; $B^{\prime}$ is a section of a male branch, showing three of the organs that produce the sperms.

cells much like those of algæ. As they cannot reach the egg cells except by swimming, fertilization takes place only when the moss is wet. When the sperm unites with the egg, it forms an oöspore.

Asexual reproduction. The oöspore germinates while still on top of the parent stem, and produces a long, stalklike body. The base of this body grows downward into the parent stem and draws water and nourishment from it. At the top of the stalk a sporangium or capsule develops which contains asexual spores. The stalk and sporangium live parasitically on the green, leafy moss plant and are a distinct stage in the life of the plant. 
The first stage in the life history of the plant ends with the production of oöspores. The second stage ends with the formation of asexual spores. When the asexual spores germinate, they again produce the protonema and the leafy moss plants. The asexual spores are small, firm-walled, rounded bodies that are able to withstand the drying effects of the air. They are fitted to be blown about, and so to start the growth of the plant in new areas. Most moss plants are perennials, and they produce both oöspores and asexual spores on new branches for several years.

Summary. Liverworts and mosses constitute a group of rather simple land and amphibious plants. They are of particular interest because they show some of the steps by which simple water plants become adjusted to conditions on land. This group represents the most complex of the land plants that lack a conductive system. In the next group, the ferns, the plant has a well-developed water-conducting and foodconducting system, and correlated with this it has greater size and more complex tissue systems. 


\section{Suggestions for Laboratory and Field Work to Precede}

\section{Chapter Twenty-one}

1. Make a field trip to study ferns and their allies. Ferns are common in rich woods and on moist cliffs. Equisetums may be found along streams and railway embankments, and in swamps. The club mosses occur in low grounds, in rich woods, and in moist, sandy depressions along lake and sea beaches. Tropical forms may be seen in conservatories and greenhouses. Note especially the relative development of leaves, stems, and roots. Compare them with the seed plants growing in the same habitats. Have they any advantages over the mosses, liverworts, and algæ that live near them?

2. Examine growing plants and note how fern leaves unfold. Note the sporangia and spores on the under sides of the leaves. Plant some of the spores on moist soil in a flower pot and cover with a glass plate. Examine the prothalli that develop from the spores.

3. If field work is impossible, examine a collection of pressed specimens of ferns and allied plants, in order to get an idea of the great variety of forms belonging to these groups. 


\section{CHAPTER TWENTY-ONE}

\section{THE FERNS AND THEIR ALLIES}

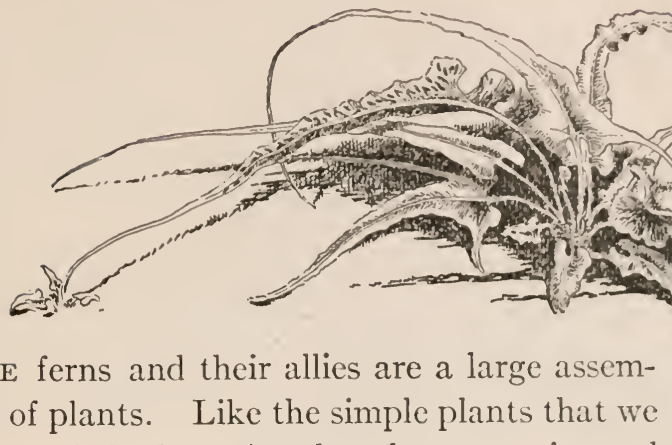

THE ferns and their allies are a large assemblage of plants. Like the simple plants that we have studied, they reproduce by spores instead of seeds; but, like the seed plants, they possess water-conducting and food-conducting tissues. They appeared on the earth earlier than the seed plants, and were more abundant during the carboniferous or coal-making period of the earth's history than they are now. Indeed, judging by the fossils in coal, ferns and fernlike plants dominated the vegetation of that time, and the seed plants were much less prominent than now. Ever since that period the seed plants have been gaining in importance; and now the ferns have been to a large extent displaced, especially in the temperate and colder parts of the earth. Three groups of these plants that are sufficiently distinct to be readily recognized occur rather commonly in North America. They are the forns, equisctums, and club mosses.

Fig. I66. The walking fern. New plants are developed from buds at the ends of the leaves. 


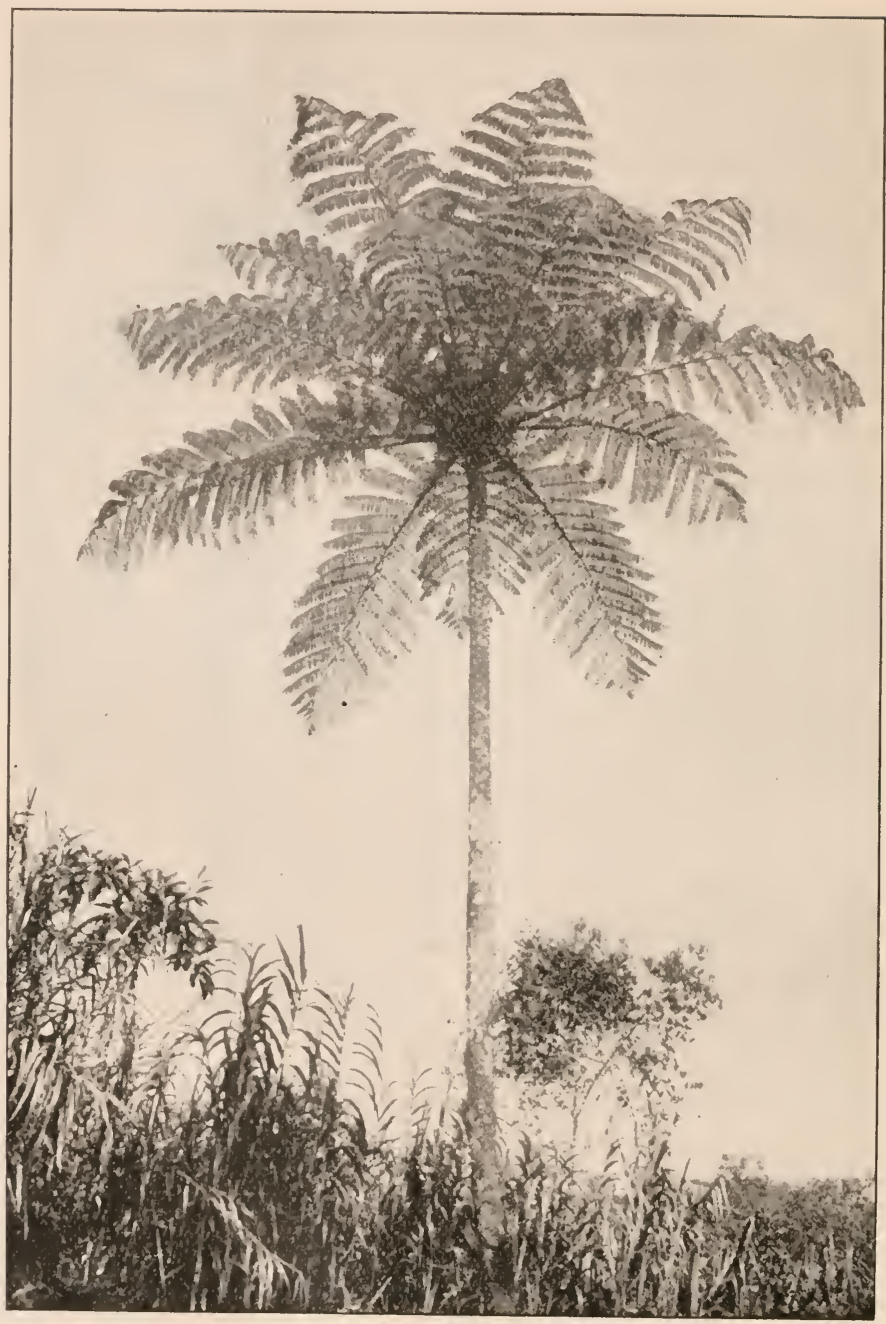

FIG. 167. A tree fern. 


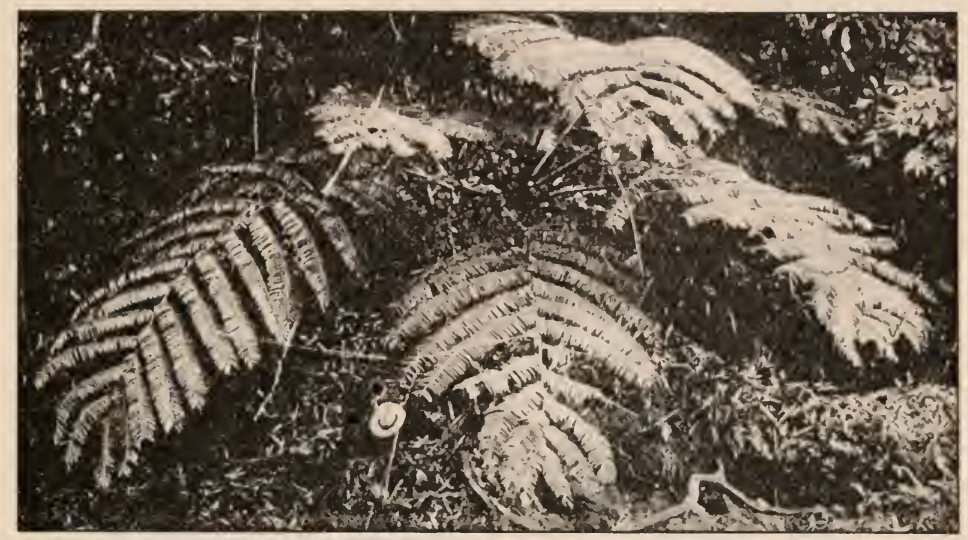

FIG. I68: A large tropical fern (Marratia), with leaves over 30 feet in length. Philippine Islands.

The ferns. The ferns are noted for the large size of their foliage leaves. In temperate regions these leaves are much branched and in some species attain lengths of from 3 to 6 feet. They usually rise from underground stems, which may be long, slender, and horizontal or short, thick, and upright. The venation of the leaves differs from that of seed plants in being forked; that is, each vein divides into two smaller ones, and each of these subdivides in the same manner. The root systems of the ferns are all small and scantily branched as compared with those of the seed plants. This is probably the reason why ferns as a rule are confined to moist habitats.

In the moist tropics there are many species of tree ferns with upright columnar stems bearing a rosette of leaves at the summit. The stems may attain heights of from io to 50 feet, and they bear leaves 5 to 5 feet in length.

The equisetums, or horsetails. In swamps, on the banks of streams, and on railroad embankments one can find slender, 
columnar plants with scale leaves and spore-bearing cones on the ends of the upright branches. These are the remnants of a group that made up a large part of the vegetation during the carboniferous period. Many of the species are evergreen.

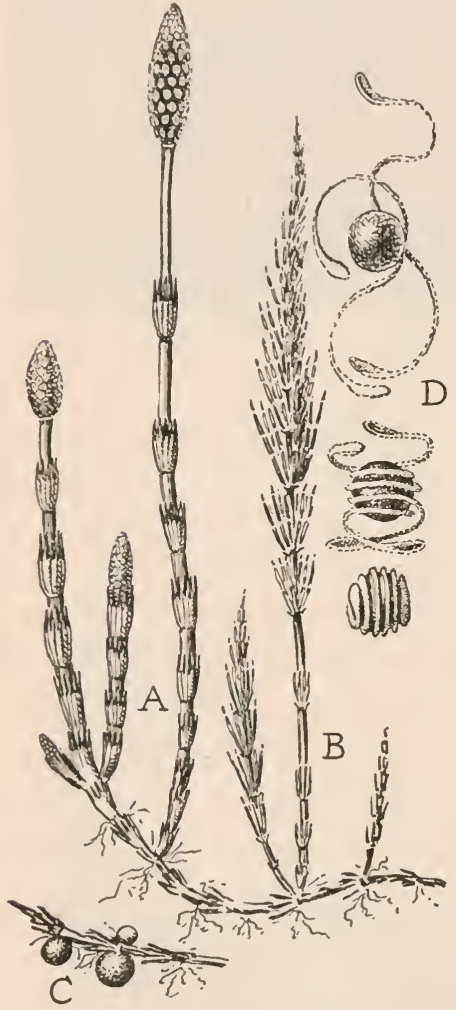

FIG. 169. The common field equisetum. Rootstock with sterile branches $(B)$, spore-bearing branches $(A)$, and tubers (C). $D$ shows the spores with their appendages.
The equisetums are for the most part stream-margin and swamp plants, and, as might be expected, the stems have air cavities extending throughout. In some species the stems develop at each node whorls of slender branches, which together form a brush, suggesting the common name "horse-tail" for the group.

Like the ferns, most of the species develop an extensive system of underground stems from which the upright branches rise. In the absence of foliage leaves, the stems do all the photosynthetic work. The roots are small, like those of the ferns. Spores are produced in the cones which terminate the upright stems.

The club mosses. These are creeping and trailing evergreen plants found in rich woods and bogs, particularly in the northern United States. They 
are much used for decorative purposes at Christmas time and are sold under various names such as "ground pine"

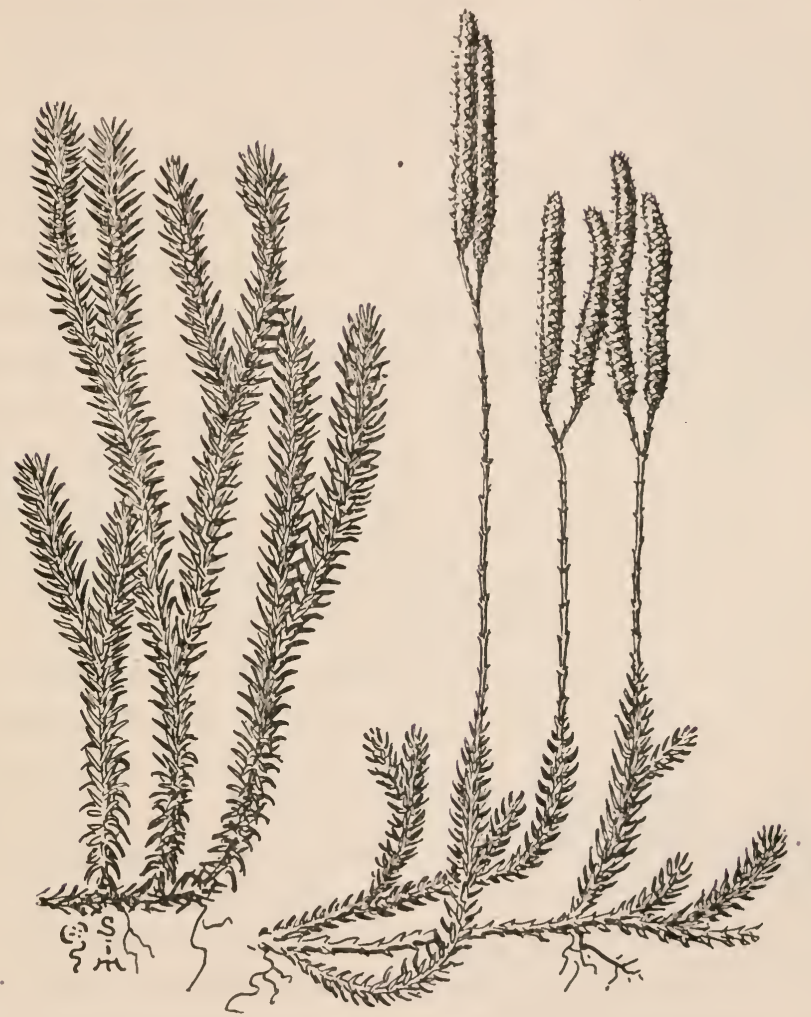

FIG. I70. Two species of club mosses (Lycopodium). In one species (left) the sporangia are borne in the axils of the upper leaves, in the other (right) they are borne in terminal cones.

and "running cypress." The main stems are prostrate on the soil and may be many feet long. They are anchored at intervals by short roots. Numerous upright branches rise 
from the prostrate stems. The stems bear large numbers of scale leaves, and the spores are produced in terminal cones. The spores are sold in drug stores under the name "lycopodium powder." They are used as a drying powder and in the manufacture of fireworks.

The club mosses were of large size and very abundant during the time when the carboniferous rocks were deposited, and with the ferns and equisetums they formed the chief part of the forests of that geological period. The coal which we now burn is the last remnant of the carbon compounds formed by plants from the carbon dioxid then present in the atmosphere. Certain of the club mosses, like some of the ferns, show stages in the transition from reproduction by spores to reproduction by seeds. The club mosses and equisetums have highly branched stems and many small, scalelike leaves. In the ferns there is little branching of the stem and the leaves are large and often much divided.

The two generations of the ferns. One of the most interesting features of the life history of the fernlike plants is the fact that there are two very different plants produced during one life cycle. Asexual spores are produced on the under surfaces of fern leaves, and when these are planted on soil and allowed to germinate, we find that in about 6 weeks the soil is covered with small, heart-shaped thalli which look very much like liverworts. These thalli represent one generation of the fern plant. Each thallus consists of an irregular plate of cells, a single cell layer in thickness except toward the middle, where it may consist of several layers (Fig. I 72 ). The prothallus, as the plant is called in this stage, is anchored to the soil by one-celled rhizoids. It manufactures its own food and has an existence similar to that of a liverwort. 
When mature, the prothallus produces egg cells and sperms in small organs on its under surface. The sperms are small and swim actively, and they reach the egg cells when the thallus is wet. The sperm unites with the egg and forms an oöspore. The formation of the oöspore completes the life of this, the sexual, generation of the fern.

The oöspore germinates while still attached to the little prothallus, and from it develops the large fern plant with which we are familiar. This second generation has true roots, stems, and leaves, and on the lower side of the leaves great numbers of sporangia are produced. These lie in groups which may be seen with the naked eye as

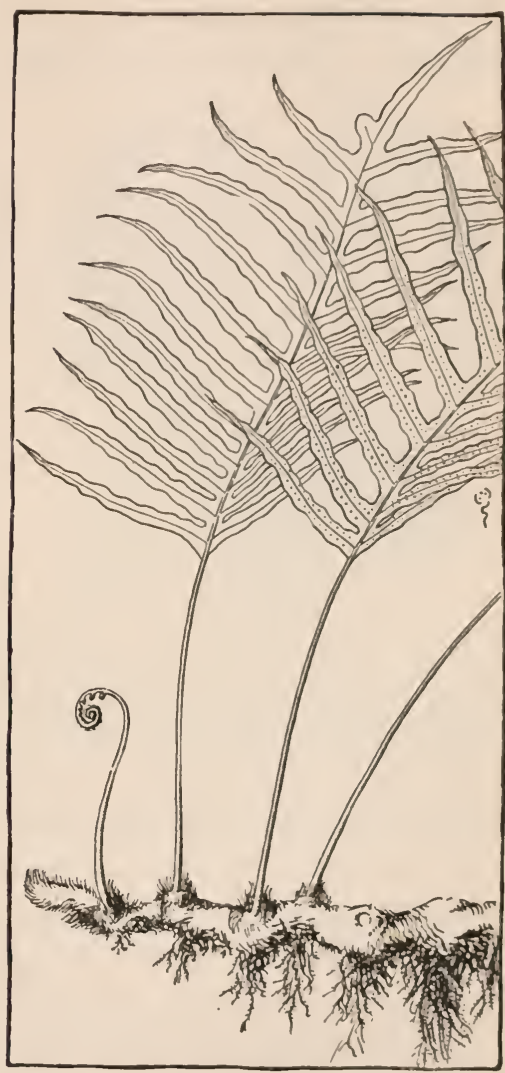

FIG. I7I. Underground stem, roots, and leaves of fern.

brown dots. Within the sporangia asexual spores are formed, and because asexual spores are produced by this generation, it may be called the asexual generation of the plant.

The ferns, therefore, do not reproduce themselves directly. The plants with the large, feathery leaves that we know as 
ferns produce asexual spores from which small, flat prothalli develop. The prothalli in turn produce gametes and sexual

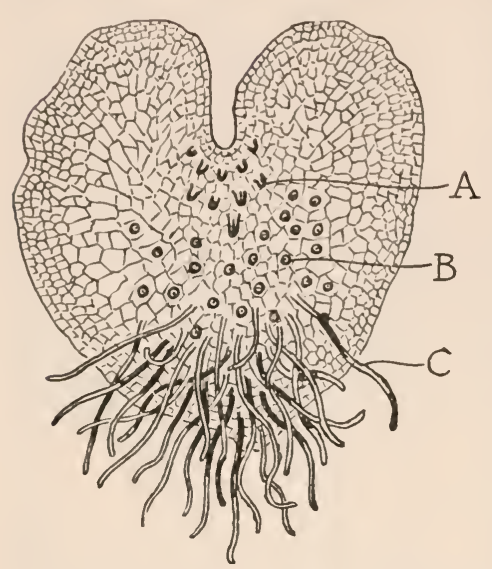

Fig. I72. Under side of fern prothallus, showing egg-producing organs (archegonia) $(A)$, the sperm-producing organs (antheridia) $(B)$, and the rhizoids $(C)$. spores, which then germinate to form the fern plants proper. This alternation of two unlike generations in the life history of the fern is most interesting. The alternation of an asexual generation with a small sexual generation occurs in mosses (page 279) as well as in ferns, and it is found also in most of the other great plant groups. However, the alternation of generations is not so easy to study in groups, other than the ferns, in which the two generations do not grow independently of each other. In some of the ferns and also in some of the club mosses, the sporangia and the sexual generations show stages in the development of these structures into the seeds of the higher plants; but the origin of seeds is too complex a question to be discussed here.

The significance of the conductive system in plants. The algæ, being immersed in water, have a constant water supply. The fungi have an adequate water supply because they live inside other plants that have water-conducting tissue, or because they grow in moist soil or within stumps and logs. A water balance is maintained among the mosses and liverworts by their growing in spongelike masses and in close contact with the soil water; but within these plants water 


\section{The Ferns and Their Allies}

can be transmitted from one part to another only slowly by diffusion from cell to cell. They have no water-conducting
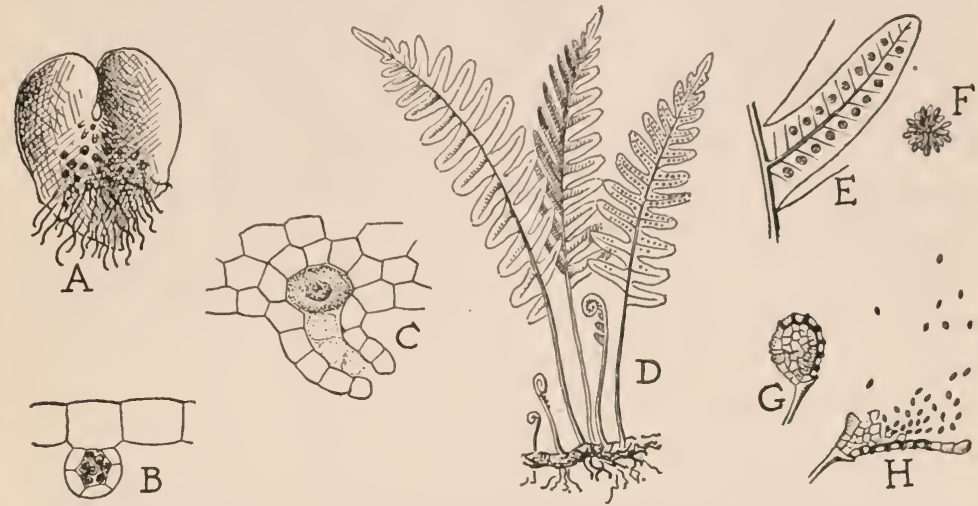

FIG. I73. The life history of a fern. The prothallus (A) produces egg cells and sperms in organs on the lower surface. One of the sperms set free from $B$ unites with an egg cell (shown in $C$ ), and produces a sexual spore. This germinates and produces the leafy fern plant $(D)$, which in turn produces asexual spores $(G)$ on the lower side of the leaves. By the bursting of the walls of the sporangium $(I)$, the spores are set free. They then germinate on the soil (in some species on rocks or trees) and produce a new generation of prothalli like the one shown in $A$. The prothallus is here shown about 4 times its natural size.

or food-conducting tissues, and for this reason they are all of small size.

The development of a conductive system is, therefore, an additional step in the complete adjustment of plants to a land environment. With a conductive system, the water may be carried rapidly from one part of a plant to another. Consequently stems and leaves may be raised far above the ground level and yet receive sufficient water from the roots to replace that lost through transpiration. Likewise an adequate supply of food may be transferred to the roots, which makes it possible for them to live in the soil, where they are unable to 
manufacture food for themselves. This permits a great increase in the size of the plant body, and makes possible a high degree of specialization in plant organs and tissues. As far as is known, the ferns and their relatives were the first plants to develop a conductive system. We do not know how the conductive system originated, but its coming into existence marked perhaps the most important step in the progress of the plant kingdom.

Summary. The ferns and their allies constitute the remnant of a very ancient and important group of spore plants. In the study of the evolution of seed plants they are of interest (I) because they have two entirely separate generations, a small, sexual one which produces gametes, and the large, leafy plant which produces asexual spores; (2) because they show some of the stages in the transition from plants which reproduce only by spores to plants that produce seeds; and (3) because they were the first plants to develop a conductive system. The presence of a conductive system enables these plants to raise leaves and stems well above the soil and to expose their photosynthetic tissues to the light far better than any of the preceding groups. The ferns do not have extensive root systems, and consequently are more closely confined to moist habitats than are the seed plants. 


\section{Suggestions for Laboratory and Field Work to Precede Chapter Twenty-two}

1. Field work or a trip to a greenhouse will help to make clear some of the characteristics of seed plants, and the differences in the plants belonging to the several divisions of the group.

2. Examine vegetative shoots of pine, hemlock, spruce, cypress, arbor vitæ, or other available conifers, and compare their leaves and stems with those of the ferns and angiosperms.

3. Material collected from one of the conifers in the spring, showing the staminate and carpellate cones, should be studied in the laboratory. Mature cones may be obtained at any time, and they will show the relation of seeds to scales. 


\section{CHAPTER TWENTY-TWO}

\section{SEED PLANTS: GYMNOSPERMS}

SEED plants form the most conspicuous part of the earth's vegetation, and they include the majority of the plants that are of interest as sources of food, lumber, and fibers. They are the plants with which we are most familiar, and for this reason the first seventeen chapters of this book have been devoted to a description of their structures, processes, and environmental relations. Here the great groups into which the seed plants are divided will be described, and some of the more important families in these larger groups will be briefly discussed. The two most important groups of living seed plants are the Gymnosperms and the Angiosperms.

The gymnosperms. The familiar representatives of the gymnosperm group are the conifers, or cone-bearing trees. The name "gymnosperm" (Greek: gymnos, naked, and sperm, seed) suggests the most distinctive feature of the group. 'The seeds are borne exposed on the upper surface of scales, which make up the cones. They are not inclosed by a pistil wall as are the seeds of the next group.

The conifers. The conifers have scale and needle leaves. The red cedar and arbor vita are of the scale-leaf type; the pines, spruces, and hemlocks are of the needle-leaf type. The stems are woody, much branched, and of large size. Indeed, the largest trees in the world, the giant sequoias, or Big Trees, of California, belong to this group. The distinctive feature of gymnosperm wood is the absence of water-conducting tubes. The wood cells perform the double function of supporting the tree and conducting the water. Many of the conifers have large resin tubes extending throughout the plant. Just what advantage comes to a plant through 


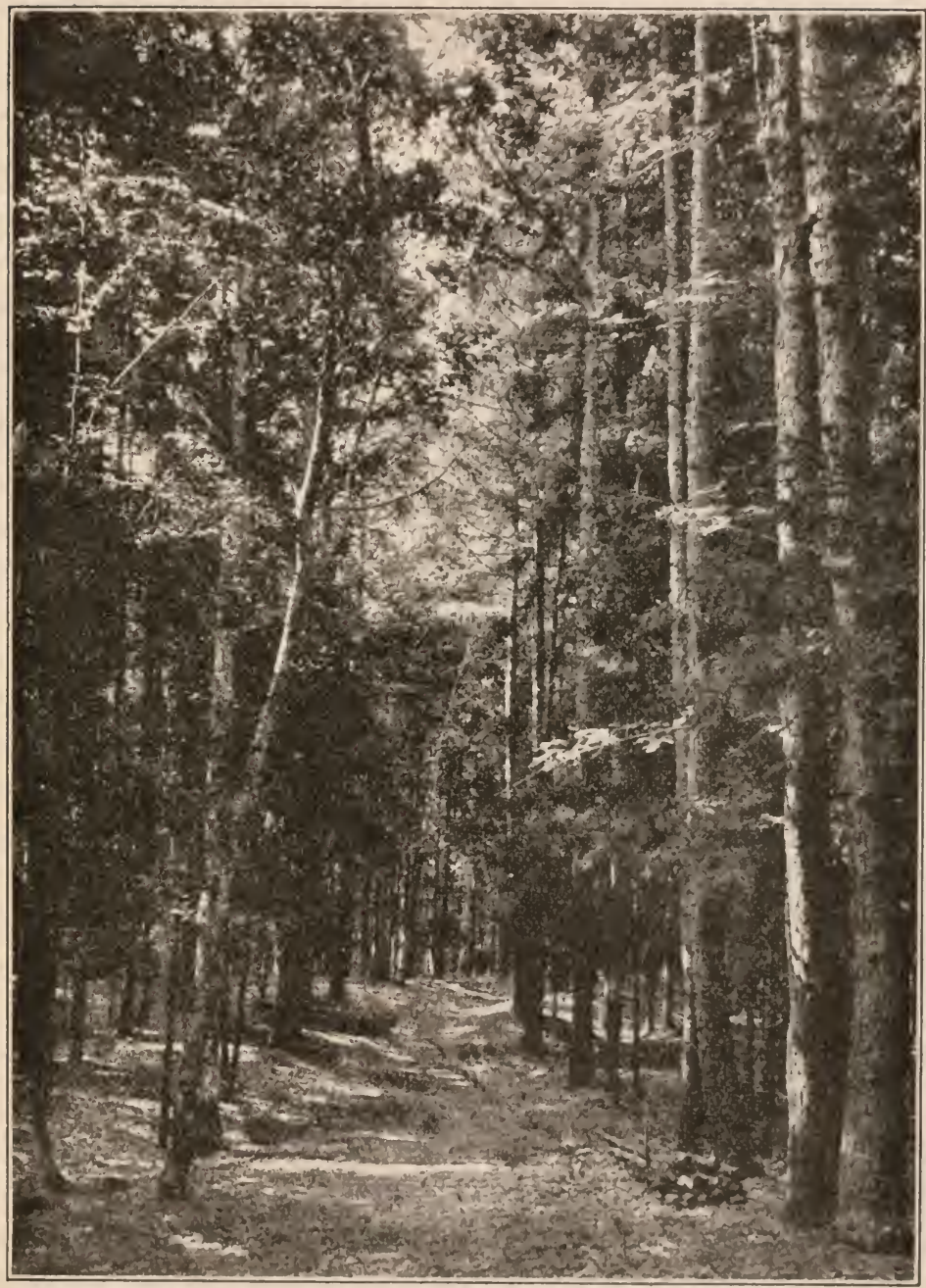

Fig. 174. Pine forest, witl an uccasional maple, birch, or aspen. 
the formation of resin is not known. Resin is a valuable commercial product, and in the Southern states the longleaf pine furnishes the crude rosin and the turpentine of commerce.

Leaves of conifers. The leaves of most conifers are evergreen and remain on the trees for a period of from 2 to 10 years, depending somewhat upon climatic conditions. In general they last longer in moist habitats. The Northern larch or tamarack and the Southern cypress are deciduous trees with soft needle leaves that contrast strongly with the hard needle leaves of the evergreens; the hardness of the evergreen needles makes it possible for them to withstand the winter droughts.

Roots of conifers. The roots of conifers are far better developed than are those of the ferns. Like deciduous trees, they have root systems that gradually taper from the stem base and spread over a wide area. The great root system makes possible the development of a large crown and the exposure of a greater leaf surface than in the ferns.

Production of seeds. The production of seeds in conifers may be illustrated by the pine. Two kinds of cones are produced: the staminate cones that produce the pollen, and the ovulate cones that bear the seeds (Fig. I75). The staminate cones are short-lived structures of early spring. Each scale bears two pollen sacs, which contain the pollen grains. The pollen is blown about by the wind, and each grain has on its sides two little air sacs that cause it to be carried through the air easily. It is produced in enormous quantities; and when it is shed, it oftentimes colors the ground yellow in the vicinity of pine woods. The staminate cone of the conifers corresponds to a staminate flower in the flowering plants; 
it lacks a calyx and a corolla, but its scales produce pollen and therefore correspond to the stamens of a lily or rose.

Each scale of the ovulate cone has two ovules, or young seeds, on its upper surface. At the time when the pollen is shed these scales stand open, or are separated from one another, so that the pollen falls on them and slides down to the bases of the scales, where it comes into contact with the young ovules. Then the scales of the cone

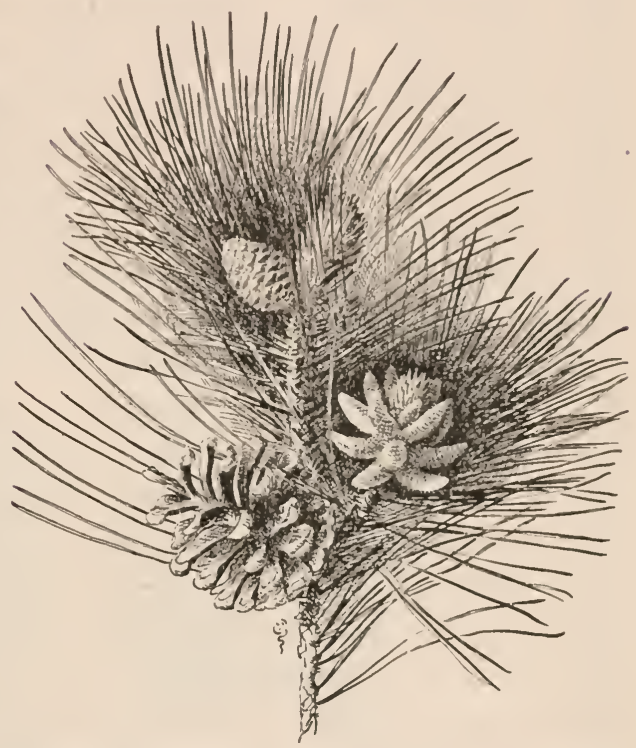
close up tightly, and the pollen grains develop pollen tubes.

FIG. 175. Spray of Austrian pine. At the left (above) is a $\mathrm{I}$-year-old and (below) a 2 -year-old ovulate cone. On the right is a cluster of staminate cones.

These grow down into the ovules and produce sperms which finally fertilize the eggs. As a result of fertilization, an embryo is produced, and the ovule walls become the seed coats: The growth of the pollen tube is very slow in conifers, and it is only at the close of one or two years' growth that the seeds mature and the ovulate cones die. Then the drying out and spreading of the scales permits the winged seeds to fall out or to be blown out and carricd to the ground.

In many cases the seeds of conifers have hard waterproof 
coats which may cause them to remain dormant for long periods. When planted, some of the seeds germinate the first season, others the second, and some not until the third or fourth year. This tends to insure some of the seedlings favorable conditions for growth. All the seeds will germinate the first season if the waterproof outer coat is ground off by shaking the seeds with sharp sand. In tree nurseries seeds are usually treated in this way, so as to insure the rapid and uniform development of the seedlings.

The conifer forests of North America. The greater part of the forested area of this continent is occupied by conifers. One of the striking characteristics of conifer forests is the fact that extensive areas are often occupied by a single species. In the Northern Evergreen Forest, which stretches from the lower St. Lawrence basin to Alaska and extends southward in the Alleghanies to northern Alabama, the principal trees are the white and black spruce, white pine, hemlock, jack pine, balsam fir, tamarack, and arbor vitæ. The spruces are the principal source of the wood pulp used in the manufacture of paper. The white pine formerly furnished the most durable and most desirable lumber in the Eastern states, but the supply of this lumber is now almost exhausted.

In the Southeastern Evergreen Forest, which extends along the coastal plain from New Jersey to Texas, the long-leafed and short-leafed pines, the loblolly pine, the cypress, and the red cedar are the most important timber trees. The longleafed pine is the source of rosin and turpentine, and with other pines and the cypress it supplies much of the lumber for interior finishings and other building purposes. Cypress lumber is noted for its durability in moist situations where other lumber soon decays through the attacks of fungi. 


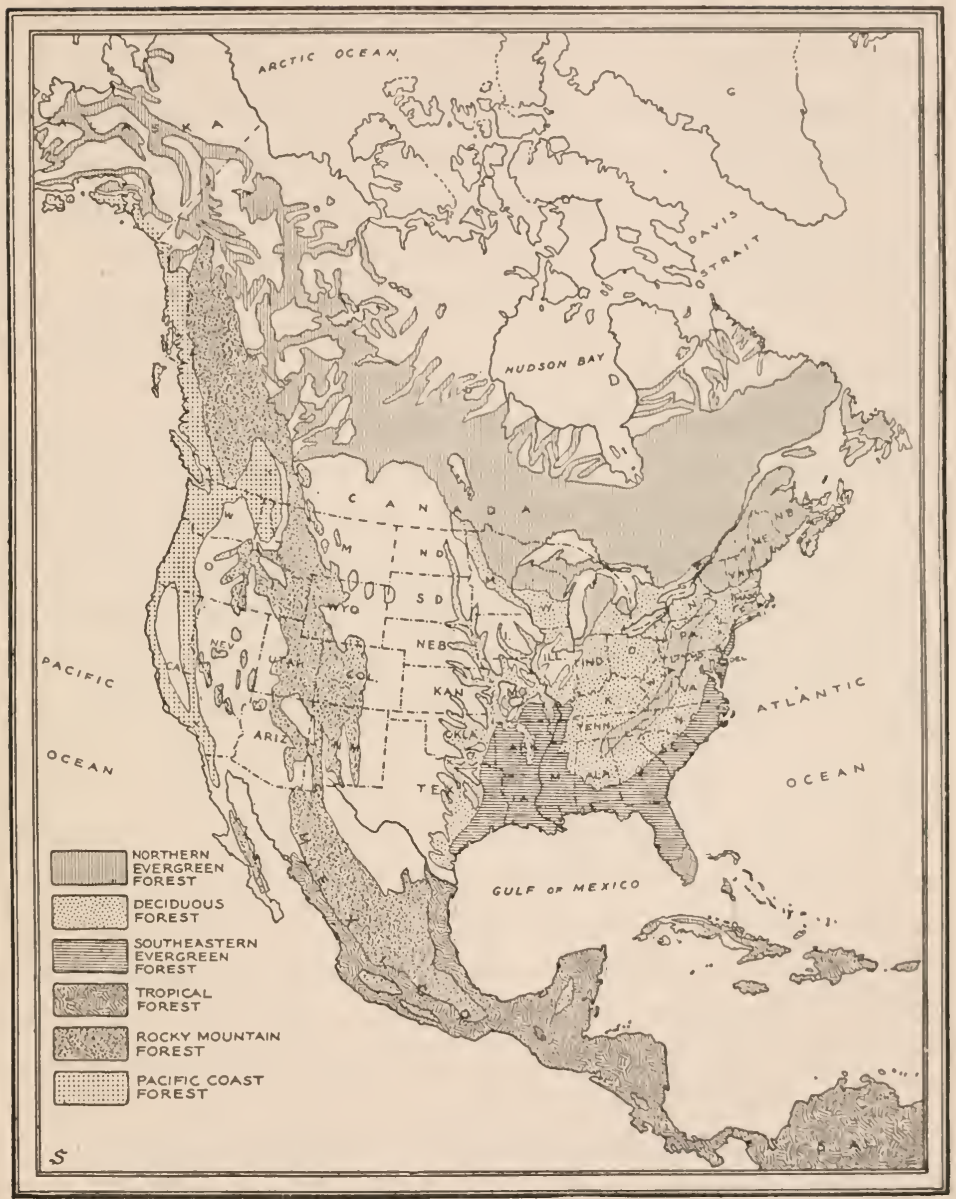

FIg. 176. Map showing the distribution of the forests of North America.

The Western Evergreen Forest covers the Rockies, Selkirks, and Sierra Nevada and Coast ranges, from southern Alaska to Mexico. Throughout this vast area the dominant 
trees are the Western yellow pine, Douglas fir, lodgepole pine, redwood, pin̄on, and Sitka spruce; and there are numerous less important cedars, spruces, firs, and pines. With the increasing demand for lumber and the gradual destruction of the Eastern forests, more and more of the wood from the Western forests is reaching Eastern lumber markets. The seeds of the piñon are large and pleasantly flavored, and formerly they furnished much of the food for the Indians of California and the lower Great Basin region.

The significance of reproduction by seeds. In a former chapter (page 207) some details of the manner in which a seed is produced were given, and it was pointed out that the seed is a structure containing a young plant (embryo) developed from a fertilized egg. The seed is better fitted to undergo a period of dormancy and to carry a plant over an unfavorable period than are the small spores of ferns, mosses, and fungi, or even the resting spores that are produced by certain algal forms. This is because the seed contains (I) a plant already partly developed, (2) a larger supply of nourishment to start the young plant when development begins, and (3) seed coats that afford better protection during the dormant period. So efficient, indeed, is the seed in passing over periods unfavorable for growth, that nearly all seeds will retain their vitality for from one to several years; and the seeds of certain plants have been found to be alive after 25 years.

Summary of the development of the plant kingdom. At this point it may be well to review the most notable steps in the development of plant life on the earth. These steps are :

(I) The development from previously existing water plants of land forms with epidermis, rhizoids, and other adjustments to a land environment. 
(2) The development of a conductive system which made possible the growth of aërial parts situated at a distance from the water supply, and which also made possible the transportation of food to roots that live in the dark and therefore are not able to make their own food.

(3) The development of seeds as a means of dispersing the plant and of preserving it during seasons unfavorable for vegetative life.

(4) The development of an extensive root system by which larger amounts of water and mineral salts are made accessible. Correlated with this is the development of large, much-branched tree forms.

(5) The development of true flowers made up of floral leaves, stamens, and pistils. With this step came insect pollination and the production of seeds inclosed in an ovulary. In some cases the ovulary is fleshy and at maturity becomes an edible fruit. 


\section{Suggestions for Laboratory Work to Precede Chapter Twenty-three}

1. A lily, tulip, or wild onion may be used in studying the flowers of the monocotyledons. Attention should also be given to the leaf and stem characters of this group. Narcissus bulbs grown in water will furnish excellent material.

2. Any convenient dicotyledon may be used to show the type of flower and the associated leaf and stem characteristics. Geraniums, oxalis, and impatiens may be obtained at all seasons of the year. In autumn and spring many plants are available.

3. A collection of the more important grain plants, fibers, and fiber plants is easily made. These will be helpful in studying the economic uses of plants.

4. The examination of pressed specimens representing the more important families of angiosperms will be an aid in learning family characteristics. Fresh specimens are always to be preferred, if they can be obtained. 


\section{CHAPTER TWENTY-THREE}

\section{SEED PLANTS: ANGIOSPERMS}

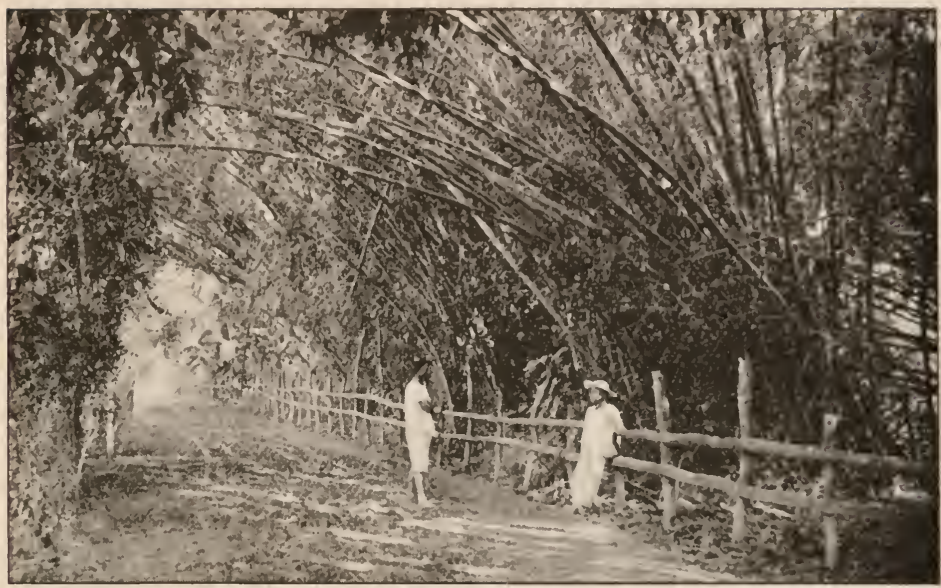

FIG. 177. Roadside clump of bamboo, Philippine Islands. The bamboo is a very important tropical monocot.

Angiosperms (Greek: angio, receptacle, and sperm, seed) form the second division of seed plants. The seeds are inclosed in a pistil which later ripens into a pod or fruit. The Angiosperms make up by far the largest part of the present vegetation of the earth. There are more than I 30,000 species, as contrasted with 500 species of Gymnosperms and about 4500 species belonging to the fern group. In many forms the stamens and pistils are surrounded by brightly colored floral leaves. As compared with other groups of seed plants, a most striking diversity of vegetative and reproductive structures is shown within the group. This diversity of form enables Angiosperms to live in all land and water habitats, from the margin of the ocean to alpine summits, and from the tropics to the polar deserts. 
Diversification among the Angiosperms. The great differences in the stems of Angiosperms may be realized by calling to mind the elm, palm, cactus, dandelion, grape, morningglory, bamboo, tumbleweed, pondweed, water lily, dodder, and duckweed. The leaves may be simple or divided into leaflets; and in size they range from the minute scales of the heather to the leaves of the palm and banana, which may be from 20 to 30 feet long. The form, color, and venation of the leaves show a corresponding diversity, so that all shapes and sizes of leaves may be found within the group. The Angiosperms have extensively developed root systems that are capable of anchoring the plants and absorbing water under the greatest variety of soil conditions. The reproductive structures are very diverse and are more complex than in the Gymnosperms. In addition to a great number of methods of vegetative multiplication by leaves, stems, and roots, there is the production of seeds from flowers. In the higher Angiosperms there are brightly colored floral parts which are helpful in securing the transfer of pollen by insects. The seeds are inclosed in fruits which protect the developing ovules and frequently aid in the scattering of the seeds.

Two great groups of Angiosperms. The Angiosperms naturally fall into two great groups: the monocotyledons and the dicotyledons. These groups have already been discussed (page 209), and only a general summary of their characteristics will be presented here.

Monocotyledons. The Monocotyledons have their floral parts usually in groups of three (rarely in four); the bundles are closed and scattered throughout the pith of the stem; in most forms the veins of the leaves are parallel; and the embryo has but one well-developed cotyledon. With the 


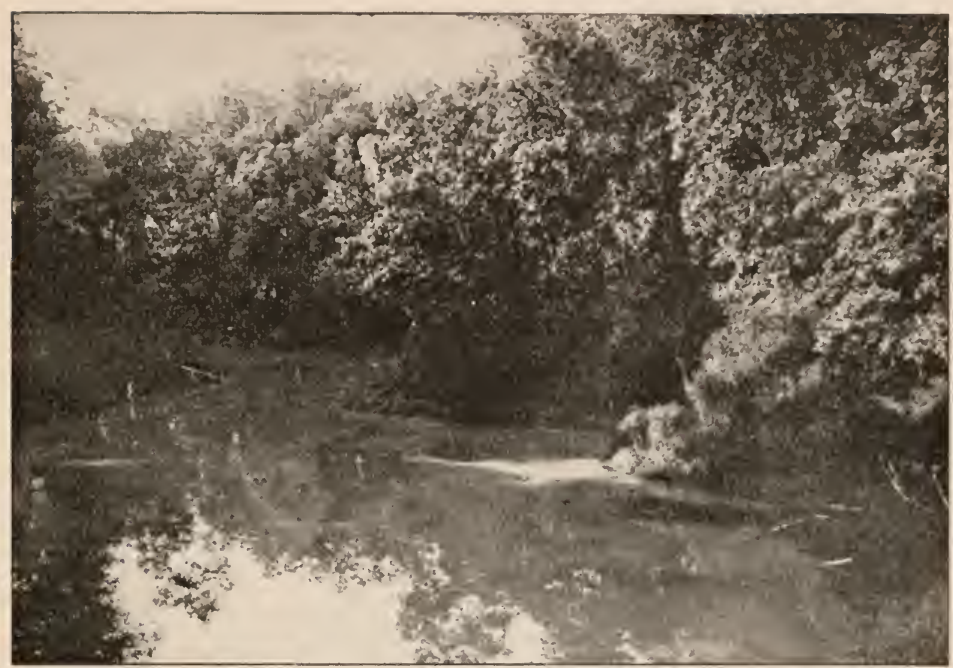

FIG. I78. A deciduous forest in Illinois. The trees are oak, hickory, and elm, important and typical dicot trees.

exception of the palms, bamboos, and a few other species, the Monocotyledons are herbs; and the tissues of even the woody Monocotyledons are generally less woody than are those of the conifers and the dicotyledonous trees and shrubs. This great assemblage of flowering plants includes not fewer than 25,000 species.

Dicotyledons. The floral parts of Dicotyledons are usually in groups of five or four; the vascular bundles are arranged in a circle about a central pith; the bundles are open, which makes possible an increase in stem diameter and permits forms like the trees to reach a great size; the leaves, with few exceptions, are net-veined; and the embryo has two cotyledons. In size the Dicotyledons range from the smallest herbs to the largest of our hardwood trees. 


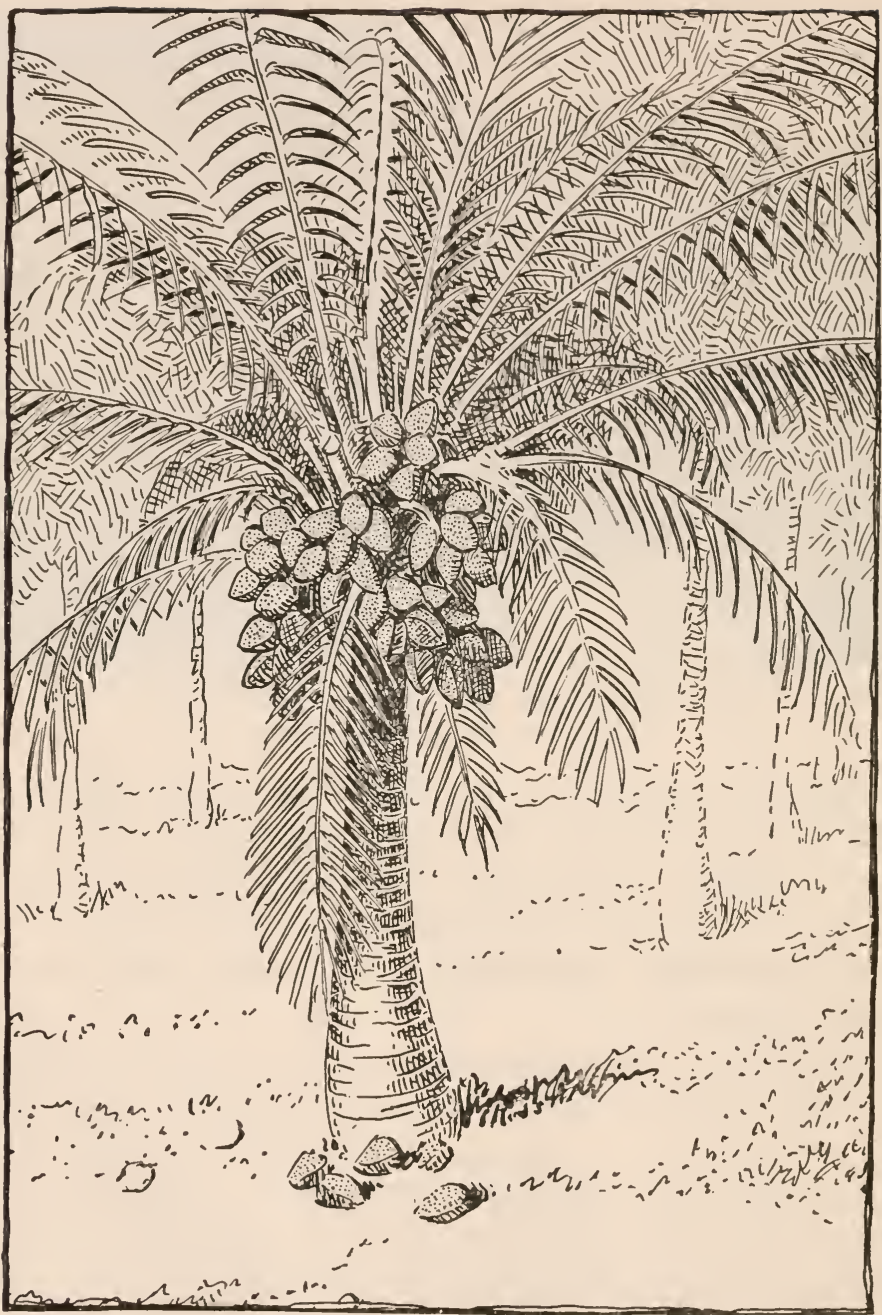

FIG. I79. Coconut palm in fruit. The palm family is very important in the tropics. 


\section{Sced Plants: Angiosperms}

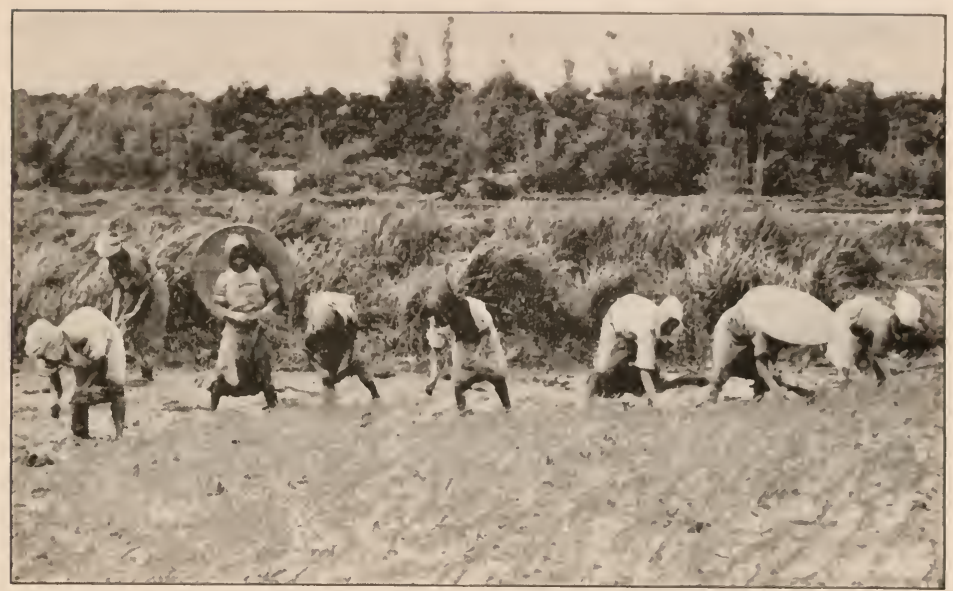

FIG. ISo. Transplanting lowland rice in the Philippines. The seed is germinated in beds, and at the opening of the rainy season the seedlings are transplanted to the flooded fields. The rice plant and other members of the grass family furnish most of the food supply of animals and men.

The important families of the Monocotyledons. The Monocotyledons are usually grouped in about forty families, four of which are of surpassing interest. These four families are the palms, grasses, lilies, and orchids.

The palm family. The palms form a large group abundant throughout the tropics. They resemble the tree ferns and cycads in having columnar, unbranched stems. The stem increases in thickness during the first few years and then grows only at the top. The leaves are often branched and of gigantic size. In the fan palms they are rounded and split radially.

Palms are very useful to the natives of the tropics, furnishing much of the material for thatching roofs and for the weaving of mats, hats, and bags. They also produce fruits and seeds, like the date and coconut, that are most important 


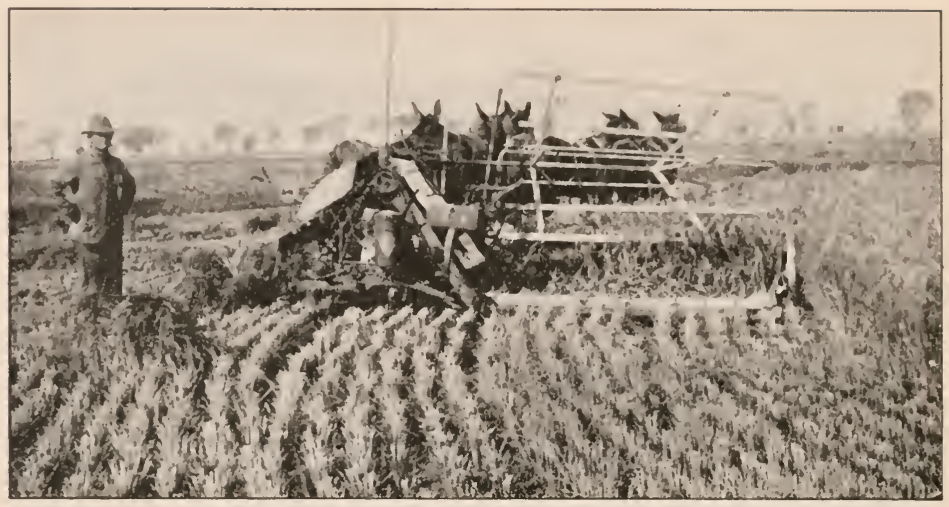

U.S. Depl. of Agriculture

FIG. I8r. Harvesting rice in California.

sources of food. The rattan is a climbing palm, for the "fiber" of which there is a world-wide market. This fiber, which consists of flat or cylindrical strips of the stem, is used in the making of chairs, tables, and baskets.

The grass family. The grasses furnish the bulk of the food of animals and men; and with the possible exception of the trees, no other group of plants compares with them in usefulness. They form the natural covering of a large part of the earth's surface. The prairies and plains of North America, the steppes of Russia, and the pampas of Argentina are vast areas that were originally dominated by grasses. These supported great herds of grazing animals before the coming of man, and since that time they have been the centers for cattle, horse, and sheep production. Grasses are cultivated on most farms to furnish pasturage for the live stock.

The stems of grasses are cylindrical and usually hollow, except at the nodes. The leaves are usually two-ranked, the basal portion forming a sheath about the stem, as may be 
seen on a stalk of corn. The flowers are borne on spikelets surrounded by green bracts.

The grasses reach their greatest size in the bamboos. These have long been one of the chief sources of lumber in eastern Asia and the East Indies. From the bamboos come the materials for the native houses, furniture, and a large number of articles of household use. In subtropical America these plants are being used as windbreaks for the pineapple fields and citrus orchards.

Sugar cane and sorghum are members of the grass family that are cultivated for their sugar. The former is the source of the sugar that is produced in our Gulf Coast region and in the tropics. Sorghum is grown farther north and is used for the manufacture of molasses. Broom corn is closely related to sorghum, and is grown for the stiff branches of the flower cluster, which are used in the manufacture of brooms

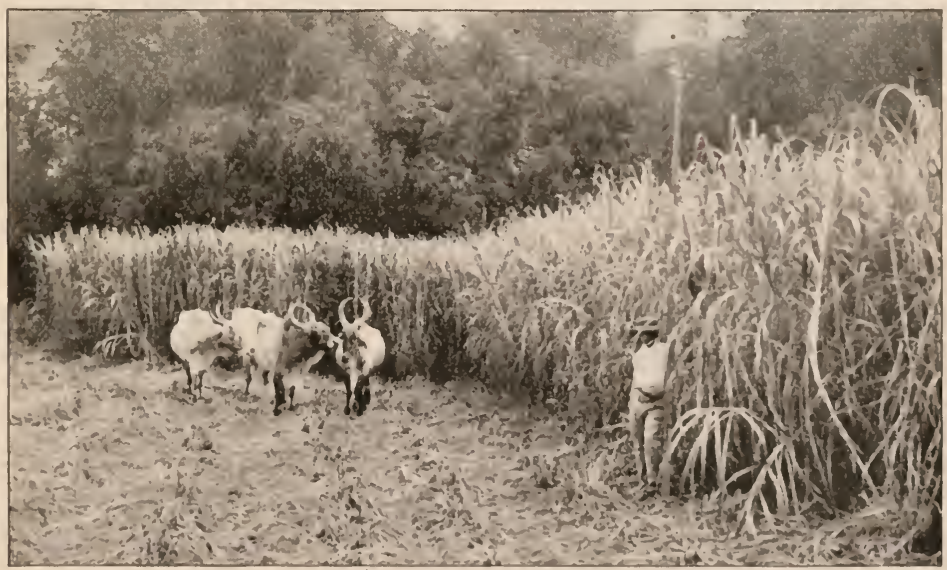

Burcau of A gricu'lure, $P$. I.

FIG. IS2. Japanese cane, a near relative of the sugar cane, grown as a fudder crop in the I'hilippine: 
and brushes. Kafir corn and milo are other relatives of the sorghum that have become important forage crops in parts

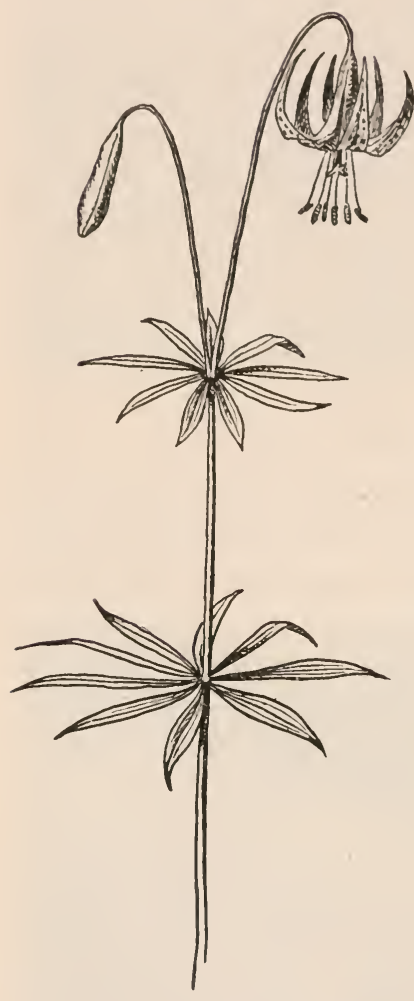

FIG. I83. The wood lily. Many members of the lily family are cultivated for their flowers. of our country that are too dry for the successful production of corn.

But the most important of all the grasses are the grains: wheat, rye, barley, oats, rice, millet, and corn. Most of the world's food is derived from these plants; and, depending upon the yield of these several crops, human beings are well supplied with food or famine prevails. All other foods are of secondary importance to the grains.

The lily family. This is one of the important families of the monocots because of the large number of species, their wide distribution, and the beautiful flowers that are borne by many of them. The flowers usually have six colored parts forming the floral envelope. There are six stamens, and the pistil is made up of three divisions. The onion and asparagus are members of the lily family that are used for food. The Mexican century plants and the New Zealand flax are fiber-producing plants that belong to this group. Many of the bulbous forms like 
the Easter lily, tulip, hyacinth, and narcissus are of commercial importance because of their flowers.

The orchid family. This is a large family most abundant in the tropics, and it includes about a fifth of all the monocots. In temperate America there are many species growing in bogs, swamps, and shaded woods, some of which are noted for their beautiful flowers. The pink moccasin flower and the yellow lady's slipper are examples. In the tropics most of the species found are epiphytes (page I89). These species are world-renowned for their marvelous shapes and for the coloring of their flowers.

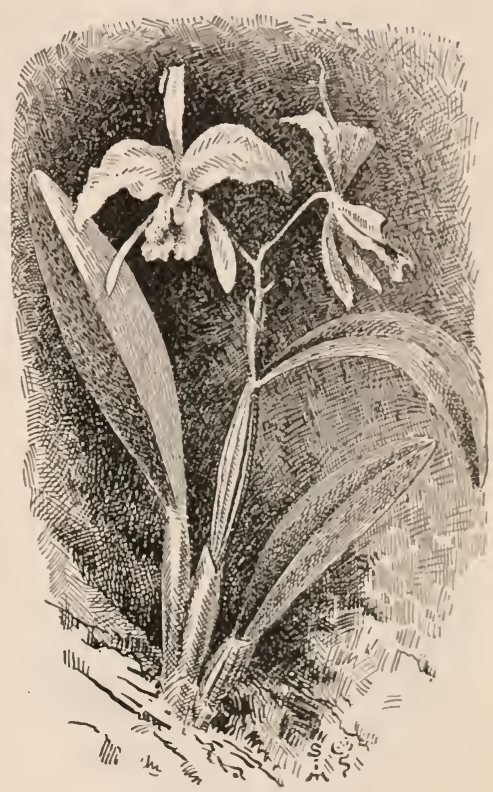
Among flower fanciers the FIG. 184. A tropical epiphytic orchid. orchids are the most sought- beautiful flowers. after plants, and prices of more than \$rooo have been paid for single plants of the rarer species. They hybridize freely, and there are innumerable hybrid varieties in cultivation.

Important families of the dicotyledons. This division of the flowering plants contains over 200 families and more than roo,000 species. Consequently only a few conspicuous families can be discussed here, and they will be dealt with briefly. In this group belong our broad-leafed trees and shrubs, and 
the vast majority of our herbs. The poplars, oaks, hickories, maples, and elms, and the chestnut, beech, and ash, largely make up the Deciduous Forest of the eastern United States, which dominates the area east of the Great Plains between the upper Lake region and the Gulf coastal plain.

The mustard family. This family includes the mustards, cabbages, radishes, turnips, and cresses. It is of great economic importance. The flower is characterized by four petals placed at right angles in the form of a cross. The development of cultivated plants from wild species is nowhere better exemplified than in the case of the cabbage. The small

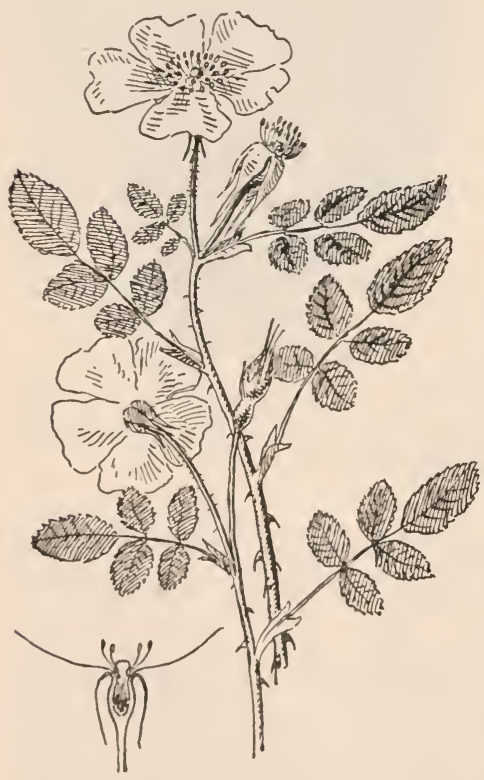

FIg. 185. Wild rose, and a vertical section of the flower. Most of the important tree and shrub fruits belong to the rose family. wild plant from which it was derived produced neither heads nor swollen stems. From it, by the selection of mutations, have been developed several distinct forms of cabbage and also cauliflower, Brussels sprouts, kohl-rabi, kale, and collards. These differ so much in appearance that one would scarcely guess that they had a common wild origin. The histories of cultivated plants afford many examples of far-reaching changes in the forms of plants, brought about in the same way.

The rose family. This family is characterized by flowers with five petals, five 
sepals, and many stamens. The fruits are fleshy, and in many species they are edible. The group is of particular interest to the horticulturist, as it includes most of our important tree and shrub fruits, as well as many beautiful wild and cultivated flowering plants. Among the fruits included are strawberries, raspberries, dewberries, and blackberries; apples, pears, and quinces; and peaches, plums, cherries, prunes, and almonds. All these cultivated fruits, as compared with their wild ancestors, have been improved in flavor and greatly increased in size and productiveness.

The legume family. The legumes received their name

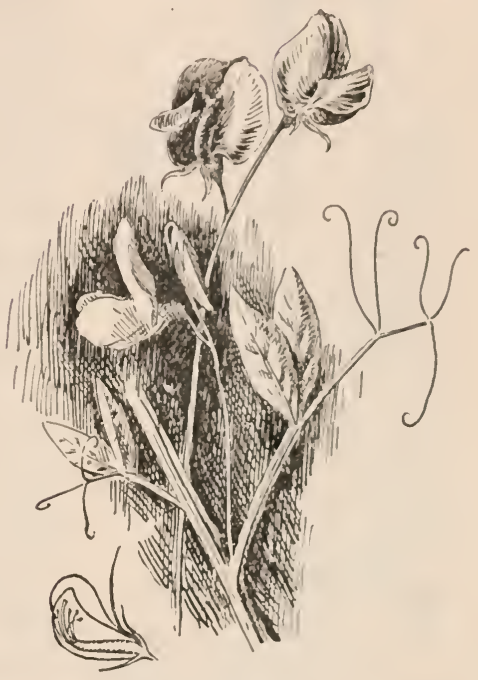

FIG. I86. Sweet pea, and a vertical section of the flower. from the peculiar fruit or pod which contains the seeds. Typical legumes are the pea and the bean. In the best-known members of the family the flower has one large upper petal which stands erect, two lateral petals forming wings, and two lower petals united and inclosing the pistil and stamens. The sweet pea shows the typical flower form.

There are several reasons for the great importance of the legume family: (I) beans, soy beans, and peas furnish food material that contains a high percentage of protein; (2) all legumes, through the aid of bacteria in their root nodules, accumulate nitrogen compounds (page 258); (3) clover, 


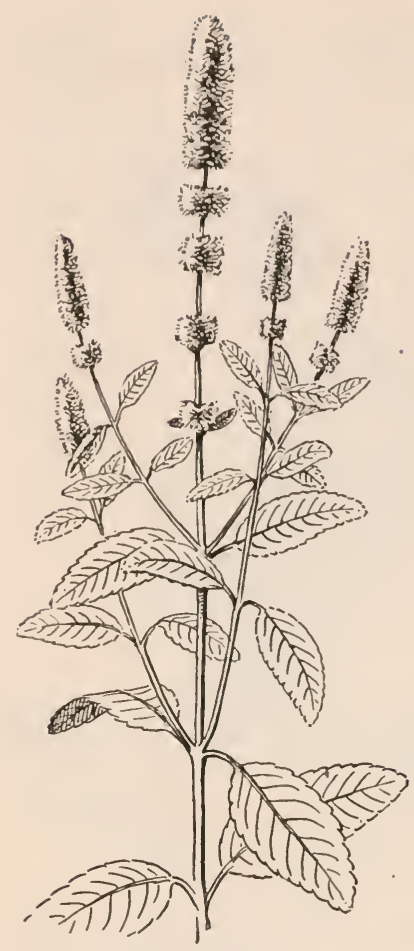

FIG. I87. Peppermint. The square stems and opposite leaves are characteristic of the mint family.

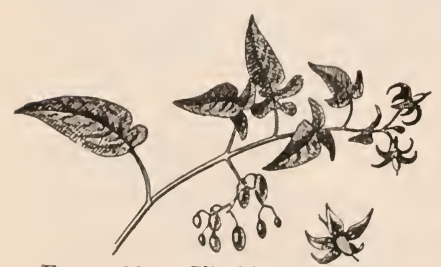

FIG. 188. Climbing nightshade, one of the wild species belonging to the potato family. alfalfa, and soy beans supply large quantities of rich hay for horses, cattle, and sheep. The sweet peas are among the most beautiful of cultivated flowering plants. The locust, which furnishes a very enduring wood, also is a legume; and many of the valuable woods of tropical forests belong to this group.

In the tropics and subtropics one of the divisions of this family is represented by the acacias, in which the flowers are radial and have numerous long stamens that give the flower clusters the appearance of balls of coarse hair. The acacias are frequently cultivated as ornamental trees, and they are a source of commercial gums. Related to the acacias are the sensitive plants (Mimosa), one of which is shown on page 44. In South Africa flat-topped Mimosa trees are common and form one of the characteristic features of the landscape.

The mint family. This family is marked by square stems, peculiar two-lipped flowers, opposite leaves, and in many species an aromatic odor. Peppermint and spearmint 
are now cultivated extensively on bog soils in the northern United States, for the production of peppermint oil and menthol. Catnip, scarlet sage, water horehound, and hyssop are common plants belonging to this family.

The potato family. This family is composed of herbs and small woody plants with expanded or tubular flowers. The fruits are capsules or berries containing numerous seeds. Among the useful representatives are the potato and the tomato, eggplant, and red pepper. Several plants containing narcotics, of which the best-known example is tobacco, belong here. Common weeds that belong to the potato family are the nightshade, horse nettle, ground cherry, and Jimson weed.

The carrot family. This family

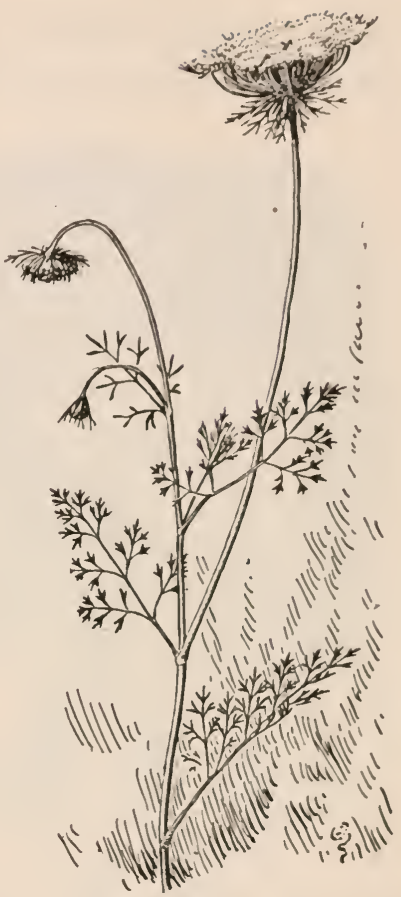

Fig. I89. Wild carrot. The flattopped flower cluster characterizes the family to which the carrot belongs.

is readily recognized by the flat-topped, much-branched flower cluster (umbel). The parsnips, carrots, celery, and sweet cicely are familiar examples. In addition to the foodyielding forms, the water hemlocks should be known because of their poisonous character.

The heath family. Small, bell-shaped flowers and leathery leaves are characteristics of the heath family. To it belong the cranberries, blueberries, huckleberries, low-growing tea- 
berry, trailing arbutus, laurel, azalea, and rhododendron. The cranberry has long been cultivated on sandy bog lands.

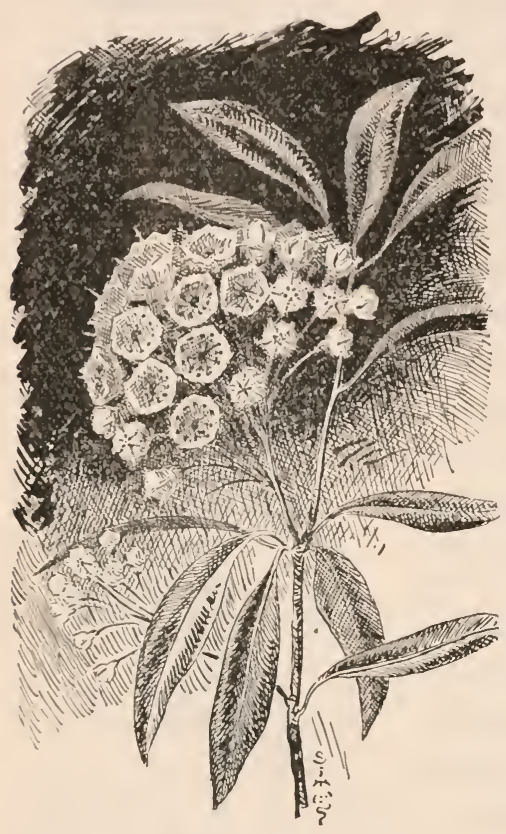

FIG. Igo. Mountain laurel, a member of the heath family. Blueberries are just coming into cultivation, and much may be expected of them in the future. They grow best on acid soils, and are capable of great improvement in size and flavor through hybridization and selection.

The composite family. The composite family is the culminating family of the dicots, including more than 12,000 species, or nearly one tenth of all seed plants. The distinguishing character of the family is that the small flowers are closely grouped in heads, so that the entire flower clusters, in forms like the sunflowers, asters, chrysanthemums, and dandelions, are often mistaken for single flowers. The calyx-like outside covering is merely several rows of small leaves (bracts). The whole inner* part of the head is made up of many individual flowers, each with its own stamens, pistils, and corolla. Sometimes the flowers are all alike, as in the dandelion. Sometimes the outer flowers are petaloid, as in the sunflower, while the inner flowers are tubular and less conspicuous. The floriculturist has modified the chrysanthemum, aster, and dahlia to 


\section{Seed Plants: Angiosperms}

such an extent that there are now hundreds of forms in cultivation that bear little resemblance to the wild stock from which they were derived.
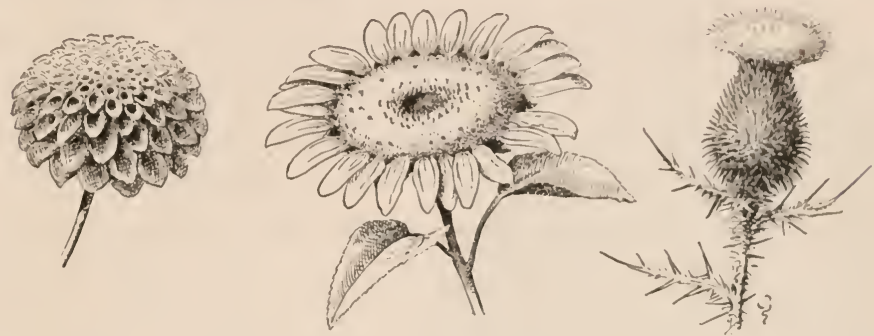

Fig. I9I. Flower clusters of dahlia, sunflower, and thistle, members of the composite family. The small flowers are collected in heads, which are characteristic of the family.

In the United States the composites bloom chiefly in summer and autumn, and often conspicuously color the landscape. The daisies, goldenrods, and asters of the Eastern states and the sunflowers of the prairie states are well known. The ragweeds, which are troublesome as weeds, are one of the chief causes of hay fever. Their pollen is highly irritating to the mucous membrane of the nose, and it is advisable that city and village streets be kept clear of them.

Many other families of the dicots are of interest and importance, but descriptions of them must be sought in more specialized botanical texts. 


\section{CHAPTER TWENTY-FOUR}

\section{THE EVOLUTION OF PLANTS}

Those who have studied plants most have been led to the conclusion that simple plants lived first on the earth, and that from these simple forms all the varied and highly complex plants of today have been derived; that is, they believe that the present-day plants were evolved from those that existed on the earth in former times. Some of the simple plants of the past still persist, and many plants of intermediate degrees of complexity survive; but during the development of the plant world, new and increasingly complex forms have been produced, and these higher forms now dominate the vegetation of the earth. The process by which the plants of today have come from the plants of the past is called evolution (Latin: evolutio, an unrolling). Evolution, with regard to plants, implies (I) that the plants of today are the modified descendants of earlier forms, (2) that modifications are going on now as in the past, and (3) that the new plants of the future will be evolved from plants now living through modification of present plant forms.

The proofs of evolution in plants have been gathered from many sources by many different students. These proofs include the evidence furnished (I) by plant remains found in rocks and coal, (2) by the distribution of plants on the earth's surface, (3) by the remarkable similarity of organs, tissues, and cells among the thousands of plants now in existence, (4) by the similarity in the life histories of all plants, (5) by intergrading species, (6) by the experience of plant breeders and the history of our cultivated plants.

The record of plants of the past. When a leaf falls from a tree on soft mud, it may become imbedded in it. Later the 
mud may be covered by other layers of sediment. When the mud dries, a perfect imprint of the outline and veins may be left. As time goes on and the mud becomes more deeply buried, it may harden into rock and retain the imprint of the leaf as a record of a plant that lived when the rock was merely soft mud. In this way leaves, fruits, seeds, stems, and roots have left their imprints to testify, thousands and millions of years afterward, to their former existence.

Plant remains also accumulate in deep water or in water containing large

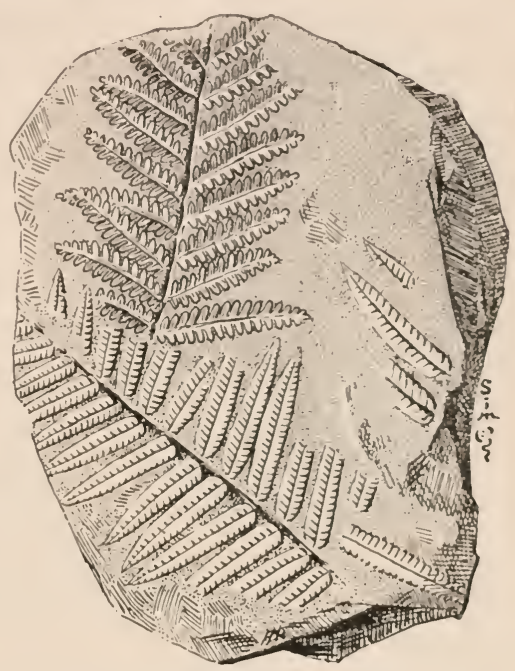

FIG. 192. Fossil imprints of fern leaves in a rock of the Carboniferous period. amounts of mineral matter in solution. In such places they may not decay, but the material of which they are composed may gradually be oxidized and replaced by the mineral substances in the water. Under the most favorable conditions the internal structures of the plant are preserved. As animal remains are preserved in the same way, we have in the rocks a record of the plants and animals of the past. These petrified plant and animal remains and the plant and animal imprints from former geological ages are called fossils.

When large collections of fossils are studied, we find in the oldest fossil-bearing rocks few, if any, plant remains. This is as we should expect, for plants like algæ and liverworts are 
so minute and delicate that we cannot hope to find their fossil remains. Yet we know that plants of some kind did exist on the earth at that time, for the fossils of corals and of shell animals are abunclant in these rocks, and without plants to manufacture food for them, life would have been impossible for these animals. In rocks that were formed later than these first fossil-bearing strata, remains of fernlike plants are found. Later there were seed-bearing fernlike plants and several groups of plants intermediate between the ferns and modern gymnosperms. Still later, gymnosperms resembling in many ways our coniferous trees became prominent, and then came Angiosperms with very simple flowers of the windpollinated type. Finally, Angiosperms with conspicuous insect-pollinated flowers appeared. There is reason to believe that the first seed plants and the first flowering plants were woody shrubs and trees, and that the flowering herbs came last.

The meaning of the record. The fossil record of plants reaches many millions of years into the past, and it shows that changes in plants came about only very slowly. The plants of each geological period resembled in some respects those of the previous period; in each period certain new characters were added to the old ones, or they replaced the old ones. To reproduction by spores was added reproduction by seeds. The first seeds were exposed on the sides of foliage leaves; later came seeds borne on scales arranged in cones; and finally came seeds inclosed in pistils.

Leaves and stems also show progressive changes in form and structure. Although the fossil record is very fragmentary, being made up of chance imprints and petrified remains, it is possible in some instances to discover when a group of 
plants appeared and how the group became more widely distributed and more highly diversified in form and structure. Some of these ancient plant groups that at one time formed a considerable part of the earth's regetation have entirely disappeared; others are now represented by only a few species.

These facts all lead to the conclusion that existing plants have been derived from those of the past. The flowering plants are the culmination of a long series of constructive changes in plants, which enabled them to live in a greater variety of environments. Increasingly complex and efficient structures for vegetative life and reproduction were developed,

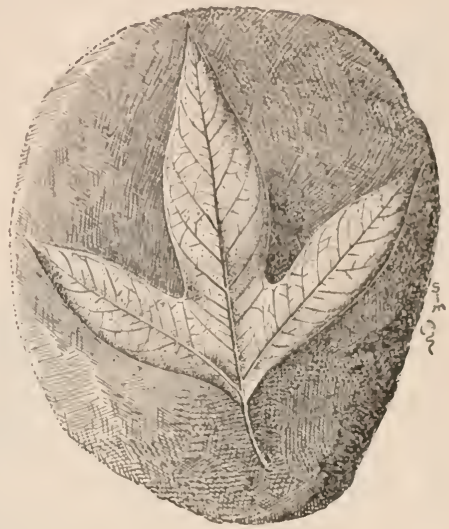

FIG. 193. Fossil imprint of a leaf of a species of sassafras in rock of the Cretaceous period. The Cretaceous rocks were formed much later than the Carboniferous rocks, and it is only in these later rocks that the fossil remains of Angiosperms are found.

and these structures made the plants better able to endure unfavorable conditions. The progressive changes in plant life have occurred during a geological history extending through many millions of years, and it now scems impossible to account for the geological record except on the basis of evolution. Certainly no one has suggested any other plausible way to explain the long series of gradually changing fossil forms that begins with simple fernlike plants and ends in plants like those found on the earth today.

Geographic distribution and evolution. When the geographic distribution of plant families is studied, it becomes 


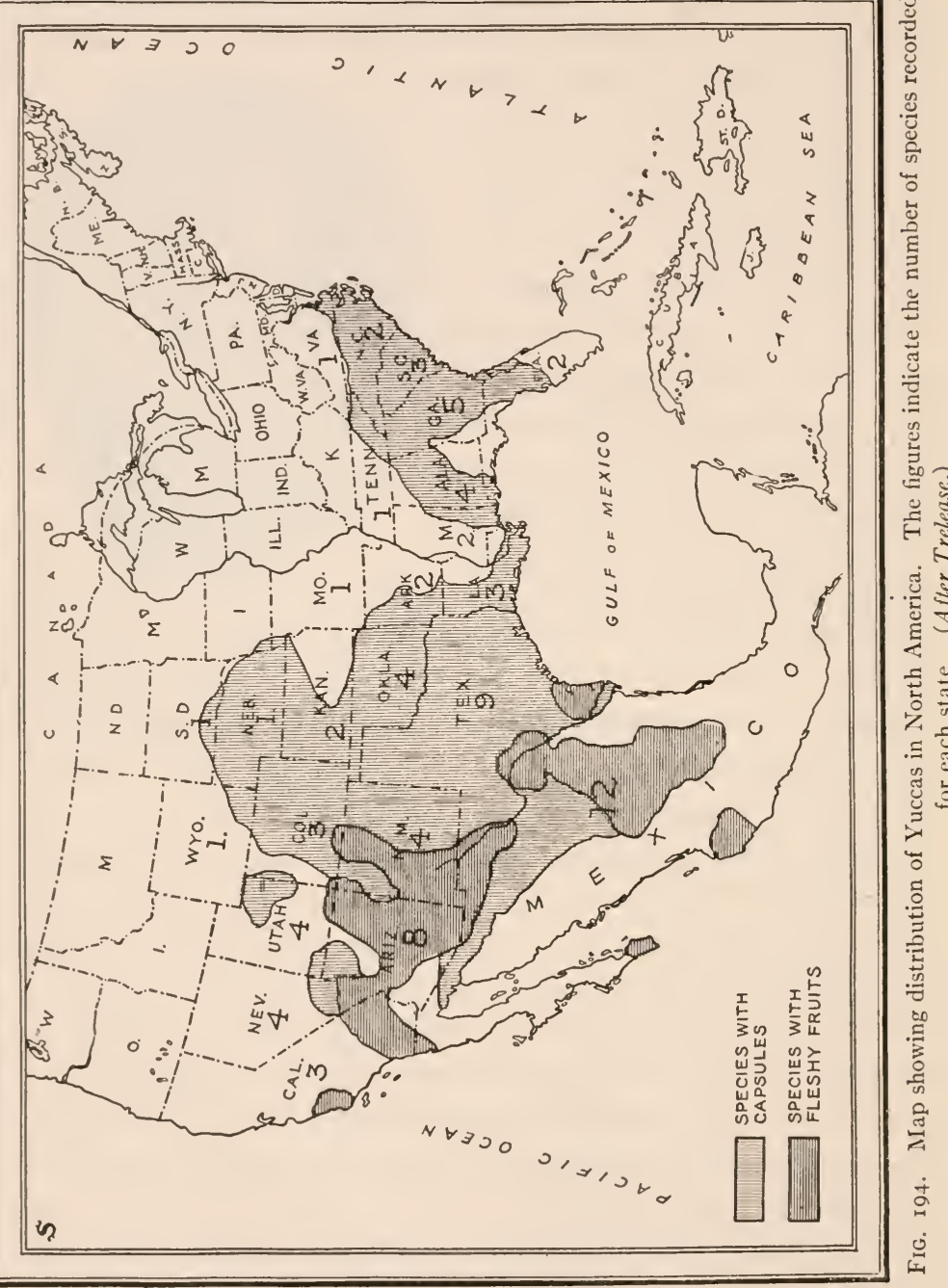


apparent that the species belonging to any particular group are not scattered haphazard over the earth. Many families bear evidence of having originated on some particular continent or part of a continent, and of then having spread from the center of origin. Commonly, in the center of origin there is or was the greatest variety of species, and away from the center the species are fewer and less varied. For example, the Cactus family, represented by more than a thousand species, is native in North and South America only. In North America the family is best developed in Mexico, but it has spread northward and eastward into the United States and to the islands of the West Indies. The geographic distribution of all the North American species points to a common origin in the Mexican plateau. The Yucca family and the Agave (century plant) family also appear to have originated there and to have spread in a similar way to the United States and the West Indies.

Sometimes the record is incomplete because the families are very ancient and most of the species have become extinct. In other families the record is so complete that it is possible from the distribution to trace the origin and relationship of many of the species. The geography of plants, therefore, furnishes a second line of evidence that existing plant species have been derived from preëxisting forms.

Similarity of structures of plants belonging to diverse groups. One of the most striking proofs of evolution is found in the remarkable similarity of the cells, tissues, and organs that make up plants belonging to very different groups. The conductive system, for example, is not very different in the ferns and in the Angiosperms. The bundles are arranged differently in these groups, and their arrangement becomes in- 
creasingly more complex from the ferns to the flowering plants; but the cells of which the bundles are composed are very similar. The reproductive structures also show a gradual modification in plants. They are comparatively simple in the ferns and very complex in the flowering plants, and between the two extremes there are many gradations. These gradations occur in such an order that they point to the gradual coming into existence of complex reproductive structures, culminating in those of insect-pollinated flowers.

Life histories of plants. Again, when we compare the detailed life histories of plants belonging to the different groups, the close resemblances among them point to their origin by gradual evolution from common ancestors. As one passes from the algx through the mosses and ferns to the Gymnosperms and Angiosperms, the life histories of the plants, like their structures, become more and more complicated. This increase in complexity of the life history is brought about by gradual modification and by the addition of new steps and new structures. The life histories of related groups are similar in essentials and differ only in details. This repetition of the stages in the life cycles of the plants of different groups can be explained only by assuming that the plants with the more complex life histories have evolved from those with less complex life histories. Increase in complexity is one of the general tendencies of evolution. The order in which we should arrange plants on the basis of the geological records is the same as the order suggested by their life histories and structures.

Intergrading species. All who have attempted to classify plants - that is, to determine the species to which individual specimens belong - have been impressed by the intergrading of related species. The existence of individuals intermediate 
between species long ago suggested that the one species may have arisen from the other. For example, the common asters, violets, hawthorns, evening primroses, and willows are highly variable, and it is frequently impossible definitely to classify a particular specimen and to say that it belongs to this or that species. If such intermediate forms were rare, they would only suggest the possibility of erolution; but they are numerous, occurring in hundreds of families throughout the plant kingdom. These intergrades make it impossible for us to think of the plant kingdom as being composed of distinct and unrelated species, and so they must be regarded as evidences of evolution.

Plant breeding and evolution. If we study the histories of various cultivated plants, - for example, the many varieties of cabbage, tomatoes, corn, wheat, apples, peaches, chrysanthemums, and asters, - we find abundant evidence that they have been derived from wild plants. The plant breeder has simply selected and preserved desirable forms that have arisen by mutation and through hybridization.

When we realize the extent to which these plants have been modified from the types of their wild ancestors in the comparatively short time that plants have been cultivated, it is less difficult to understand the great changes in plant life that may have occurred during the long period since plants first grew on the earth.

Plant breeding furnishes us with experimental evidence that plants may change in various ways, so that not all the plants of succeeding generations are like their ancestors. Here and there an individual arises that is different from its parents, and such new individuals are the beginnings of new races, varieties, and perhaps species. The experience of plant 
breeders is in harmony with the theory of evolution, and plant breeding has furnished us suggestions as to the methods by which evolution has taken place.

Evolution proved; methods of evolution not proved. Among the thousands of students of modern and ancient plants, there are few, if any, who do not regard evolution itself as a fact. The evidence points so clearly toward evolution, and all other explanations for the origin of the plant species now on the earth have proved so inadequate, that botanists consider evolution as proved. At the same time, we know comparatively little today concerning the agencies that have brought about evolution. Evolution as a process has been studied only recently, and merely a beginning has been made in unraveling the tangled skein of causes and methods by which modern plants have come to be what they are.

Factors of evolution. When we seek to learn the reasons for the changes in plant life during geological times, we find that many factors were probably involved. We can get an idea of some of the possible factors from suggestions that have been made by students of evolution, but we must keep in mind the fact that there is today little real evidence concerning the factors of evolution and that the suggestions merely indicate how evolution may have come about. It seems probable, however, that in the production of new kinds of plants variation and selection play a part. Certainly there may be among the offspring of a plant individuals that differ from the parent, and some variations are known to be inheritable. In order to explain evolution, it is necessary to assume that new characters are produced in plants by variation, and that the changes in the plants are transmitted from generation to generation. 
Natural selection. Most plants produce offspring by the hundreds, thousands, or even millions, and there is room for only a small part of the offspring to live. It is said that those plants survive that are more vigorous, that are better adjusted to their environments, or that happen to start in favorable places; the weak and the unfortunate perish. Certain variations, or mutations, may fit plants the better to survive, and the persistence of the forms showing these changes may lead to the formation of new varieties and species. The wholesale destruction of individual plants in nature, with the survival of a few, is called Natural Selection, and it has been thought to resemble in some respects the selection made by the plant breeder. It is unquestionably true that most of the plants that start life in nature die before reaching maturity; but there are great differences of opinion as to whether or not the plants that do survive can through repeated selections in nature develop into new species. Man can pick out new forms that originate in the plants that he cultivates and by breeding from them secure new varieties, but it is believed by some that in nature the variations would be lost by interbreeding with the parent forms.

Changes in environment. Another factor in Natural Selection is the fact that climates and environments are ever changing. We know, for example, that for a long period of time tropical plants grew in polar regions, for the fossils of tropical plants are now found there in the rocks. At a later period the climate of the earth was much colder than it is now, and all of northern North America was covered with ice that reached as far south as the Ohio and Missouri rivers. As climates change, plants either become adjusted to the changes or perish. These changes in climate afford 
opportunities for new sets of plants to take possession of the land. They are perhaps also the cause of mutations in plants that give rise to new forms which replace the species from which they were derived.

The land areas have changed many times in the earth's history. Sometimes large parts of the continents have been under water; at other times the continents have been more elevated than at present. These changes in the land areas have resulted in the extinction of many species of plants. Forms derived from them may have survived on the land not submerged. So the great changes in climate and in land surfaces, and the less pronounced changes in plant habitats, act as selective agencies, determining the kinds of plants that survive.

Isolation. If a continuous land area, having a number of elevations, were submerged so that the elevations became islands, a plant that had been originally distributed over the whole area might persist on a number of the islands. The plants on the several islands would then be isolated from one another. As time went on these isolated individuals might give rise to new forms that were quite distinct in their characteristics. Different new forms might arise on different islands, and since the selective agencies on the various islands would not be the same, the varieties that persisted on one island might come to be quite distinct from those on other islands. The production of the new forms depends on variation, but isolation tends to preserve new forms by preventing their spreading and interbreeding.

The deciduous forest of eastern North America was formerly continuous with the forests of China through Alaska. Since then the connecting land has been depressed, and the 


\section{The Evolution of Plants}

two continents, Asia and North America, have become separated and their climates have changed. This separation resulted in the isolation of the deciduous forest plants of eastern Asia from those of eastern America. Many of the same species are still found in both areas. But in the two widely separated regions there are many other quite distinct species that have arisen by evolution from a common ancestor. The American sycamore, or example, is distinct from the Chinese sycamore; but the resemblance between the two is sufficient to suggest that they have a common ancestry.

Variations; the elimination of many individuals through lack of room in which to grow ; changes in climates and in land areas; and isolation are believed to be important factors in the evolution of plants. 



\section{INDEX}

Abscission, 67.

Absorption, 170; and rise of sap, 135, 176; and transpiration, 170 .

Accumulation, of food, $74,75,77,105,125$, 159, 179; of water, $58,106,158$.

Aconite, 195 .

Acre, food products from an, 34 .

Advantages, of deciduous habit, $63 ;$ of horizontal stems, I04; of spreatding roots, 169; of upright stems, 102.

Aërial roots, Isq.

Agar, 246.

A gave, 58, 90, 91, 97 .

Agriculture, 4, 99; and food accumulation, 78 .

Alcohol, 26r.

Alder, 198, 201.

Alfalfa, I 94 .

Alga, 234; blue-green, 245; brown and red, 246 ; living conditions of, 239 ; reproduction among, 243; structure of, 23.

Alligator pear, 212.

Amanita, 267.

Amaryllis, 16I.

Angiosperms, 21 I, 303; divisions of, 304; seeds of, 211 .

Animals, 149, 231.

Annual growth, 129; rings, I 23, 129.

Annuals, 94.

Anther, 200.

Anthocyan, 65 .

Antitoxins, 253.

Apple, 76, 79; May, 98.

Artichoke, 214; Jerusalem, 97, x6r, x63.

Arts, plant-producing, 99.

Asparagus, 163.

Assimilation, 82, 85 .

Autophytes, 249 .

Autumn coloration, 65 .

Avens leaf, 15.

Avocado, 212.

Axil, 106.

Bacteria, 2, 250; and discase, 253; and legumes, 194,258 ; and sanitation, 252; and soils, 257; and soil nitrogen, 258 ; in the dairy, 256 .

Bamboo, I64; leaf, It; stem, I24, I30, 303.

Banana, 79, 97, 219.

Bark, $129,170$.

Bast, I 19; fibers, 123.

Bean, 43, 207, 223; soy; 33, 78 .

Beech, 194.

Beets, 96, 194.

Begonia leaf, 14.
Benedict's solution, 73 .

Bermurla grass, 150 .

Biennials, 04, 05, 90.

Black locust, igs.

Blade, 13,14 ; position and light, $4 \mathrm{r}$.

Bloom, 54.

Blue-green algie, 245 .

Bostun fern, 226 ; ivy, 182,189 .

Botany, 3, 4; sublivisions, 15 I.

Bread making, 26r.

Breeding, plint, 220.

Bromelias, I80, I0I.

Brown color of leaves, 66.

Bryophyllum, 2 I8.

Buckeye leaf, I5; twig, 107.

Buds, ro6; and plint form, roo; kinds of, I09, 160; opening of, 108; scars, 107, I I3, II 4 .

Budding, 132 .

Bulbs, 97, $160,219$.

Bulrushes, 157 .

Bundle, dicut, I2I ; monocot, 126.

Bundles, leaf, 20; root, 169 ; stem, I20, I 2 I, I 25, I 26, I 28.

Burdock, 102.

Cabbage, 06, 225.

Cactus, 56, 158 , 190 ; spineless, 6.

Caladium, 160, 219.

Calorie, 34 .

Calyx, 200.

Cambium, I19, I24; and grafting, I 32 .

Camphor, $\mathrm{I}_{3}$.

Canna, 2 I 9.

Capsule, 2 I 2.

Carbohydrates, 27, 135 .

Carboniferous plants, 283 .

Carotin, 63 .

Carrot, 96, I86, I9\$; family, 315; wild, 3 I 6.

Castor bean, 207.

Catkin, ros.

Cat-tail, 157, 198 .

Cauliflower, $214,225$.

Celandine leaf, 15 .

Celeriac, I9.4.

Cells, 15, 16, 21; guard, 18; tissues and organs, 21,178 .

Cell sap, i6.

Celluluse, I6, 86, 100.

Cell walls, 16, 276; making of, 86 .

Century plant, 58, 76, 96, 97 .

Cereus, 58.

Chlorophyll, 22, 63 .

Chluroplasts, 22 .

Cion, 132.

Cludonia, 269. 
Clavaria, 267.

Cleft grafting, 132 .

Climbers, 155 .

Closed bundle, 126.

Clover leaf, I6, 44; root, 194.

Club mosses, 286.

Coconut, 214,2 I $5,306$.

Color of leaves, 43,45 .

Commercial products, from leaves, 9I ; from roots, I94; from stems, I6I.

Compass plants, 40 .

Composite family, 3I5.

Concord grape, 225.

Conduction, food, I05, I2I; water, I2I.

Conductive system, I2I ; significance of, 290.

Conductive tissues, leaves, 20 ; roots, 160 ; stems, I05, I 2 I.

Conifer forests, 298.

Conifers, II8, 294; leaves of, 296; seeds of, 296 ; stem structure in, 128 .

Copra, 214.

Cork, I63.

Corm, I 60, 2 I 9 .

Corn, 8, 50, 78, 79, 142, I64, 167, I79, I99, 202, 205, 207, 209, 21 5, 221, 222.

Corolla, 200.

Cortex, II9, I20.

Cotton fiber, 2 I 5 .

Cotyledon, 207.

Cowpeas, I94.

Craterellus, 267.

Crop yiclds, 34, 230; and water supply, 5 I.

Cucumber, wild, 155 .

Cuticle, I8, 54 .

Cutin, I 7.

Cuttings, 167.

Cypress, 296.

Cytoplasm, I5, I 75.

Dahlias, 97, 317.

Dandelion, 103, I66, 229 ; leaf, I5 ; root, I67.

Dasheen, I6o, I63.

Date palm, i io.

Deciduous forest, 305,312 ; habit, 63 .

Deliquescent stems, II $\mathrm{I}$.

Desert plants, 58, 59, I 54, I 57 .

Devclopment of plant kingdom, 300 .

Diastase, 75 .

Diatoms, 244 .

Dicots, II8, 209; stem structure, I2O.

Dicotyledons, families of, 3 II.

Diffusion, I 7 I.

Digestion, 74 .

Diseases, bacterial, 253.

Dodder, 250.
Dogwood, 39.

Dulse, 246.

Duration, of leaves, 69 ; of stems, 94 ; of roots, 185 .

Ecological factors, I40, I5I; types of leaves, $42,43,44,56,57$; types of roots, I 86 ; types of stems, I 54 .

Ecology, I 5 I.

Economic importance, of algæ, 245 ; of bactcria, $25 \mathrm{I}$; of flowers, 214 ; of fruits, $2 \mathrm{I}_{4}$; of pond scums, 245 ; of seeds, 214 .

Eel grass, 57, 9I.

Egg cells, 205.

Elements of soil, I4I.

Elodea, 28, 29, 57.

Embryo, 206.

Endosperm, 207.

Energy, 82.

Environment, 8, I39; changes in, 327; complexity of, 150; factors of, 139 ; responses to, I30, I3I, 275 .

Enzymes, 74.

Epidermis, 1 5, 17, 50, 276 ; importance of, I 8; stem, 1 20; root, I69.

Epiphytes, 188, I89.

Equisetums, 285 .

Eucalyptus, 99.

Euphorbia, 58.

Evening primrose, r 86.

Evergreen habit, 69, 7 I.

Evergreens, 64, 69.

Evolution, 300, 318; and geographic distribution, $32 \mathrm{I}$; and intergrading species, 324 ; and life histories, 324 ; and plant breeding, 325; and plant structures, 323 ; factors of, 326 .

Excurrent stems, II I.

Fabrics from plants, I.

Factors, of evolution, 326 ; of the environment, I39.

Fats, production of, $3 \mathrm{I}$.

Fermentation, 26r.

Ferns, 59, 98, 298; leaves of, 15,88, г 85 , 283 ; life history of, 288 ; number of, 303 ; walking, 283 .

Fertilization, 205; in conifers, 296; in ferns, 289 ; in mosses, 280 .

Fiber, I, 9I, 21 5, 228; Manila, 91.

Filament, 200.

Flax, I 63.

Floral envelope, 200.

Floriculture, Ioo.

Flower, I98, 200; clusters, I9S; dicot, 209; monocot, 209. 
Flowers, variety of, 200; economic importance of, 214.

Fog, I 4 S.

Fomes, 245.

Food, 25; per acre, 33 .

Food accumulation, and agriculture, 78 ; in roots, 77,179 ; in leaves, 75 ; in stems, 105, I 59, r 6 r.

Food-conducting tissue, 20.

Food conduction, 21, I 78 .

Foods, produced per acre, 33; utilization of, $8_{2}$.

Forests of North America, 299, 312.

Fossils, 3 I 9.

Fructose, 28.

Fruit, 21 2; economic importance of, 214.

Fuel, 2.

Fungi, 260; and roots, I94.

Gametes, 24 I.

Geaster, 267.

Gemmx, 273.

Geographic distribution, 321 .

Geotropism, I31, 182.

Ginseng, 195.

Glucose, 27, 28.

Grafting, I32.

Grape, 225.

Grass family, 308.

Gravity, 140, 149, 182 .

Ground pine, 287.

Growing point, I29, I80.

Growing region, $88,129,180$; of leaves, 87 ; of roots, 180 ; of stems, I 29.

Growth, 82,85 ; conditions for, 87 ; determination of annual, II 4 ; of roots, I79; of stems, 128 ; pressure, $1 S_{2}, 1 S_{4}$; stages of, I 80.

Guard cells, 18 .

Guayule, I63.

Guinea grass, 42 .

Gymnosperms, 211, 294; number of, 303; seeds of, 2I I ; wood of, 294.

Habitat, 56.

Heartwood, 130.

Heath family, 3 I5.

Hemp, I 63.

Herbs, 94 ; shrubs and trees, 98 .

II ippuris, 56 .

Horseradish, 167, 219.

Horsetails, 286.

Horticulture, 4 , 100 .

Host, 250.

Humus, I 43, 257.

Hyacinth, 97, I60.

Hybridization, 226, 255 .
Hybrids, 220, 226.

Hydnum, 267.

Hydrophytes, 56, 57, 60, 156, 179, 273.

Hydrotropism, 131, 183 .

Hypocotyl, 207.

Imbibition, 172 .

Indian cucumber root, 38 .

Indian pipe, 249.

Insect pollination, $104,202$.

Internodes, 106.

Iodin, 246.

Ipecac, 195 .

Iris, $4 \mathrm{I}$.

Irish moss, 246.

Irrigation, $141,144,145$.

Isolation, 328 .

Jack-in-the-pulpit, 160 .

Jerusalem artichoke, 97, I6 1, 163.

Johnson grass, 159.

Jute, I63.

Kelps, 246.

Kohl-rabi, 163.

Landscape architecture, 100.

Lantana leaf, 14 .

Laurel, 3 I6.

Leaf, arrangement, 37 ; coloration, 63 ; fall, 67 ; parts of, 13 ; pigments, 63,65 ; position and light, 37,46 ; scars, 113 ; structure, 13, 42, 54, 56; tissues, I 4 .

Leaves, $\mathrm{r} 3$; commercial products from, $9 \mathrm{I}$; effects of light on, 42 ; floating, 57 ; horizontal, 43 ; motile, 43 ; of conifers, 296 ; of shade plants, 44 ; relation to light, 37 , 46 ; submerged, 45,56 ; vertical, 42 ; water relations of, 48 ; white, 66 .

Legume family, 313.

Legumes and bacteria, 194, 258.

Lenticels, 106, I 15.

Lichens, 59, 260.

Lifting of water, 134 .

Light, 148 .

Lignification, 123.

Lignin, I 22.

Lily family, 3 ro.

Lipase, 75.

Liverworts, 272.

Longevity of plants, 94 .

Lumbering, 161 .

Lycopodium, 287 .

Magnolia, 37 .

Mango, 211. 
Mangrove, seedlings, 20S; swamp, 209.

Maple, 30, 38, 201; flow of sap, I35; sugar, $30,163$.

Marchantia, 272, 275.

May apple, 98, I 59 .

Mechanical tissue, 2 I.

Membranes, 173 .

Mertensia, 54.

Mesophyll, I5, I9.

Mesophytes, 60 .

Microspora, 236, 238.

Midrib, I3.

Milkweed, I98.

Mimosa, 44, 3 I 4 .

Mint family, 3I4.

Mistletoe, 249.

Mnium, 230.

Molds, 262.

Monocots, IIS, 209; families of, 307; stem structure, 125 .

Morphology, I5I.

Mosses, 23, 59, 277; life history of, 279.

Moth mullein, 95 .

Motile leaves, 43 .

Multiplication, vegetative, $217,243,279$.

Mushrooms, 249, 267, 268.

Mustard family, 3I2.

Mutants, 225.

Mutation, 224, 327; bud, 226.

Naiad, 57.

Nasturtium leaf, I4.

Natural selection, 327 .

Nectar, 202.

Nectaries, 202.

Net-veined leaves, 88 , I 8 .

Nightshade, 315.

Nitrifying bacteria, 258 .

Nitrogen, 32, 14I; fixation, 258.

Nodes, ro6.

Nucleus, I5.

Nutritive phase of plants, 197.

Oak, I6r, I98.

Oats, 147.

Oedogonium, 236, 241 .

Oils, 3I, 2 I 5 .

Onion, 79, 160, 198.

Ö̈spore, 242.

Open bundle, I 27.

Orange leaf, I4.

Orchid family, 3 II.

Orchids, 190, 204, 311 .

Organs, 2 I.

Osier willow, 163 .

Osmosis, I73; in roots, 175.

Ovulary, 200.

Orule, 200.

Oxalis leaf, I 5,44 .

Oxidation, $\mathrm{S}_{2}$.

Palisade cell, 17 ; layers, I9.

Palm, coconut, 2I4, 306; date, IIo; family, 307; hat, $9 \mathrm{r}$.

Parallel-veined leaves, 88, i 8 ; growing region of, 87 .

Parasites, 249.

Parenchyma, I 20.

Parmelia, 260.

Parsnip, 79, 96.

Pasteurization, 256.

Pea leaf, i6.

Peach leaf, it.

Peanut, 78, 79 .

Pedicel, 200.

Peduncle, r 99.

Peppermint, 3 I $_{4}$.

Pepsin, 75.

Perennials, 96.

Permeability, 173 .

Persimmon, 213.

Petal, 200.

Petiole, I4.

Phloem $=$ food conducting and bast tissues, Irg.

Photosynthesis, 26; summary of, $3 \mathrm{r}$.

Phototropism, I3 I, 183 .

Physiology, I $5 \mathrm{r}$.

Pigments, green, 63; red, 65; yellow, 63 .

Pine, 202; Japanese dwarf, 99 ; trees, III.

Pineapple, 2 ro.

Pistil, 200.

Pith, I20, I25; rays, I 20.

Plant, breeding, 220; characteristics, 99; fibers, I, 9I, 21 5, 228; kingdom, development of, 300 ; producing arts, 99.

Plants, desert, 58, I 57 ; importance of, $\mathrm{I}$; living things, 7,8 ; mutual dependence

- of parts, 8, 9; of the past, 3 I 8 ; relation to environment, 8, 140; source of all food, I, 25.

Plastids, 22.

Plumule, 208.

Pod, 2 I 2.

Pollen, 200, 205; tube, 204.

Pollination, 20I ; cross, 203 ; in conifers, 202 ; self, 203.

Pond scums, 237, 245; living conditions of, 239.

Pondweed, 57.

Poplar leaf, it.

Potassium, source of, 247 .

Potato, 10, 76, 79, 87; sweet, 97, 194; tuber cell, I7; family, 315. 
Preservation of foods, 257 .

Pressure, of growth, rs 4 ; osmotic, 174; root, 177 .

Prickly lettuce, to; pear, 58 .

I'roteins, making of, 32 ; use of, 32,33 .

Prothallus, 288.

Protococcus, 235.

Protonema, 279.

Protoplasm, I5 I.

Puffballs, 267.

Pulvinus, 45 .

Raceme, ros.

Rainfall, distribution of, 51, I H4; effect on yicld of corm, 48,51 .

Raspberry, 213, 217.

Rattan, I 25, 163 .

Receptacle, 200.

Red-bud tree, 44.

Red pigment, 65 .

Reproduction, 10, 197, 206; and agriculture, 217; asexual, 243; by seeds, 207, 300; sexual, 205, 2.43.

Reproductive phase of plant life, I97.

Reservoirs, cleaning, 246 .

Respiration, 82 ; and shipping, 84 ; contrasted with photosynthesis, $8_{3}$; in roots, 82,179 ; rate of, 84 .

Response, I3I; to aërial environment, 275 ; to gravity, I30, I49, I 82 ; to light, I $31,149,183$; to water, I3I, I57, I83.

Rhizoids, 273,276 ; moss, 278 .

Rhododendrons, 194 .

Rhubarb, 195, 10\$.

Rice, 77, I45, 307, 308 .

Root, contraction, I 85 ; hairs, I68; pressure, I77; processes, I 66.

Roots, and bacteria, 104, 258; and fungi, 194; and transplanting, I90; classification of, 166; commercial uses of, 194; distribution of, $\mathrm{I}_{3}$; of climbers, 182 , 187 ; of conifers, 296 ; of ferns, 285 ; of hydrophytes, 187 ; of mesophytes, 187 ; response to gravity, 182 ; response to light, $\mathrm{I}_{3}$; tissues of, $\mathrm{I} 60$.

Rootstock, 159, 219; calamus, I22.

Rose family, 312.

Rosin, I61, 162 .

Rubber, $163,215$.

Running cypress, 287 .

Rushes, 157.

Russula, 267.

Rusts, 263.

Salsify, r 94.

Sand-reed grass, 159.

Sanitation, 252.
Saprophytes, 249

Sapwood, r 30.

Sassafras, 105.

Scale leaves, $160,16 \mathrm{r}$.

Science, defined, 3 .

Seaweeds, 246.

Sedges, $38,157$.

Seeds, 198, 205, 207; economic importance of, 214; of conifers, 198, 211 .

Selaginella, 50 .

Selection, 220, 228; natural, 327 .

Self-pruning, 69 .

Sensitive plant, 44 .

Sepal, 200.

Sequoi:1, 98, 154, 229.

Shasta daisy, 222.

Shrubs, 94 .

Sieve tubes, I 22.

Silviculture, roo.

Simple plants, summary of, 270 .

Sirup, 163.

Sisisl, 90, 9 r.

Smilax, 107 .

Smuts, 266.

Snapdragon, I 98 .

Soil, I.41; bacteria, 257; cultivation of, I 43 ; elements, I4I; erosion, 186,187 ; temperature, 146 .

Solomon's seal, 98, 159, $18_{5}$.

Sorghum, 163 .

Soy bean, $33,78,194$.

Sperms, 205.

Spike, 198.

Spirogyra, 236.

Spores, asexual, 241 ; resting, 238 ; sexual, $2+\mathrm{I}$; swimming, 238 .

Sports, 225 ; bud, 226.

Spruce, IIt.

Stamen, 200.

Starch, 28, 74, 77 .

Stem, processes, II 8 ; structure, II 8 , II9, I 54 .

Stems, advantages of horizontal, ro4; as photosynthetic organs, I06; commercial products from, i6r; excurrent and deliquescent, III; external features of, 102 ; growth of, 128 ; in relation to light, $13 \mathrm{r}$; of climbing plants, 155 ; of hydrophytes, 156; of xerophytes, 157; underground, 97, 130; upright, 102 .

Stigma, 200.

Stipules, 14.

Stock, 132.

Stomata, I9, I1 5 .

Storage, food, $74,77,105,125,159,160$, 161 ; water, 58 , 106, 158, 189 .

Strawberry, ro. 


\section{Index}

Structure, conifer stems, I 28 ; dicot bundle, I 2 I ; dicot stems, I 20; monocot bundle, I 26 ; monocot stem, I25.

Style, 200.

Subsidiary cells, I9.

Sugar, 28, 202; beet, 77, 79, I95; cane, $77,163,219$.

Sugar cane, 77, 78, 1+1, 163, 231.

Sunflower, 10, 50, 97, 102, 198, 203, 222, 228,317 .

Synthesis, of carbohydrates, 26, 27, 3I ; of fats, 31 ; of proteins, 32 .

Tamarack, 296.

Tank epiphytes, I89.

Tannic acid, 161 .

Temperature, 146 .

Tendrils, I07, I 55 .

Test, for oil, 73 ; for proteins, 73 ; for starch, 26, 73; for sugar, 73 .

Thallus, 272 .

Thistle, 317 .

Timothy, 220.

Tissues, 21; epidermal, I5, I6, 50, I19, I69; food-conducting, I5, I 21,169 ; mechanical, I5, I22; storage, 125.

Toadstools, 268 .

Tobacco, 89, 203, 224.

Tomato, 225 .

Toxins, 253.

Tracheæ, I 2 I, I 23.

Transfer of food, 76 .

Transpiration, 49, I49; and absorption, I76; and lifting of water, $134 ;$ and water balance, 52 ; rate of, 50.

Transplanting, I92; and roots, 190; and water balance, 55 .

Tree-of-heaven, I07.

Trees, 94; size of, 99, I 54 .

Tropisms, I 31 .

Tubers, 97, 161.

Tulip, I60, 200; tree leaf, I3.

Turf, I 59.

Turnips, 96, 194 .

Turpentine, $16 \mathrm{I}$.

Typhoid fever, 253.

Ulothrix, 236, 240.

Umbel, 198 .

Underground stems, 75, 97, 130, I 59, I60, I6I.

Utilization of foods, 83 .

Vacuoles, I6, 49.

Variations, 220, 222, 327; kinds of, 223.

Vaucheria, 236.

Vegetative multiplication, 21 7, 243, 279; propagation, 218.

Veins, 13, 20, 88; principal, 13.

Vertical leaves, $4 \mathrm{I}, 42$.

Vessels, food-conducting, I2I ; water-conducting, I $21,123$.

Vinca, 14, 18, 21 .

Vinegar making, 26r.

Walnut, 79.

Wandering Jew, 19.

Water, balance, 52,54 ; balance and plant habitats, 56 ; balance and transplanting, 55 ; balance illustrated, 53 ; conducting tissue, 18, 20, 105, I19, I I , 169; importance of, $48,51,52$; plants, 56,57 , $60,156,244,273$; storage, 58 , 106, 158 , 189; supply and crop yields, 5I; why necessary, 48.

Water lily, 57; yellow, I59.

Weeds, 229; and crop production, 230.

Wheat, 5, 79, 96, I44; rust, 263.

White clover, 44 .

White leaves, 66.

White pine blister rust, 265 .

Willow, $16,56,163,198$.

Wilt disease, 254 .

WVind, I 48 , I49; pollination, Ic3.

Wintergreen oil, 163 .

Wood, I 23; fibers, I 24; gymnosperm, 294; pulp, I6I.

Xanthophyll, 63 .

Xerophyte, 58, 59, 60, I57.

Xylem $=$ water conducting and wood tissues, IIg.

Yam, I94.

Yeast, 26r.

Yucca, 58, 204, 21 $3,322$.

Zebrina, I9.

\section{PROPERTY LIBRARY N. C. State College}










(1)

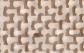

